\title{
UP780, a Chromone-Enriched Aloe Composition, Enhances Adipose Insulin Receptor Signaling and Decreases Liver Lipid Biosynthesis
}

\author{
Julie Tseng-Crank ${ }^{1 *}$, Seon-Gil Do ${ }^{2}$, Brandon Corneliusen ${ }^{1}$, Carmen Hertel ${ }^{1}$, Jennifer Homan ${ }^{1}$, \\ Mesfin Yimam ${ }^{1}$, Jifu Zhao ${ }^{1}$, Qi Jia ${ }^{1}$ \\ ${ }^{1}$ Unigen, Seattle, USA \\ ${ }^{2}$ Unigen Korea, Songjung-Ri, Byeongchen-Myeon, Vheonan-Si, Chungnam, South Korea \\ Email: jtsengcrank@gmail.com
}

Received 12 May 2013; revised 17 June 2013; accepted 17 July 2013

Copyright (C) 2013 Julie Tseng-Crank et al. This is an open access article distributed under the Creative Commons Attribution License, which permits unrestricted use, distribution, and reproduction in any medium, provided the original work is properly cited.

\begin{abstract}
Nutrigenomic studies were conducted to uncover the mechanism of action for the hypoglycemic and insulin sensitizing effects of UP780. From high fat diet-induced obesity mouse model for UP780, livers and white adipose tissues (WAT) from groups of lean control, high fat diet (HFD), and HFD treated with UP780 were collected for microarray study. Microarray generated gene expression changes were applied to Ingenuity Pathway Analysis for changes in canonical metabolic and signaling pathways. Microarray was validated by quantitative reverse transcriptase-polymerase chain reaction (QPCR), Western blots, liver triglyceride, liver cholesterol, liver steatosis, and insulin ELISA. UP780 treatment decreased liver gene expressions for multiple enzymes involved in fatty acid biosynthesis and triglyceride production. UP780 treatment increased gene expressions globally for the insulin receptor signaling pathway in WAT. Both liver triglyceride and liver cholesterol levels were significantly reduced by UP780 over HFD. The reduction of liver fat was confirmed by microscopic analysis of liver steatosis. Finally, UP780 significantly decreased fasting plasma insulin level over HFD. The mechanism of action for UP780 indicated a reduction of liver fat accumulation and an enhancement in adipose tissue insulin signaling pathway. This provided mechanistic explanation for the in vivo UP780 effects of enhanced insulin sensitiveity and decreased blood glucose in mouse diabetes and prediabetes models.
\end{abstract}

Keywords: Nutrigenomics; Insulin Signaling Pathway; Liver Fatty Acid Biosynthesis; Liver Steatosis; Aloe Vera

${ }^{*}$ Corresponding author.

\section{INTRODUCTION}

Diabetes and prediabetes have become epidemic globally. In recent US surveys, $26.9 \%$ of the population aged 65 years and older had diabetes and $35 \%$ of those 20 years or older had prediabetes [1]. WHO of the United Nations estimated in 2011 that 346 million people worldwide had diabetes, and that number was likely to double by 2030 [2]. Complications of diabetes include heart disease, stroke, hypertension, blindness, kidney disease, neuropathy, amputation, and dental disease. Economic burden of diabetes was high, in US, the 2007 direct and indirect cost of diabetes amounted to $\$ 174$ billion [1].

The culprit for the epidemic of type II diabetes and prediabetes/metabolic syndrome is obesity. Obesity predisposes patients to a complex metabolic pathology, characterized by a cluster of closely related clinical features of central obesity, hyperglycemia, insulin resistance, dyslipidaemia and hypertension [3]. Metabolic syndrome is associated with increased risk of type II diabetes and cardiovascular disease; cardiovascular diseases ultimately are responsible for a large proportion of diabetic mortality [4]. The epidemics in type II diabetes calls for interventions at the stage of metabolic syndrome, with diet, exercise, and medications/dietary supplements targeting insulin resistance, to decrease the societal burden from diabetes.

For thousands of years, herbal medicine was the only treatment available to mankind. What is old is not necessarily worthless in the modern world. Recently, traditional herbal medicines with a history in diabetic treatment, now as nutritional supplements or as alternate medicines, were rediscovered by the medical world for obesity, metabolic syndrome, and diabetes: Aloe vera leaf gel [5], berberine [6,7], bitter melon [8], ginsenoside $\mathrm{Rb} 1$ 
[9], genistein [10], and cinnamon [11], to name a few. In addition, resveratrol from red grape was recently discovered to improve obesity and aging related disorders [12].

Aloe vera inner leaf gel and whole leaf extract had been reported to produce a hypoglycemic effect in diabetic animal models of alloxan-induced diabetic mice [13-15] and type I/type II diabetic rats [16,17]. UP780, the Aloe vera inner leaf gel extract standardized with aloesin, was found to decrease fasting blood glucose levels and insulin resistance in mouse diet-induced obesity (DIO) model and $d b$ diabetic model [18]. Significantly, UP780 was the subject of a double blind, placebo controlled clinical pilot study of prediabetic patients. After eight weeks of treatment, UP780 significantly reduced fasting blood glucose, insulin, $\mathrm{HbAlc}$, fructosamine, and urinary F2-isoprostanes compared to placebo [19].

Although aloe was traditionally used for diabetes treatment, and shown to reduce blood glucose, improve lipid profile, and provide anti-oxidants in diabetic animal models $[13,15-17,20,21]$, there is a paucity of aloe mechanism of action study. From the UP780 prediabetic DIO mouse study [18], livers and white adipose tissues (WAT) collected from the DIO animals were used in a nutrigenomic study. By microarray/pathway analysis and QPCR gene expression, UP780 decreased fatty acid biosynthesis and triglyceride production in liver and increased insulin receptor signaling pathway in WAT. The microarray and QPCR gene expression data was validated by Western blot, liver triglyceride/cholesterol, liver steatosis, and plasma insulin ELISA.

\section{MATERIALS AND METHODS}

\subsection{Composition of UP780}

UP780 is a combination of Aloe vera inner leaf gel powder $\left(\mathrm{QMatrix}{ }^{\circledR}\right.$ ) standardized to contain $2 \%$ - $4 \%$ aloesin. QMatrix ${ }^{\circledR}$ is produced from Aloe vera gel carbon-filtered to remove anthraquinone, which has laxative effect [22]. Aloesin, an aromatic chromone isolated from Aloe ferox, was discovered by high throughput screening of 2059 plant extracts to increase adiponectin secretion from differentiated 3T3-L1 adipocytes [18]. In the preparation of QMatrix $^{\circledR}$, aloesin was removed by carbon filtration. Aloesin was added to QMatrix ${ }^{\circledR}$ with an expectation of broadening the aloe action for glycemic control. GW1929 is a specific non-thiazolidinedione, tyrosinederived agonist of peroxisome proliferatoractivated receptor gamma (PPAR $\alpha$, Tocris Bioscience). Thiazolidinedione class PPAR agonists are standard medicines for type II diabetes [23].

\subsection{Methods}

Methods for tissue collection from DIO mice, RNA ex- traction, microarray, Ingenuity Pathway Analysis, realtime RT-QPCR, Western blot, liver triglyceride and cholesterol assays, liver steatosis, and plasma insulin ELISA are described in the supplemental materials.

\section{RESULTS}

\subsection{Microarray/QPCR and UP780 Mechanism of Action}

HFD feeding of C57BL/6J mice is known to induce gene expression variations in organs that respond to high caloric intake such as liver, fat, and muscle [12]. It was of great interest to observe the effects of UP780 treatment over HFD-induced changes in gene expressions. Microarray gene expression variations were applied to the construction of a hypothesis for UP780 mechanism of action, based on the canonical metabolic and signaling pathway analysis, and taken into account of known gene functions $[24,25]$. The large volume of pathway analysis results were allocated to the supplemental materials. Only key genes involved in the interpretation of biological significance of UP780 were validated by QPCR (Table 1). An equivalent Table 2 was generated for WAT. Concordance between liver microarray and liver QPCR was good, 11 out of 14, when the genes loosely categorized as Signaling were not counted (Table 1) Concordance between WAT microarray and QPCR was excellent, 11 out of the 13 key genes tested (Table 2)

The liver key gene list in Table $\mathbf{1}$ emphasized the metabolic pathways. Liver responds to the nutritional state of the body by modifying the enzyme/gene activities involved in metabolism, either by protein phosphorylation or by gene expression variation. With liver, genes encoding relevant members of metabolic pathways of fatty acid biosynthesis, fatty acid metabolism, glycollysis/gluconeogenesis, and fat transport were all found to be strikingly up-regulated by HFD and down-regulated by UP780 (Table 1). The hypoglycemic effect of UP780 suggested a decreased gluconeogenesis pathway. Many genes in glycolysis/gluconeogenesis pathway were upregulated by HFD and down-regulated by UP780 (Table 1, Supplement Figure 5 and Supplement Table 1). While this may suggest a decrease of gluconeogenesis by UP780, close examination of the functions of the genes involved indicated contradictions that cannot be resolved by gene expression data alone. In particular, phosphoenolpyruvate carboxykinase (PEPCK) is a rate-limiting enzyme for gluconeogenesis. The cytosolic PEPCK1 was up-regulated by HFD/UP780, opposing gluconeogenesis as a mechanism of hypoglycemic control. Effect of UP780 on carbohydrate metabolism in liver will need further studies.

Strong evidence of UP780-modulated metabolic pathways in support of UP780 insulin-sensitiziing effect was 
Table 1. Liver gene expression variations from microarray and QPCR. For microarray, up-regulations $\geq 0.8$ and with a p-value $<0.05$ are highlighted with red and marked with " $\uparrow+$ ", down-regulations $\leq-0.8$ and with a p-value $<0.05$ are high- lighted with green and marked by “ $\downarrow$-". For QPCR, up- and down-regulations over 2 fold difference are highlighted with red and green, respectively. Concordances in between microarray and QPCR are marked with $\bullet$.

\begin{tabular}{|c|c|c|c|c|c|c|c|c|}
\hline \multirow{2}{*}{ Genes } & \multirow{2}{*}{ Description } & \multicolumn{3}{|c|}{ Microarray (Fold Change) } & \multicolumn{4}{|c|}{ QPCR (Relative Expression) } \\
\hline & & LUP-LV & LUP-LC & LV-LC & $\mathbf{L C}$ & LV & LUP & \\
\hline \multicolumn{9}{|c|}{ Fatty Acid Biosynthesis } \\
\hline $\mathrm{ACC} 1$ & ACACA, Acetyl-CoA carboxylase 1 & $\downarrow-1.80$ & $\downarrow-1.36$ & $\uparrow+1.32$ & & & & \\
\hline $\mathrm{ACC} 2$ & ACACB, Acetyl-CoA carboxylase 2 & $\downarrow-3.11$ & $\downarrow-2.82$ & $\uparrow+1.10$ & $1.00 \pm 0.13$ & $0.81 \pm 0.06$ & $0.33 \pm 0.16$ & - \\
\hline ACSL3 & Acyl-CoA synthetase long chain 3 & $\downarrow-1.77$ & $\downarrow-1.43$ & $\uparrow+1.24$ & & & & \\
\hline FASN & Fatty acid synthase & $\downarrow-3.89$ & $\downarrow-2.53$ & $\uparrow+1.54$ & $1.00 \pm 0.02$ & $0.93 \pm 0.03$ & $0.35 \pm 0.01$ & $\bullet$ \\
\hline FADS1 & Fatty acid desaturase 1 & $\downarrow-1.90$ & $\downarrow-1.32$ & $\uparrow+1.43$ & & & & \\
\hline FADS2 & Fatty acid desaturase 2 & $\downarrow-3.48$ & $\downarrow-1.32$ & $\uparrow+2.79$ & & & & \\
\hline SCD1 & Stearyl-CoA desaturase & $\downarrow-4.50$ & $\downarrow-4.25$ & $\uparrow+1.07$ & $1.00 \pm 0.00$ & $0.98 \pm 0.02$ & $0.26 \pm 0.01$ & $\bullet$ \\
\hline ELOV5 & Elongation of long chain fatty acids 5 & $\downarrow-2.44$ & $\downarrow-1.34$ & $\uparrow+1.83$ & & & & \\
\hline ELOV6 & Elongation of long chain fatty acids 6 & $\downarrow-2.89$ & $\downarrow-2.39$ & $\uparrow+1.25$ & & & & \\
\hline \multicolumn{9}{|c|}{ Fatty Acid Metabolism } \\
\hline ACOX1 & Acyl-CoA oxidase 1, palmitoyl & $\downarrow-1.87$ & $\downarrow-1.15$ & $\uparrow+1.62$ & $1.00 \pm 0.01$ & $1.12 \pm 0.02$ & $0.92 \pm 0.02$ & \\
\hline ACOT1 & Acyl-CoA thioesterase 1, peroxisome & $\downarrow-6.42$ & $\downarrow-3.26$ & $\uparrow+2.53$ & & & & \\
\hline CPT1A & Carnitine palmitoyl transferase $1 \mathrm{~A}$ & $\downarrow-1.78$ & $\uparrow+1.21$ & $\uparrow+2.16$ & $1.00 \pm 0.04$ & $1.43 \pm 0.04$ & $1.06 \pm 0.05$ & - \\
\hline CRAT & Carnitine acetyltransferase & $\downarrow-2.41$ & $\downarrow-1.10$ & $\uparrow+2.18$ & & & & \\
\hline $\mathrm{HAO} 2$ & Hydroxyacid oxidase 2, peroxisome & $\downarrow-2.33$ & $\downarrow-1.15$ & $\uparrow+2.03$ & & & & \\
\hline \multicolumn{9}{|c|}{ Steroid Biosynthesis } \\
\hline FDPS & Farnesyl diphosphate synthase & $\downarrow-1.39$ & $\downarrow-1.99$ & $\downarrow-1.43$ & & & & \\
\hline HMGCR & 3-Hydroxy-3-methylglutaryl-CoA reductase & $\downarrow-1.19$ & $\downarrow-2.26$ & $\downarrow-1.90$ & $1.00 \pm 0.03$ & $0.41 \pm 0.01$ & $0.47 \pm 0.01$ & $\bullet$ \\
\hline MVD & Mevalonate decarboxylase & $\downarrow-2.70$ & $\downarrow-2.51$ & $\uparrow+1.07$ & & & & \\
\hline \multicolumn{9}{|c|}{ Bile Acid Biosynthesis } \\
\hline CYP7A1 & Cytochrome P450 7A1 & $\uparrow+2.77$ & $\downarrow-2.45$ & $\downarrow-4.89$ & $1.06 \pm 0.42$ & $0.07 \pm 0.03$ & $0.97 \pm 0.02$ & $\bullet$ \\
\hline CYP7B1 & Cytochrome P450 7B1 & $\uparrow+2.76$ & $\uparrow+2.30$ & $\downarrow-1.22$ & $1.00 \pm 0.50$ & $0.56 \pm 0.02$ & $2.53 \pm 0.08$ & $\bullet$ \\
\hline \multicolumn{9}{|c|}{ Fat Transport } \\
\hline APOA4 & Apolipoprotein A4, chylomicron & $\downarrow-3.48$ & $\uparrow+2.41$ & $\uparrow+8.40$ & & & & \\
\hline CD36 & Fat transporter & $\downarrow-3.29$ & $\downarrow-1.34$ & $\uparrow+2.45$ & $1.00 \pm 0.07$ & $1.98 \pm 0.08$ & $0.98 \pm 0.04$ & - \\
\hline FABP4 & Fatty acid binding protein 4 & $\uparrow+1.07$ & $\uparrow+2.70$ & $\uparrow+2.52$ & $1.00 \pm 0.04$ & $0.54 \pm 0.08$ & $2.77 \pm 0.03$ & \\
\hline FABP5 & Fatty acid binding protein 5 & $\uparrow+2.63$ & $\downarrow-1.49$ & $\downarrow-3.91$ & $1.00 \pm 0.06$ & $0.08 \pm 0.01$ & $0.64 \pm 0.14$ & - \\
\hline LDLR & LDL receptor & $\downarrow-2.75$ & $\downarrow-1.54$ & $\uparrow+1.67$ & & & & \\
\hline \multicolumn{9}{|c|}{ Glycolysis/Gluconeogenesis } \\
\hline ALDH1B1 & Aldehyde dehydrogenase 1B1 & $\downarrow-3.04$ & $\downarrow-1.77$ & $\uparrow+1.72$ & & & & \\
\hline GCK & Glucokinase, MODY2 & $\downarrow-2.29$ & $\uparrow+1.13$ & $\uparrow+2.04$ & & & & \\
\hline GYS2 & Glycogen synthase 2 & $\downarrow-1.40$ & $\uparrow+1.05$ & $\uparrow+1.47$ & $1.00 \pm 0.09$ & $1.08 \pm 0.06$ & $1.14 \pm 0.03$ & \\
\hline HK1 & Hexokinase 1 & $\downarrow-2.55$ & $\downarrow-1.77$ & $\downarrow-1.39$ & & & & \\
\hline PDK4 & Pyruvate dehydrogenase kinase 4 & $\downarrow-2.59$ & $\downarrow-1.41$ & $\uparrow+1.83$ & $1.03 \pm 0.32$ & $1.70 \pm 0.44$ & $0.11 \pm 0.04$ & $\bullet$ \\
\hline PKLR & Pyruvate kinase, liver \& RBC & $\downarrow-2.26$ & $\downarrow-1.54$ & $\uparrow+1.62$ & & & & \\
\hline PEPCK1 & PCK1, Phosphoenolpyruvate carboxykinase 1 & $\uparrow+1.09$ & $\uparrow+2.34$ & $\uparrow+2.23$ & $1.00 \pm 0.04$ & $1.73 \pm 0.05$ & $2.72 \pm 0.08$ & $\bullet$ \\
\hline \multicolumn{9}{|l|}{ Signaling } \\
\hline AMPK $\alpha 2$ & PRKAA2, AMP-activated kinase $\alpha 2$ & $\downarrow-1.60$ & $\downarrow-1.49$ & $\uparrow+1.07$ & $1.00 \pm 0.02$ & $0.85 \pm 0.13$ & $0.96 \pm 0.03$ & \\
\hline $\mathrm{AMPK} \gamma 2$ & PRKAG2, AMP-activated kinase $\gamma 2$ & $\downarrow-1.40$ & $\downarrow-1.38$ & $\downarrow-1.01$ & $1.00 \pm 0.05$ & $0.79 \pm 0.11$ & $0.75 \pm 0.01$ & \\
\hline SLC2A2 & GLUT2, solute carrier family 2 , member 2 & $\downarrow-1.50$ & $\downarrow-1.37$ & $\uparrow+1.09$ & $1.00 \pm 0.02$ & $0.84 \pm 0.06$ & $0.77 \pm 0.04$ & \\
\hline HNF4A & Hepatocyte nuclear factor $4 \alpha$ & $\downarrow-1.18$ & $\downarrow-1.27$ & $\downarrow-1.07$ & $1.00 \pm 0.04$ & $0.74 \pm 0.04$ & $1.06 \pm 0.04$ & \\
\hline mTOR & $\begin{array}{l}\text { FRAP1, FK } 506 \text { binding protein } 12 \text {, rapamycin- } \\
\text { associated protein } 1\end{array}$ & $\downarrow-1.10$ & $\uparrow+1.18$ & $\uparrow+1.43$ & $1.00 \pm 0.06$ & $0.93 \pm 0.01$ & $0.88 \pm 0.04$ & \\
\hline PGC1A & PPAR $\gamma$ coactivator $1 \mathrm{~A}$ & $\downarrow-1.66$ & $\downarrow-1.45$ & $\uparrow+1.22$ & $1.46 \pm 1.46$ & $1.13 \pm 0.79$ & $2.53 \pm 0.54$ & \\
\hline PGC1B & $\operatorname{PPAR} \gamma$ coactivator $1 \mathrm{~B}$ & $\downarrow-2.32$ & $\downarrow-1.59$ & $\uparrow+1.46$ & $1.08 \pm 0.55$ & $1.05 \pm 0.26$ & $1.32 \pm 0.07$ & \\
\hline $\operatorname{PPAR} \alpha$ & Peroxisome proliferator-activated receptor & $\downarrow-2.41$ & $\uparrow+1.07$ & $\uparrow+2.25$ & $1.00 \pm 0.09$ & $1.42 \pm 0.03$ & $1.44 \pm 0.05$ & \\
\hline $\operatorname{PPAR} \delta$ & Peroxisome proliferators-activated receptor & $\downarrow-1.11$ & $\uparrow+1.07$ & $\uparrow+1.22$ & $1.00 \pm 0.05$ & $1.12 \pm 0.08$ & $0.99 \pm 0.14$ & \\
\hline SREBF1 & Sterol regulatory element binding factor 1 & $\downarrow-2.40$ & $\downarrow-1.58$ & $\uparrow+1.52$ & $1.00 \pm 0.09$ & $0.92 \pm 0.04$ & $0.88 \pm 0.09$ & \\
\hline
\end{tabular}

LUP: Livers from UP780 treated DIO mice. LV: Livers from high fat diet, HFD, treated DIO mice. LC: Livers from lean control mice. 
Table 2. WAT gene expression variations from microarray and QPCR. For microarray, up-regulations $\geq 0.8$ and with a $p$-value $<0.05$ are highlighted with red and marked with " $\uparrow+$ ", down-regulations $\leq-0.8$ and with a p-value $<0.05$ are highlighted with green and marked with “ $\downarrow$-". For QPCR, up- and down-regulations over 2 fold difference are highlighted with red and green, respectively. Concordances in between microarray and QPCR are marked with $\bullet$.

\begin{tabular}{|c|c|c|c|c|c|c|c|c|}
\hline \multirow{2}{*}{ Gene } & \multirow{2}{*}{ Description } & \multicolumn{3}{|c|}{ Microarray (Fold Change) } & \multicolumn{4}{|c|}{ QPCR (Relative Expression) } \\
\hline & & FUP/FV & FUP/FC & FV/FC & FC & FV & FUP & \\
\hline \multicolumn{9}{|c|}{ Insulin Receptor Signaling } \\
\hline EIF4EBP1 & Eeukaryotic translation initiation factor $4 \mathrm{E}$ & $\uparrow+2.16$ & $\uparrow+1.02$ & $\downarrow-2.23$ & & & & \\
\hline & binding protein 1 & & & & & & & \\
\hline FOXO1 & Forkhead box O1 & $\uparrow+1.58$ & $\downarrow-1.25$ & $\downarrow-1.97$ & & & & \\
\hline FRAP1 & $\begin{array}{l}\text { FK506 binding protein 12-rapamycin } \\
\text { associated protein } 1, \text { mTOR }\end{array}$ & $\downarrow-1.77$ & $\downarrow-1.10$ & $\uparrow+1.92$ & & & & \\
\hline GYS1 & Glycogen synthase 1 (muscle) & $\uparrow+2.14$ & $\downarrow-1.17$ & $\downarrow-2.50$ & & & & \\
\hline GYS2 & Glycogen synthase 2 (liver) & $\downarrow-3.18$ & $\uparrow+1.75$ & $\uparrow+5.58$ & & & & \\
\hline IGF1R & Insulin-like growth factor 1 receptor & $\uparrow+1.68$ & $\downarrow-1.21$ & $\downarrow-2.03$ & & & & \\
\hline INSR & Insulin receptor & $\uparrow+1.59$ & $\downarrow-1.21$ & $\downarrow-1.92$ & $1.00 \pm 0.07$ & $0.24 \pm 0.07$ & $0.30 \pm 0.22$ & - \\
\hline IRS1 & Insulin receptor substrate 1 & $\uparrow+2.62$ & $\downarrow-1.60$ & $\downarrow-4.19$ & $1.01 \pm 0.18$ & $0.58 \pm 0.05$ & $1.06 \pm 0.08$ & $\bullet$ \\
\hline PIK3CA & Phosphoinositide-3-kinase, catalytic, p110 & $\uparrow+1.56$ & $\downarrow-1.19$ & $\downarrow-1.76$ & & & & \\
\hline PIK3R1 & Phosphoinositide-3-kinase, regulatory 1, p85 & $\uparrow+1.55$ & $\downarrow-1.62$ & $\downarrow-2.64$ & & & & \\
\hline PRKCH & Protein kinase $\mathrm{C}$, eta & $\downarrow-1.67$ & $\uparrow+2.00$ & $\uparrow+3.02$ & & & & \\
\hline SLC2A4 & GLUT4, solute carrier family 2 , member 4 & $\uparrow+2.58$ & $\downarrow-1.31$ & $\downarrow-2.31$ & $1.00 \pm 0.06$ & $0.64 \pm 0.05$ & $0.87 \pm 0.05$ & • \\
\hline STXBP4 & Syntaxin binding protein 4 & $\uparrow+1.81$ & $\downarrow-1.08$ & $\downarrow-1.96$ & & & & \\
\hline VAMP2 & Synaptobrevin 2 & $\uparrow+1.38$ & $\downarrow-1.38$ & $\downarrow-1.90$ & & & & \\
\hline \multicolumn{9}{|l|}{ Cell Cycle } \\
\hline BRCA1 & Breast cancer 1 , early onset & $\downarrow-3.30$ & $\uparrow+1.79$ & $\uparrow+5.91$ & & & & \\
\hline CCNB1 & Cyclin B1 & $\downarrow-2.97$ & $\uparrow+2.32$ & $\uparrow+6.89$ & & & & \\
\hline CCNB2 & Cyclin B2 & $\downarrow-2.87$ & $\uparrow+2.43$ & $\uparrow+6.97$ & & & & \\
\hline CCNE1 & Cyclin E1 & $\downarrow-1.59$ & $\uparrow+1.44$ & $\uparrow+2.29$ & & & & \\
\hline $\mathrm{CDC} 2$ & Cell division cycle $2, \mathrm{G} 1$ to $\mathrm{S}$ and $\mathrm{G} 2$ to $\mathrm{M}$ & $\downarrow-2.63$ & $\uparrow+2.38$ & $\uparrow+6.27$ & & & & \\
\hline CDK6 & Cyclin-dependent kinase 6 & $\downarrow-1.70$ & $\uparrow+1.55$ & $\uparrow+2.31$ & & & & \\
\hline CDKN1A & Cyclin-dependent kinase inhibitor 1A (p21, Cip1) & $\downarrow-1.60$ & $\uparrow+2.77$ & $\uparrow+4.43$ & & & & \\
\hline CDKN1B & Cyclin-dependent kinase inhibitor 1B (p27, Kip1) & $\uparrow+1.31$ & $\downarrow-1.35$ & $\downarrow-1.77$ & & & & \\
\hline CDKN2B & $\begin{array}{l}\text { Cyclin-dependent kinase inhibitor 2B } \\
\text { (p15, inhibits CDK4) }\end{array}$ & $\downarrow-2.02$ & $\uparrow+1.02$ & $\uparrow+2.06$ & & & & \\
\hline E2F1 & $\mathrm{E} 2 \mathrm{~F}$ transcription factor 1 & $\downarrow-1.28$ & $\uparrow+1.58$ & $\uparrow+1.87$ & & & & \\
\hline E2F6 & E2F transcription factor 6 & $\downarrow-2.24$ & $\uparrow+2.08$ & $\uparrow+4.66$ & & & & \\
\hline RB1 & Retinoblastoma 1 (including osteosarcoma) & $\downarrow-1.57$ & $\uparrow+1.40$ & $\uparrow+2.19$ & & & & \\
\hline SIRT1 & Sirtuin & $\uparrow+1.28$ & $\downarrow-1.37$ & $\downarrow-1.75$ & & & & \\
\hline TOP2A & Topoisomerase (DNA) II alpha 170 kDa & $\downarrow-2.89$ & $\uparrow+2.12$ & $\uparrow+6.12$ & & & & \\
\hline \multicolumn{9}{|c|}{ Metabolism } \\
\hline ACACA & ACC1, acetyl-Coenzyme A carboxylase alpha & $\uparrow+1.84$ & $\downarrow-4.20$ & $\downarrow-3.32$ & $1.04 \pm 0.32$ & $0.04 \pm 0.01$ & $0.51 \pm 0.10$ & • \\
\hline
\end{tabular}


Continued

\begin{tabular}{|c|c|c|c|c|c|c|c|c|}
\hline $\mathrm{ACACB}$ & ACC2, acetyl-Coenzyme A carboxylase beta & $\uparrow+2.24$ & $\uparrow+1.04$ & $\downarrow-2.15$ & & & & \\
\hline ADIPOQ & Adiponectin & $\uparrow+1.15$ & $\downarrow-1.03$ & $\downarrow-1.18$ & $1.00 \pm 0.12$ & $0.63 \pm 0.15$ & $1.01 \pm 0.17$ & \\
\hline ALDOB & Aldolase B, fructose bisphosphate & $\uparrow+2.74$ & $\downarrow-2.76$ & $\downarrow-7.57$ & $1.00 \pm 0.10$ & $0.006 \pm 0.003$ & $0.016 \pm 0.004$ & 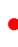 \\
\hline CPT1A & Carnitine palmitoyltransferase 1A (liver) & $\uparrow+1.05$ & $\uparrow+1.49$ & $\uparrow+1.42$ & & & & \\
\hline FABP4 & Fatty acid binding protein 4 & $\uparrow+3.41$ & $\downarrow-1.19$ & $\downarrow-4.05$ & $1.00 \pm 0.03$ & $1.21 \pm 0.26$ & $1.41 \pm 0.29$ & \\
\hline FASN & Fatty acid synthase & $\uparrow+1.14$ & $\downarrow-1.39$ & $\downarrow-1.59$ & $1.00 \pm 0.02$ & $0.54 \pm 0.13$ & $0.64 \pm 0.14$ & 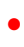 \\
\hline LEP & Leptin & $\downarrow-1.17$ & $\uparrow+1.59$ & $\uparrow+1.51$ & $1.05 \pm 0.36$ & $2.84 \pm 0.13$ & $1.77 \pm 0.15$ & $\bullet$ \\
\hline PEPCK1 & PCK1, Phosphoenolpyruvate carboxykinase 1 & $\uparrow+4.57$ & $\uparrow+1.13$ & $\downarrow-4.69$ & $1.00 \pm 0.06$ & $0.25 \pm 0.11$ & $1.46 \pm 0.11$ & 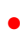 \\
\hline SLC27A1 & FATP1, fatty acid transporter & $\uparrow+1.76$ & $\uparrow+1.54$ & $\downarrow-1.14$ & & & & \\
\hline UCP2 & Uncoupling protein 2 & $\downarrow-1.45$ & $\uparrow+1.79$ & $\uparrow+2.58$ & $1.03 \pm 0.29$ & $1.78 \pm 0.18$ & $1.49 \pm 0.22$ & 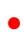 \\
\hline \multicolumn{9}{|c|}{ Nuclear Receptors } \\
\hline AR & Androgen receptor & $\uparrow+1.82$ & $\downarrow-1.36$ & $\downarrow-2.48$ & & & & \\
\hline ESR1 & Estrogen receptor 1 & $\uparrow+1.43$ & $\downarrow-1.47$ & $\downarrow-2.10$ & & & & \\
\hline $\mathrm{NR} 3 \mathrm{C} 1$ & Glucocorticoid receptor & $\uparrow+3.97$ & $\downarrow-1.46$ & $\downarrow-2.72$ & $1.02 \pm 0.21$ & $0.60 \pm 0.04$ & $0.98 \pm 0.29$ & 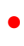 \\
\hline NCOR1 & Nuclear receptor co-repressor 1 & $\uparrow+1.82$ & $\downarrow-1.51$ & $\downarrow-2.19$ & & & & \\
\hline THRA & Throid hormone receptor alpha & $\uparrow+1.41$ & $\downarrow-1.47$ & $\downarrow-2.07$ & & & & \\
\hline PGC1A & PPAR $\gamma$ coactivator $1 \mathrm{~A}$ & $\uparrow+1.16$ & $\downarrow-1.37$ & $\downarrow-1.77$ & & & & \\
\hline PGC1B & PPAR $\gamma$ coactivator $1 \mathrm{~B}$ & $\uparrow+1.14$ & $\downarrow-1.70$ & $\downarrow-1.68$ & & & & \\
\hline $\operatorname{PPAR} \gamma$ & Peroxisome proliferator-activated receptor & $\uparrow+1.18$ & $\downarrow-1.43$ & $\downarrow-1.68$ & $1.00 \pm 0.08$ & $0.68 \pm 0.14$ & $0.80 \pm 0.13$ & 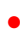 \\
\hline \multicolumn{8}{|c|}{ Immunity/inflammation } & \\
\hline CCL3 & Chemokine (C-C motif) ligand 3 & $\downarrow-2.49$ & $\uparrow+2.84$ & $\uparrow+7.07$ & & & & \\
\hline CCL13 & Chemokine (C-C motif) ligand 13 & $\downarrow-2.69$ & $\uparrow+3.21$ & $\uparrow+8.63$ & & & & \\
\hline CERK & Ceramide kinase & $\downarrow-1.40$ & $\uparrow+1.61$ & $\uparrow+2.25$ & & & & \\
\hline CXCL3 & Chemokine (C-X-C motif) ligand 3 & $\uparrow+1.04$ & $\uparrow+2.68$ & $\uparrow+2.57$ & & & & \\
\hline CXCR4 & Chemokine (C-X-C motif) ligand 4 & $\downarrow-1.32$ & $\uparrow+1.74$ & $\uparrow+2.29$ & & & & \\
\hline FOS & v-fos FBJ viral oncogen homolog & $\downarrow-2.13$ & $\uparrow+1.65$ & $\uparrow+3.51$ & & & & \\
\hline IL1R2 & Interleukin 1 receptor, type II & $\downarrow-2.74$ & $\uparrow+1.24$ & $\uparrow+3.38$ & & & & \\
\hline IL1RN & Interleukin 1 receptor antagonist & $\downarrow-3.49$ & $\uparrow+9.85$ & $\uparrow+24.08$ & & & & \\
\hline SPHK1 & Sphingosine kinase 1 & $\downarrow-2.25$ & $\uparrow+1.59$ & $\uparrow+3.58$ & & & & \\
\hline
\end{tabular}

FUP: Fat tissues from UP780 treated DIO mice. FV: Fat tissues from high fat diet, HFD, treated DIO mice. FC: Fat tissues from lean control mice.

found in lipid biosynthesis (Figure 1). First, the fatty acid biosynthesis depends on two major cytoplasmic enzymes, acetyl-CoA carboxylase (ACC1) and fatty acid synthase (FASN). Both ACC1 and FASN were decreased by UP780 (Table 1 and Figure 1). Second, the pentose phosphate pathway, which produces NADPH for fatty acid biosynthesis, was also down-regulated by UP780 (Supplement Table 1). Third, fatty acid desaturases (SCD1 and FADS1/2) and fatty acid elongases (ELOV5/ 6) were decreased by UP780, strongly supporting the mechanism that UP780 decreased liver fatty acid and triglyceride biosyntheses (Table 1 and Figure 1). Free fatty acid infusion in human induced systemic insulin resistance [26], UP780 could enhance systemic insulin sensitivity by a reduced lipotoxicity, resulting in enhanced blood glucose control.

Pathway analysis also suggested a cholesterol lowering effect by UP780, by 1) decreasing the rate-limiting enzyme HMG-CoA reductase (HMGCR) for cholesterol biosynthesis, 2) increasing the bile acid biosynthesis enzymes CYP7A1 and CYP7B1 for increased elimination of cholesterol through gut, and 3) decreasing apolipoprotein B for decreased LDL level (Table 1 and Figure 1). 


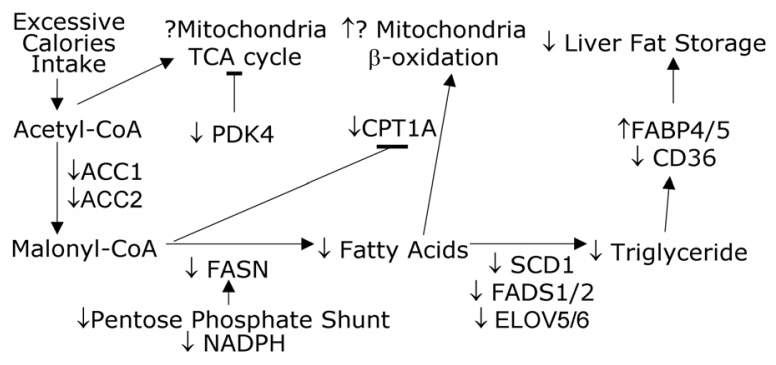

Figure 1. Liver metabolism modulated by UP780 over high fat diet. A schematic diagram is constructed to illustrate the influences exerted by UP780 to the metabolism of carbohydrates and lipids in liver.

Increased mitochondrial $\beta$-oxidation is a prominent mechanism of glycemic control [27]. The rate-limiting enzyme for mitochondrial fatty acid $\beta$-oxidation, carnitine palmitoyl transferase 1A (CPT1A), was decreased from HFD-elevated level (2-fold) by UP780 to lean control level, suggesting decreased $\beta$-oxidation. CPT1A activity is regulated by the feedback metabolite malonylCoA. Malonyl-CoA concentration in mitochondria depends on the mitochondrial ACC2. ACC2 expression in UP780 liver was $\sim 3$-fold lower than in HFD, suggesting increased $\beta$-oxidation (Table 1). The overall activity of fatty acid $\beta$-oxidation in liver might well be increased; a mechanism that will support a role of UP780 in better lipid metabolism control but will need further study (Table 1 and Figure 1).

Microarray analysis of WAT gene expression offered a clear explanation for the insulin sensitizing effect by UP780. Key genes in the insulin receptor signaling pathway were globally decreased by HFD and globally increased by UP780 (Table 2 and Supplement Figure 6). Among these key genes, insulin receptor (INSR), IRS-1, and glucose transporter 4 (GLUT4) were validated by QPCR (Table 2). With DIO mouse model, HFD feeding was known to induce insulin resistance [12]. Insulin activates INSR tyrosine kinase, which by phosphorylation of the IRS proteins, transduces insulin signal through protein kinases to the translocation of GLUTs to plasma membrane, thereafter increases glucose uptake. This increased glucose uptake from blood in WAT increases the usage of glucose for lipid biosynthesis and energy storage [28]. Lowered plasma glucose enhances systemic insulin sensitivity. The concerted down-regulation of insulin signaling pathway by HFD and opposing upre- gulation by UP780 strongly pointed to a reversal of in- sulin-resistance as an important mechanism underlying the UP780 normalization of glycemic control and insulin sensitivity.

Two more categories in WAT gene list were regulated similarly to the insulin receptor pathway: those involved in metabolism and nuclear receptor/co-activator/co-repressor. Again, multiple gene expression variations were confirmed by QPCR (Table 2). Of note was adiponectin (ADIPOQ) gene expression, reduced by HFD and restored to control level by UP780 (Table 2 QPCR).

HFD is also known to induce adipose tissue inflammation and secretion of inflammatory cytokines such as TNF- $\alpha$ [29]. Many inflammatory genes were among the highest of up-regulated genes by HFD, with UP780 reducing these gene expressions (Table 2). Similarly, many genes in the cell cycle pathway were up-regulated by HFD and decreased by UP780 (Table 2).

\subsection{Functional Validation}

Quantification at mRNA levels, although powerful in generating a global pattern of UP780 mechanism of action, is limited in depicting protein levels. Western blotting therefore was used to validate at the protein level for liver FASN (Figure 2(a), upper). After normalization with $\beta$-actin loading control (Figure 2(a), lower) to lean control $=1$, HFD decreased FASN to 0.7, UP780 further decreased FASN to 0.5, and GW1929 to 0.6. Therefore liver FASN protein levels by Western blot correlated to microarray and QPCR data (Table 1 and Figure 2(a)).
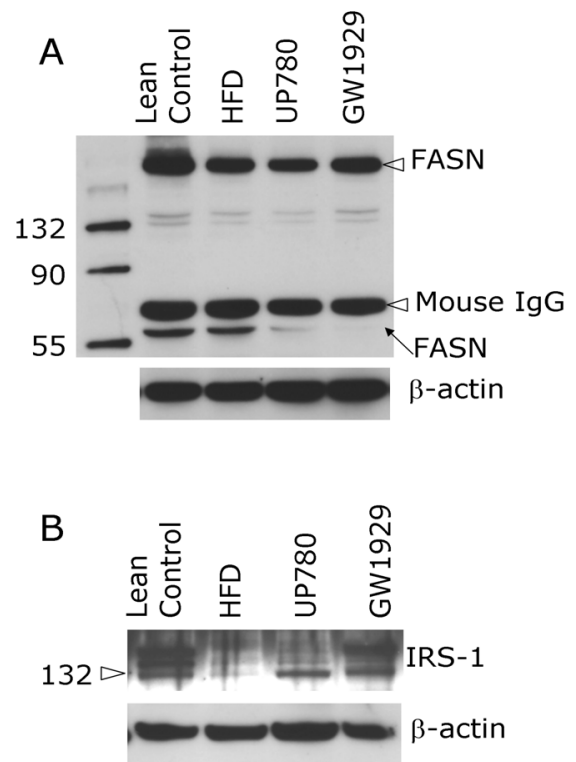

Figure 2. Western blotting for protein expression levels modified by UP780. (A) Liver proteins were probed with a mouse monoclonal anti-FASN antibody. A fulllength 270 $\mathrm{kD}$ FASN and a smaller $60 \mathrm{kD}$ degradation fragment were reproducible in Western blots. The blot was re-probed with anti- $\alpha$-actin antibody for protein loading control. (B) WAT Western blot was probed for IRS-1 protein levels and re-probed for $\alpha$-actin loading control. Three protein bands $132 \mathrm{kD}$ and up were reproducibly observed. Positions of molecular weight markers are either shown in A or marked in B at the left. 
For WAT, IRS-1 protein level in the insulin signaling pathway was validated by Western blot (Figure 2(b)) IRS-1 proteins were dramatically decreased by HFD, much more than the $42 \%$ reduction by QPCR (Figure 2(b) and Table 2). UP780 restored some of the IRS-1 proteins (Figure 2(b), upper). Quantification was not attempted even though $\beta$-actin loading control was available (Figure 2(b), lower) due to background interference.

Liver triglyceride and cholesterol levels were measured from liver lipid extracts to validate the UP780 mechanism of action. HFD increased liver triglyceride level 12-fold above lean control. UP780 treatment decreased liver triglyceride level to $60 \%$ of HFD (Figure 3(a)) with statistical significance of $\mathrm{P}=0.029$ by T-test. Liver cholesterol levels were not dramatically changed by HFD over lean control. HFD increased liver cholesterol 25\% over lean control. In correlation to microarray pathway analysis, UP780 decreased liver cholesterol to $65 \%$ of HFD with statistical significance of $\mathrm{P}=0.016$ by T-test (Figure 3(b)).

Morphology of hepatosteatosis was examined (Figure 4). In lean control liver, lipid droplet was not visible. Vast amount of lipid droplets (black arrowheads) were observed in HFD liver sections. The liver functional unit of liver parenchyma is centered around the central vein (indicated in Figure 4) with nutrient supply from hepatic artery and portal vein reaching first to the hepatocytes distal from the central vein [30]. It was clear from Figure 4 that in HFD liver more lipid droplets and ballooning were observed in hepatocytes distal from central vein than proximal. Lipid droplets disappeared almost completely in the UP780-treated livers. When observed, the number of lipid droplets per cell in UP780 livers was much lower than HFD. Lymphocytes (white arrowhead)

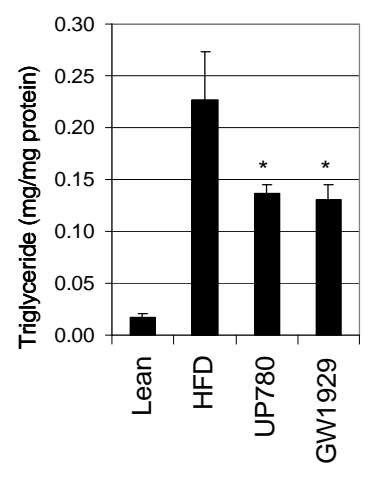

(a)

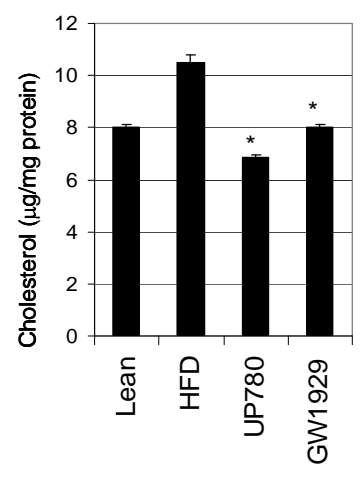

(b)
Figure 3. UP780 decreased liver triglyceride and cholesterol over HFD. Total lipids extracted from liver were used for (a) triglyceride and (b) cholesterol assays. Liver triglyceride and liver cholesterol were assayed in replicates and in dilutions, and independently multiple times. Representative assays were displayed. ${ }^{*}$ indicated T-test $\mathrm{P}$ value $<0.05$ compared to HFD.

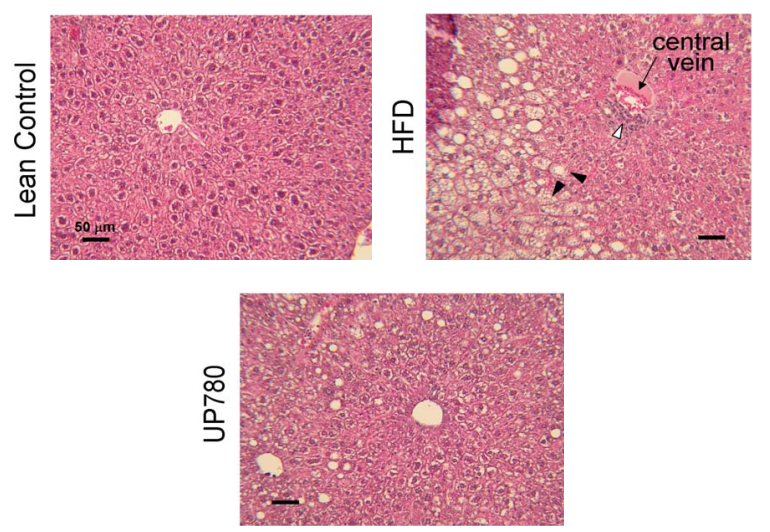

Figure 4. Liver steatosis. Formalin-fixed liver thin sections were stained with hematoxylin-eosin. Liver steatosis analyses were done for individual animals for each treatment group. Representative photomicrographs were shown. Black arrowheads, lipid droplets and ballooning. White arrowhead, inflammation. Central vein was indicated on the HFD liver, and existed in lean control and UP780 liver sections. Scale bars, $50 \mu \mathrm{m}$.

infiltration into liver was observed in HFD liver, not in lean control liver, and infrequently in UP780 liver (not shown).

Improvement of insulin sensitivity should be accompanied by decreased fasting plasma insulin levels; therefore fasting plasma insulin levels were measured for baseline, week-7 and week-10. In Figure 5, data were plotted by individual animals within the treatment groups. Lean control fasting plasma insulin levels were similarly low at baseline, week-7, and week-10. For HFD, week-7 showed higher fasting plasma insulin levels, but by week-10, two animals showed decreased fasting plasma insulin levels. After 18 weeks of high fat feeding, these two animals probably developed pancreatic islet degeneration. GW1929 was as expected. For the UP780 group, plasma insulin levels were decreased by week-7, and trended to decrease further at week-10 (Figure 5). Twoway ANOVA statistical analysis indicated that UP780 significantly decreased fasting plasma insulin compared to HFD, with $\mathrm{P}=0.05$, and GW1929 with $\mathrm{P}=4.67 \mathrm{E}-6$.

\section{DISCUSSION}

Microarray pathway analysis and validation indicated the mechanism of the UP780 effects in increasing insulin sensitivity and decreasing plasma glucose [18] by decreasing liver fatty acid and triglyceride biosynthesis, increasing liver mitochondria fatty acid $\alpha$-oxidation (possibly), and increasing WAT insulin signaling pathway (therefore increasing insulin sensitivity).

UP780 was discovered by high throughput screening of differentiated 3T3-L1 adipocytes that identified botanic substances capable of increasing adiponectin secretion [18]. Adiponectin together with leptin, another adi- 

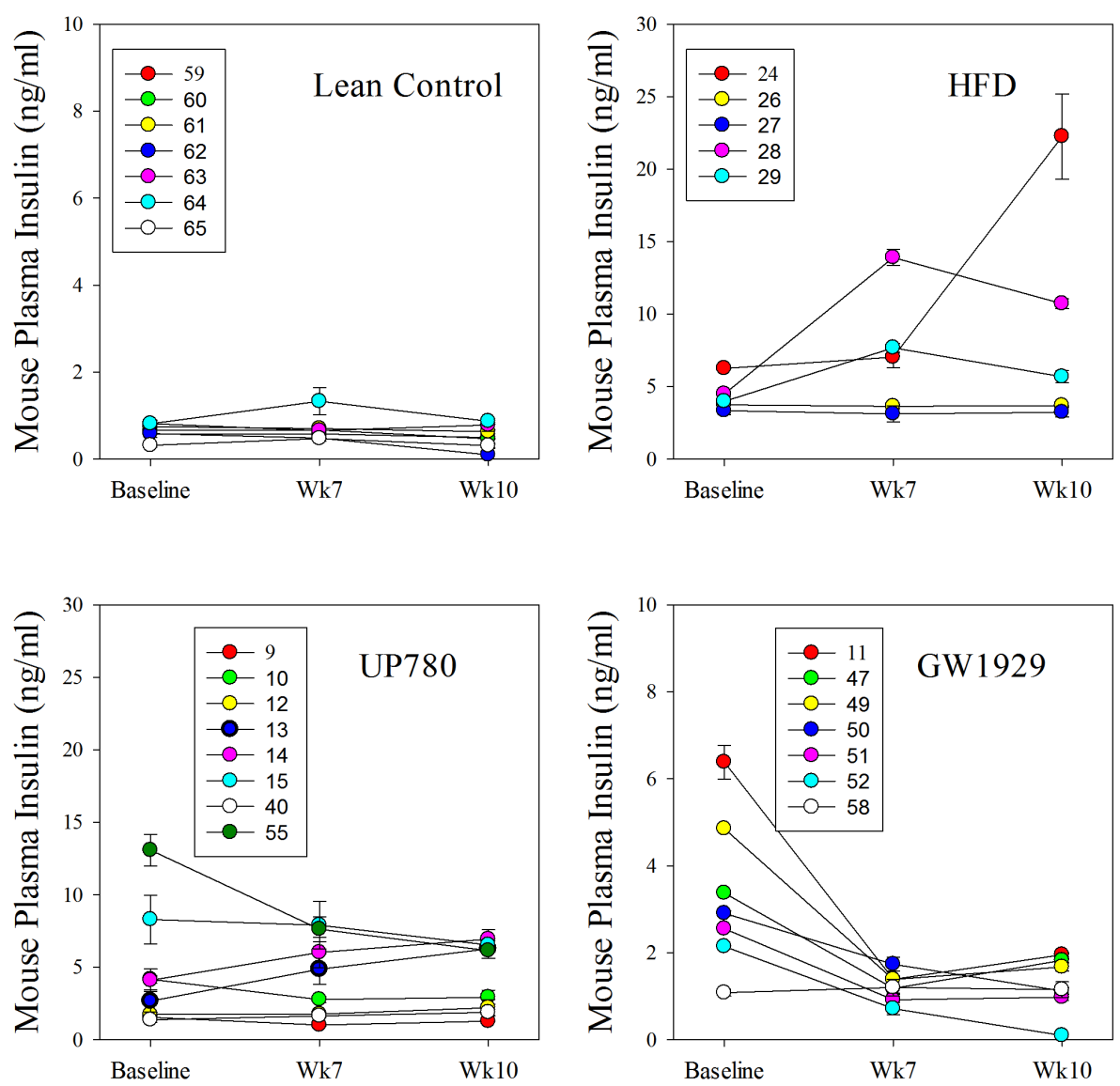

Figure 5. Fasting plasma insulin. Plasma insulin levels were plotted by individual animals per treatment groups of week-0, week-7 and week-10 plasma samples, using SigmaPlot. The animal numbers indicated were from experimental assignments. The treatment groups of lean control, HFD, UP780, and GW1929 were indicated in the plots. Each plasma sample was assayed in dilutions and in duplicates, and sometimes in repeats, therefore each data point contained $>2$ individual measurements. Statistical analysis was by 2-way ANOVA comparing UP780/GW groups to HFD group, with ${ }^{*}$ indicate $\mathrm{P} \leq 0.05$ and ${ }^{* *}$ indicated $\mathrm{P} \leq 0.01$.

pokine, in an insulin-resistant lipoatrophic mouse model completely reversed insulin resistance, but only partially by adiponectin or leptin alone [31]. In obese and diabetic rodents and humans, adiponectin levels were decreased, which were reversed with weight loss and diabetic treatments [31]. Adiponectin, together with adiponectin receptors AdipoR1 and AdipoR2, sensitizes tissues to insulin through regulation of glucose and fatty acid metabolism, activation of AMP-activated protein kinase (AMPK), activation of PPAR $\alpha$ signaling pathway, and conversion of the toxic ceramide to beneficial sphingosine through a ceramidase domain in AdipoR1/2 [32, 33]. This UP780 nutrigenomic study was successful in demonstrating decreased liver fatty acid biosynthesis and increased WAT insulin sensitivity, in line with adiponectin mechanism. Activation of AMPK by aloe, furthermore, was demonstrated by western blots of AMPK phosphorylation in WAT of DIO model [34]. Increased adiponectin gene expression in WAT by UP780 (Table 2) correlated with its discovery by screening.

Multiple animal/human studies agreed on the hypoglycemic effect of aloe [5,13-17,19,35-39] but not the lipid-lowering effects. A double-blind, placebo-controlled pilot clinic trial by Devaraj et al. showed significant cholesterol/LDL reduction by Qmatrix $^{\circledR}$ but not triglyceride, while UP780 caused no change to either blood triglyceride or cholesterol level [19]. Clinic trial by Huseini et al. claimed that aloe gel reduced both blood cholesterol and triglyceride, but the conclusion should be dismissed due to faulty statistical data analysis [38]. Clinic trial by Yagi et al. showed reduced blood triglyceride, but not cholesterol, by a high molecular weight fraction of Aloe vera gel. The Yagi study was not blinded and was without placebo control [39]. The Yongchaiyudha et al./Bunyapraphatsara et al. clinic studies of Aloe vera juice also showed reduced blood triglyceride, but not cholesterol; the studies were single-blinded and placebo-controlled [36,37]. 
In UP780 DIO studies [18], blood triglyceride levels could be significantly reduced in one experiment but not another, including the experiment that livers were collected for triglyceride and cholesterol assays (Figure 3) and for liver steatosis photomicrography (Figure 4). Such was the variation observed for animal DIO model where diet was strictly controlled. Fasting blood triglyceride and cholesterol levels are influenced by diet and additional environmental factors, which is difficult to control in clinic trials. Compounded with the variations in aloe preparations and the human genomes, modification of Aloe vera gel to blood lipid levels may have too much variation to be detected reliably. Perhaps, future clinic studies of Aloe vera gel effect to liver steatosis will achieve more uniform results.

\section{ACKNOWLEDGEMENTS}

The authors thank Mr. William Lee, the owner of Unigen, Inc., who supported the research. The authors thank Dr. Cannon for critical reading of this manuscript. The authors thank Dr. Yuan Zhao, Ms. Julia Foo, and Ms. Mei Hong for the screening of Unigen plant extract library.

\section{REFERENCES}

[1] CDC (2011) National diabetes factsheet. http://www.cdc.gov/diabetes/pubs/factsheet11.htm

[2] WHO (2011) Diabetes: Fact sheet. http://www.who.int/mediacentre/factsheets/fs312/en/inde x.html

[3] Reaven, G.M. (1988) Banting lecture 1988. Role of insulin resistance in human disease. Diabetes, 37, 1595-1607. doi:10.2337/diabetes.37.12.1595

[4] Kahn, S.E., Hull, R.L. and Utzschneider, K.M. (2006) Mechanisms linking obesity to insulin resistance and type 2 diabetes. Nature, 444, 840-846. doi:10.1038/nature05482

[5] Kim, K., Kim, H., Kwon, J., Lee, S., Kong, H., Im, S.A., Lee, Y.H., Lee, Y.R., Oh, S.T., Jo, T.H., Park, Y.I. and Lee, C.K. (2009) Hypoglycemic and hypolipidemic effects of processed Aloe vera gel in a mouse model of non-insulin-dependent diabetes mellitus. Phytomedicine, 16, 856863. doi:10.1016/j.phymed.2009.02.014

[6] Zhang, X., Zhao, Y., Zhang, M., Pang, X., Xu, J., Kang, C., Li, M., Zhang, C., Zhang, Z., Zhang, Y., Li, X., Ning, G. and Zhao, L. (2012) Structural changes of gut microbiota during berberine-mediated prevention of obesity and insulin resistance in high-fat diet-fed rats. PLoS One, 7, e42529. doi:10.1371/journal.pone.0042529

[7] Zhao, H.L, Sui, Y., Qiao, C.F., Yip, K.Y., Leung, R.K., Tsui, S.K., Lee, H.M., Wong, H.K., Zhu, X., Siu, J.J., He, L., Guan, J., Liu, L.Z., Xu, H.X., Tong, P.C. and Chan, J.C. (2012) Sustained antidiabetic effects of a berberine-containing Chinese herbal medicine through regulation of hepatic gene expression. Diabetes, 61, 933-943. doi:10.2337/db11-1164

[8] Chen, Q., Chan, L.L. and Li, E.T. (2003) Bitter melon (Momordica charantia) reduces adiposity, lowers serum insulin and normalizes glucose tolerance in rats fed a high fat diet. Journal of Nutrition, 133, 1088-1093.

[9] Xiong, Y., Shen, L., Liu, K.J., Tso, P., Wang, G., Woods, S.C. and Liu, M. (2010) Antiobesity and antihyperglycemic effects of ginsenoside $\mathrm{Rb} 1$ in rats. Diabetes, 59, 2505-2512. doi:10.2337/db10-0315

[10] Liu, D., Zhen, W., Yang, Z., Carter, J.D., Si, H. and Reynolds, K.A. (2006) Genistein acutely stimulates insulin secretion in pancreatic beta-cells through a cAMP-dependent protein kinase pathway. Diabetes, 55, 10431050. doi:10.2337/diabetes.55.04.06.db05-1089

[11] Dugoua, J.J., Seely, D., Perri, D., Cooley, K., Forelli, T., Mills, E. and Koren, G. (2007) From type 2 diabetes to antioxidant activity: A systematic review of the safety and efficacy of common and cassia cinnamon bark. Canadian Journal of Physiology and Pharmacology, 85, 837-847. doi:10.1139/Y07-080

[12] Baur, J.A., Pearson, K.J., Price, N.L., Jamieson, H.A., Lerin, C., Kalra, A, Prabhu, V.V., Allard, J.S., Lopez-Lluch, G., Lewis, K., Pistell, P.J., Poosala, S., Becker, K.G., Boss, O., Gwinn, D., Wang, M., Ramaswamy, S., Fishbein, K.W., Spencer, R.G., Lakatta, E.G., Le Couteur, D., Shaw, R.J., Navas, P., Puigserver, P., Ingram, D.K., de Cabo, R. and Sinclair, D.A. (2006) Resveratrol improves health and survival of mice on a high-calorie diet. Nature, 444, 337-342. doi:10.1038/nature05354

[13] Ajabnoor, M.A. (1990) Effect of aloes on blood glucose levels in normal and alloxan diabetic mice. Journal of Ethnopharmacology, 28, 215-220. doi:10.1016/0378-8741(90)90031-N

[14] Ghannam, N., Kingston, M., Al-Meshaal, I.A., Tariq, M., Parman, N.S. and Woodhouse, N. (1986) The antidiabetic activity of aloes: Preliminary clinical and experimental observations. Hormone Research, 24, 288-294. doi:10.1159/000180569

[15] Chacko, S., Sabatha, T. and Kuttan, R. (2008) Amelioration of alloxan-induced hyperglycemia by Aloe arborescens Miller and its possible mechanism. Pharmacologyonline, 2, 112-125.

[16] Can, A., Akev, N., Ozsoy, N., Bolkent, S., Arda, B.P., Yanardag, R. and Okyar, A. (2004) Effect of Aloe vera leaf gel and pulp extracts on the liver in type-II diabetic rat models. Biological \& Pharmaceutical Bulletin, 27, 694698. doi:10.1248/bpb.27.694

[17] Rajasekaran, S., Sivagnanam, K., Ravi, K. and Subramanian, S. (2004) Hypoglycemic effect of Aloe vera gel on streptozotocin-induced diabetes in experimental rats. Journal of Medicinal Food, 7, 61-66. doi:10.1089/109662004322984725

[18] Yimam, M., Zhao, J., Corneliusen, B., Pantier, M., Brownell, L. and Jia, Q. (2013) UP780, a chromone enriched Aloe composition, improves insulin sensitivity. Metabolic Syndrome and Related Disorders, 10, 319-386. doi:10.1089/met.2012.0135

[19] Devaraj, S., Yimam, M., Brownell, L., Jialal, I., Singh, S. and Jia, Q. (2012) Effects of aloe vera supplementation in subjects with pre-diabetes/metabolic syndrome. Metabolic Syndrome and Related Disorders, 10, 319-386.

[20] Rajasekaran, S., Ravi, K., Sivagnanam, K. and Subrama- 
nian, S. (2006) Beneficial effects of aloe vera leaf gel extract on lipid profile status in rats with streptozotocin diabetes. Clinical and Experimental Pharmacology and Physiology, 33, 232-237.

doi:10.1111/j.1440-1681.2006.04351.X

[21] Tanaka, M., Misawa, E., Ito, Y., Habara, N., Nomaguchi, K., Yamada, M., Toida, T., Hayasawa, H., Takase, M., Inagaki, M. and Higuchi, R. (2006) Identification of five phytosterols from Aloe vera gel as anti-diabetic compounds. Biological \& Pharmaceutical Bulletin, 29, 14181422. doi:10.1248/bpb.29.1418

[22] Hamman, J.H. (2008) Composition and applications of Aloe vera leaf gel. Molecules, 13, 1599-1616. doi:10.3390/molecules 13081599

[23] Berger, J. and Moller, D.E. (2002) The mechanisms of action of PPARs. Annual Review of Medicine, 53, 409435. doi:10.1146/annurev.med.53.082901.104018

[24] OMIM': Online mendelian inheritance in $\operatorname{Man}^{\circledR}$. http://omim.org/

[25] Ingenuity pathway analysis. http://www.ingenuity.com/

[26] Shulman, G.I. (2004) Unraveling the cellular mechanism of insulin resistance in humans: New insights from magnetic resonance spectroscopy. Physiology (Bethesda), 19, 183-190. doi:10.1152/physiol.00007.2004

[27] Le Gouill, E., Jimenez, M., Binnert, C., Jayet, P.Y., Thalmann, S., Nicod, P., Scherrer, U. and Vollenweider, P. (2007) Endothelial nitric oxide synthase (eNOS) knockout mice have defective mitochondrial beta-oxidation. $\mathrm{Di}$ abetes, 56, 2690-2696. doi: 10.2337/db06-1228

[28] Saltiel, A.R. and Kahn, C.R. (2001) Insulin signalling and the regulation of glucose and lipid metabolism. Nature, 414, 799-806. doi:10.1038/414799a

[29] Powell, K. (2007) Obesity: The two faces of fat. Nature, 447, 525-527. doi:10.1038/447525a

[30] Anderson, N. and Borlak, J. (2008) Molecular mechanisms and therapeutic targets in steatosis and steatohepatitis. Pharmacological Reviews, 60, 311-357. doi:10.1124/pr.108.00001

[31] Kadowaki, T. and Yamauchi, T. (2005) Adiponectin and adiponectin receptors. Endocrine Reviews, 26, 439-451. doi:10.1210/er.2005-0005

[32] Hardie, D.G. (2004) The AMP-activated protein kinase
pathway-New players upstream and downstream. Journal of Cell Science, 117, 5479-5487. doi: $10.1242 /$ jes. 01540

[33] Holland, W.L., Miller, R.A., Wang, Z.V., Sun, K., Barth, B.M., Bui, H.H., Davis, K.E., Bikman, B.T., Halberg, N., Rutkowski, J.M., Wade, M.R., Tenorio, V.M., Kuo, M.S, Brozinick, J.T., Zhang, B.B., Birnbaum, M.J., Summers, S.A. and Scherer, P.E. (2011) Receptor-mediated activation of ceramidase activity initiates the pleiotropic actions of adiponectin. Nature Medicine, 17, 55-63. doi: $10.1038 / \mathrm{nm} .2277$

[34] Shin, E., Shin, S., Kong, H., Lee, S., Do, S.G., Jo, T.H., Park, Y.I., Lee, C.K., Hwang, I.K. and Kim, K. (2011) Dietary aloe reduces adipogenesis via the activation of AMPK and suppresses obesity-related inflammation in obese mice. Immune Netw, 11, 107-113. doi:10.4110/in.2011.11.2.107

[35] Ngo, M.Q., Nguyen, N.N. and Shah, S.A. (2010) Oral aloe vera for treatment of diabetes mellitus and dyslipidemia. American Journal of Health-System Pharmacy, 67, 1804-1808.

[36] Yongchaiyudha, S., Rungpitarangsi, V., Bunyapraphatsara, N. and Chokechaijaroenporn, O. (1996) Antidiabetic activity of aloe vera L. juice. I. Clinical trial in new cases of diabetes mellitus. Phytomedicine, 3, 241-243. doi:10.1016/S0944-7113(96)80060-2

[37] Bunyapraphatsara, N., Yongchaiyudha, S., Rungpitarangsi, V. and Chokechaijaroenporn, O. (1996) Antidiabetic activity of Aloe vera L. juice. II. Clinical trial in diabetes mellitus patients in combination with glibenclamide. Phytomedicine, 3, 245-248. doi:10.1016/S0944-7113(96)80061-4

[38] Huseini, H.F., Kianbakht, S., Hajiaghaee, R. and Dabaghian, F.H. (2011) Anti-hyperglycemic and anti-hypercholesterolemic effects of Aloe vera leaf gel in hyperlipidemic type 2 diabetic patients: A randomized doubleblind placebo-controlled clinical trial. Planta Medica, 78, 311-316. doi:10.1055/s-0031-1280474

[39] Yagi, A., Hegazy, S., Kabbash, A. and Abd-El Wahab, E. (2009) Possible hypoglycemic effect of aloe vera L. high molecular weight fractions on type 2 diabetic patients. Saudi Pharmaceutical Journal, 17, 209-215. doi:10.1016/j.jsps.2009.08.007 


\section{SUPPLEMENTAL MATERIALS}

\section{MATERIALS AND METHODS}

\subsection{Tissue Collection from Dio Mouse Model}

DIO mice were as described in the companion paper [1]. Lean, HFD, UP780, and GW1929 fasting blood samples were taken before treatment (baseline), during treatment (7 weeks), and at the time of euthanasia (10 weeks). Mice were anesthetized with $\mathrm{CO}_{2}$; liver and visceral WAT tissues were collected within 5 minutes of euthanasia. For RNA isolation, $5 \mathrm{~mm}$ tissue strips were preserved in RNALater (Ambion). For Western blots, triglyceride and cholesterol assays, tissues were snap frozen in liquid nitrogen and stored at $-80^{\circ} \mathrm{C}$. For histology, one lobe of the livers were fixed in $10 \%$ formalin/phosphate buffered saline (SIGMA) and stored at $4^{\circ} \mathrm{C}$. Fixed livers were thin sectioned and stained with hematoxylin-eosin for microscopic observations.

\subsection{RNA Extraction}

For total RNA extraction, RNEasy kit was used for total liver RNA extraction, and RNEasy for Fatty Tissue kit was used for WAT RNA extraction (Qiagen). RNA quailties were determined with glyoxal agarose gel electrophoresis (Ambion). When genomic DNA was observed, a second extraction was carried out.

\subsection{Microarray}

Affymetrix mouse genome 4302.0 array was used for microarray analysis of liver and WAT gene expression. Microarray procedures followed the standard protocol of Affymetrix GeneChip one-cycle target preparation [2]. The mouse samples were coded LC, LV, and LUP for livers of lean-control, HFD, and UP780, respectively, and FC, FV, and FUP for WAT. Three mice per treatment group, 3 treatment groups, and 2 tissues, in total $18 \mathrm{mi}$ croarray chips were used. All microarray datasets passed quality controls, including GCOS [3] and Bioconductor package affy [4] (Supplement Figures 1 and 2). Details of microarray data analysis followed published procedures $[5,6]$.

\subsection{Pathway Analysis}

Analysis of microarray data, in the range of 45,000 probe sets, benefited greatly from the Ingenuity pathway analysis (IPA) software to develop a sense of the biological significance. The microarray analysis results by Bioconductor of eBayes-adjusted p-values, log2 fold changes, and $\log 2$ expression values were uploaded into the IPA server. Cutoff criteria of $\mathrm{p} \leq 0.05, \log 2$ fold change $\geq 0.8$, and $\log 2$ intensity $\geq 3.5$ were applied. Furthermore, due to multiple probe sets per gene minimal p-value was set to resolve among multiple probe sets. IPA results of canonical pathways were further analyzed in detail. Information of gene functions were from IPA and OMIM databases $[7,8]$.

\subsection{Real-Time QPCR}

Total RNAs in excess of the needs for microarray were

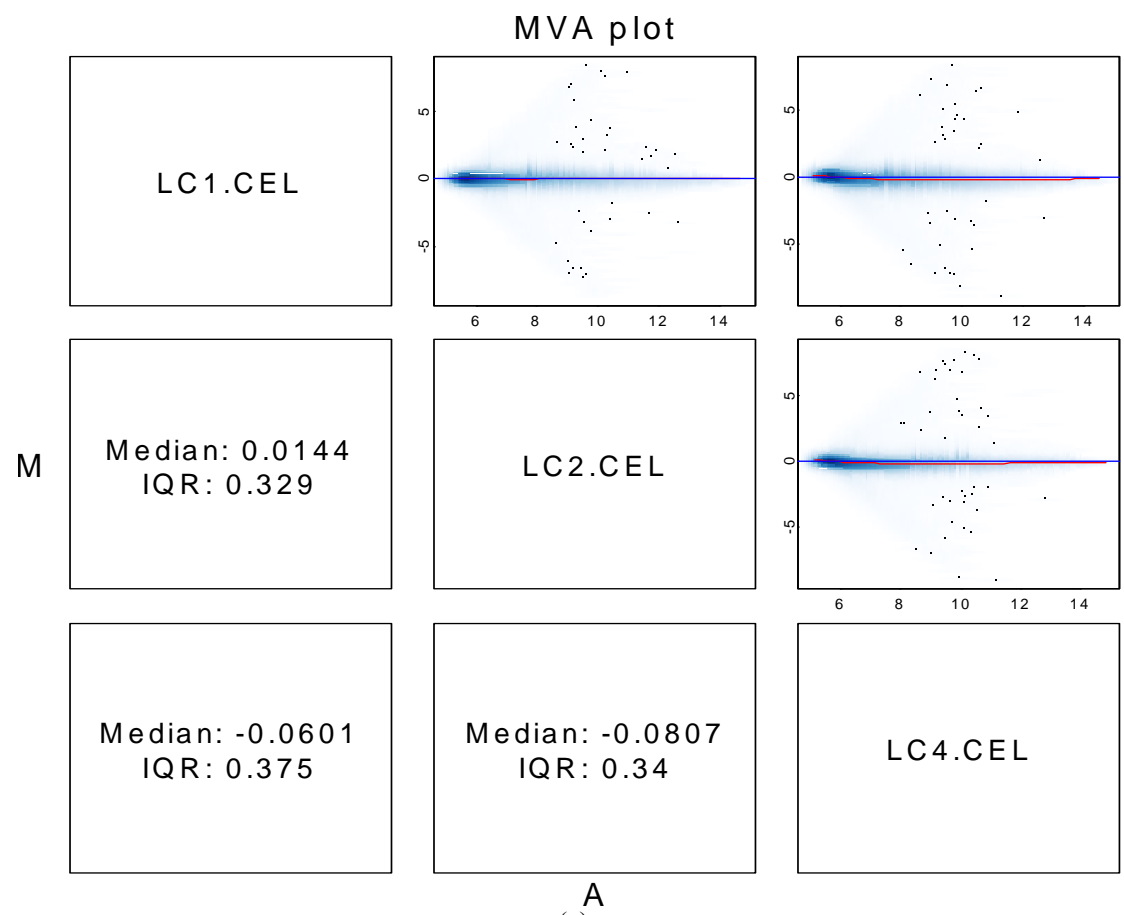

(a) 

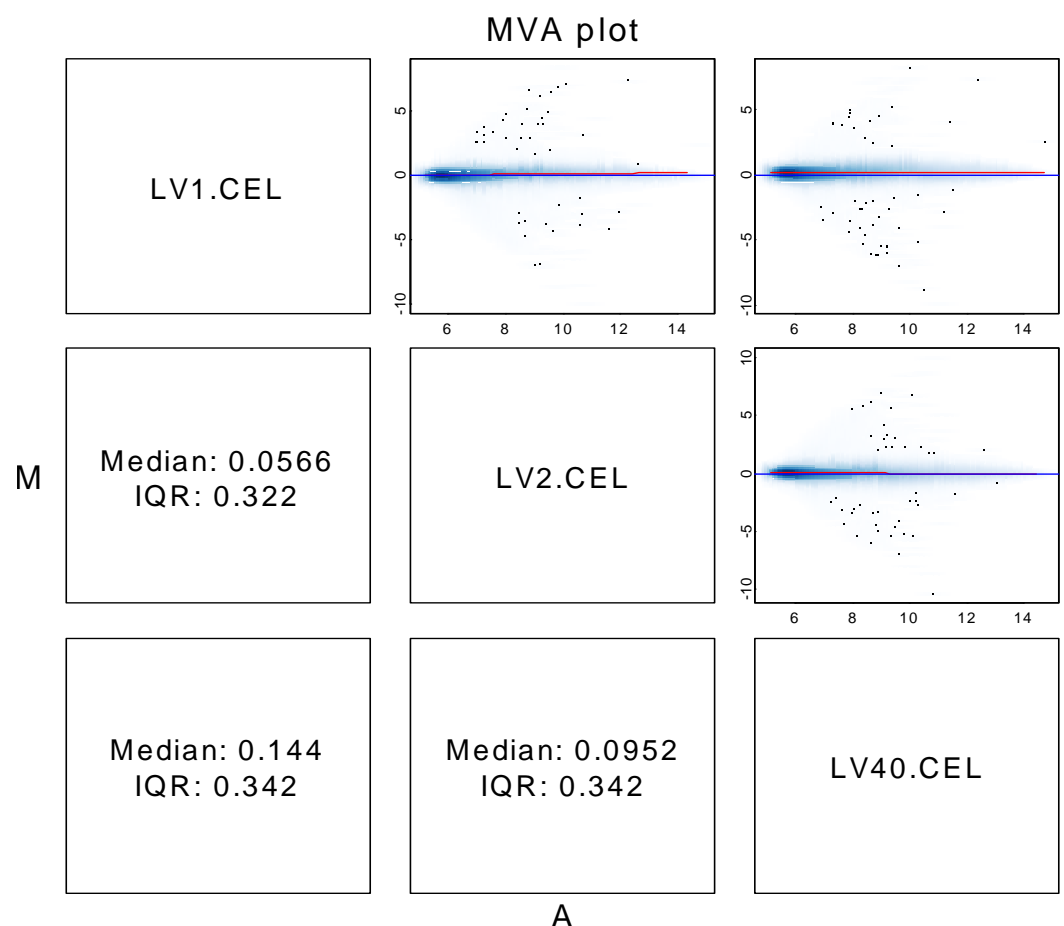

(b)
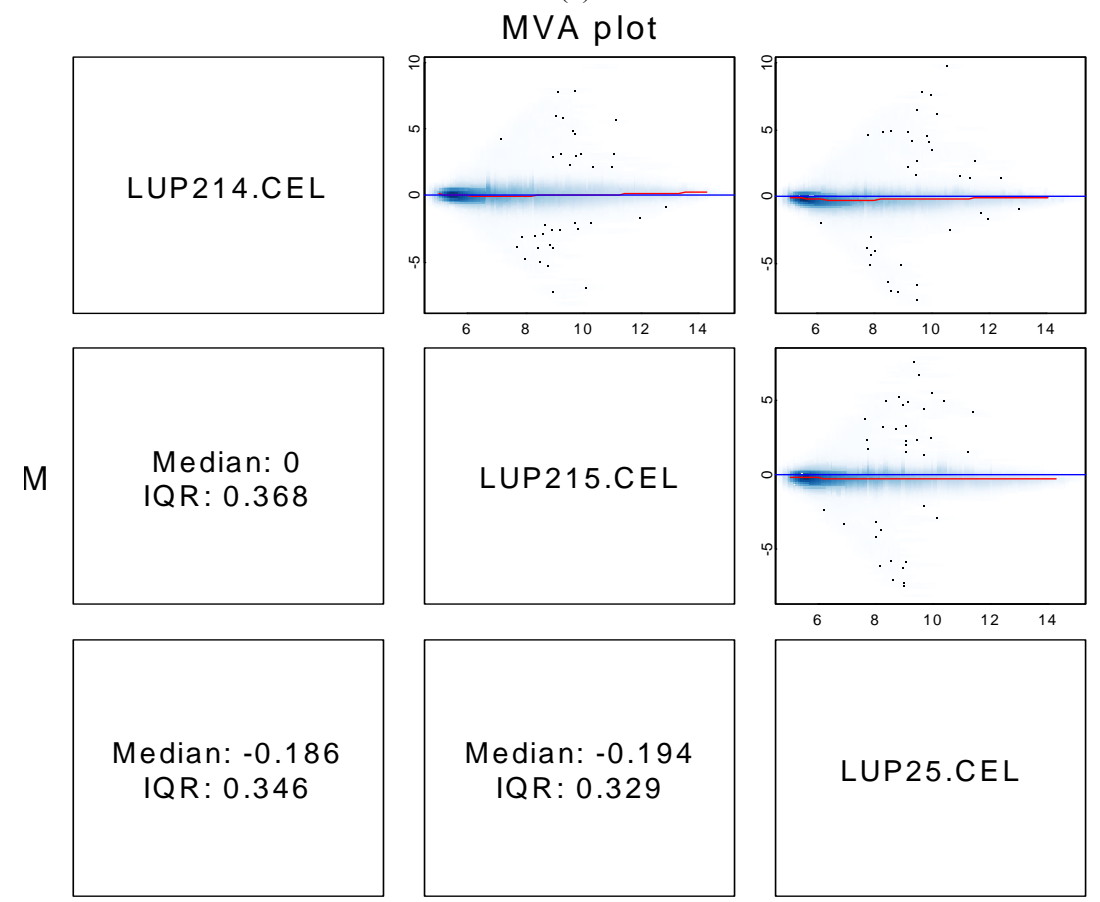

A
$(\mathrm{c})$

Supplement Figure 1. Microarray data quality control plots for the nine liver microarray chips. Probe level data/object (before gcrma, affy preprocessing of background subtraction, normalization, and summarization of intensities) from the Bioconductor affy package was used for quality control plots. MVA plots were used for assessing the three biological replicates each for A. lean control (LC1, LC2, and LC4), B. HFD (LV1, LV2, and LV40), and C. HFD + UP780 (LUP25, LUP214, and LUP215) chips. The MVA plots of all pairwise comparisons were particularly useful in diagnosing problems in replicate sets of arrays. The plots indicated tight correlation among the replicate sets of arrays. Based on these quality control plots, the nine liver microarray chips were judged to be of good quality. 

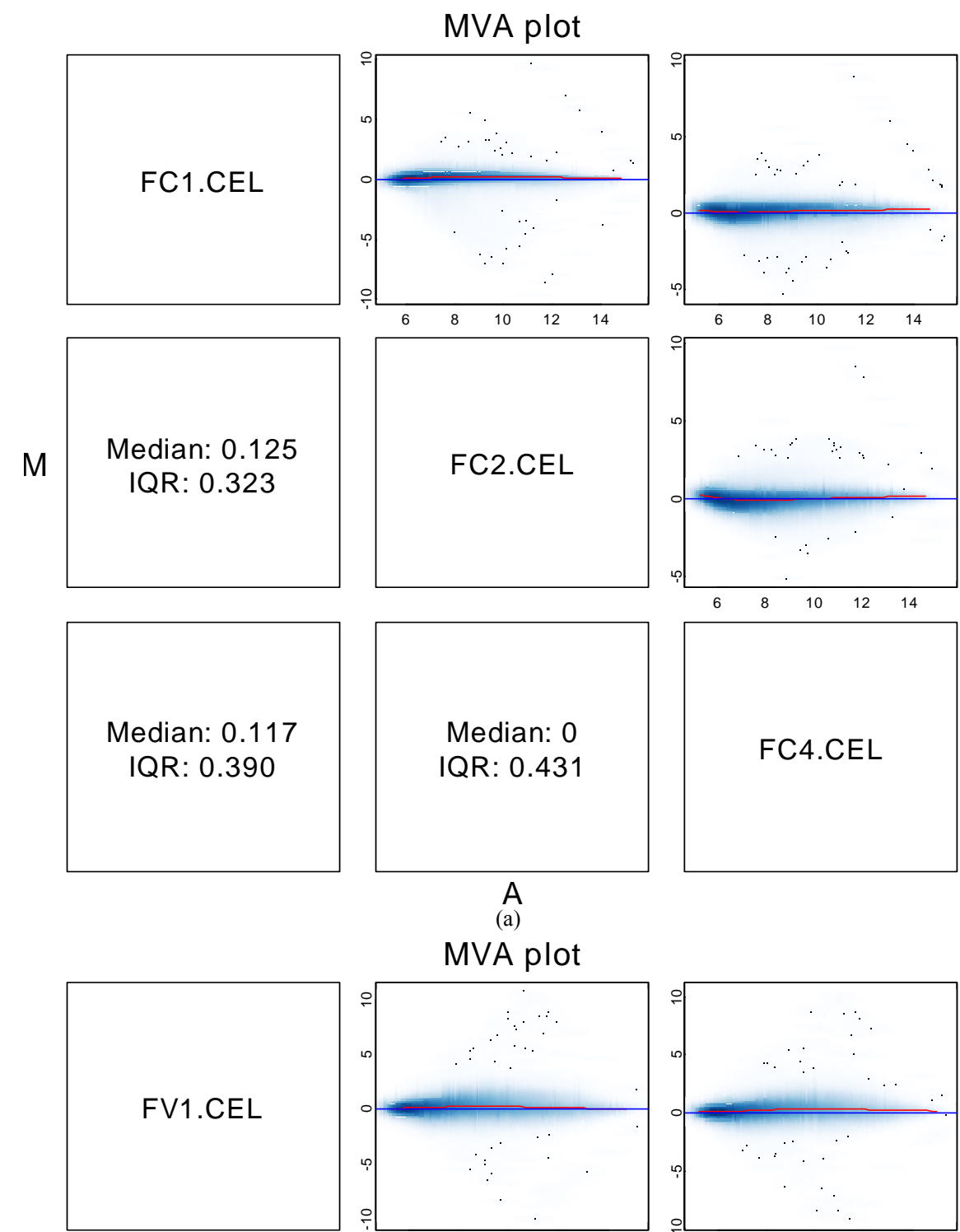

(a)

MVA plot
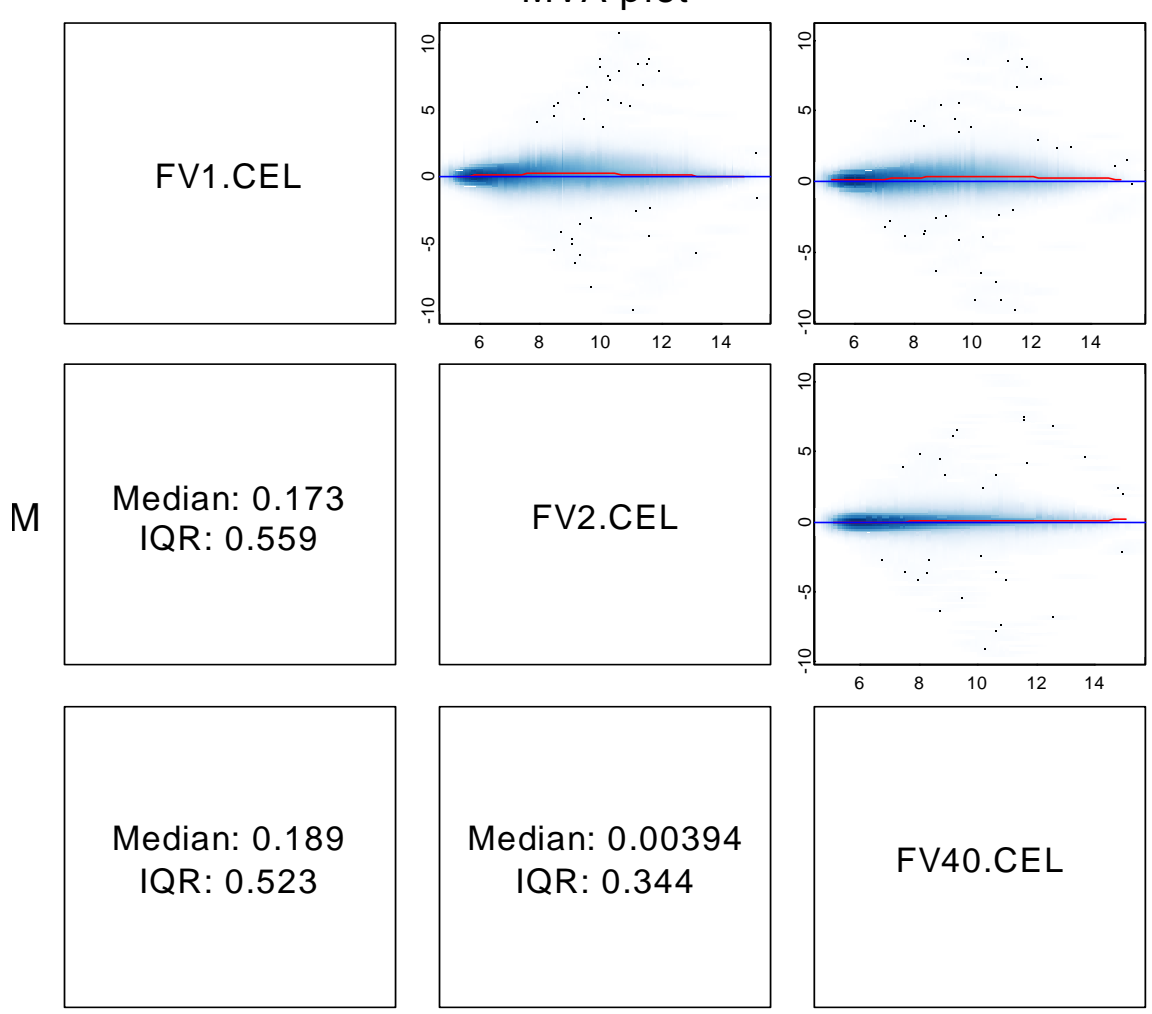

A 


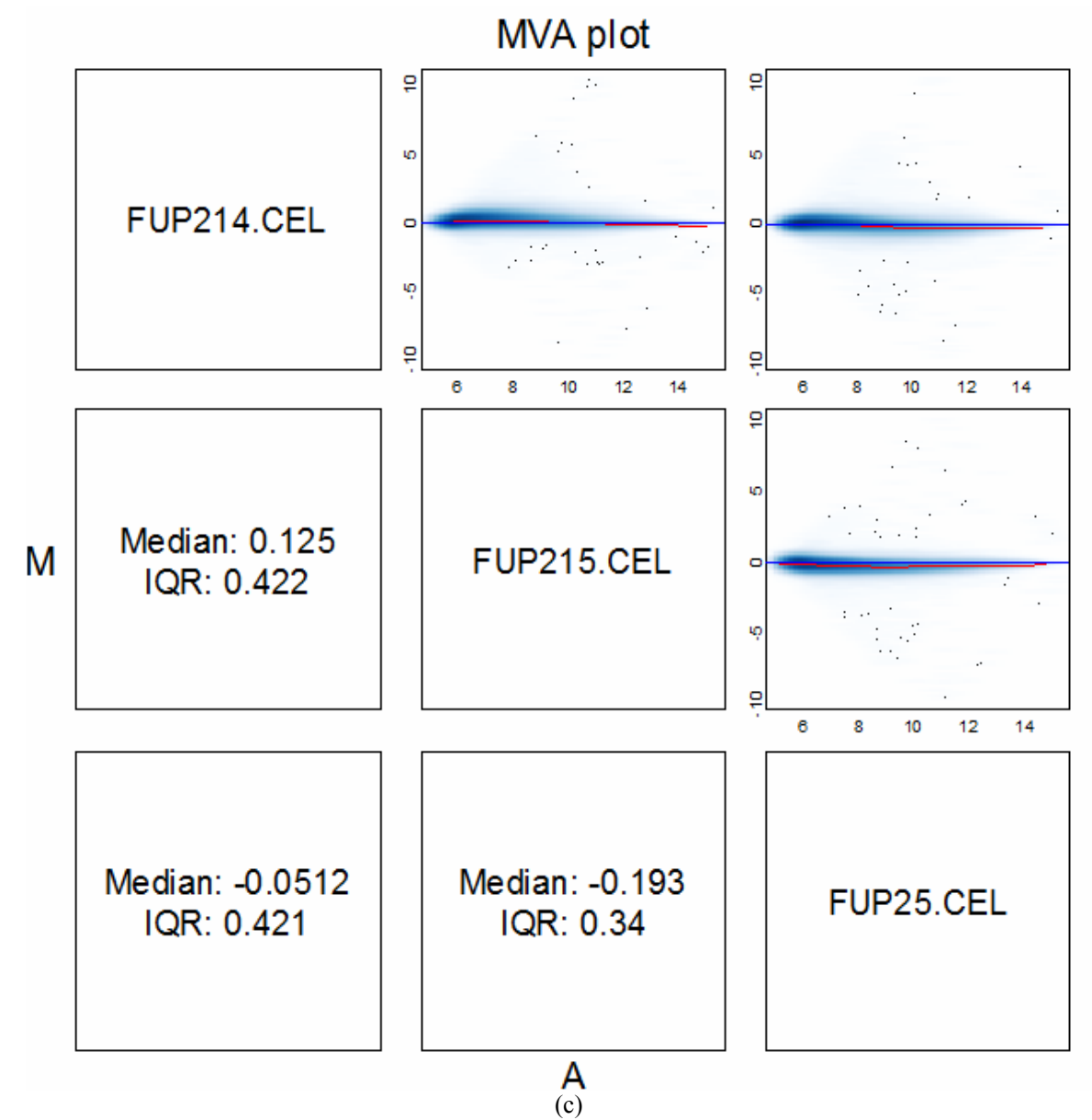

Supplement Figure 2. Microarray data quality control plots for the nine WAT microarray chips. Probe level data/object from affy package (before gcrma preprocessing of background subtraction, normalization, and summarization of intensities), the Bioconductor affy package was used for quality control plots. MVA plots were used for assessing the three biological replicates each for A. lean control (FC1, FC2, and FC4), B. HFD (FV1, FV2, and FV40), and C. HFD + UP780 (FUP25, FUP214, and FUP215) chips. The MVA plots of all pairwise comparisons were particularly useful in diagnosing problems in replicate sets of arrays. The plots indicated tight correlation among the replicate sets of arrays. Based on these quality control plots, the nine WAT microarray chips were judged to be of good quality.

combined for QPCR. Superscript III reverse transcriptase (Invitrogen) was used for cDNA synthesis. The ABI TaqMan Gene Expression assays for the selected genes were confirmed by RefSeq accession numbers before use, to ensure the sequences used by the Affymetrix mouse genome 4302.0 array and the ABI TaqMan Gene Expression assays were compatible. Thermal cycling and fluorescence detection was performed by an ABI 7700 Sequence Detector. The relative quantification method of $\triangle \triangle \mathrm{CT}$ was used for data analysis. Most QPCR runs were multiplex reactions and each plate contained at least one control cDNA (the lean control) and each well contained the GAPDH internal control. Singleplex QPCR was used for abundant transcripts such as adiponectin with GAPDH controls in separate wells. QPCR reactions were run in triplicates and results expressed as mean \pm S.D.

\subsection{Western Blot}

Mouse liver and WAT were homogenized in RIPA buffer (50 mM Tris. $\mathrm{HCl} \mathrm{pH} 7.4,150 \mathrm{mM} \mathrm{NaCl}, 1 \%$ Triton X-100, $0.25 \%$ deoxycholate, supplemented with a protease inhibitor cocktail (Roche) and a phosphatase inhibitor cocktail (Pierce)) and debris removed by centrifugation at $5000 \mathrm{~g}$ for $5 \mathrm{~min}$. Protein concentrations were determined by BCA protein assay (Pierce). Twenty five $\mu \mathrm{g}$ of liver proteins and $50 \mu \mathrm{g}$ of WAT proteins were used per lane for $4 \%-12 \%$ Bis-Tris gel electrophoresis (Invitrogen). The proteins were electroporated onto PVDF 
membranes and immunoblotted: mouse monoclonal antibody specific for fatty acid synthase (FASN) at 1:1000 dilution, rabbit polyclonal antibody specific for insulin receptor substrate-1 (IRS-1) at 1:200 dilution, and secondary HRP-conjugated antibodies at 1:3000 dilution for antimouse IgG and 1:5000 dilution for anti-rabbit IgG (Santa Cruz); detected with ECL-Plus chemiluminescence solution and ECL film (GE Healthcare). For quantification, ECL films were scanned and the band intensities analyzed with NIH ImageJ software.

\subsection{Liver Triglyceride and Cholesterol Assays}

Liver homogenates and protein BCA assay were as described for Western blot. Liver homogenates were mixed with two volumes of methanol and chloroform (1:3, by volume) and shook vigorously for 10 minutes, then centrifuged for 15 minutes at 14,000 rpm. The organic layers were transferred to clean tubes. Extraction was repeated and the two organic fractions combined. The organic fractions were dried under $\mathrm{N}_{2}$ gas, then resuspended in ethanol. The extracted lipids were assayed in duplicate using triglyceride assay kits (Cayman Chemicals and Sigma-Aldrich) and a cholesterol assay kit (Cayman Chemicals). Each assay plate included a standard curve (Cayman Chemicals). Several dilutions for each sample were tested. The total liver triglyceride and cholesterol concentrations were normalized by protein concentrations in the initial liver homogenates, and expressed as mean \pm S.D. Statistical analysis used T-test.

\subsection{Insulin ELISA Assay}

Plasma samples collected at baseline, week-7 and week10 of treatments were used for mouse insulin ELISA (Crystal Chem). A standard curve was included in every assay plate and all samples were assayed in duplicates. For assay results that fell outside the range of the standard curves, ELISA assays were repeated with dilutions. SigmaPlot was used for standard curve-fitting (logistic 4-parameter) and X-Y conversion. Results were expressed as mean \pm S.D. Statistical analysis used 2-way ANOVA (SigmaStat).

\section{RESULTS AND DISCUSSIONS}

\subsection{Microarray Data Analysis}

The nine-chip datasets from tissue samples (liver or WAT) were read-in together using the Bioconductor affy package [5] as one object, so that the subsequent preprocessing steps could be conducted as one experiment. The preprocessing steps of background correction, normalization, and summarization of the expression values were carried out using the gcrma package, taking advantage of the background adjustment feature with probe GC-content sequence information [9]. The expression values generated by gcrma were summarized as $\log 2$ transformed expression values. Statistical analyses for differential expressions by Student's T-test were calculated by using the linear model as implemented in the limma package [6]. Three contrasts, HFD + UP780 vs. HFD, HFD + UP780 vs. lean control, and HFD vs. lean control, were computed using the lmfit function, followed by the eBayes function to adjust the standard errors of the $\log 2$-fold changes for the 3 contrasts, or false discovery rate (FDR) [6]. The analysis results of adjusted p-values, $\log 2$ fold changes, and $\log 2$ expression values were uploaded to the Ingenuity IPA [8] website for pathway analysis.

Global views of gene expression variations influenced by HFD and by UP780 on top of HFD were extracted from the results of limma linear model fits [6]. In Supplement Figures 3(a) and (b), Venn diagrams show the number of significant gene expression variations scored by limma and the number of overlapping genes shared by the comparisons between lean control (LC and FC), HFD (LV and FV), and HFD+UP780 (LUP and FUP). The distributions of up- or down-regulations are plotted in Supplement Figure 3(c) for liver and Supplement Figure 3(d) for WAT. Among the 729 LUP-LC significant genes, 425 were up-regulated and 304 were down regulated. Among the 661 LV-LC significant genes, 486 were upregulated and 175 were down regulated (Supplement Figure 3(c)). Apparently in liver, HFD tends to induce gene expression levels and UP780 tends to reduce gene expression levels. This trend became clear when individual genes in significant metabolic and signaling pathways were examined (Table 1 and Supplement Tables 1 and 2).

From WAT far more genes were scored significant, and had larger fold-changes as compared to liver (Supplement Figure 3(c) and (d)). Among the 660 FUP-FC significant genes, 278 were up-regulated and 382 were down-regulated. Among the 2705 significant FV-FC genes, 1025 were up-regulated and 1680 were down-regulated (Supplement Figure 3(d)). The large gene number difference between FUP-FC and FV-FC suggested that in WAT, HFD caused wide-spread and strong gene expression regulations, and UP780 treatment decreased globally these gene expression regulations to be closer to the lean control.

\subsection{IPA Pathway Analysis}

The pathways were ranked by right-tailed Fisher's exact test for the significance of changes between two contrasts, taken into consideration 1) the number of genes that passed the cutoff and were also in the pathway, 2) 


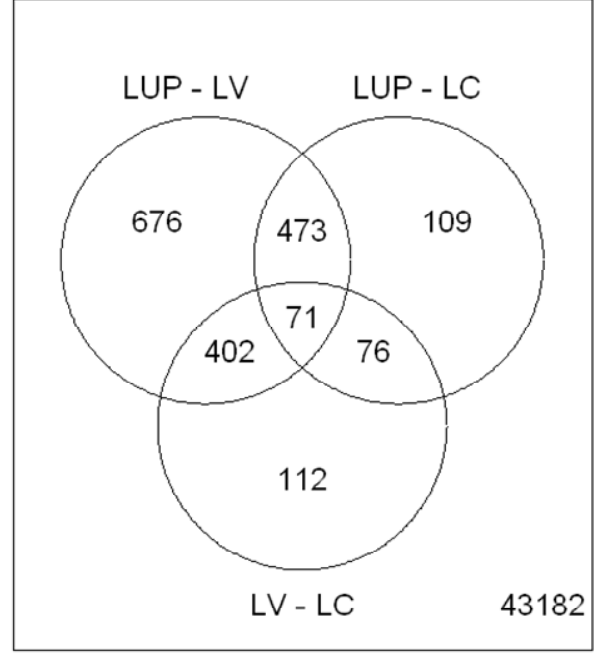

(a)

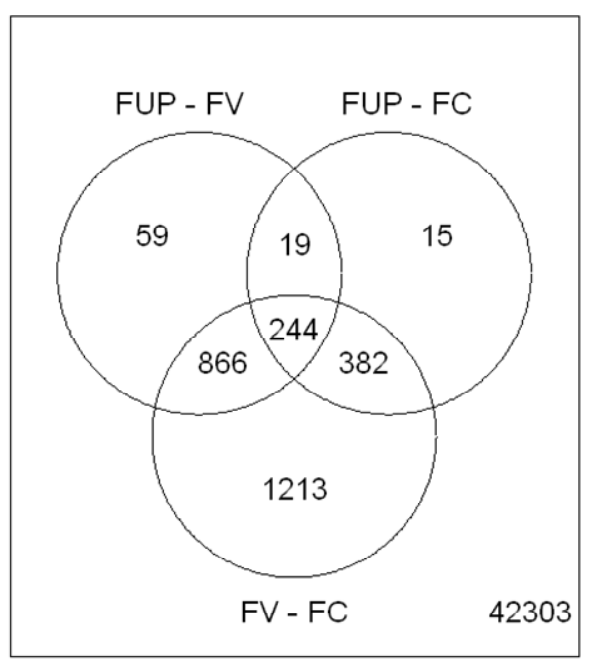

(b)

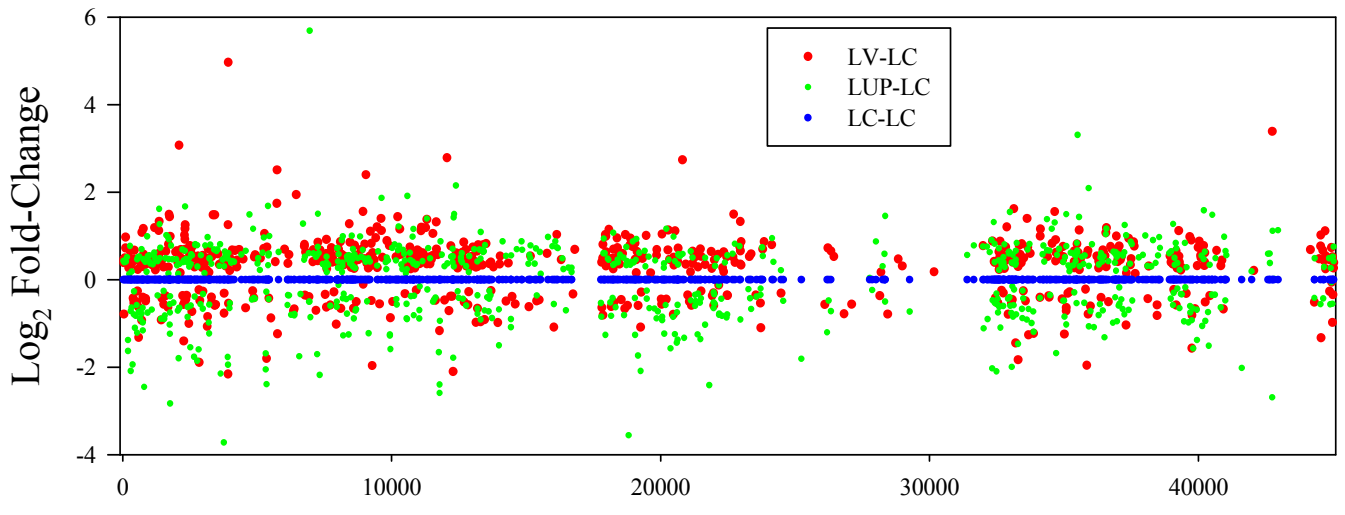

Gene Index

(c)

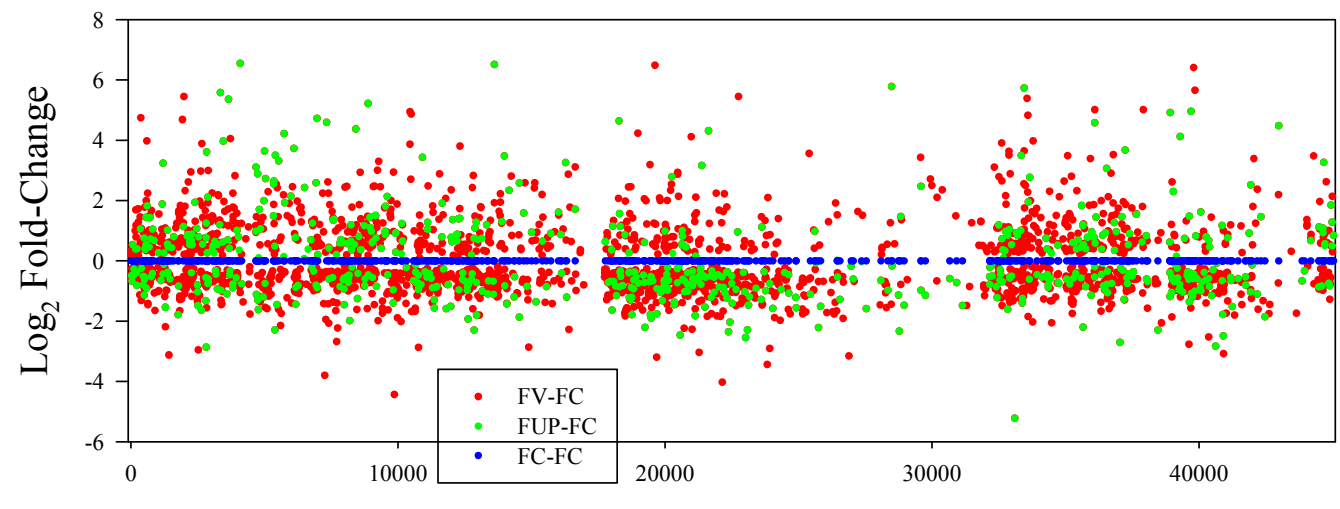

Gene Index

(b)

Supplement Figure 3. Gene Expression variations by linear model fit. Significant gene expression variations were data exported from limma linear model fit. Venn diagrams show the numbers of genes with differential expression from the three comparisons and the gene numbers of overlapping distribution between and among the three comparisons, A liver, B WAT. The differentially expressed genes in individual comparisons of Venn diagrams were plotted to show the distribution of up- or down-regulated genes influenced by HFD and by HFD + UP780, using the lean controls as the baseline, C liver, D WAT. Gene index was numbered according to the gene-ID list of the Affymetrix mouse genome 430.2 chip. 
Supplement Table 1.

\begin{tabular}{|c|c|c|c|c|c|c|c|c|c|c|c|}
\hline \multirow{2}{*}{ Name } & \multirow{2}{*}{ Description } & \multirow{2}{*}{ RefSeq ID } & \multicolumn{3}{|c|}{$\mathbf{L U P} / \mathbf{L V}$} & \multicolumn{3}{|c|}{ LUP/LC } & \multicolumn{3}{|c|}{ LV/LC } \\
\hline & & & p-value & $\begin{array}{l}\text { Log2 } \\
\text { Ratio }\end{array}$ & Intensity & p-value & $\begin{array}{l}\text { Log2 } \\
\text { Ratio }\end{array}$ & Intensity & p-value & $\begin{array}{l}\text { Log2 } \\
\text { Ratio }\end{array}$ & Intensity \\
\hline ACACB & $\begin{array}{l}\text { acetyl-Coenzyme A } \\
\text { carboxylase beta }\end{array}$ & NM_133904 & 0.01 & -1.641 & 5.459 & 0.015 & -1.498 & 6.957 & 0.762 & 0.143 & 7.1 \\
\hline ACAT2 & $\begin{array}{l}\text { acetyl-Coenzyme A } \\
\text { acetyltransferase } 2 \\
\text { acyl-CoA }\end{array}$ & NM_009338 & 0.035 & -0.586 & 10.935 & 0.005 & -0.927 & 11.862 & 0.117 & 0.152 & 12.068 \\
\hline ACSL3 & $\begin{array}{l}\text { synthetase long-chain } \\
\text { family member } 3\end{array}$ & NM_001033606 & 0.011 & -0.825 & 7.664 & 0.064 & -0.519 & 8.184 & 0.233 & 0.305 & 8.489 \\
\hline ACSS2 & $\begin{array}{l}\text { acyl-CoA synthetase } \\
\text { short-chain } \\
\text { family member } 2\end{array}$ & NM_019811 & 0.313 & -0.529 & 11.218 & 0.02 & -1.499 & 12.717 & 0.054 & -1.03 & 11.548 \\
\hline ACYP1 & $\begin{array}{l}\text { acylphosphatase } 1 \text {, } \\
\text { erythrocyte } \\
\text { (common) type }\end{array}$ & NM_025421 & 0.004 & 1.214 & 7.721 & 0.013 & 0.937 & 6.784 & 0.234 & -0.386 & 7.339 \\
\hline AKR1B1 & $\begin{array}{l}\text { aldo-keto reductase } \\
\text { family } 1, \text { member B1 } \\
\text { (aldose reductase) }\end{array}$ & NM_009658 & 0.002 & 0.852 & 7.936 & 0.026 & 0.472 & 7.464 & 0.018 & -0.587 & 5.291 \\
\hline ALDH1B1 & $\begin{array}{l}\text { aldehyde dehydrogenase } \\
1 \text { family, member B1 }\end{array}$ & NM_028270 & 0.008 & -1.606 & 6.814 & 0.094 & -0.827 & 7.641 & 0.111 & 0.779 & 8.419 \\
\hline ALDH3A2 & $\begin{array}{l}\text { aldehyde dehydrogenase } \\
3 \text { family, member A2 }\end{array}$ & NM_007437 & 0.048 & -0.654 & 11.296 & 0.516 & 0.184 & 11.112 & 0.019 & 0.838 & 11.949 \\
\hline ALDH5A1 & $\begin{array}{l}\text { aldehyde dehydrogenase } \\
5 \text { family, member A1 } \\
\text { (succinate-semialdehyde } \\
\text { dehydrogenase) }\end{array}$ & NM_172532 & 0.008 & -0.808 & 8.158 & 0.09 & -0.422 & 8.58 & 0.114 & 0.387 & 8.966 \\
\hline DLAT & $\begin{array}{l}\text { dihydrolipoamide } \\
\text { S-acetyltransferase } \\
\text { malic enzyme } 1 \text {, }\end{array}$ & NM_145614 & 0.003 & -0.895 & 8.757 & 0.003 & -0.903 & 9.66 & 0.803 & 0.084 & 7.625 \\
\hline ME1 & $\begin{array}{l}\text { NADP }(+) \text {-dependent, } \\
\text { cytosolic }\end{array}$ & NM_008615 & 0.012 & -1.137 & 11.44 & 0.017 & -1.058 & 12.499 & 0.7 & -0.172 & 11.28 \\
\hline $\mathrm{PC}$ & pyruvate carboxylase & NM_008797 & 0.011 & -0.632 & 11.029 & 0.043 & 0.45 & 10.579 & 0.001 & 1.081 & 11.66 \\
\hline PKLR & $\begin{array}{l}\text { pyruvate kinase, liver } \\
\text { and } \mathrm{RBC}\end{array}$ & NM_001099779 & 0.006 & -1.179 & 9.396 & 0.142 & -0.626 & 8.63 & 0.049 & 0.7 & 10.574 \\
\hline \multicolumn{12}{|c|}{ Glycolysis/Gluconeogenesis } \\
\hline ACSL3 & $\begin{array}{l}\text { acyl-CoA synthetase } \\
\text { long-chain family } \\
\text { member } 3\end{array}$ & NM_001033606 & 0.011 & -0.825 & 7.664 & 0.064 & -0.519 & 8.184 & 0.233 & 0.305 & 8.489 \\
\hline ACSS2 & $\begin{array}{l}\text { acyl-CoA synthetase } \\
\text { short-chain family } \\
\text { member } 2\end{array}$ & NM_019811 & 0.313 & -0.529 & 11.218 & 0.02 & -1.499 & 12.717 & 0.054 & -1.03 & 11.548 \\
\hline ACYP1 & $\begin{array}{l}\text { acylphosphatase } 1, \\
\text { erythrocyte (common) } \\
\text { type }\end{array}$ & NM_025421 & 0.004 & 1.214 & 7.721 & 0.013 & 0.937 & 6.784 & 0.234 & -0.386 & 7.339 \\
\hline ALDH1B1 & $\begin{array}{l}\text { aldehyde dehydrogenase } \\
1 \text { family, member B1 }\end{array}$ & NM_028270 & 0.008 & -1.606 & 6.814 & 0.094 & -0.827 & 7.641 & 0.111 & 0.779 & 8.419 \\
\hline ALDH3A2 & $\begin{array}{l}\text { aldehyde dehydrogenase } \\
3 \text { family, member A2 }\end{array}$ & NM_007437 & 0.048 & -0.654 & 11.296 & 0.516 & 0.184 & 11.112 & 0.019 & 0.838 & 11.949 \\
\hline ALDH5A1 & $\begin{array}{l}\text { aldehyde dehydrogenase } \\
5 \text { family, member A1 } \\
\text { (succinate-semialdehyde } \\
\text { dehydrogenase) }\end{array}$ & NM_172532 & 0.008 & -0.808 & 8.158 & 0.09 & -0.422 & 8.58 & 0.114 & 0.387 & 8.966 \\
\hline ALDOC & $\begin{array}{l}\text { aldolase } \mathrm{C} \text {, fructose- } \\
\text { bisphosphate }\end{array}$ & NM_009657 & 0.544 & 0.214 & 8.518 & 0.066 & -0.744 & 9.262 & 0.027 & -0.958 & 8.304 \\
\hline BPGM & $\begin{array}{l}\text { 2,3-bisphosphoglycerate } \\
\text { mutase }\end{array}$ & NM_007563 & 0.004 & -1.09 & 7.804 & 0.001 & -1.632 & 9.436 & 0.072 & -0.542 & 8.894 \\
\hline DLAT & $\begin{array}{l}\text { dihydrolipoamide } \\
\text { S-acetyltransferase }\end{array}$ & NM_145614 & 0.003 & -0.895 & 8.757 & 0.003 & -0.903 & 9.66 & 0.803 & 0.084 & 7.625 \\
\hline G6PC & $\begin{array}{l}\text { glucose-6-phosphatase, } \\
\text { catalytic subunit }\end{array}$ & NM_008061 & 0.098 & -0.641 & 12.013 & 0.641 & 0.161 & 11.851 & 0.049 & 0.803 & 12.654 \\
\hline
\end{tabular}


Continued

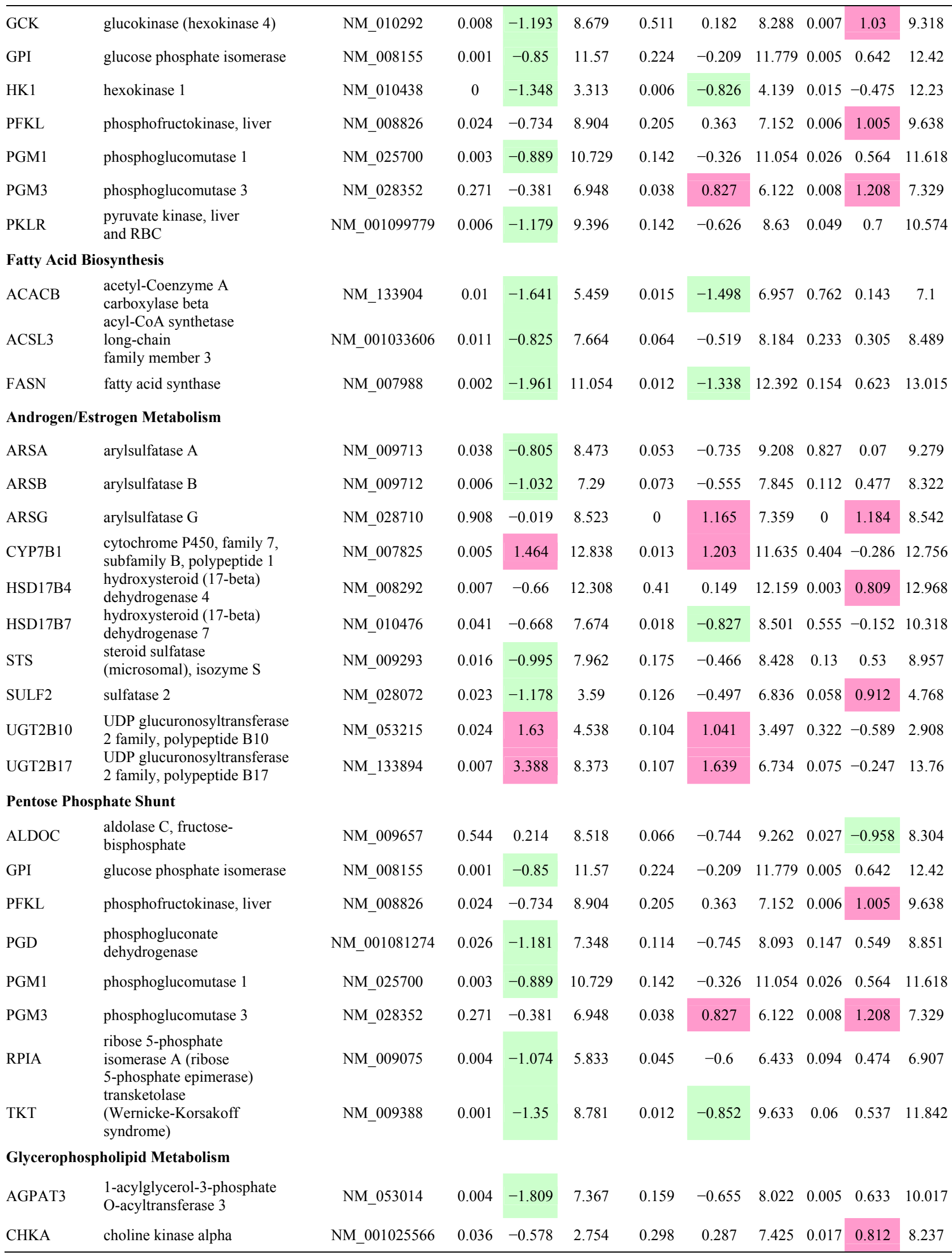




\section{Continued}

\begin{tabular}{|c|c|c|c|c|c|c|c|c|c|c|c|}
\hline GPAM & $\begin{array}{l}\text { glycerol-3-phosphate } \\
\text { acyltransferase, } \\
\text { mitochondrial }\end{array}$ & NM_008149 & 0.013 & -1.213 & 11.802 & 0.05 & -0.862 & 12.663 & 0.36 & 0.351 & 13.015 \\
\hline GPD1 & $\begin{array}{l}\text { glycerol-3-phosphate } \\
\text { dehydrogenase } 1 \text { (soluble) }\end{array}$ & NM_010271 & 0.003 & -0.861 & 10.337 & 0.258 & -0.227 & 10.565 & 0.012 & 0.634 & 11.199 \\
\hline GPD2 & $\begin{array}{l}\text { glycerol-3-phosphate } \\
\text { dehydrogenase } 2 \\
\text { (mitochondrial) }\end{array}$ & NM_010274 & 0.004 & -0.871 & 8.968 & 0.254 & -0.011 & 2.295 & 0.002 & 0.989 & 9.839 \\
\hline LIPG & lipase, endothelial & NM_010720 & 0.075 & -0.718 & 3.694 & 0.193 & 0.422 & 5.104 & 0.012 & 1.016 & 6.12 \\
\hline MGLL & monoglyceride lipase & NM_011844 & 0.003 & -0.801 & 11.244 & 0.112 & 0.317 & 10.927 & 0.001 & 1.118 & 12.045 \\
\hline PCYT1A & $\begin{array}{l}\text { phosphate cytidylyltransferase } \\
1 \text {, choline, alpha }\end{array}$ & NM_009981 & 0.001 & -1.323 & 6.718 & 0.007 & -0.806 & 7.524 & 0.043 & 0.517 & 8.041 \\
\hline PIGF & $\begin{array}{l}\text { phosphatidylinositol glycan } \\
\text { anchor biosynthesis, class F }\end{array}$ & NM_008838 & 0.001 & 1.213 & 7.798 & 0.011 & 0.726 & 7.072 & 0.052 & -0.488 & 6.585 \\
\hline PPAP2B & $\begin{array}{l}\text { phosphatidic acid } \\
\text { phosphatase type } 2 \mathrm{~B}\end{array}$ & NM_080555 & 0.014 & -0.831 & 10.244 & 0.057 & -0.573 & 10.817 & 0.305 & 0.181 & 11.441 \\
\hline \multicolumn{12}{|c|}{ Xenobiotic Metabolism by $\mathbf{P 4 5 0}$} \\
\hline CYP1A2 & $\begin{array}{l}\text { cytochrome P } 450 \text {, family } 1 \text {, } \\
\text { subfamily A, polypeptide } 2\end{array}$ & NM_009993 & 0.069 & 0.399 & 12.721 & 0.003 & -0.847 & 13.568 & 0 & -1.246 & 12.323 \\
\hline CYP2A13 & $\begin{array}{l}\text { cytochrome } \mathrm{P} 450 \text {, family } 2, \\
\text { subfamily A, polypeptide } 13\end{array}$ & NM_007812 & 0.503 & -0.321 & 11.504 & 0.02 & -1.399 & 12.903 & 0.052 & -1.078 & 11.825 \\
\hline $\begin{array}{l}\text { CYP2B6 } \\
\text { (includes EG:1555) }\end{array}$ & $\begin{array}{l}\text { cytochrome P } 450 \text {, family } 2 \text {, } \\
\text { subfamily B, polypeptide } 6\end{array}$ & NM_009998 & 0.026 & -0.948 & 2.434 & 0.002 & -1.753 & 4.175 & 0.044 & -0.546 & 2.408 \\
\hline CYP2B9 & $\begin{array}{l}\text { cytochrome P } 450 \text {, family } 2 \text {, } \\
\text { subfamily b, polypeptide } 9\end{array}$ & NM_010000 & 0.001 & -5.322 & 2.896 & 0.684 & -0.354 & 3.249 & 0.001 & 4.969 & 8.218 \\
\hline CYP2C38 & $\begin{array}{l}\text { cytochrome P450, family } 2 \text {, } \\
\text { subfamily c, polypeptide } 38\end{array}$ & NM_010002 & 0.001 & -2.033 & 7.649 & 0.015 & -1.247 & 8.896 & 0.079 & 0.786 & 9.682 \\
\hline CYP2C54 & $\begin{array}{l}\text { cytochrome P450, family } 2 \text {, } \\
\text { subfamily c, polypeptide } 54\end{array}$ & NM_206537 & 0.019 & 0.494 & 13.689 & 0.088 & -0.32 & 14.01 & 0.002 & -0.815 & 13.195 \\
\hline CYP2D13 & $\begin{array}{l}\text { cytochrome P450, family } 2 \text {, } \\
\text { subfamily d, polypeptide } 13 \\
\text { cytochrome P450, family }\end{array}$ & NR_003552 & 0.005 & 0.973 & 6.427 & 0.044 & 0.582 & 5.845 & 0.141 & -0.391 & 5.454 \\
\hline CYP2G1P & $\begin{array}{l}2 \text {, subfamily } \mathrm{G} \text {, polypeptide } \\
1 \text { pseudogene }\end{array}$ & NM_013809 & 0.874 & 0.037 & 3.222 & 0.002 & -1.19 & 4.411 & 0.001 & -1.227 & 3.185 \\
\hline GSTA4 & glutathione S-transferase A4 & NM_010357 & 0.417 & 0.149 & 10.43 & 0.003 & -0.779 & 11.209 & 0.001 & -0.928 & 10.281 \\
\hline GSTA5 & glutathione S-transferase A5 & NM_008181 & 0.133 & -1.013 & 7.634 & 0.001 & -2.393 & 10.925 & 0.004 & -1.8 & 9.126 \\
\hline $\begin{array}{l}\text { GSTM1 } \\
\text { (includes EG:14862) }\end{array}$ & glutathione S-transferase, mu 1 & NM_010358 & 0 & -0.86 & 13.665 & 0 & -1.256 & 7.021 & 0.016 & -0.409 & 6.612 \\
\hline $\begin{array}{l}\text { GSTM1 } \\
\text { (includes EG:2944) }\end{array}$ & glutathione S-transferase M1 & NM_008183 & 0.001 & -0.997 & 8.965 & 0 & -1.162 & 10.127 & 0.332 & -0.165 & 9.962 \\
\hline $\begin{array}{l}\text { GSTM3 } \\
\text { (includes EG:14864) }\end{array}$ & glutathione S-transferase, mu 3 & NM_010359 & 0.016 & -1.416 & 9.939 & 0.001 & -2.399 & 12.338 & 0.061 & -0.982 & 11.356 \\
\hline GSTM4 & glutathione S-transferase M4 & NM_026764 & 0.097 & -0.469 & 9.231 & 0.002 & -1.226 & 10.456 & 0.019 & -0.757 & 9.699 \\
\hline GSTM5 & glutathione S-transferase M5 & NM_008184 & 0.376 & -0.149 & 10.351 & 0.002 & -0.818 & 11.169 & 0.005 & -0.669 & 10.501 \\
\hline GSTT3 & $\begin{array}{l}\text { glutathione S-transferase, } \\
\text { theta } 3\end{array}$ & NM_133994 & 0.002 & -1.072 & 8.57 & 0.001 & -1.275 & 9.845 & 0.366 & -0.203 & 9.642 \\
\hline MGST3 & $\begin{array}{l}\text { microsomal glutathione } \\
\text { S-transferase } 3\end{array}$ & NM_025569 & 0.131 & -0.459 & 7.726 & 0.009 & -0.982 & 8.708 & 0.093 & -0.523 & 8.185 \\
\hline UGT2B10 & $\begin{array}{l}\text { UDP glucuronosyltransferase } \\
2 \text { family, polypeptide B10 }\end{array}$ & NM_053215 & 0.024 & 1.63 & 4.538 & 0.104 & 1.041 & 3.497 & 0.322 & -0.589 & 2.908 \\
\hline UGT2B17 & $\begin{array}{l}\text { UDP glucuronosyltransferase } \\
2 \text { family, polypeptide B17 }\end{array}$ & NM_133894 & 0.007 & 3.388 & 8.373 & 0.107 & 1.639 & 6.734 & 0.075 & -0.247 & 13.76 \\
\hline \multicolumn{12}{|c|}{ Fatty Acid Metabolism } \\
\hline ACAA1B & $\begin{array}{l}\text { acetyl-Coenzyme A } \\
\text { acyltransferase 1B }\end{array}$ & NM_130864 & 0.002 & -0.912 & 12.809 & 0.048 & -0.279 & 14.769 & 0.027 & 0.441 & 14.5 \\
\hline
\end{tabular}


Continued

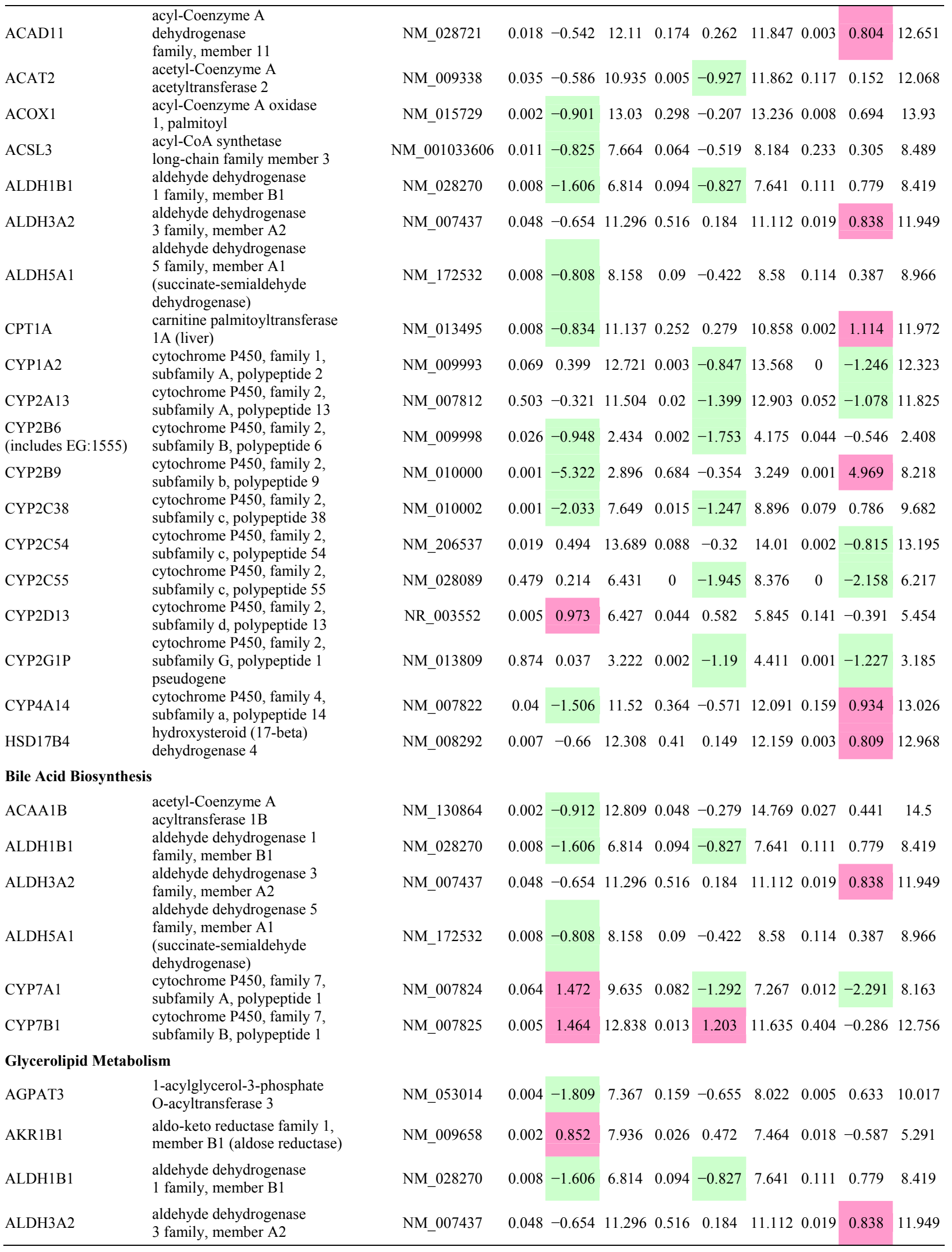




\section{Continued}

\begin{tabular}{|c|c|c|c|c|c|c|c|c|c|c|c|}
\hline ALDH5A1 & $\begin{array}{l}\text { aldehyde dehydrogenase } \\
5 \text { family, member A1 } \\
\text { (succinate-semialdehyde } \\
\text { dehydrogenase) }\end{array}$ & NM_172532 & 0.008 & -0.808 & 8.158 & 0.09 & -0.422 & 8.58 & 0.114 & 0.387 & 8.966 \\
\hline GPAM & $\begin{array}{l}\text { glycerol-3-phosphate } \\
\text { acyltransferase, } \\
\text { mitochondrial }\end{array}$ & NM_008149 & 0.013 & -1.213 & 11.802 & 0.05 & -0.862 & 12.663 & 0.36 & 0.351 & 13.015 \\
\hline LIPG & lipase, endothelial & NM_010720 & 0.075 & -0.718 & 3.694 & 0.193 & 0.422 & 5.104 & 0.012 & 1.016 & 6.12 \\
\hline MGLL & monoglyceride lipase & NM_011844 & 0.003 & -0.801 & 11.244 & 0.112 & 0.317 & 10.927 & 0.001 & 1.118 & 12.045 \\
\hline MOGAT1 & $\begin{array}{l}\text { monoacylglycerol } \\
\text { O-acyltransferase } 1\end{array}$ & NM_026713 & 0.074 & -1.178 & 3.038 & 0.654 & 0.259 & 2.779 & 0.038 & 1.438 & 4.217 \\
\hline PPAP2B & $\begin{array}{l}\text { phosphatidic acid } \\
\text { phosphatase type } 2 \mathrm{~B}\end{array}$ & NM_080555 & 0.014 & -0.831 & 10.244 & 0.057 & -0.573 & 10.817 & 0.305 & 0.181 & 11.441 \\
\hline \multicolumn{12}{|c|}{ Aminosugar Metabolism } \\
\hline CYB5R3 & cytochrome b5 reductase 3 & NM_029787 & 0.009 & -0.809 & 11.975 & 0.03 & -0.605 & 12.58 & 0.231 & 0.235 & 13.42 \\
\hline GCK & glucokinase (hexokinase 4) & NM_010292 & 0.008 & -1.193 & 8.679 & 0.511 & 0.182 & 8.288 & 0.007 & 1.03 & 9.318 \\
\hline GFPT1 & $\begin{array}{l}\text { glutamine-fructose-6- } \\
\text { phosphate } \\
\text { transaminase } 1\end{array}$ & NM_013528 & 0.024 & -0.809 & 6.724 & 0.272 & 0.001 & 2.286 & 0.044 & 0.169 & 2.533 \\
\hline HK1 & hexokinase 1 & NM_010438 & 0 & -1.348 & 3.313 & 0.006 & -0.826 & 4.139 & 0.015 & -0.475 & 12.23 \\
\hline NQO1 & $\begin{array}{l}\mathrm{NAD}(\mathrm{P}) \mathrm{H} \text { dehydrogenase, } \\
\text { quinone } 1\end{array}$ & NM_008706 & 0.064 & -0.883 & 3.705 & 0.035 & -1.056 & 4.761 & 0.677 & -0.172 & 4.589 \\
\hline PDE2A & $\begin{array}{l}\text { phosphodiesterase } 2 \mathrm{~A} \\
\text { cGMP-stimulated }\end{array}$ & NM_001008548 & 0.001 & -1.426 & 4.773 & 0.002 & -1.319 & 6.092 & 0.653 & 0.116 & 9.205 \\
\hline PDE4B & $\begin{array}{l}\text { phosphodiesterase 4B, } \\
\text { cAMP-specific } \\
\text { (phosphodiesterase E4 } \\
\text { dunce homolog, Drosophila) }\end{array}$ & NM_019840 & 0.004 & -0.967 & 2.681 & 0.254 & -0.007 & 2.321 & 0.009 & 0.808 & 3.647 \\
\hline PGM3 & phosphoglucomutase 3 & NM_028352 & 0.271 & -0.381 & 6.948 & 0.038 & 0.827 & 6.122 & 0.008 & 1.208 & 7.329 \\
\hline \multicolumn{12}{|c|}{ Sphingolipid Metabolism } \\
\hline ARSA & arylsulfatase A & NM_009713 & 0.038 & -0.805 & 8.473 & 0.053 & -0.735 & 9.208 & 0.827 & 0.07 & 9.279 \\
\hline ARSB & arylsulfatase B & NM_009712 & 0.006 & -1.032 & 7.29 & 0.073 & -0.555 & 7.845 & 0.112 & 0.477 & 8.322 \\
\hline ARSG & arylsulfatase $\mathrm{G}$ & NM_028710 & 0.908 & -0.019 & 8.523 & 0 & 1.165 & 7.359 & 0 & 1.184 & 8.542 \\
\hline CYP26A1 & $\begin{array}{l}\text { cytochrome } \mathrm{P} 450 \text {, family } 26 \text {, } \\
\text { subfamily A, polypeptide } 1\end{array}$ & NM_007811 & 0.022 & -1.991 & 5.192 & 0.001 & -3.72 & 8.911 & 0.037 & -1.729 & 7.183 \\
\hline PPAP2B & $\begin{array}{l}\text { phosphatidic acid } \\
\text { phosphatase type } 2 \mathrm{~B}\end{array}$ & NM_080555 & 0.014 & -0.831 & 10.244 & 0.057 & -0.573 & 10.817 & 0.305 & 0.181 & 11.441 \\
\hline SULF2 & sulfatase 2 & NM_028072 & 0.023 & -1.178 & 3.59 & 0.126 & -0.497 & 6.836 & 0.058 & 0.912 & 4.768 \\
\hline VNN1 & vanin 1 & NM_011704 & 0.059 & -0.882 & 9.365 & 0.086 & 0.764 & 10.887 & 0.004 & 1.658 & 10.247 \\
\hline \multicolumn{12}{|c|}{ Glutathione Metabolism } \\
\hline ACSS2 & $\begin{array}{l}\text { acyl-CoA synthetase } \\
\text { short-chain } \\
\text { family member } 2\end{array}$ & NM_019811 & 0.313 & -0.529 & 11.218 & 0.02 & -1.499 & 12.717 & 0.054 & -1.03 & 11.548 \\
\hline GSTA4 & glutathione S-transferase A4 & NM_010357 & 0.417 & 0.149 & 10.43 & 0.003 & -0.779 & 11.209 & 0.001 & -0.928 & 10.281 \\
\hline GSTA5 & glutathione S-transferase A5 & NM_008181 & 0.133 & -1.013 & 7.634 & 0.001 & -2.393 & 10.925 & 0.004 & -1.8 & 9.126 \\
\hline $\begin{array}{l}\text { GSTM1 } \\
\text { (includes EG:14862) }\end{array}$ & glutathione S-transferase, mu 1 & NM_010358 & 0 & -0.86 & 13.665 & 0 & -1.256 & 7.021 & 0.016 & -0.409 & 6.612 \\
\hline $\begin{array}{l}\text { GSTM1 } \\
\text { (includes EG:2944) }\end{array}$ & glutathione S-transferase M1 & NM_008183 & 0.001 & -0.997 & 8.965 & 0 & -1.162 & 10.127 & 0.332 & -0.165 & 9.962 \\
\hline $\begin{array}{l}\text { GSTM3 } \\
\text { (includes EG:14864) } \\
\end{array}$ & glutathione S-transferase, mu 3 & NM_010359 & 0.016 & -1.416 & 9.939 & 0.001 & -2.399 & 12.338 & 0.061 & -0.982 & 11.356 \\
\hline
\end{tabular}


Continued

\begin{tabular}{|c|c|c|c|c|c|c|c|c|c|c|c|}
\hline GSTM4 & glutathione S-transferase M4 & NM_026764 & 0.097 & -0.469 & 9.231 & 0.002 & -1.226 & 10.456 & 0.019 & -0.757 & 9.699 \\
\hline GSTM5 & glutathione S-transferase M5 & NM_008184 & 0.376 & -0.149 & 10.351 & 0.002 & -0.818 & 11.169 & 0.005 & -0.669 & 10.501 \\
\hline GSTT3 & $\begin{array}{l}\text { glutathione S-transferase, } \\
\text { theta } 3\end{array}$ & NM_133994 & 0.002 & -1.072 & 8.57 & 0.001 & -1.275 & 9.845 & 0.366 & -0.203 & 9.642 \\
\hline MGST3 & $\begin{array}{l}\text { microsomal glutathione } \\
\text { S-transferase } 3\end{array}$ & NM_025569 & 0.131 & -0.459 & 7.726 & 0.009 & -0.982 & 8.708 & 0.093 & -0.523 & 8.185 \\
\hline PGD & $\begin{array}{l}\text { phosphogluconate } \\
\text { dehydrogenase }\end{array}$ & NM_001081274 & 0.026 & -1.181 & 7.348 & 0.114 & -0.745 & 8.093 & 0.147 & 0.549 & 8.851 \\
\hline \multicolumn{12}{|c|}{ Biosynthesis of Steroid } \\
\hline CYP26A1 & $\begin{array}{l}\text { cytochrome P450, family } 26 \text {, } \\
\text { subfamily A, polypeptide } 1\end{array}$ & NM_138656 & 0.022 & -1.991 & 5.192 & 0.001 & -3.72 & 8.911 & 0.037 & -1.729 & 7.183 \\
\hline CYP7B1 & $\begin{array}{l}\text { cytochrome } \mathrm{P} 450 \text {, family } 7 \text {, } \\
\text { subfamily } \mathrm{B} \text {, polypeptide } 1\end{array}$ & NM_007811 & 0.005 & 1.464 & 12.838 & 0.013 & 1.203 & 11.635 & 0.404 & -0.286 & 12.756 \\
\hline DHCR7 & $\begin{array}{l}\text { 7-dehydrocholesterol } \\
\text { reductase } \\
\text { farnesyl diphosphate } \\
\text { synthase (farnesyl }\end{array}$ & NM_146006 & 0.085 & -0.676 & 9.689 & 0.022 & -1.006 & 10.694 & 0.289 & 0 & 2.285 \\
\hline FDPS & $\begin{array}{l}\text { pyrophosphate synthetase, } \\
\text { dimethylallyltranstransferase, } \\
\text { geranyltranstransferase) }\end{array}$ & NM_007825 & 0.072 & -0.476 & 11.331 & 0.004 & -0.996 & 12.327 & 0.055 & -0.52 & 11.807 \\
\hline HMGCR & $\begin{array}{l}\text { 3-hydroxy-3-methylglutaryl- } \\
\text { Coenzyme A reductase }\end{array}$ & NM_134469 & 0.428 & -0.254 & 6.79 & 0.007 & -1.179 & 7.969 & 0.02 & -0.925 & 7.044 \\
\hline IDI1 & $\begin{array}{l}\text { isopentenyl-diphosphate } \\
\text { delta isomerase } 1\end{array}$ & NM_008706 & 0.14 & 0.561 & 10.519 & 0.226 & -0.446 & 10.965 & 0.022 & -1.007 & 9.958 \\
\hline LSS & $\begin{array}{l}\text { lanosterol synthase } \\
(2,3 \text {-oxidosqualene- } \\
\text { lanosterol cyclase })\end{array}$ & NM_145360 & 0.412 & 0.04 & 2.469 & 0.023 & -1.037 & 6.498 & 0.04 & -0.889 & 5.609 \\
\hline MVD & $\begin{array}{l}\text { mevalonate (diphospho) } \\
\text { decarboxylase }\end{array}$ & NM_008255 & 0.005 & -1.431 & 6.181 & 0.008 & -1.329 & 7.51 & 0.776 & 0.102 & 7.613 \\
\hline NQO1 & $\begin{array}{l}\mathrm{NAD}(\mathrm{P}) \mathrm{H} \text { dehydrogenase, } \\
\text { quinone } 1\end{array}$ & NM_026784 & 0.064 & -0.883 & 3.705 & 0.035 & -1.056 & 4.761 & 0.677 & -0.172 & 4.589 \\
\hline PMVK & phosphomevalonate kinase & NM_007856 & 0.941 & 0.026 & 8.598 & 0.041 & -0.87 & 9.467 & 0.037 & -0.896 & 8.571 \\
\hline \multicolumn{12}{|c|}{ Tryptophan Metabolism } \\
\hline ACAT2 & $\begin{array}{l}\text { acetyl-Coenzyme A } \\
\text { acetyltransferase } 2\end{array}$ & NM_009338 & 0.035 & -0.586 & 10.935 & 0.005 & -0.927 & 11.862 & 0.117 & 0.152 & 12.068 \\
\hline AFMID & arylformamidase & NM_027827 & 0.008 & 0.527 & 6.536 & 0.001 & -0.78 & 8.825 & 0 & -1.084 & 6.009 \\
\hline ALDH1B1 & $\begin{array}{l}\text { aldehyde dehydrogenase } 1 \\
\text { family, member B1 }\end{array}$ & NM_028270 & 0.008 & -1.606 & 6.814 & 0.094 & -0.827 & 7.641 & 0.111 & 0.779 & 8.419 \\
\hline ALDH3A2 & $\begin{array}{l}\text { aldehyde dehydrogenase } 3 \\
\text { family, member A2 }\end{array}$ & NM_007437 & 0.048 & -0.654 & 11.296 & 0.516 & 0.184 & 11.112 & 0.019 & 0.838 & 11.949 \\
\hline ALDH5A1 & $\begin{array}{l}\text { aldehyde dehydrogenase } 5 \\
\text { family, member A1 } \\
\text { (succinate-semialdehyde } \\
\text { dehydrogenase) }\end{array}$ & NM_172532 & 0.008 & -0.808 & 8.158 & 0.09 & -0.422 & 8.58 & 0.114 & 0.387 & 8.966 \\
\hline CYP1A2 & $\begin{array}{l}\text { cytochrome P450, family } 1 \text {, } \\
\text { subfamily A, polypeptide } 2\end{array}$ & NM_009993 & 0.069 & 0.399 & 12.721 & 0.003 & -0.847 & 13.568 & 0 & -1.246 & 12.323 \\
\hline CYP2A13 & $\begin{array}{l}\text { cytochrome P450, family } 2 \text {, } \\
\text { subfamily A, polypeptide } 13\end{array}$ & NM_007812 & 0.503 & -0.321 & 11.504 & 0.02 & -1.399 & 12.903 & 0.052 & -1.078 & 11.825 \\
\hline $\begin{array}{l}\text { CYP2B6 } \\
\text { (includes EG:1555) }\end{array}$ & $\begin{array}{l}\text { cytochrome P } 450 \text {, family } 2 \text {, } \\
\text { subfamily B, polypeptide } 6\end{array}$ & NM_009998 & 0.026 & -0.948 & 2.434 & 0.002 & -1.753 & 4.175 & 0.044 & -0.546 & 2.408 \\
\hline CYP2B9 & $\begin{array}{l}\text { cytochrome } \mathrm{P} 450 \text {, family } 2 \text {, } \\
\text { subfamily b, polypeptide } 9\end{array}$ & NM_010000 & 0.001 & -5.322 & 2.896 & 0.684 & -0.354 & 3.249 & 0.001 & 4.969 & 8.218 \\
\hline CYP2C38 & $\begin{array}{l}\text { cytochrome } \mathrm{P} 450 \text {, family } 2 \text {, } \\
\text { subfamily c, polypeptide } 38\end{array}$ & NM_010002 & 0.001 & -2.033 & 7.649 & 0.015 & -1.247 & 8.896 & 0.079 & 0.786 & 9.682 \\
\hline CYP2C54 & $\begin{array}{l}\text { cytochrome } \mathrm{P} 450 \text {, family } 2 \text {, } \\
\text { subfamily c, polypeptide } 54\end{array}$ & NM_206537 & 0.019 & 0.494 & 13.689 & 0.088 & -0.32 & 14.01 & 0.002 & -0.815 & 13.195 \\
\hline CYP2C55 & $\begin{array}{l}\text { cytochrome P } 450 \text {, family } 2 \text {, } \\
\text { subfamily c, polypeptide } 55\end{array}$ & NM_028089 & 0.479 & 0.214 & 6.431 & 0 & -1.945 & 8.376 & 0 & -2.158 & 6.217 \\
\hline CYP2D13 & $\begin{array}{l}\text { cytochrome } \mathrm{P} 450 \text {, family } 2 \text {, } \\
\text { subfamily d, polypeptide } 13\end{array}$ & NR_003552 & 0.005 & 0.973 & 6.427 & 0.044 & 0.582 & 5.845 & 0.141 & -0.391 & 5.454 \\
\hline CYP2G1P & $\begin{array}{l}\text { cytochrome P450, family } 2 \text {, } \\
\text { subfamily G, polypeptide } 1 \\
\text { pseudogene }\end{array}$ & NM_013809 & 0.874 & 0.037 & 3.222 & 0.002 & -1.19 & 4.411 & 0.001 & -1.227 & 3.185 \\
\hline
\end{tabular}


Continued

\begin{tabular}{|c|c|c|c|c|c|c|c|c|c|c|c|}
\hline CYP7B1 & $\begin{array}{l}\text { cytochrome P450, family } 7 \text {, } \\
\text { subfamily B, polypeptide } 1\end{array}$ & NM_007825 & 0.005 & 1.464 & 12.838 & 0.013 & 1.203 & 11.635 & 0.404 & -0.286 & 12.756 \\
\hline DHCR24 & $\begin{array}{l}\text { 24-dehydrocholesterol } \\
\text { reductase }\end{array}$ & NM_053272 & 0.007 & -1.058 & 11.196 & 0.037 & -0.704 & 11.9 & 0.231 & 0.354 & 12.254 \\
\hline HSD17B4 & $\begin{array}{l}\text { hydroxysteroid (17-beta) } \\
\text { dehydrogenase } 4\end{array}$ & NM_008292 & 0.007 & -0.66 & 12.308 & 0.41 & 0.149 & 12.159 & 0.003 & 0.809 & 12.968 \\
\hline NEDD4 & $\begin{array}{l}\text { neural precursor cell } \\
\text { expressed, developmentally } \\
\text { down-regulated } 4\end{array}$ & NM_010890 & 0.003 & -1.586 & 7.541 & 0.021 & -1.061 & 8.602 & 0.127 & 0.433 & 11.085 \\
\hline SYVN1 & $\begin{array}{l}\text { synovial apoptosis } \\
\text { inhibitor } 1, \text { synoviolin }\end{array}$ & NM_028769 & 0.031 & -1.076 & 8.032 & 0.79 & 0.104 & 7.534 & 0.031 & 1.079 & 9.109 \\
\hline \multicolumn{12}{|c|}{ Linoleic Acid Metabolism } \\
\hline CYP1A2 & $\begin{array}{l}\text { cytochrome P450, family } 1 \text {, } \\
\text { subfamily A, polypeptide } 2\end{array}$ & NM_009993 & 0.069 & 0.399 & 12.721 & 0.003 & -0.847 & 13.568 & 0 & -1.246 & 12.323 \\
\hline CYP2A13 & $\begin{array}{l}\text { cytochrome P450, family } 2, \\
\text { subfamily A, polypeptide } 13\end{array}$ & NM_007812 & 0.503 & -0.321 & 11.504 & 0.02 & -1.399 & 12.903 & 0.052 & -1.078 & 11.825 \\
\hline $\begin{array}{l}\text { CYP2B6 } \\
\text { (includes EG:1555) }\end{array}$ & $\begin{array}{l}\text { cytochrome } \mathrm{P} 450 \text {, family } 2 \text {, } \\
\text { subfamily B, polypeptide } 6\end{array}$ & NM_009998 & 0.026 & -0.948 & 2.434 & 0.002 & -1.753 & 4.175 & 0.044 & -0.546 & 2.408 \\
\hline CYP2B9 & $\begin{array}{l}\text { cytochrome P450, family } 2 \text {, } \\
\text { subfamily b, polypeptide } 9\end{array}$ & NM_010000 & 0.001 & -5.322 & 2.896 & 0.684 & -0.354 & 3.249 & 0.001 & 4.969 & 8.218 \\
\hline CYP2C38 & $\begin{array}{l}\text { cytochrome P450, family } 2 \text {, } \\
\text { subfamily c, polypeptide } 38\end{array}$ & NM_010002 & 0.001 & -2.033 & 7.649 & 0.015 & -1.247 & 8.896 & 0.079 & 0.786 & 9.682 \\
\hline CYP2C54 & $\begin{array}{l}\text { cytochrome P450, family } 2 \text {, } \\
\text { subfamily c, polypeptide } 54\end{array}$ & NM_206537 & 0.019 & 0.494 & 13.689 & 0.088 & -0.32 & 14.01 & 0.002 & -0.815 & 13.195 \\
\hline CYP2C55 & $\begin{array}{l}\text { cytochrome P } 450 \text {, family } 2 \text {, } \\
\text { subfamily c, polypeptide } 55\end{array}$ & NM_028089 & 0.479 & 0.214 & 6.431 & 0 & -1.945 & 8.376 & 0 & -2.158 & 6.217 \\
\hline CYP2D13 & $\begin{array}{l}\text { cytochrome } \mathrm{P} 450 \text {, family } 2 \text {, } \\
\text { subfamily d, polypeptide } 13\end{array}$ & NR_003552 & 0.005 & 0.973 & 6.427 & 0.044 & 0.582 & 5.845 & 0.141 & -0.391 & 5.454 \\
\hline CYP2G1P & $\begin{array}{l}\text { cytochrome } \mathrm{P} 450 \text {, family } 2 \text {, } \\
\text { subfamily } \mathrm{G} \text {, polypeptide } 1 \\
\text { pseudogene }\end{array}$ & NM_013809 & 0.874 & 0.037 & 3.222 & 0.002 & -1.19 & 4.411 & 0.001 & -1.227 & 3.185 \\
\hline FADS1 & fatty acid desaturase 1 & NM_146094 & 0.005 & -0.924 & 12.436 & 0.106 & -0.405 & 12.841 & 0.051 & 0.519 & 13.36 \\
\hline FADS2 & fatty acid desaturase 2 & NM_019699 & 0.001 & -1.798 & 10.549 & 0.243 & -0.399 & 10.947 & 0.002 & 1.482 & 11.893 \\
\hline GRN & granulin & NM_008175 & 0.014 & -0.862 & 10.889 & 0.094 & -0.501 & 11.391 & 0.11 & 0.493 & 10.695 \\
\hline PLA2G4A & $\begin{array}{l}\text { phospholipase A2, } \\
\text { group IVA (cytosolic, } \\
\text { calcium-dependent) }\end{array}$ & NM_008869 & 0.004 & 1.111 & 5.765 & 0.013 & 0.879 & 4.886 & 0.396 & -0.232 & 4.654 \\
\hline \multicolumn{12}{|c|}{ Butanoate Metabolism } \\
\hline AACS & acetoacetyl-CoA synthetase & NM_030210 & 0.007 & -1.215 & 7.416 & 0.002 & -1.513 & 8.93 & 0.254 & -0.082 & 2.284 \\
\hline ACAT2 & $\begin{array}{l}\text { acetyl-Coenzyme A } \\
\text { acetyltransferase } 2\end{array}$ & NM_009338 & 0.035 & -0.586 & 10.935 & 0.005 & -0.927 & 11.862 & 0.117 & 0.152 & 12.068 \\
\hline ALDH1B1 & $\begin{array}{l}\text { aldehyde dehydrogenase } 1 \\
\text { family, member B1 }\end{array}$ & NM_028270 & 0.008 & -1.606 & 6.814 & 0.094 & -0.827 & 7.641 & 0.111 & 0.779 & 8.419 \\
\hline ALDH3A2 & $\begin{array}{l}\text { aldehyde dehydrogenase } 3 \\
\text { family, member A2 }\end{array}$ & NM_007437 & 0.048 & -0.654 & 11.296 & 0.516 & 0.184 & 11.112 & 0.019 & 0.838 & 11.949 \\
\hline ALDH5A1 & $\begin{array}{l}\text { aldehyde dehydrogenase } 5 \\
\text { family, member A1 } \\
\text { (succinate-semialdehyde } \\
\text { dehydrogenase) }\end{array}$ & NM_172532 & 0.008 & -0.808 & 8.158 & 0.09 & -0.422 & 8.58 & 0.114 & 0.387 & 8.966 \\
\hline BDH1 & $\begin{array}{l}\text { 3-hydroxybutyrate } \\
\text { dehydrogenase, type } 1\end{array}$ & $\begin{array}{c}\text { NM_001122683/// } \\
\text { NM_175177 }\end{array}$ & 0.008 & -0.95 & 11.488 & 0.024 & 0.646 & 7.796 & 0.001 & 1.188 & 8.984 \\
\hline HSD17B4 & $\begin{array}{l}\text { hydroxysteroid (17-beta) } \\
\text { dehydrogenase } 4\end{array}$ & NM_008292 & 0.007 & -0.66 & 12.308 & 0.41 & 0.149 & 12.159 & 0.003 & 0.809 & 12.968 \\
\hline \multicolumn{12}{|c|}{ Galactose Metabolism } \\
\hline AKR1B1 & $\begin{array}{l}\text { aldo-keto reductase family } 1 \text {, } \\
\text { member B1 (aldose } \\
\text { reductase) }\end{array}$ & NM_009658 & 0.002 & 0.852 & 7.936 & 0.026 & 0.472 & 7.464 & 0.018 & -0.587 & 5.291 \\
\hline G6PC & $\begin{array}{l}\text { glucose-6-phosphatase, } \\
\text { catalytic subunit }\end{array}$ & NM_008061 & 0.098 & -0.641 & 12.013 & 0.641 & 0.161 & 11.851 & 0.049 & 0.803 & 12.654 \\
\hline GCK & glucokinase (hexokinase 4) & NM_010292 & 0.008 & -1.193 & 8.679 & 0.511 & 0.182 & 8.288 & 0.007 & 1.03 & 9.318 \\
\hline HK1 & hexokinase 1 & NM_010438 & 0 & -1.348 & 3.313 & 0.006 & -0.826 & 4.139 & 0.015 & -0.475 & 12.23 \\
\hline
\end{tabular}


Continued

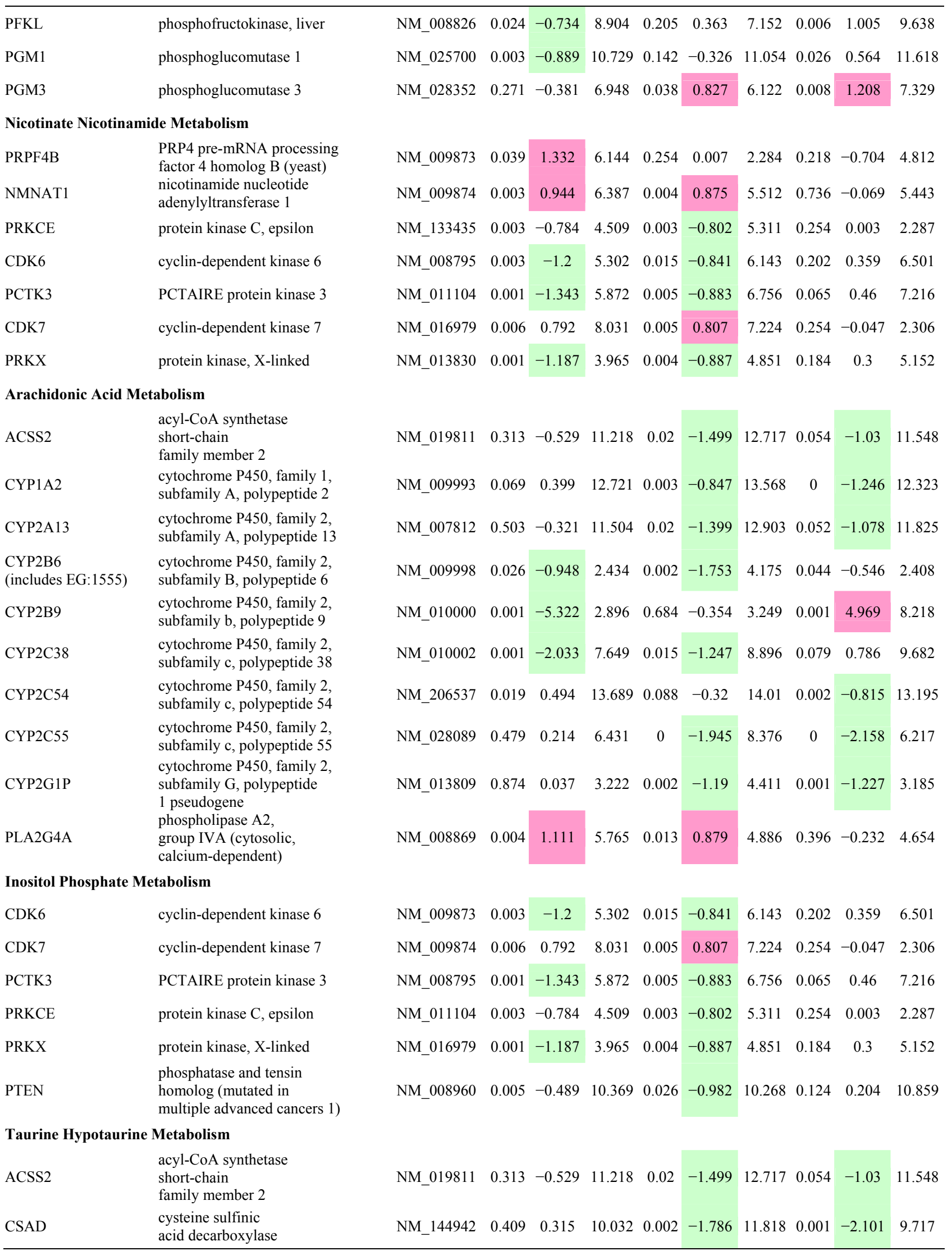


Supplement Table 2.

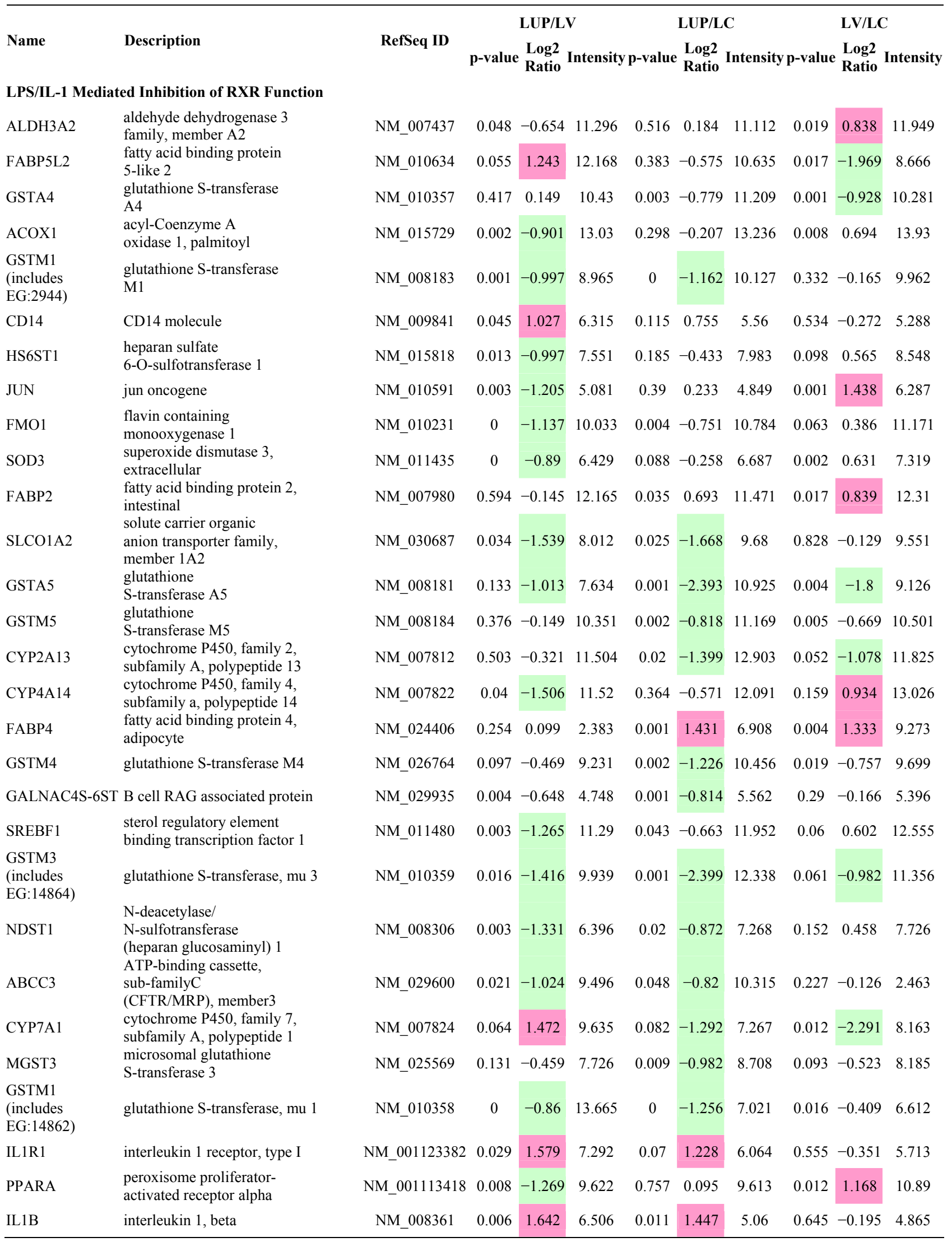


Continued

\begin{tabular}{|c|c|c|c|c|c|c|c|c|c|c|c|}
\hline SULT1C2 & $\begin{array}{l}\text { sulfotransferase family, } \\
\text { cytosolic, 1C, member } 2\end{array}$ & NM_026935 & 0.027 & -0.873 & 6.347 & 0.137 & -0.52 & 6.867 & 0.289 & 0.353 & 7.22 \\
\hline NR0B2 & $\begin{array}{l}\text { nuclear receptor subfamily } 0 \text {, } \\
\text { group } B \text {, member } 2\end{array}$ & NM_011850 & 0.012 & -1.395 & 9.029 & 0.062 & -0.913 & 9.942 & 0.275 & 0.482 & 10.424 \\
\hline FMO5 & $\begin{array}{l}\text { flavin containing } \\
\text { monooxygenase } 5\end{array}$ & NM_010232 & 0.001 & -0.887 & 11.336 & 0.038 & -0.37 & 11.706 & 0.006 & 0.695 & 10.173 \\
\hline FABP7 & $\begin{array}{l}\text { fatty acid binding } \\
\text { protein } 7 \text {, brain }\end{array}$ & NM_021272 & 0.002 & 0.876 & 7.398 & 0.387 & 0.161 & 7.237 & 0.005 & -0.715 & 6.521 \\
\hline ALDH1B1 & $\begin{array}{l}\text { aldehyde dehydrogenase } \\
1 \text { family, member B1 } \\
\text { acyl-CoA synthetase }\end{array}$ & NM_028270 & 0.008 & -1.606 & 6.814 & 0.094 & -0.827 & 7.641 & 0.111 & 0.779 & 8.419 \\
\hline ACSL3 & $\begin{array}{l}\text { long-chain } \\
\text { family member } 3 \\
\text { aldehyde dehydrogenase }\end{array}$ & NM_001033606 & 0.011 & -0.825 & 7.664 & 0.064 & -0.519 & 8.184 & 0.233 & 0.305 & 8.489 \\
\hline ALDH5A1 & $\begin{array}{l}5 \text { family, member A1 } \\
\text { (succinate-semialdehyde } \\
\text { dehydrogenase) }\end{array}$ & NM_172532 & 0.008 & -0.808 & 8.158 & 0.09 & -0.422 & 8.58 & 0.114 & 0.387 & 8.966 \\
\hline PLTP & phospholipid transfer protein & NM_011125 & 0.027 & -1.201 & 9.997 & 0.011 & -1.493 & 11.49 & 0.51 & -0.292 & 11.198 \\
\hline CPT1A & $\begin{array}{l}\text { carnitine palmitoyltransferase } \\
\text { 1A (liver) }\end{array}$ & NM_013495 & 0.008 & -0.834 & 11.137 & 0.252 & 0.279 & 10.858 & 0.002 & 1.114 & 11.972 \\
\hline \multicolumn{12}{|c|}{ Aryl Hydrocarbon Receptor Signaling } \\
\hline ALDH1B1 & $\begin{array}{l}\text { aldehyde dehydrogenase } \\
1 \text { family, member B1 }\end{array}$ & NM_028270 & 0.008 & -1.606 & 6.814 & 0.094 & -0.827 & 7.641 & 0.111 & 0.779 & 8.419 \\
\hline ALDH3A2 & $\begin{array}{l}\text { aldehyde dehydrogenase } \\
3 \text { family, member A2 }\end{array}$ & NM_007437 & 0.048 & -0.654 & 11.296 & 0.516 & 0.184 & 11.112 & 0.019 & 0.838 & 11.949 \\
\hline ALDH5A1 & $\begin{array}{l}\text { aldehyde dehydrogenase } \\
5 \text { family, member A1 } \\
\text { (succinate-semialdehyde } \\
\text { dehydrogenase) }\end{array}$ & NM_172532 & 0.008 & -0.808 & 8.158 & 0.09 & -0.422 & 8.58 & 0.114 & 0.387 & 8.966 \\
\hline $\mathrm{BAX}$ & BCL2-associated X protein & NM_007527 & 0.003 & -0.844 & 6.969 & 0.173 & -0.28 & 7.248 & 0.02 & 0.564 & 7.812 \\
\hline CCND1 & cyclin D1 & NM_007631 & 0 & -1.599 & 5.005 & 0 & -1.239 & 6.244 & 0.041 & 0.355 & 7.465 \\
\hline $\mathrm{CCND} 2$ & cyclin D2 & NM_009829 & 0.001 & -0.606 & 4.175 & 0.001 & -0.944 & 5.89 & 0.132 & -0.175 & 2.597 \\
\hline CDK6 & cyclin-dependent kinase 6 & NM_009873 & 0.003 & -1.2 & 5.302 & 0.015 & -0.841 & 6.143 & 0.202 & 0.359 & 6.501 \\
\hline CYP1A2 & $\begin{array}{l}\text { cytochrome P450, family } 1 \text {, } \\
\text { subfamily A, polypeptide } 2\end{array}$ & NM_009993 & 0.069 & 0.399 & 12.721 & 0.003 & -0.847 & 13.568 & 0 & -1.246 & 12.323 \\
\hline ESR1 & estrogen receptor 1 & NM_007956 & 0.012 & -0.862 & 8.244 & 0.02 & -0.763 & 9.007 & 0.622 & -0.111 & 4.922 \\
\hline FASN & fatty acid synthase & NM_007988 & 0.002 & -1.961 & 11.054 & 0.012 & -1.338 & 12.392 & 0.154 & 0.623 & 13.015 \\
\hline GSTA4 & $\begin{array}{l}\text { glutathione } \\
\text { S-transferase A4 }\end{array}$ & NM_010357 & 0.417 & 0.149 & 10.43 & 0.003 & -0.779 & 11.209 & 0.001 & -0.928 & 10.281 \\
\hline GSTA5 & glutathione S-transferase A5 & NM_008181 & 0.133 & -1.013 & 7.634 & 0.001 & -2.393 & 10.925 & 0.004 & -1.8 & 9.126 \\
\hline $\begin{array}{l}\text { GSTM1 } \\
\text { (includes } \\
\text { EG:14862) }\end{array}$ & glutathione S-transferase, mu 1 & NM_010358 & 0 & -0.86 & 13.665 & 0 & -1.256 & 7.021 & 0.016 & -0.409 & 6.612 \\
\hline $\begin{array}{l}\text { GSTM1 } \\
\text { (includes } \\
\text { EG:2944) }\end{array}$ & glutathione S-transferase M1 & NM_008183 & 0.001 & -0.997 & 8.965 & 0 & -1.162 & 10.127 & 0.332 & -0.165 & 9.962 \\
\hline $\begin{array}{l}\text { GSTM3 } \\
\text { (includes } \\
\text { EG:14864) }\end{array}$ & glutathione S-transferase, mu 3 & NM_010359 & 0.016 & -1.416 & 9.939 & 0.001 & -2.399 & 12.338 & 0.061 & -0.982 & 11.356 \\
\hline GSTM4 & glutathione S-transferase M4 & NM_026764 & 0.097 & -0.469 & 9.231 & 0.002 & -1.226 & 10.456 & 0.019 & -0.757 & 9.699 \\
\hline GSTM5 & glutathione S-transferase M5 & NM_008184 & 0.376 & -0.149 & 10.351 & 0.002 & -0.818 & 11.169 & 0.005 & -0.669 & 10.501 \\
\hline IL1B & interleukin 1 , beta & NM_008361 & 0.006 & 1.642 & 6.506 & 0.011 & 1.447 & 5.06 & 0.645 & -0.195 & 4.865 \\
\hline JUN & jun oncogene & NM_010591 & 0.003 & -1.205 & 5.081 & 0.39 & 0.233 & 4.849 & 0.001 & 1.438 & 6.287 \\
\hline MGST3 & $\begin{array}{l}\text { microsomal glutathione } \\
\text { S-transferase } 3\end{array}$ & NM_025569 & 0.131 & -0.459 & 7.726 & 0.009 & -0.982 & 8.708 & 0.093 & -0.523 & 8.185 \\
\hline NFIA & nuclear factor I/A & NM_001122952 & 0.008 & -1.234 & 7.955 & 0.026 & -0.941 & 8.896 & 0.09 & 0.275 & 2.694 \\
\hline
\end{tabular}




\section{Continued}

\begin{tabular}{|c|c|c|c|c|c|c|c|c|c|c|c|}
\hline NFIB & nuclear factor I/B & NM_001113209 & 0.001 & -0.8 & 8.03 & 0.005 & -0.622 & 8.652 & 0.064 & 0.59 & 3.579 \\
\hline NFIC & $\begin{array}{l}\text { nuclear factor } \mathrm{I} / \mathrm{C} \\
\text { (CCAAT-binding } \\
\text { transcription factor) }\end{array}$ & NM_008688 & 0.002 & -2.153 & 2.894 & 0.067 & -1.007 & 10.325 & 0.009 & 1.488 & 6.18 \\
\hline NFIX & $\begin{array}{l}\text { nuclear factor } \mathrm{I} / \mathrm{X} \\
\text { (CCAAT-binding } \\
\text { transcription factor) }\end{array}$ & NM_001081981 & 0.013 & -0.839 & 9.742 & 0.049 & -0.287 & 4.334 & 0.261 & 0.3 & 10.581 \\
\hline NQO1 & $\begin{array}{l}\text { NAD(P)H dehydrogenase, } \\
\text { quinone } 1\end{array}$ & NM_008706 & 0.064 & -0.883 & 3.705 & 0.035 & -1.056 & 4.761 & 0.677 & -0.172 & 4.589 \\
\hline NR0B2 & $\begin{array}{l}\text { nuclear receptor subfamily } 0 \text {, } \\
\text { group B, } \\
\text { member } 2\end{array}$ & NM_011850 & 0.012 & -1.395 & 9.029 & 0.062 & -0.913 & 9.942 & 0.275 & 0.482 & 10.424 \\
\hline NRIP1 & $\begin{array}{l}\text { nuclear receptor interacting } \\
\text { protein } 1\end{array}$ & NM_173440 & 0.003 & -1.221 & 5.919 & 0.031 & -0.715 & 6.634 & 0.095 & 0.506 & 7.14 \\
\hline SMARCA4 & $\begin{array}{l}\text { SWI/SNF related, matrix } \\
\text { associated, actin dependent } \\
\text { regulator of chromatin, } \\
\text { subfamily a, member } 4\end{array}$ & NM_011417 & 0.003 & -1.241 & 7.787 & 0.363 & -0.302 & 5.462 & 0.004 & 1.198 & 9.028 \\
\hline \multicolumn{12}{|c|}{ LXR/RXR Activation } \\
\hline APOA4 & apolipoprotein A-IV & NM_007468 & 0.003 & -1.8 & 11.795 & 0.014 & 1.271 & 10.524 & 0 & 3.071 & 13.595 \\
\hline CD14 & CD14 molecule & NM_009841 & 0.045 & 1.027 & 6.315 & 0.115 & 0.755 & 5.56 & 0.534 & -0.272 & 5.288 \\
\hline CD36 & $\begin{array}{l}\text { CD36 molecule } \\
\text { (thrombospondin receptor) }\end{array}$ & NM_007643 & 0.014 & -1.72 & 5.253 & 0.432 & -0.427 & 5.68 & 0.042 & 1.293 & 6.973 \\
\hline CYP7A1 & $\begin{array}{l}\text { cytochrome P450, family } 7 \text {, } \\
\text { subfamily A, polypeptide } 1\end{array}$ & NM_007824 & 0.064 & 1.472 & 9.635 & 0.082 & -1.292 & 7.267 & 0.012 & -2.291 & 8.163 \\
\hline FASN & fatty acid synthase & NM_007988 & 0.002 & -1.961 & 11.054 & 0.012 & -1.338 & 12.392 & 0.154 & 0.623 & 13.015 \\
\hline HMGCR & $\begin{array}{l}\text { 3-hydroxy-3-methylglutaryl- } \\
\text { Coenzyme A reductase }\end{array}$ & NM_008255 & 0.428 & -0.254 & 6.79 & 0.007 & -1.179 & 7.969 & 0.02 & -0.925 & 7.044 \\
\hline IL1B & interleukin 1 , beta & NM_008361 & 0.006 & 1.642 & 6.506 & 0.011 & 1.447 & 5.06 & 0.645 & -0.195 & 4.865 \\
\hline IL1R1 & interleukin 1 receptor, type I & NM_001123382 & 0.029 & 1.579 & 7.292 & 0.07 & 1.228 & 6.064 & 0.555 & -0.351 & 5.713 \\
\hline LDLR & $\begin{array}{l}\text { low density lipoprotein receptor } \\
\text { (familial hypercholesterolemia) }\end{array}$ & NM_010700 & 0.005 & -1.457 & 9.068 & 0.121 & -0.625 & 9.692 & 0.043 & 0.743 & 3.31 \\
\hline MSR1 & macrophage scavenger receptor 1 & NM_001113326 & 0.001 & 1.087 & 6.778 & 0.014 & 0.588 & 6.19 & 0.027 & -0.499 & 5.691 \\
\hline PLTP & phospholipid transfer protein & NM_011125 & 0.027 & -1.201 & 9.997 & 0.011 & -1.493 & 11.49 & 0.51 & -0.292 & 11.198 \\
\hline SCD & $\begin{array}{l}\text { stearoyl-CoA desaturase } \\
\text { (delta-9-desaturase) }\end{array}$ & NM_009127 & 0.003 & -2.169 & 9.694 & 0.003 & -2.087 & 11.781 & 0.596 & 0.101 & 15.081 \\
\hline SREBF1 & $\begin{array}{l}\text { sterol regulatory element } \\
\text { binding transcription factor } 1\end{array}$ & NM_011480 & 0.003 & -1.265 & 11.29 & 0.043 & -0.663 & 11.952 & 0.06 & 0.602 & 12.555 \\
\hline \multicolumn{12}{|c|}{ Xenobiotic Metabolism Signaling } \\
\hline $\mathrm{ABCC} 3$ & $\begin{array}{l}\text { ATP-binding cassette, } \\
\text { sub-familyC (CFTR/MRP), } \\
\text { member3 }\end{array}$ & NM_029600 & 0.021 & -1.024 & 9.496 & 0.048 & -0.82 & 10.315 & 0.227 & -0.126 & 2.463 \\
\hline ALDH1B1 & $\begin{array}{l}\text { aldehyde dehydrogenase } \\
1 \text { family, member B1 }\end{array}$ & NM_028270 & 0.008 & -1.606 & 6.814 & 0.094 & -0.827 & 7.641 & 0.111 & 0.779 & 8.419 \\
\hline ALDH3A2 & $\begin{array}{l}\text { aldehyde dehydrogenase } \\
3 \text { family, member A2 }\end{array}$ & NM_007437 & 0.048 & -0.654 & 11.296 & 0.516 & 0.184 & 11.112 & 0.019 & 0.838 & 11.949 \\
\hline ALDH5A1 & $\begin{array}{l}\text { aldehyde dehydrogenase } \\
5 \text { family, member A1 } \\
\text { (succinate-semialdehyde } \\
\text { dehydrogenase) }\end{array}$ & NM_172532 & 0.008 & -0.808 & 8.158 & 0.09 & -0.422 & 8.58 & 0.114 & 0.387 & 8.966 \\
\hline CAMK1D & $\begin{array}{l}\text { calcium/calmodulin- } \\
\text { dependent protein kinase ID }\end{array}$ & NM_177343 & 0.04 & -0.702 & 6.781 & 0.006 & -1.12 & 7.901 & 0.172 & -0.418 & 7.483 \\
\hline $\begin{array}{l}\text { CES1 } \\
\text { (includes } \\
\text { EG:12623) }\end{array}$ & carboxylesterase 1 & NM_021456 & 0.159 & -0.509 & 9.847 & 0.02 & -0.988 & 10.835 & 0.182 & -0.478 & 10.357 \\
\hline $\begin{array}{l}\text { CES2 } \\
\text { (includes } \\
\text { EG:234671) }\end{array}$ & carboxylesterase 2 & NM_145603 & 0.207 & 0.338 & 10.019 & 0.037 & -0.632 & 10.651 & 0.006 & -0.97 & 9.681 \\
\hline CREBBP & $\begin{array}{l}\text { CREB binding protein } \\
\text { (Rubinstein-Taybi syndrome) }\end{array}$ & NM_001025432 & 0.005 & -1.363 & 5.911 & 0.161 & -0.511 & 6.422 & 0.018 & 0.027 & 2.313 \\
\hline
\end{tabular}


Continued

\begin{tabular}{|c|c|c|c|c|c|c|c|c|c|c|c|}
\hline CYP1A2 & $\begin{array}{l}\text { cytochrome P450, family } 1 \text {, } \\
\text { subfamily A, polypeptide } 2\end{array}$ & NM_009993 & 0.069 & 0.399 & 12.721 & 0.003 & -0.847 & 13.568 & 0 & -1.246 & 12.323 \\
\hline EIF2AK3 & $\begin{array}{l}\text { eukaryotic translation } \\
\text { initiation factor } 2 \text {-alpha kinase } 3\end{array}$ & NM_010121 & 0.014 & -0.805 & 5.143 & 0.817 & -0.058 & 5.2 & 0.019 & 0.748 & 5.948 \\
\hline FMO1 & $\begin{array}{l}\text { flavin containing } \\
\text { monooxygenase } 1\end{array}$ & NM_010231 & 0 & -1.137 & 10.033 & 0.004 & -0.751 & 10.784 & 0.063 & 0.386 & 11.171 \\
\hline FMO5 & $\begin{array}{l}\text { flavin containing } \\
\text { monooxygenase } 5\end{array}$ & NM_010232 & 0.001 & -0.887 & 11.336 & 0.038 & -0.37 & 11.706 & 0.006 & 0.695 & 10.173 \\
\hline $\begin{array}{l}\text { GALNAC4S } \\
-6 \mathrm{ST}\end{array}$ & B cell RAG associated protein & NM_029935 & 0.004 & -0.648 & 4.748 & 0.001 & -0.814 & 5.562 & 0.29 & -0.166 & 5.396 \\
\hline GSTA4 & glutathione S-transferase A4 & NM_010357 & 0.417 & 0.149 & 10.43 & 0.003 & -0.779 & 11.209 & 0.001 & -0.928 & 10.281 \\
\hline GSTA5 & glutathione S-transferase A5 & NM_008181 & 0.133 & -1.013 & 7.634 & 0.001 & -2.393 & 10.925 & 0.004 & -1.8 & 9.126 \\
\hline $\begin{array}{l}\text { GSTM1 } \\
\text { (includes } \\
\text { EG:14862) }\end{array}$ & glutathione S-transferase, mu 1 & NM_010358 & 0 & -0.86 & 13.665 & 0 & -1.256 & 7.021 & 0.016 & -0.409 & 6.612 \\
\hline $\begin{array}{l}\text { GSTM1 } \\
\text { (includes } \\
\text { EG:2944) }\end{array}$ & glutathione S-transferase M1 & NM_008183 & 0.001 & -0.997 & 8.965 & 0 & -1.162 & 10.127 & 0.332 & -0.165 & 9.962 \\
\hline $\begin{array}{l}\text { GSTM3 } \\
\text { (includes } \\
\text { EG:14864) }\end{array}$ & glutathione S-transferase, mu 3 & NM_010359 & 0.016 & -1.416 & 9.939 & 0.001 & -2.399 & 12.338 & 0.061 & -0.982 & 11.356 \\
\hline GSTM4 & glutathione S-transferase M4 & NM_026764 & 0.097 & -0.469 & 9.231 & 0.002 & -1.226 & 10.456 & 0.019 & -0.757 & 9.699 \\
\hline GSTM5 & glutathione S-transferase M5 & NM_008184 & 0.376 & -0.149 & 10.351 & 0.002 & -0.818 & 11.169 & 0.005 & -0.669 & 10.501 \\
\hline HS6ST1 & $\begin{array}{l}\text { heparan sulfate } \\
6 \text {-O-sulfotransferase } 1\end{array}$ & NM_015818 & 0.013 & -0.997 & 7.551 & 0.185 & -0.433 & 7.983 & 0.098 & 0.565 & 8.548 \\
\hline IL1B & interleukin 1 , beta & NM_008361 & 0.006 & 1.642 & 6.506 & 0.011 & 1.447 & 5.06 & 0.645 & -0.195 & 4.865 \\
\hline KEAP1 & $\begin{array}{l}\text { kelch-like ECH-associated } \\
\text { protein } 1\end{array}$ & $\begin{array}{c}\text { NM_001110305 } \\
\text { ///NM_001110306 } \\
\text { /// NM_001110307 } \\
\text { /// NM_016679 }\end{array}$ & 0.005 & -0.977 & 5.151 & 0.041 & -0.593 & 5.744 & 0.054 & 0.26 & 9.147 \\
\hline MAF & $\begin{array}{l}\text { v-maf musculoaponeurotic } \\
\text { fibrosarcoma oncogene } \\
\text { homolog (avian) }\end{array}$ & NM_001025577 & 0.007 & -0.852 & 4.264 & 0.001 & -1.235 & 5.499 & 0.081 & -0.334 & 5.989 \\
\hline MGST3 & $\begin{array}{l}\text { microsomal glutathione } \\
\text { S-transferase } 3\end{array}$ & NM_025569 & 0.131 & -0.459 & 7.726 & 0.009 & -0.982 & 8.708 & 0.093 & -0.523 & 8.185 \\
\hline NDST1 & $\begin{array}{l}\text { N-deacetylase/N-sulfotransferase } \\
\text { (heparan glucosaminyl) } 1\end{array}$ & NM_008306 & 0.003 & -1.331 & 6.396 & 0.02 & -0.872 & 7.268 & 0.152 & 0.458 & 7.726 \\
\hline NQO1 & $\begin{array}{l}\text { NAD }(\mathrm{P}) \mathrm{H} \text { dehydrogenase, } \\
\text { quinone } 1\end{array}$ & NM_008706 & 0.064 & -0.883 & 3.705 & 0.035 & -1.056 & 4.761 & 0.677 & -0.172 & 4.589 \\
\hline NRIP1 & $\begin{array}{l}\text { nuclear receptor interacting } \\
\text { protein } 1\end{array}$ & NM_173440 & 0.003 & -1.221 & 5.919 & 0.031 & -0.715 & 6.634 & 0.095 & 0.506 & 7.14 \\
\hline PIK3R1 & $\begin{array}{l}\text { phosphoinositide-3-kinase, } \\
\text { regulatory subunit } 1 \text { (alpha) }\end{array}$ & NM_001024955 & 0.001 & -1.124 & 6.417 & 0.061 & -0.437 & 3.074 & 0.003 & 0.891 & 7.234 \\
\hline PPP2R5E & $\begin{array}{l}\text { protein phosphatase } 2, \\
\text { regulatory subunit } \mathrm{B}^{\prime}, \\
\text { epsilon isoform }\end{array}$ & NM_012024 & 0 & -0.905 & 7.187 & 0 & -0.59 & 7.777 & 0.001 & 0.314 & 8.091 \\
\hline PRKCE & protein kinase $\mathrm{C}$, epsilon & NM_011104 & 0.003 & -0.784 & 4.509 & 0.003 & -0.802 & 5.311 & 0.254 & 0.003 & 2.287 \\
\hline SOD3 & $\begin{array}{l}\text { superoxide dismutase } 3 \text {, } \\
\text { extracellular }\end{array}$ & NM_011435 & 0 & -0.89 & 6.429 & 0.088 & -0.258 & 6.687 & 0.002 & 0.631 & 7.319 \\
\hline SULT1C2 & $\begin{array}{l}\text { sulfotransferase family, } \\
\text { cytosolic, } 1 \mathrm{C} \text {, member } 2\end{array}$ & NM_026935 & 0.027 & -0.873 & 6.347 & 0.137 & -0.52 & 6.867 & 0.289 & 0.353 & 7.22 \\
\hline UGT2B10 & $\begin{array}{l}\text { UDP glucuronosyltransferase } \\
2 \text { family, polypeptide B10 }\end{array}$ & NM_053215 & 0.024 & 1.63 & 4.538 & 0.104 & 1.041 & 3.497 & 0.322 & -0.589 & 2.908 \\
\hline UGT2B17 & $\begin{array}{l}\text { UDP glucuronosyltransferase } \\
2 \text { family, polypeptide B } 17\end{array}$ & NM_133894 & 0.007 & 3.388 & 8.373 & 0.107 & 1.639 & 6.734 & 0.075 & -0.247 & 13.76 \\
\hline \multicolumn{12}{|c|}{ NRF2-mediated Oxidative Stress Response } \\
\hline ACTG1 & actin, gamma 1 & NM_009609 & 0.002 & -0.945 & 11.935 & 0.88 & 0.028 & 11.907 & 0.001 & 0.973 & 12.88 \\
\hline GSTA4 & glutathione S-transferase A4 & NM_010357 & 0.417 & 0.149 & 10.43 & 0.003 & -0.779 & 11.209 & 0.001 & -0.928 & 10.281 \\
\hline $\begin{array}{l}\text { GSTM1 } \\
\text { (includes } \\
\text { EG:2944) }\end{array}$ & glutathione S-transferase M1 & NM_008183 & 0.001 & -0.997 & 8.965 & 0 & -1.162 & 10.127 & 0.332 & -0.165 & 9.962 \\
\hline
\end{tabular}


Continued

\begin{tabular}{|c|c|c|c|c|c|c|c|c|c|c|c|}
\hline DNAJC15 & $\begin{array}{l}\text { DnaJ (Hsp40) homolog, } \\
\text { subfamily C, member } 15\end{array}$ & NM_025384 & 0.001 & 0.817 & 11.075 & 0.013 & 0.51 & 10.565 & 0.082 & -0.306 & 10.258 \\
\hline JUN & jun oncogene & NM_010591 & 0.003 & -1.205 & 5.081 & 0.39 & 0.233 & 4.849 & 0.001 & 1.438 & 6.287 \\
\hline FMO1 & $\begin{array}{l}\text { flavin containing } \\
\text { monooxygenase } 1\end{array}$ & NM_010231 & 0 & -1.137 & 10.033 & 0.004 & -0.751 & 10.784 & 0.063 & 0.386 & 11.171 \\
\hline SOD3 & $\begin{array}{l}\text { superoxide dismutase } 3 \text {, } \\
\text { extracellular }\end{array}$ & NM_011435 & 0 & -0.89 & 6.429 & 0.088 & -0.258 & 6.687 & 0.002 & 0.631 & 7.319 \\
\hline GSTA5 & glutathione S-transferase A5 & NM_008181 & 0.133 & -1.013 & 7.634 & 0.001 & -2.393 & 10.925 & 0.004 & -1.8 & 9.126 \\
\hline GSTM5 & glutathione S-transferase M5 & NM_008184 & 0.376 & -0.149 & 10.351 & 0.002 & -0.818 & 11.169 & 0.005 & -0.669 & 10.501 \\
\hline $\mathrm{VCP}$ & valosin-containing protein & NM_009503 & 0.001 & -0.821 & 11.941 & 0.361 & -0.144 & 12.085 & 0.003 & 0.677 & 12.762 \\
\hline NQO1 & $\begin{array}{l}\text { NAD }(\mathrm{P}) \mathrm{H} \text { dehydrogenase, } \\
\text { quinone } 1\end{array}$ & NM_008706 & 0.064 & -0.883 & 3.705 & 0.035 & -1.056 & 4.761 & 0.677 & -0.172 & 4.589 \\
\hline GSTM4 & glutathione S-transferase M4 & NM_026764 & 0.097 & -0.469 & 9.231 & 0.002 & -1.226 & 10.456 & 0.019 & -0.757 & 9.699 \\
\hline $\begin{array}{l}\text { GSTM3 } \\
\text { (includes } \\
\text { EG:14864) }\end{array}$ & glutathione S-transferase, mu 3 & NM_010359 & 0.016 & -1.416 & 9.939 & 0.001 & -2.399 & 12.338 & 0.061 & -0.982 & 11.356 \\
\hline DNAJB14 & $\begin{array}{l}\text { DnaJ (Hsp40) homolog, } \\
\text { subfamily B, member } 14\end{array}$ & XM_001473173 & 0.003 & -1.225 & 4.7 & 0.216 & -0.361 & 5.062 & 0.016 & 0.864 & 5.925 \\
\hline MAF & $\begin{array}{l}\text { v-maf musculoaponeurotic } \\
\text { fibrosarcoma oncogene } \\
\text { homolog (avian) }\end{array}$ & NM_001025577 & 0.007 & -0.852 & 4.264 & 0.001 & -1.235 & 5.499 & 0.081 & -0.334 & 5.989 \\
\hline CREBBP & $\begin{array}{l}\text { CREB binding protein } \\
\text { (Rubinstein-Taybi syndrome) }\end{array}$ & NM_001025432 & 0.005 & -1.363 & 5.911 & 0.161 & -0.511 & 6.422 & 0.018 & 0.027 & 2.313 \\
\hline PRKCE & protein kinase $\mathrm{C}$, epsilon & NM_011104 & 0.003 & -0.784 & 4.509 & 0.003 & -0.802 & 5.311 & 0.254 & 0.003 & 2.287 \\
\hline PIK3R1 & $\begin{array}{l}\text { phosphoinositide-3-kinase, } \\
\text { regulatory subunit } 1 \text { (alpha) } \\
\text { activating transcription }\end{array}$ & NM_001024955 & 0.001 & -1.124 & 6.417 & 0.061 & -0.437 & 3.074 & 0.003 & 0.891 & 7.234 \\
\hline ATF4 & $\begin{array}{l}\text { factor } 4 \text { (tax-responsive } \\
\text { enhancer element B67) }\end{array}$ & NM_009716 & 0.011 & 0.869 & 9.16 & 0.017 & 0.784 & 8.377 & 0.734 & -0.076 & 10.489 \\
\hline MGST3 & $\begin{array}{l}\text { microsomal glutathione } \\
\text { S-transferase } 3\end{array}$ & NM_025569 & 0.131 & -0.459 & 7.726 & 0.009 & -0.982 & 8.708 & 0.093 & -0.523 & 8.185 \\
\hline $\begin{array}{l}\text { GSTM1 } \\
\text { (includes } \\
\text { EG:14862) }\end{array}$ & glutathione S-transferase, mu 1 & NM_010358 & 0 & -0.86 & 13.665 & 0 & -1.256 & 7.021 & 0.016 & -0.409 & 6.612 \\
\hline JUND & jun D proto-oncogene & NM_010592 & 0.002 & -0.832 & 9.321 & 0.115 & -0.309 & 9.63 & 0.02 & 0.523 & 10.153 \\
\hline EIF2AK3 & $\begin{array}{l}\text { eukaryotic translation } \\
\text { initiation factor } \\
\text { 2-alpha kinase } 3\end{array}$ & NM_010121 & 0.014 & -0.805 & 5.143 & 0.817 & -0.058 & 5.2 & 0.019 & 0.748 & 5.948 \\
\hline BACH1 & $\begin{array}{l}\text { BTB and CNC homology } 1 \text {, } \\
\text { basic leucine zipper } \mathrm{t} \\
\text { ranscription factor } 1\end{array}$ & NM_007520 & 0.009 & -0.761 & 4.05 & 0.004 & -0.915 & 4.965 & 0.038 & -0.575 & 8.737 \\
\hline KEAP1 & $\begin{array}{l}\text { kelch-like ECH-associated } \\
\text { protein } 1\end{array}$ & NM_001110305 & 0.005 & -0.977 & 5.151 & 0.041 & -0.593 & 5.744 & 0.054 & 0.26 & 9.147 \\
\hline GSK3B & $\begin{array}{l}\text { glycogen synthase kinase } \\
3 \text { beta }\end{array}$ & NM_019827 & 0.003 & -1.35 & 4.392 & 0.027 & -0.818 & 5.21 & 0.108 & 0.627 & 6.711 \\
\hline \multicolumn{12}{|c|}{ PXR/RXR Activation } \\
\hline $\mathrm{ABCC} 3$ & $\begin{array}{l}\text { ATP-binding cassette, } \\
\text { sub-familyC (CFTR/MRP), } \\
\text { member3 }\end{array}$ & NM_029600 & 0.021 & -1.024 & 9.496 & 0.048 & -0.82 & 10.315 & 0.227 & -0.126 & 2.463 \\
\hline ALDH3A2 & $\begin{array}{l}\text { aldehyde dehydrogenase } 3 \\
\text { family, member A } 2\end{array}$ & NM_007437 & 0.048 & -0.654 & 11.296 & 0.516 & 0.184 & 11.112 & 0.019 & 0.838 & 11.949 \\
\hline CPT1A & $\begin{array}{l}\text { carnitine palmitoyltransferase } \\
\text { 1A (liver) }\end{array}$ & NM_013495 & 0.008 & -0.834 & 11.137 & 0.252 & 0.279 & 10.858 & 0.002 & 1.114 & 11.972 \\
\hline CYP1A2 & $\begin{array}{l}\text { cytochrome P } 450 \text {, family } 1 \text {, } \\
\text { subfamily A, polypeptide } 2\end{array}$ & NM_009993 & 0.069 & 0.399 & 12.721 & 0.003 & -0.847 & 13.568 & 0 & -1.246 & 12.323 \\
\hline $\begin{array}{l}\text { CYP2B6 } \\
\text { (includes } \\
\text { EG:1555) }\end{array}$ & $\begin{array}{l}\text { cytochrome P450, family } 2 \text {, } \\
\text { subfamily B, polypeptide } 6\end{array}$ & NM_009998 & 0.026 & -0.948 & 2.434 & 0.002 & -1.753 & 4.175 & 0.044 & -0.546 & 2.408 \\
\hline CYP7A1 & $\begin{array}{l}\text { cytochrome P450, family } 7, \\
\text { subfamily A, polypeptide } 1\end{array}$ & NM_007824 & 0.064 & 1.472 & 9.635 & 0.082 & -1.292 & 7.267 & 0.012 & -2.291 & 8.163 \\
\hline FOXO3 & forkhead box O3 & NM_019740 & 0.01 & -0.858 & 7.286 & 0.043 & -0.591 & 7.877 & 0.091 & -0.29 & 4.357 \\
\hline
\end{tabular}


Continued

\begin{tabular}{|c|c|c|c|c|c|c|c|c|c|c|c|}
\hline G6PC & $\begin{array}{l}\text { glucose-6-phosphatase, } \\
\text { catalytic subunit }\end{array}$ & NM_008061 & 0.098 & -0.641 & 12.013 & 0.641 & 0.161 & 11.851 & 0.049 & 0.803 & 12.654 \\
\hline GSTA5 & glutathione S-transferase A5 & NM_008181 & 0.133 & -1.013 & 7.634 & 0.001 & -2.393 & 10.925 & 0.004 & -1.8 & 9.126 \\
\hline $\begin{array}{l}\text { GSTM1 } \\
\text { (includes } \\
\text { EG:14862) }\end{array}$ & glutathione S-transferase, mu 1 & NM_010358 & 0 & -0.86 & 13.665 & 0 & -1.256 & 7.021 & 0.016 & -0.409 & 6.612 \\
\hline $\begin{array}{l}\text { GSTM1 } \\
\text { (includes } \\
\text { EG:2944) }\end{array}$ & glutathione S-transferase M1 & NM_008183 & 0.001 & -0.997 & 8.965 & 0 & -1.162 & 10.127 & 0.332 & -0.165 & 9.962 \\
\hline NR0B2 & $\begin{array}{l}\text { nuclear receptor subfamily } 0 \text {, } \\
\text { group B, member } 2\end{array}$ & NM_011850 & 0.012 & -1.395 & 9.029 & 0.062 & -0.913 & 9.942 & 0.275 & 0.482 & 10.424 \\
\hline PPARA & $\begin{array}{l}\text { peroxisome proliferator- } \\
\text { activated receptor alpha }\end{array}$ & NM_001113418 & 0.008 & -1.269 & 9.622 & 0.757 & 0.095 & 9.613 & 0.012 & 1.168 & 10.89 \\
\hline PRKACA & $\begin{array}{l}\text { protein kinase, cAMP- } \\
\text { dependent, catalytic, alpha }\end{array}$ & NM_008854 & 0.001 & -0.837 & 6.149 & 0.164 & -0.235 & 6.384 & 0.006 & 0.603 & 6.986 \\
\hline SCD & $\begin{array}{l}\text { stearoyl-CoA desaturase } \\
\text { (delta-9-desaturase) }\end{array}$ & NM_009127 & 0.003 & -2.169 & 9.694 & 0.003 & -2.087 & 11.781 & 0.596 & 0.101 & 15.081 \\
\hline \multicolumn{12}{|c|}{ FXR/RXR Activation } \\
\hline $\mathrm{ABCB} 4$ & $\begin{array}{l}\text { ATP-binding cassette, } \\
\text { sub-family B (MDR/TAP), } \\
\text { member } 4\end{array}$ & NM_008830 & 0.131 & -0.345 & 11.391 & 0.016 & 0.651 & 10.74 & 0.002 & 0.996 & 11.736 \\
\hline APOB & $\begin{array}{l}\text { apolipoprotein } \mathrm{B} \\
\text { (including } \operatorname{Ag}(\mathrm{x}) \text { antigen) }\end{array}$ & NM_009693 & 0.025 & -1.82 & 9.83 & 0.701 & -0.068 & 13.11 & 0.015 & 2.064 & 11.65 \\
\hline CREBBP & $\begin{array}{l}\text { CREB binding protein } \\
\text { (Rubinstein-Taybi syndrome) }\end{array}$ & NM_001025432 & 0.005 & -1.363 & 5.911 & 0.161 & -0.511 & 6.422 & 0.018 & 0.027 & 2.313 \\
\hline CYP7A1 & $\begin{array}{l}\text { cytochrome P450, family } 7 \text {, } \\
\text { subfamily A, polypeptide } 1\end{array}$ & NM_007824 & 0.064 & 1.472 & 9.635 & 0.082 & -1.292 & 7.267 & 0.012 & -2.291 & 8.163 \\
\hline FASN & fatty acid synthase & NM_007988 & 0.002 & -1.961 & 11.054 & 0.012 & -1.338 & 12.392 & 0.154 & 0.623 & 13.015 \\
\hline G6PC & $\begin{array}{l}\text { glucose-6-phosphatase, } \\
\text { catalytic subunit }\end{array}$ & NM_008061 & 0.098 & -0.641 & 12.013 & 0.641 & 0.161 & 11.851 & 0.049 & 0.803 & 12.654 \\
\hline IL1B & interleukin 1 , beta & NM_008361 & 0.006 & 1.642 & 6.506 & 0.011 & 1.447 & 5.06 & 0.645 & -0.195 & 4.865 \\
\hline NR0B2 & $\begin{array}{l}\text { nuclear receptor subfamily } \\
0, \text { group B, member } 2\end{array}$ & NM_011850 & 0.012 & -1.395 & 9.029 & 0.062 & -0.913 & 9.942 & 0.275 & 0.482 & 10.424 \\
\hline OSTBETA & organic solute transporter beta & NM_178933 & 0 & 0.803 & 3.951 & 0 & 0.834 & 3.117 & 0.692 & 0.031 & 3.148 \\
\hline PKLR & pyruvate kinase, liver and RBC & NM_001099779 & 0.006 & -1.179 & 9.396 & 0.142 & -0.626 & 8.63 & 0.049 & 0.7 & 10.574 \\
\hline PLTP & phospholipid transfer protein & NM_011125 & 0.027 & -1.201 & 9.997 & 0.011 & -1.493 & 11.49 & 0.51 & -0.292 & 11.198 \\
\hline PPARA & $\begin{array}{l}\text { peroxisome proliferator- } \\
\text { activated receptor alpha }\end{array}$ & NM_001113418 & 0.008 & -1.269 & 9.622 & 0.757 & 0.095 & 9.613 & 0.012 & 1.168 & 10.89 \\
\hline SLC22A7 & $\begin{array}{l}\text { solute carrier family } 22 \\
\text { (organic anion transporter), } \\
\text { member } 7\end{array}$ & NM_144856 & 0.304 & 0.502 & 10.384 & 0.014 & 1.509 & 8.875 & 0.064 & 1.007 & 9.882 \\
\hline SREBF1 & $\begin{array}{l}\text { sterol regulatory element } \\
\text { binding transcription factor } 1\end{array}$ & NM_011480 & 0.003 & -1.265 & 11.29 & 0.043 & -0.663 & 11.952 & 0.06 & 0.602 & 12.555 \\
\hline VLDLR & $\begin{array}{l}\text { very low density lipoprotein } \\
\text { receptor }\end{array}$ & NM_013703 & 0.032 & -1.159 & 3.548 & 0.1 & -0.816 & 4.363 & 0.09 & 0.481 & 2.856 \\
\hline \multicolumn{12}{|c|}{ PPARa/RXRa Activation } \\
\hline $\mathrm{ACOX} 1$ & $\begin{array}{l}\text { acyl-Coenzyme A oxidase } 1 \text {, } \\
\text { palmitoyl }\end{array}$ & NM_015729 & 0.002 & -0.901 & 13.03 & 0.298 & -0.207 & 13.236 & 0.008 & 0.694 & 13.93 \\
\hline CD36 & $\begin{array}{l}\text { CD36 molecule } \\
\text { (thrombospondin receptor) }\end{array}$ & NM_007643 & 0.014 & -1.72 & 5.253 & 0.432 & -0.427 & 5.68 & 0.042 & 1.293 & 6.973 \\
\hline CREBBP & $\begin{array}{l}\text { CREB binding protein } \\
\text { (Rubinstein-Taybi syndrome) }\end{array}$ & NM_001025432 & 0.005 & -1.363 & 5.911 & 0.161 & -0.511 & 6.422 & 0.018 & 0.027 & 2.313 \\
\hline CYP2C38 & $\begin{array}{l}\text { cytochrome P450, family } 2 \text {, } \\
\text { subfamily c, polypeptide } 38\end{array}$ & NM_010002 & 0.001 & -2.033 & 7.649 & 0.015 & -1.247 & 8.896 & 0.079 & 0.786 & 9.682 \\
\hline CYP2C54 & $\begin{array}{l}\text { cytochrome P } 450 \text {, family } 2 \text {, } \\
\text { subfamily c, polypeptide } 54\end{array}$ & NM_206537 & 0.019 & 0.494 & 13.689 & 0.088 & -0.32 & 14.01 & 0.002 & -0.815 & 13.195 \\
\hline CYP2C55 & $\begin{array}{l}\text { cytochrome P450, family } 2 \text {, } \\
\text { subfamily c, polypeptide } 55\end{array}$ & NM_028089 & 0.479 & 0.214 & 6.431 & 0 & -1.945 & 8.376 & 0 & -2.158 & 6.217 \\
\hline FASN & fatty acid synthase & NM_007988 & 0.002 & -1.961 & 11.054 & 0.012 & -1.338 & 12.392 & 0.154 & 0.623 & 13.015 \\
\hline
\end{tabular}


Continued

\begin{tabular}{|c|c|c|c|c|c|c|c|c|c|c|c|}
\hline GNAQ & $\begin{array}{l}\text { guanine nucleotide binding } \\
\text { protein (G protein), } \\
\text { q polypeptide }\end{array}$ & NM_008139 & 0.001 & -0.923 & 5.957 & 0.011 & -0.605 & 6.563 & 0.043 & 0.514 & 6.285 \\
\hline GPD1 & $\begin{array}{l}\text { glycerol-3-phosphate } \\
\text { dehydrogenase } 1 \text { (soluble) }\end{array}$ & NM_010271 & 0.003 & -0.861 & 10.337 & 0.258 & -0.227 & 10.565 & 0.012 & 0.634 & 11.199 \\
\hline GPD2 & $\begin{array}{l}\text { glycerol-3-phosphate } \\
\text { dehydrogenase } 2 \\
\text { (mitochondrial) }\end{array}$ & NM_010274 & 0.004 & -0.871 & 8.968 & 0.254 & -0.011 & 2.295 & 0.002 & 0.989 & 9.839 \\
\hline IL1B & interleukin 1 , beta & NM_008361 & 0.006 & 1.642 & 6.506 & 0.011 & 1.447 & 5.06 & 0.645 & -0.195 & 4.865 \\
\hline IL1R1 & $\begin{array}{l}\text { interleukin } 1 \text { receptor, } \\
\text { type I }\end{array}$ & NM_001123382 & 0.029 & 1.579 & 7.292 & 0.07 & 1.228 & 6.064 & 0.555 & -0.351 & 5.713 \\
\hline ITGB5 & integrin, beta 5 & NM_010580 & 0.003 & -0.94 & 9.049 & 0.075 & -0.432 & 9.482 & 0.032 & 0.474 & 9.953 \\
\hline JUN & jun oncogene & NM_010591 & 0.003 & -1.205 & 5.081 & 0.39 & 0.233 & 4.849 & 0.001 & 1.438 & 6.287 \\
\hline NR0B2 & $\begin{array}{l}\text { nuclear receptor subfamily } 0 \text {, } \\
\text { group } \mathrm{B}, \text { member } 2\end{array}$ & NM_011850 & 0.012 & -1.395 & 9.029 & 0.062 & -0.913 & 9.942 & 0.275 & 0.482 & 10.424 \\
\hline PPARA & $\begin{array}{l}\text { peroxisome proliferator- } \\
\text { activated receptor alpha }\end{array}$ & $\begin{array}{c}\text { NM_001113418/// } \\
\text { NM_011144 }\end{array}$ & 0.008 & -1.269 & 9.622 & 0.757 & 0.095 & 9.613 & 0.012 & 1.168 & 10.89 \\
\hline PRKACA & $\begin{array}{l}\text { protein kinase, cAMP- } \\
\text { dependent, catalytic, alpha }\end{array}$ & NM_008854 & 0.001 & -0.837 & 6.149 & 0.164 & -0.235 & 6.384 & 0.006 & 0.603 & 6.986 \\
\hline SMAD3 & SMAD family member 3 & NM_016769 & 0.005 & -0.99 & 4.439 & 0.105 & -0.438 & 4.877 & 0.052 & 0.552 & 5.429 \\
\hline \multicolumn{12}{|c|}{ Integrin Signaling } \\
\hline ACTG1 & actin, gamma 1 & NM_009609 & 0.002 & -0.945 & 11.935 & 0.88 & 0.028 & 11.907 & 0.001 & 0.973 & 12.88 \\
\hline ARF3 & ADP-ribosylation factor 3 & NM_007478 & 0.003 & -0.805 & 8.165 & 0.181 & -0.288 & 6.881 & 0.014 & 0.586 & 8.97 \\
\hline ARHGAP26 & $\begin{array}{l}\text { Rho GTPase activating } \\
\text { protein } 26\end{array}$ & NM_175164 & 0.023 & 0.742 & 7.574 & 0.007 & 0.98 & 6.594 & 0.1 & 0.476 & 4.812 \\
\hline CAPN8 & calpain 8 & NM_130890 & 0.023 & 1.148 & 4.258 & 0.009 & 1.428 & 2.83 & 0.491 & 0.28 & 3.11 \\
\hline CAV1 & $\begin{array}{l}\text { caveolin } 1 \text {, caveolae protein, } \\
22 \mathrm{kDa}\end{array}$ & NM_007616 & 0.018 & 0.872 & 7.171 & 0.008 & 1.046 & 6.125 & 0.549 & 0.174 & 6.3 \\
\hline GSK3B & $\begin{array}{l}\text { glycogen synthase kinase } \\
3 \text { beta }\end{array}$ & NM_019827 & 0.003 & -1.35 & 4.392 & 0.027 & -0.818 & 5.21 & 0.108 & 0.627 & 6.711 \\
\hline ITGB5 & integrin, beta 5 & NM_010580 & 0.003 & -0.94 & 9.049 & 0.075 & -0.432 & 9.482 & 0.032 & 0.474 & 9.953 \\
\hline $\begin{array}{l}\text { MYL9 } \\
\text { (includes } \\
\text { EG:98932) }\end{array}$ & $\begin{array}{l}\text { myosin, light polypeptide } 9, \\
\text { regulatory }\end{array}$ & XM_485171 & 0.008 & -0.851 & 3.726 & 0.005 & -0.95 & 4.676 & 0.67 & -0.1 & 4.577 \\
\hline PIK3R1 & $\begin{array}{l}\text { phosphoinositide-3-kinase, } \\
\text { regulatory subunit } 1 \text { (alpha) }\end{array}$ & NM_001024955 & 0.001 & -1.124 & 6.417 & 0.061 & -0.437 & 3.074 & 0.003 & 0.891 & 7.234 \\
\hline PTEN & $\begin{array}{l}\text { phosphatase and tensin } \\
\text { homolog (mutated in } \\
\text { multiple advanced cancers } 1 \text { ) }\end{array}$ & NM_008960 & 0.005 & -0.489 & 10.369 & 0.026 & -0.982 & 10.268 & 0.124 & 0.204 & 10.859 \\
\hline PXN & paxillin & NM_011223 & 0.002 & -1.146 & 9.179 & 0.031 & -0.633 & 9.812 & 0.064 & 0.513 & 10.325 \\
\hline RAP1B & $\begin{array}{l}\text { RAP1B, member of RAS } \\
\text { oncogene family }\end{array}$ & NM_024457 & 0.001 & 1.046 & 9.914 & 0.02 & 0.595 & 9.319 & 0.055 & -0.451 & 8.868 \\
\hline RAPGEF1 & $\begin{array}{l}\text { Rap guanine nucleotide } \\
\text { exchange factor (GEF) } 1\end{array}$ & NM_001039086 & 0.031 & -0.855 & 4.558 & 0.586 & -0.178 & 4.736 & 0.069 & 0.677 & 5.413 \\
\hline RHOJ & $\begin{array}{l}\text { ras homolog gene family, } \\
\text { member J }\end{array}$ & NM_023275 & 0.001 & -1.553 & 4.105 & 0.011 & -0.882 & 4.987 & 0.033 & 0.671 & 5.658 \\
\hline RHOU & $\begin{array}{l}\text { ras homolog gene family, } \\
\text { member U }\end{array}$ & NM_133955 & 0 & -1.221 & 8.933 & 0.021 & -0.436 & 9.368 & 0.001 & 0.785 & 10.154 \\
\hline RND2 & Rho family GTPase 2 & NM_009708 & 0.009 & -0.583 & 7.485 & 0.001 & -0.859 & 8.343 & 0.128 & -0.276 & 8.067 \\
\hline VCL & vinculin & NM_009502 & 0.007 & -0.852 & 7.954 & 0.158 & -0.352 & 8.305 & 0.061 & 0.501 & 8.806 \\
\hline WAS & $\begin{array}{l}\text { Wiskott-Aldrich syndrome } \\
\text { (eczema-thrombocytopenia) }\end{array}$ & NM_009515 & 0.022 & 0.807 & 4.52 & 0.064 & 0.597 & 3.923 & 0.46 & -0.21 & 3.713 \\
\hline $\begin{array}{l}\text { WASL } \\
\text { (includes } \\
\text { EG:8976) }\end{array}$ & Wiskott-Aldrich syndrome-like & NM_028459 & 0.001 & -0.808 & 6.796 & 0.016 & -0.251 & 9.173 & 0.007 & 0.549 & 7.604 \\
\hline ZYX & zyxin & NM_011777 & 0.003 & -1.279 & 6.549 & 0.007 & -1.097 & 7.646 & 0.538 & 0.182 & 7.828 \\
\hline
\end{tabular}


Continued

\begin{tabular}{|c|c|c|c|c|c|c|c|c|c|c|c|}
\hline $\mathrm{CCNH}$ & cyclin $\mathrm{H}$ & NM_023243 & 0.003 & 0.911 & 7.331 & 0.052 & 0.479 & 6.852 & 0.043 & -0.306 & 8.953 \\
\hline CDK7 & cyclin-dependent kinase 7 & NM_009874 & 0.006 & 0.792 & 8.031 & 0.005 & 0.807 & 7.224 & 0.254 & -0.047 & 2.306 \\
\hline CREBBP & $\begin{array}{l}\text { CREB binding protein } \\
\text { (Rubinstein-Taybi syndrome) }\end{array}$ & NM_001025432 & 0.005 & -1.363 & 5.911 & 0.161 & -0.511 & 6.422 & 0.018 & 0.027 & 2.313 \\
\hline CSNK2A1 & $\begin{array}{l}\text { casein kinase } 2 \text {, alpha } 1 \\
\text { polypeptide }\end{array}$ & NM_007788 & 0.001 & -1.087 & 7.111 & 0.015 & -0.604 & 7.715 & 0.036 & 0.483 & 8.198 \\
\hline CYP26A1 & $\begin{array}{l}\text { cytochrome P } 450 \text {, family } 26 \text {, } \\
\text { subfamily A, polypeptide } 1\end{array}$ & NM_007811 & 0.022 & -1.991 & 5.192 & 0.001 & -3.72 & 8.911 & 0.037 & -1.729 & 7.183 \\
\hline DUSP1 & dual specificity phosphatase 1 & NM_013642 & 0.005 & -1.426 & 7.398 & 0.586 & 0.197 & 7.201 & 0.003 & 1.623 & 8.824 \\
\hline JUN & jun oncogene & NM_010591 & 0.003 & -1.205 & 5.081 & 0.39 & 0.233 & 4.849 & 0.001 & 1.438 & 6.287 \\
\hline NR2F2 & $\begin{array}{l}\text { nuclear receptor subfamily } 2 \text {, } \\
\text { group } \mathrm{F} \text {, member } 2\end{array}$ & NM_009697 & 0.004 & -0.885 & 7.792 & 0.01 & -0.725 & 8.518 & 0.067 & 0.101 & 2.422 \\
\hline NRIP1 & $\begin{array}{l}\text { nuclear receptor } \\
\text { interacting protein } 1\end{array}$ & NM_173440 & 0.003 & -1.221 & 5.919 & 0.031 & -0.715 & 6.634 & 0.095 & 0.506 & 7.14 \\
\hline PIK3R1 & $\begin{array}{l}\text { phosphoinositide-3-kinase, } \\
\text { regulatory subunit } 1 \text { (alpha) }\end{array}$ & NM_001024955 & 0.001 & -1.124 & 6.417 & 0.061 & -0.437 & 3.074 & 0.003 & 0.891 & 7.234 \\
\hline PRKACA & $\begin{array}{l}\text { protein kinase, cAMP- } \\
\text { dependent, catalytic, alpha }\end{array}$ & NM_008854 & 0.001 & -0.837 & 6.149 & 0.164 & -0.235 & 6.384 & 0.006 & 0.603 & 6.986 \\
\hline PRKCE & protein kinase $\mathrm{C}$, epsilon & NM_011104 & 0.003 & -0.784 & 4.509 & 0.003 & -0.802 & 5.311 & 0.254 & 0.003 & 2.287 \\
\hline PTEN & $\begin{array}{l}\text { phosphatase and tensin } \\
\text { homolog (mutated in multiple } \\
\text { advanced cancers } 1 \text { ) }\end{array}$ & NM_008960 & 0.005 & -0.489 & 10.369 & 0.026 & -0.982 & 10.268 & 0.124 & 0.204 & 10.859 \\
\hline RDH11 & $\begin{array}{l}\text { retinol dehydrogenase } 11 \\
\text { (all-trans/9-cis/11-cis) }\end{array}$ & NM_021557 & 0.697 & -0.143 & 8.321 & 0.02 & -1.089 & 9.41 & 0.034 & -0.945 & 8.464 \\
\hline $\begin{array}{l}\text { RDH16 } \\
\text { (includes } \\
\text { EG:19683) }\end{array}$ & retinol dehydrogenase 16 & NM_009040 & 0.031 & -0.978 & 8.001 & 0.066 & -0.783 & 8.784 & 0.6 & 0.195 & 8.979 \\
\hline SMAD3 & SMAD family member 3 & NM_016769 & 0.005 & -0.99 & 4.439 & 0.105 & -0.438 & 4.877 & 0.052 & 0.552 & 5.429 \\
\hline SMAD6 & SMAD family member 6 & NM_008542 & 0.015 & -0.906 & 4.742 & 0.069 & -0.595 & 5.337 & 0.294 & 0.311 & 5.647 \\
\hline SMARCA2 & $\begin{array}{l}\text { SWI/SNF related, matrix } \\
\text { associated, actin dependent } \\
\text { regulator of chromatin, } \\
\text { subfamily a, member } 2\end{array}$ & NM_011416 & 0.023 & -0.889 & 4.837 & 0.436 & 0.004 & 2.325 & 0.063 & 0.674 & 5.726 \\
\hline SMARCA4 & $\begin{array}{l}\text { SWI/SNF related, matrix } \\
\text { associated, actin dependent } \\
\text { regulator of chromatin, } \\
\text { subfamily a, member } 4 \\
\text { signal transducer and activator } \\
\text { of transcription 5A }\end{array}$ & NM_011488 & 0.003 & -1.241 & 2.856 & 0.116 & -0.302 & 5.449 & 0.003 & 1.198 & 3.536 \\
\hline \multicolumn{12}{|c|}{ P53 Signaling } \\
\hline BAX & BCL2-associated $\mathrm{X}$ protein & NM_007527 & 0.003 & -0.844 & 6.969 & 0.173 & -0.28 & 7.248 & 0.02 & 0.564 & 7.812 \\
\hline CCND1 & cyclin D1 & NM_007631 & 0 & -1.599 & 5.005 & 0 & -1.239 & 6.244 & 0.041 & 0.355 & 7.465 \\
\hline CCND2 & cyclin D2 & NM_009829 & 0.001 & -0.606 & 4.175 & 0.001 & -0.944 & 5.89 & 0.132 & -0.175 & 2.597 \\
\hline FASN & fatty acid synthase & NM_007988 & 0.002 & -1.961 & 11.054 & 0.012 & -1.338 & 12.392 & 0.154 & 0.623 & 13.015 \\
\hline GSK3B & glycogen synthase kinase 3 beta & NM_019827 & 0.003 & -1.35 & 4.392 & 0.027 & -0.818 & 5.21 & 0.108 & 0.627 & 6.711 \\
\hline HIPK2 & $\begin{array}{l}\text { homeodomain interacting } \\
\text { protein kinase } 2\end{array}$ & NM_010433 & 0.013 & -1.579 & 6.149 & 0.105 & -0.872 & 7.021 & 0.04 & 0.571 & 5.961 \\
\hline JUN & jun oncogene & NM_010591 & 0.003 & -1.205 & 5.081 & 0.39 & 0.233 & 4.849 & 0.001 & 1.438 & 6.287 \\
\hline PIK3R1 & $\begin{array}{l}\text { phosphoinositide-3-kinase, } \\
\text { regulatory subunit } 1 \text { (alpha) }\end{array}$ & NM_001024955 & 0.001 & -1.124 & 6.417 & 0.061 & -0.437 & 3.074 & 0.003 & 0.891 & 7.234 \\
\hline PLAGL1 & $\begin{array}{l}\text { pleiomorphic adenoma } \\
\text { gene-like } 1\end{array}$ & NM_009538 & 0.002 & -1.83 & 3.904 & 0.093 & -0.729 & 4.633 & 0.023 & 1.101 & 5.734 \\
\hline PTEN & $\begin{array}{l}\text { phosphatase and tensin } \\
\text { homolog (mutated in multiple } \\
\text { advanced cancers } 1 \text { ) }\end{array}$ & NM_008960 & 0.005 & -0.489 & 10.369 & 0.026 & -0.982 & 10.268 & 0.124 & 0.204 & 10.859 \\
\hline TP53BP2 & $\begin{array}{l}\text { tumor protein p53 binding } \\
\text { protein, } 2\end{array}$ & NM_173378 & 0.001 & -0.835 & 4.35 & 0.169 & 0.145 & 6.649 & 0.003 & 0.695 & 5.185 \\
\hline
\end{tabular}


Continued

\begin{tabular}{|c|c|c|c|c|c|c|c|c|c|c|c|}
\hline \multicolumn{12}{|c|}{ Nucleotide Excision Repair Pathway } \\
\hline $\mathrm{CCNH}$ & cyclin $\mathrm{H}$ & NM_023243 & 0.003 & 0.911 & 7.331 & 0.052 & 0.479 & 6.852 & 0.043 & -0.306 & 8.953 \\
\hline CDK7 & cyclin-dependent kinase 7 & NM_009874 & 0.006 & 0.792 & 8.031 & 0.005 & 0.807 & 7.224 & 0.254 & -0.047 & 2.306 \\
\hline ERCC8 & $\begin{array}{l}\text { excision repair cross- } \\
\text { complementing } \\
\text { rodent repair deficiency, } \\
\text { complementation group } 8\end{array}$ & NM_028042 & 0.027 & 0.855 & 5.184 & 0.055 & 0.703 & 4.481 & 0.133 & -0.152 & 3.782 \\
\hline POLR2A & $\begin{array}{l}\text { polymerase (RNA) II } \\
\text { (DNA directed) } \\
\text { polypeptide A, } 220 \mathrm{kDa}\end{array}$ & NM_009089 & 0.025 & -1.022 & 5.64 & 0.618 & -0.183 & 5.822 & 0.051 & 0.839 & 6.661 \\
\hline POLR2C & $\begin{array}{l}\text { polymerase (RNA) II } \\
\text { (DNA directed) } \\
\text { polypeptide C, } 33 \mathrm{kDa}\end{array}$ & NM_009090 & 0.005 & 0.856 & 9.071 & 0.058 & 0.467 & 8.604 & 0.1 & -0.389 & 8.215 \\
\hline RPA3 & replication protein $\mathrm{A} 3,14 \mathrm{kDa}$ & NM_026632 & 0.012 & 1.006 & 8.22 & 0.228 & 0.387 & 7.833 & 0.074 & -0.619 & 7.215 \\
\hline \multicolumn{12}{|c|}{ ERK/MAPK Signaling } \\
\hline PPP1R14A & $\begin{array}{l}\text { protein phosphatase } 1 \text {, } \\
\text { regulatory (inhibitor) } \\
\text { subunit 14A }\end{array}$ & NM_026731 & 0.014 & 0.868 & 5.672 & 0.052 & 0.618 & 5.054 & 0.371 & -0.25 & 4.805 \\
\hline YWHAG & $\begin{array}{l}\text { tyrosine } 3 \text {-monooxygenase/ } \\
\text { tryptophan 5-monooxygenase } \\
\text { activation protein, } \\
\text { gamma polypeptide }\end{array}$ & NM_018871 & 0.001 & -0.917 & 8.857 & 0.032 & -0.405 & 9.262 & 0.012 & 0.512 & 9.774 \\
\hline MKNK2 & $\begin{array}{l}\text { MAP kinase interacting } \\
\text { serine/threonine kinase } 2\end{array}$ & NM_021462 & 0.005 & -1.582 & 9.258 & 0.012 & -1.316 & 10.574 & 0.323 & 0.335 & 5.522 \\
\hline RAP1B & $\begin{array}{l}\text { RAP1B, member of RAS } \\
\text { oncogene family }\end{array}$ & NM_024457 & 0.001 & 1.046 & 9.914 & 0.02 & 0.595 & 9.319 & 0.055 & -0.451 & 8.868 \\
\hline DUSP1 & dual specificity phosphatase 1 & NM_013642 & 0.005 & -1.426 & 7.398 & 0.586 & 0.197 & 7.201 & 0.003 & 1.623 & 8.824 \\
\hline PPP2R5E & $\begin{array}{l}\text { protein phosphatase 2, } \\
\text { regulatory subunit B', } \\
\text { epsilon isoform }\end{array}$ & NM_012024 & 0 & -0.905 & 7.187 & 0 & -0.59 & 7.777 & 0.001 & 0.314 & 8.091 \\
\hline RAPGEF1 & $\begin{array}{l}\text { Rap guanine nucleotide } \\
\text { exchange factor (GEF) } 1\end{array}$ & NM_001039086 & 0.031 & -0.855 & 4.558 & 0.586 & -0.178 & 4.736 & 0.069 & 0.677 & 5.413 \\
\hline PRKCE & protein kinase $\mathrm{C}$, epsilon & NM_011104 & 0.003 & -0.784 & 4.509 & 0.003 & -0.802 & 5.311 & 0.254 & 0.003 & 2.287 \\
\hline PRKACA & $\begin{array}{l}\text { protein kinase, cAMP- } \\
\text { dependent, catalytic, alpha }\end{array}$ & NM_008854 & 0.001 & -0.837 & 6.149 & 0.164 & -0.235 & 6.384 & 0.006 & 0.603 & 6.986 \\
\hline PIK3R1 & $\begin{array}{l}\text { Phosphoinositide-3-kinase, } \\
\text { regulatory subunit } 1 \text { (alpha) }\end{array}$ & NM_001024955 & 0.001 & -1.124 & 6.417 & 0.061 & -0.437 & 3.074 & 0.003 & 0.891 & 7.234 \\
\hline ESR1 & estrogen receptor 1 & NM_007956 & 0.012 & -0.862 & 8.244 & 0.02 & -0.763 & 9.007 & 0.622 & -0.111 & 4.922 \\
\hline PXN & paxillin & NM_011223 & 0.002 & -1.146 & 9.179 & 0.031 & -0.633 & 9.812 & 0.064 & 0.513 & 10.325 \\
\hline MAP2K1IP1 & $\begin{array}{l}\text { mitogen-activated protein } \\
\text { kinase kinase } 1 \text { interacting } \\
\text { protein } 1\end{array}$ & NM_019920 & 0.01 & 0.805 & 9.796 & 0.053 & 0.53 & 9.265 & 0.263 & -0.275 & 8.991 \\
\hline ATF4 & $\begin{array}{l}\text { activating transcription } \\
\text { factor } 4 \text { (tax-responsive } \\
\text { enhancer element B67) }\end{array}$ & NM_009716 & 0.011 & 0.869 & 9.16 & 0.017 & 0.784 & 8.377 & 0.734 & -0.076 & 10.489 \\
\hline MYCN & $\begin{array}{l}\mathrm{v} \text {-myc myelocytomatosis } \\
\text { viral related oncogene, } \\
\text { neuroblastoma derived (avian) }\end{array}$ & NM_008709 & 0.127 & -0.768 & 4.113 & 0.234 & -0.054 & 2.357 & 0.035 & 1.167 & 4.881 \\
\hline PLA2G4A & $\begin{array}{l}\text { phospholipase A2, group IVA } \\
\text { (cytosolic, calcium-dependent) }\end{array}$ & NM_008869 & 0.004 & 1.111 & 5.765 & 0.013 & 0.879 & 4.886 & 0.396 & -0.232 & 4.654 \\
\hline ELK3 & $\begin{array}{l}\text { ELK3, ETS-domain protein } \\
\text { (SRF accessory protein 2) }\end{array}$ & NM_013508 & 0.01 & -0.603 & 5.567 & 0.002 & -0.849 & 6.415 & 0.033 & 0.455 & 4.877 \\
\hline RPS6KA1 & $\begin{array}{l}\text { ribosomal protein S6 kinase, } \\
90 \mathrm{kDa} \text {, polypeptide } 1\end{array}$ & NM_009097 & 0.007 & -1.049 & 5.943 & 0.209 & -0.369 & 6.312 & 0.04 & 0.681 & 6.993 \\
\hline PPP1R3C & $\begin{array}{l}\text { protein phosphatase } 1 \text {, } \\
\text { regulatory (inhibitor) } \\
\text { subunit 3C }\end{array}$ & NM_016854 & 0.292 & -0.276 & 11.789 & 0.063 & 0.63 & 7.723 & 0.014 & 0.805 & 12.065 \\
\hline \multicolumn{12}{|c|}{ Hepatic Cholestasis } \\
\hline
\end{tabular}




\section{Continued}

\begin{tabular}{|c|c|c|c|c|c|c|c|c|c|c|c|}
\hline $\mathrm{ABCB} 4$ & $\begin{array}{l}\text { ATP-binding cassette, sub- } \\
\text { family B (MDR/TAP), } \\
\text { member } 4\end{array}$ & NM_008830 & 0.131 & -0.345 & 11.391 & 0.016 & 0.651 & 10.74 & 0.002 & 0.996 & 11.736 \\
\hline $\mathrm{ABCC} 3$ & $\begin{array}{l}\text { ATP-binding cassette, } \\
\text { sub-familyC (CFTR/MRP), } \\
\text { member } 3\end{array}$ & NM_029600 & 0.021 & -1.024 & 9.496 & 0.048 & -0.82 & 10.315 & 0.227 & -0.126 & 2.463 \\
\hline CD14 & CD14 molecule & NM_009841 & 0.045 & 1.027 & 6.315 & 0.115 & 0.755 & 5.56 & 0.534 & -0.272 & 5.288 \\
\hline CYP7A1 & $\begin{array}{l}\text { cytochrome } \mathrm{P} 450, \\
\text { family } 7 \text {, subfamily } \\
\text { A, polypeptide } 1\end{array}$ & NM_007824 & 0.064 & 1.472 & 9.635 & 0.082 & -1.292 & 7.267 & 0.012 & -2.291 & 8.163 \\
\hline CYP7B1 & $\begin{array}{l}\text { cytochrome P450, } \\
\text { family } 7 \text {, subfamily } \\
\text { B, polypeptide } 1\end{array}$ & NM_007825 & 0.005 & 1.464 & 12.838 & 0.013 & 1.203 & 11.635 & 0.404 & -0.286 & 12.756 \\
\hline ESR1 & estrogen receptor 1 & NM_007956 & 0.012 & -0.862 & 8.244 & 0.02 & -0.763 & 9.007 & 0.622 & -0.111 & 4.922 \\
\hline IL1B & interleukin 1 , beta & NM_008361 & 0.006 & 1.642 & 6.506 & 0.011 & 1.447 & 5.06 & 0.645 & -0.195 & 4.865 \\
\hline IL1R1 & $\begin{array}{l}\text { interleukin } 1 \text { receptor, } \\
\text { type I }\end{array}$ & NM_001123382 & 0.029 & 1.579 & 7.292 & 0.07 & 1.228 & 6.064 & 0.555 & -0.351 & 5.713 \\
\hline JUN & jun oncogene & NM_010591 & 0.003 & -1.205 & 5.081 & 0.39 & 0.233 & 4.849 & 0.001 & 1.438 & 6.287 \\
\hline NR0B2 & $\begin{array}{l}\text { nuclear receptor subfamily } 0 \text {, } \\
\text { group B, member } 2\end{array}$ & NM_011850 & 0.012 & -1.395 & 9.029 & 0.062 & -0.913 & 9.942 & 0.275 & 0.482 & 10.424 \\
\hline PPARA & $\begin{array}{l}\text { peroxisome proliferator- } \\
\text { activated receptor alpha }\end{array}$ & NM_001113418 & 0.008 & -1.269 & 9.622 & 0.757 & 0.095 & 9.613 & 0.012 & 1.168 & 10.89 \\
\hline PRKACA & $\begin{array}{l}\text { protein kinase, cAMP- } \\
\text { dependent, catalytic, alpha }\end{array}$ & NM_008854 & 0.001 & -0.837 & 6.149 & 0.164 & -0.235 & 6.384 & 0.006 & 0.603 & 6.986 \\
\hline PRKCE & protein kinase $\mathrm{C}$, epsilon & NM_011104 & 0.003 & -0.784 & 4.509 & 0.003 & -0.802 & 5.311 & 0.254 & 0.003 & 2.287 \\
\hline SLC22A7 & $\begin{array}{l}\text { solute carrier family } 22 \\
\text { (organic anion transporter), } \\
\text { member } 7\end{array}$ & NM_144856 & 0.304 & 0.502 & 10.384 & 0.014 & 1.509 & 8.875 & 0.064 & 1.007 & 9.882 \\
\hline SLCO1A2 & $\begin{array}{l}\text { solute carrier organic } \\
\text { anion transporter family, } \\
\text { member } 1 \mathrm{~A} 2\end{array}$ & NM_030687 & 0.034 & -1.539 & 8.012 & 0.025 & -1.668 & 9.68 & 0.828 & -0.129 & 9.551 \\
\hline SREBF1 & $\begin{array}{l}\text { sterol regulatory element } \\
\text { binding transcription factor } 1\end{array}$ & NM_011480 & 0.003 & -1.265 & 11.29 & 0.043 & -0.663 & 11.952 & 0.06 & 0.602 & 12.555 \\
\hline \multicolumn{12}{|c|}{ Glucocorticoid Receptor Signaling } \\
\hline $\mathrm{AR}$ & $\begin{array}{l}\text { androgen receptor } \\
\text { (dihydrotestosterone receptor; } \\
\text { testicular feminization; spinal } \\
\text { and bulbar muscular atrophy; } \\
\text { Kennedy disease) }\end{array}$ & NM_013476 & 0.007 & -0.93 & 3.522 & 0.002 & -1.25 & 4.772 & 0.061 & -0.626 & 5.533 \\
\hline CCL5 & chemokine (C-C motif) ligand 5 & NM_013653 & 0.603 & 0.125 & 4.088 & 0.008 & -0.878 & 4.965 & 0.004 & -1.003 & 3.963 \\
\hline $\mathrm{CCNH}$ & cyclin $\mathrm{H}$ & NM_023243 & 0.003 & 0.911 & 7.331 & 0.052 & 0.479 & 6.852 & 0.043 & -0.306 & 8.953 \\
\hline CDK7 & cyclin-dependent kinase 7 & NM_009874 & 0.006 & 0.792 & 8.031 & 0.005 & 0.807 & 7.224 & 0.254 & -0.047 & 2.306 \\
\hline CREBBP & $\begin{array}{l}\text { CREB binding protein } \\
\text { (Rubinstein-Taybi syndrome) }\end{array}$ & NM_001025432 & 0.005 & -1.363 & 5.911 & 0.161 & -0.511 & 6.422 & 0.018 & 0.027 & 2.313 \\
\hline DUSP1 & dual specificity phosphatase 1 & NM_013642 & 0.005 & -1.426 & 7.398 & 0.586 & 0.197 & 7.201 & 0.003 & 1.623 & 8.824 \\
\hline ESR1 & estrogen receptor 1 & NM_007956 & 0.012 & -0.862 & 8.244 & 0.02 & -0.763 & 9.007 & 0.622 & -0.111 & 4.922 \\
\hline FCGR1A & $\begin{array}{l}\text { Fc fragment of IgG, high } \\
\text { affinity Ia, receptor (CD64) }\end{array}$ & NM_010186 & 0.003 & 1 & 6.698 & 0.1 & 0.421 & 6.276 & 0.037 & -0.579 & 5.698 \\
\hline GTF2A2 & $\begin{array}{l}\text { general transcription factor } \\
\text { IIA, } 2,12 \mathrm{kDa}\end{array}$ & NM_001039519 & 0.003 & 1.047 & 9.899 & 0.048 & 0.562 & 9.337 & 0.077 & -0.485 & 8.852 \\
\hline HSPA4 & heat shock $70 \mathrm{kDa}$ protein 4 & NM_008300 & 0.011 & -0.424 & 9.2 & 0.15 & -0.194 & 9.394 & 0.016 & 1.251 & 7.18 \\
\hline IL1B & interleukin 1 , beta & NM_008361 & 0.006 & 1.642 & 6.506 & 0.011 & 1.447 & 5.06 & 0.645 & -0.195 & 4.865 \\
\hline JUN & jun oncogene & NM_010591 & 0.003 & -1.205 & 5.081 & 0.39 & 0.233 & 4.849 & 0.001 & 1.438 & 6.287 \\
\hline NRIP1 & $\begin{array}{l}\text { nuclear receptor interacting } \\
\text { protein } 1\end{array}$ & NM_173440 & 0.003 & -1.221 & 5.919 & 0.031 & -0.715 & 6.634 & 0.095 & 0.506 & 7.14 \\
\hline PBX1 & pre-B-cell leukemia homeobox 1 & NM_008783 & 0.004 & -1.118 & 5.635 & 0.042 & -0.63 & 6.265 & 0.093 & 0.488 & 6.753 \\
\hline
\end{tabular}


Continued

\begin{tabular}{|c|c|c|c|c|c|c|c|c|c|c|c|}
\hline PIK3R1 & $\begin{array}{l}\text { phosphoinositide-3-kinase, } \\
\text { regulatory subunit } 1 \text { (alpha) }\end{array}$ & NM_001024955 & 0.001 & -1.124 & 6.417 & 0.061 & -0.437 & 3.074 & 0.003 & 0.891 & 7.234 \\
\hline POLR2A & $\begin{array}{l}\text { polymerase (RNA) II } \\
\text { (DNA directed) } \\
\text { polypeptide } A, 220 \mathrm{kDa}\end{array}$ & NM_009089 & 0.025 & -1.022 & 5.64 & 0.618 & -0.183 & 5.822 & 0.051 & 0.839 & 6.661 \\
\hline POLR2C & $\begin{array}{l}\text { polymerase (RNA) II } \\
\text { (DNA directed) } \\
\text { polypeptide C, } 33 \mathrm{kDa}\end{array}$ & NM_009090 & 0.005 & 0.856 & 9.071 & 0.058 & 0.467 & 8.604 & 0.1 & -0.389 & 8.215 \\
\hline PRKACA & $\begin{array}{l}\text { protein kinase, cAMP- } \\
\text { dependent, catalytic, alpha }\end{array}$ & NM_008854 & 0.001 & -0.837 & 6.149 & 0.164 & -0.235 & 6.384 & 0.006 & 0.603 & 6.986 \\
\hline SMAD3 & SMAD family member 3 & NM_016769 & 0.005 & -0.99 & 4.439 & 0.105 & -0.438 & 4.877 & 0.052 & 0.552 & 5.429 \\
\hline SMARCA2 & $\begin{array}{l}\text { SWI/SNF related, matrix } \\
\text { associated, actin dependent } \\
\text { regulator of chromatin, } \\
\text { subfamily a, member } 2\end{array}$ & NM_011416 & 0.023 & -0.889 & 4.837 & 0.436 & 0.004 & 2.325 & 0.063 & 0.674 & 5.726 \\
\hline SMARCA4 & $\begin{array}{l}\text { SWI/SNF related, matrix } \\
\text { associated, actin dependent } \\
\text { regulator of chromatin, } \\
\text { subfamily a, member } 4\end{array}$ & NM_011417 & 0.003 & -1.241 & 7.787 & 0.363 & -0.302 & 5.462 & 0.004 & 1.198 & 9.028 \\
\hline STAT5A & $\begin{array}{l}\text { signal transducer and activator } \\
\text { of transcription } 5 \mathrm{~A}\end{array}$ & NM_011488 & 0.009 & -0.68 & 2.856 & 0.116 & 0.493 & 5.449 & 0.003 & 0.83 & 3.536 \\
\hline TBP & TATA box binding protein & NM_013684 & 0.004 & 0.863 & 6.324 & 0.002 & 0.98 & 5.344 & 0.576 & 0.117 & 5.461 \\
\hline \multicolumn{12}{|c|}{ NFkB Signaling } \\
\hline CARD10 & $\begin{array}{l}\text { caspase recruitment domain } \\
\text { family, member } 10\end{array}$ & NM_130859 & 0 & -1.27 & 5.419 & 0.001 & -0.993 & 6.413 & 0.142 & 0.276 & 6.689 \\
\hline CREBBP & $\begin{array}{l}\text { CREB binding protein } \\
\text { (Rubinstein-Taybi syndrome) }\end{array}$ & NM_001025432 & 0.005 & -1.363 & 5.911 & 0.161 & -0.511 & 6.422 & 0.018 & 0.027 & 2.313 \\
\hline CSNK2A1 & $\begin{array}{l}\text { casein kinase } 2 \text {, alpha } 1 \\
\text { polypeptide }\end{array}$ & NM_007788 & 0.001 & -1.087 & 7.111 & 0.015 & -0.604 & 7.715 & 0.036 & 0.483 & 8.198 \\
\hline EGFR & $\begin{array}{l}\text { epidermal growth factor } \\
\text { receptor (erythroblastic } \\
\text { leukemia viral (v-erb-b) } \\
\text { oncogene homolog, avian) }\end{array}$ & NM_007912 & 0.009 & 1.053 & 10.54 & 0.035 & 1.053 & 9.481 & 0.039 & -0.733 & 9.487 \\
\hline GSK3B & $\begin{array}{l}\text { glycogen synthase kinase } \\
3 \text { beta }\end{array}$ & NM_019827 & 0.003 & -1.35 & 4.392 & 0.027 & -0.818 & 5.21 & 0.108 & 0.627 & 6.711 \\
\hline IL1B & interleukin 1 , beta & NM_008361 & 0.006 & 1.642 & 6.506 & 0.011 & 1.447 & 5.06 & 0.645 & -0.195 & 4.865 \\
\hline IL1R1 & interleukin 1 receptor, type I & NM_001123382 & 0.029 & 1.579 & 7.292 & 0.07 & 1.228 & 6.064 & 0.555 & -0.351 & 5.713 \\
\hline KLK1B4 & kallikrein 1-related pepidase b4 & NM_010915 & 0.202 & -0.411 & 4.457 & 0.03 & -0.808 & 5.265 & 0.216 & -0.397 & 4.869 \\
\hline PDGFRB & $\begin{array}{l}\text { platelet-derived growth factor } \\
\text { receptor, beta polypeptide }\end{array}$ & NM_008809 & 0 & -1.144 & 5.035 & 0.007 & -0.598 & 5.633 & 0.01 & 0.546 & 6.179 \\
\hline PIK3R1 & $\begin{array}{l}\text { phosphoinositide-3-kinase, } \\
\text { regulatory subunit } 1 \text { (alpha) }\end{array}$ & NM_001024955 & 0.001 & -1.124 & 6.417 & 0.061 & -0.437 & 3.074 & 0.003 & 0.891 & 7.234 \\
\hline PRKACA & $\begin{array}{l}\text { protein kinase, cAMP- } \\
\text { dependent, catalytic, alpha }\end{array}$ & NM_008854 & 0.001 & -0.837 & 6.149 & 0.164 & -0.235 & 6.384 & 0.006 & 0.603 & 6.986 \\
\hline TGFA & $\begin{array}{l}\text { transforming growth } \\
\text { factor, alpha }\end{array}$ & NM_031199 & 0.011 & -0.891 & 6.539 & 0.051 & -0.604 & 7.143 & 0.254 & -0.099 & 2.284 \\
\hline TRAF3 & $\begin{array}{l}\text { TNF receptor-associated } \\
\text { factor } 3\end{array}$ & NM_001048206 & 0.018 & -1.553 & 4.619 & 0.272 & -0.176 & 2.538 & 0.014 & 1.636 & 6.172 \\
\hline \multicolumn{12}{|c|}{ IL-10 Signaling } \\
\hline BLVRA & biliverdin reductase $\mathrm{A}$ & NM_026678 & 0.000 & 0.840 & 9.077 & 0.001 & 0.535 & 8.542 & 0.015 & -0.305 & 8.237 \\
\hline $\mathrm{CD} 14$ & CD14 molecule & NM_009841 & 0.045 & 1.027 & 6.315 & 0.115 & 0.755 & 5.560 & 0.534 & -0.272 & 5.288 \\
\hline FCGR2A & $\begin{array}{l}\text { Fc fragment of IgG, low } \\
\text { affinity IIa, receptor (CD32) }\end{array}$ & NM_010188 & 0.001 & 1.333 & 7.116 & 0.038 & 0.542 & 6.574 & 0.008 & -0.791 & 5.783 \\
\hline IL1B & interleukin 1 , beta & NM_008361 & 0.006 & 1.642 & 6.506 & 0.011 & 1.447 & 5.060 & 0.645 & -0.195 & 4.865 \\
\hline IL1R1 & interleukin 1 receptor, type I & $\begin{array}{l}\text { NM_001123382 } \\
\text { /// NM_008362 }\end{array}$ & 0.029 & 1.579 & 7.292 & 0.070 & 1.228 & 6.064 & 0.555 & -0.351 & 5.713 \\
\hline JUN & jun oncogene & NM_010591 & 0.003 & -1.205 & 5.081 & 0.390 & 0.233 & 4.849 & 0.001 & 1.438 & 6.287 \\
\hline SOCS3 & $\begin{array}{l}\text { suppressor of cytokine } \\
\text { signaling } 3\end{array}$ & NM_007707 & 0.006 & 0.900 & 5.801 & 0.000 & 1.482 & 4.318 & 0.039 & 0.582 & 4.901 \\
\hline
\end{tabular}


Continued

\begin{tabular}{|c|c|c|c|c|c|c|c|c|c|c|c|}
\hline \multicolumn{12}{|c|}{ PTEN Signaling } \\
\hline BCL2L11 & $\begin{array}{l}\text { BCL2-like } 11 \\
\text { (apoptosis facilitator) }\end{array}$ & NM_009754 & 0.006 & -1.103 & 3.951 & 0.193 & -0.311 & 2.762 & 0.035 & 0.715 & 5.053 \\
\hline CCND1 & cyclin D1 & NM_007631 & 0 & -1.599 & 5.005 & 0 & -1.239 & 6.244 & 0.041 & 0.355 & 7.465 \\
\hline CSNK2A1 & $\begin{array}{l}\text { casein kinase } 2 \text {, alpha } 1 \\
\text { polypeptide }\end{array}$ & NM_007788 & 0.001 & -1.087 & 7.111 & 0.015 & -0.604 & 7.715 & 0.036 & 0.483 & 8.198 \\
\hline EGFR & $\begin{array}{l}\text { epidermal growth factor } \\
\text { receptor (erythroblastic } \\
\text { leukemia viral (v-erb-b) } \\
\text { oncogene homolog, avian) }\end{array}$ & NM_007912 & 0.009 & 1.053 & 10.54 & 0.035 & 1.053 & 9.481 & 0.039 & -0.733 & 9.487 \\
\hline FOXO3 & forkhead box O3 & NM_019740 & 0.01 & -0.858 & 7.286 & 0.043 & -0.591 & 7.877 & 0.091 & -0.29 & 4.357 \\
\hline GSK3B & $\begin{array}{l}\text { glycogen synthase kinase } \\
3 \text { beta }\end{array}$ & NM_019827 & 0.003 & -1.35 & 4.392 & 0.027 & -0.818 & 5.21 & 0.108 & 0.627 & 6.711 \\
\hline INPPL1 & $\begin{array}{l}\text { inositol polyphosphate } \\
\text { phosphatase-like } 1\end{array}$ & NM_001122739 & 0.006 & -0.981 & 5.224 & 0.058 & -0.561 & 5.785 & 0.132 & 0.42 & 6.205 \\
\hline PDGFRB & $\begin{array}{l}\text { factor receptor, } \\
\text { beta polypeptide }\end{array}$ & NM_008809 & 0 & -1.144 & 5.035 & 0.007 & -0.598 & 5.633 & 0.01 & 0.546 & 6.179 \\
\hline PIK3R1 & $\begin{array}{l}\text { phosphoinositide-3-kinase, } \\
\text { regulatory subunit } 1 \text { (alpha) }\end{array}$ & NM_001024955 & 0.001 & -1.124 & 6.417 & 0.061 & -0.437 & 3.074 & 0.003 & 0.891 & 7.234 \\
\hline PTEN & $\begin{array}{l}\text { phosphatase and tensin } \\
\text { homolog (mutated in } \\
\text { multiple advanced cancers } 1)\end{array}$ & NM_008960 & 0.005 & -0.489 & 10.369 & 0.026 & -0.982 & 10.268 & 0.124 & 0.204 & 10.859 \\
\hline \multicolumn{12}{|c|}{ Estrogen Receptor Signaling } \\
\hline $\mathrm{CCNH}$ & cyclin $\mathrm{H}$ & NM_023243 & 0.003 & 0.911 & 7.331 & 0.052 & 0.479 & 6.852 & 0.043 & -0.306 & 8.953 \\
\hline $\mathrm{CDK} 7$ & cyclin-dependent kinase 7 & NM_009874 & 0.006 & 0.792 & 8.031 & 0.005 & 0.807 & 7.224 & 0.254 & -0.047 & 2.306 \\
\hline CREBBP & $\begin{array}{l}\text { CREB binding protein } \\
\text { (Rubinstein-Taybi syndrome) }\end{array}$ & NM_001025432 & 0.005 & -1.363 & 5.911 & 0.161 & -0.511 & 6.422 & 0.018 & 0.027 & 2.313 \\
\hline ESR1 & estrogen receptor 1 & NM_007956 & 0.012 & -0.862 & 8.244 & 0.02 & -0.763 & 9.007 & 0.622 & -0.111 & 4.922 \\
\hline G6PC & $\begin{array}{l}\text { glucose-6-phosphatase, } \\
\text { catalytic subunit }\end{array}$ & NM_008061 & 0.098 & -0.641 & 12.013 & 0.641 & 0.161 & 11.851 & 0.049 & 0.803 & 12.654 \\
\hline HNRPD & $\begin{array}{l}\text { heterogeneous nuclear } \\
\text { ribonucleoprotein } \mathrm{D} \\
\text { (AU-rich element RNA } \\
\text { binding protein } 1,37 \mathrm{kDa} \text { ) }\end{array}$ & NM_001077265 & 0.004 & -0.918 & 7.372 & 0.064 & -0.283 & 4.374 & 0.064 & 0.472 & 8.289 \\
\hline NR0B2 & $\begin{array}{l}\text { nuclear receptor subfamily } 0 \text {, } \\
\text { group } \mathrm{B}, \text { member } 2\end{array}$ & NM_011850 & 0.012 & -1.395 & 9.029 & 0.062 & -0.913 & 9.942 & 0.275 & 0.482 & 10.424 \\
\hline NRIP1 & $\begin{array}{l}\text { nuclear receptor interacting } \\
\text { protein } 1\end{array}$ & NM_173440 & 0.003 & -1.221 & 5.919 & 0.031 & -0.715 & 6.634 & 0.095 & 0.506 & 7.14 \\
\hline POLR2A & $\begin{array}{l}\text { polymerase (RNA) II } \\
\text { (DNA directed) } \\
\text { polypeptide A, } 220 \mathrm{kDa}\end{array}$ & NM_009089 & 0.025 & -1.022 & 5.64 & 0.618 & -0.183 & 5.822 & 0.051 & 0.839 & 6.661 \\
\hline POLR2C & $\begin{array}{l}\text { polymerase (RNA) II } \\
\text { (DNA directed) } \\
\text { polypeptide C, } 33 \mathrm{kDa}\end{array}$ & NM_009090 & 0.005 & 0.856 & 9.071 & 0.058 & 0.467 & 8.604 & 0.1 & -0.389 & 8.215 \\
\hline SMARCA4 & $\begin{array}{l}\text { SWI/SNF related, matrix } \\
\text { associated, actin dependent } \\
\text { regulator of chromatin, } \\
\text { subfamily a, member } 4\end{array}$ & NM_011417 & 0.003 & -1.241 & 7.787 & 0.363 & -0.302 & 5.462 & 0.004 & 1.198 & 9.028 \\
\hline TBP & TATA box binding protein & NM_013684 & 0.004 & 0.863 & 6.324 & 0.002 & 0.98 & 5.344 & 0.576 & 0.117 & 5.461 \\
\hline \multicolumn{12}{|c|}{ 14-3-3 mediated Signaling } \\
\hline AKT1S1 & $\begin{array}{l}\text { AKT1 substrate } 1 \\
\text { (proline-rich) }\end{array}$ & NM_026270 & 0.013 & -1.145 & 7.536 & 0.155 & -0.541 & 8.077 & 0.094 & 0.464 & 5.732 \\
\hline BAX & BCL2-associated X protein & NM_007527 & 0.003 & -0.844 & 6.969 & 0.173 & -0.28 & 7.248 & 0.02 & 0.564 & 7.812 \\
\hline EGFR & $\begin{array}{l}\text { epidermal growth factor } \\
\text { receptor (erythroblastic } \\
\text { leukemia viral (v-erb-b) } \\
\text { oncogene homolog, avian) }\end{array}$ & NM_007912 & 0.009 & 1.053 & 10.54 & 0.035 & 1.053 & 9.481 & 0.039 & -0.733 & 9.487 \\
\hline GSK3B & $\begin{array}{l}\text { glycogen synthase kinase } \\
3 \text { beta }\end{array}$ & NM_019827 & 0.003 & -1.35 & 4.392 & 0.027 & -0.818 & 5.21 & 0.108 & 0.627 & 6.711 \\
\hline
\end{tabular}


Continued

\begin{tabular}{|c|c|c|c|c|c|c|c|c|c|c|c|}
\hline JUN & jun oncogene & NM_010591 & 0.003 & -1.205 & 5.081 & 0.39 & 0.233 & 4.849 & 0.001 & 1.438 & 6.287 \\
\hline PDGFRB & $\begin{array}{l}\text { platelet-derived growth } \\
\text { factor receptor, } \\
\text { beta polypeptide }\end{array}$ & NM_008809 & 0 & -1.144 & 5.035 & 0.007 & -0.598 & 5.633 & 0.01 & 0.546 & 6.179 \\
\hline PIK3R1 & $\begin{array}{l}\text { phosphoinositide-3-kinase, } \\
\text { regulatory subunit } 1 \text { (alpha) }\end{array}$ & NM_001024955 & 0.001 & -1.124 & 6.417 & 0.061 & -0.437 & 3.074 & 0.003 & 0.891 & 7.234 \\
\hline PRKCE & protein kinase $\mathrm{C}$, epsilon & NM_011104 & 0.003 & -0.784 & 4.509 & 0.003 & -0.802 & 5.311 & 0.254 & 0.003 & 2.287 \\
\hline RPS6KA1 & $\begin{array}{l}\text { ribosomal protein S6 kinase, } \\
90 \mathrm{kDa} \text {, polypeptide } 1\end{array}$ & NM_009097 & 0.007 & -1.049 & 5.943 & 0.209 & -0.369 & 6.312 & 0.04 & 0.681 & 6.993 \\
\hline SNCA & $\begin{array}{l}\text { synuclein, alpha (non A4 } \\
\text { component of amyloid } \\
\text { precursor) }\end{array}$ & NM_001042451 & 0.022 & -1.043 & 8.316 & 0.003 & -1.596 & 9.912 & 0.126 & -0.59 & 9.648 \\
\hline TUBB2A & tubulin, beta $2 \mathrm{~A}$ & NM_009450 & 0 & -1.35 & 10.868 & 0.454 & 0.196 & 4.976 & 0 & 1.32 & 12.219 \\
\hline YWHAG & $\begin{array}{l}\text { tyrosine } 3 \text {-monooxygenase/ } \\
\text { tryptophan } 5 \text {-monooxygenase } \\
\text { activation protein, } \\
\text { gamma polypeptide }\end{array}$ & NM_018871 & 0.001 & -0.917 & 8.857 & 0.032 & -0.405 & 9.262 & 0.012 & 0.512 & 9.774 \\
\hline \multicolumn{12}{|c|}{ PPAR Signaling } \\
\hline CREBBP & $\begin{array}{l}\text { CREB binding protein } \\
\text { (Rubinstein-Taybi syndrome) }\end{array}$ & NM_001025432 & 0.005 & -1.363 & 5.911 & 0.161 & -0.511 & 6.422 & 0.018 & 0.027 & 2.313 \\
\hline IL1B & interleukin 1 , beta & NM_008361 & 0.006 & 1.642 & 6.506 & 0.011 & 1.447 & 5.06 & 0.645 & -0.195 & 4.865 \\
\hline IL1R1 & interleukin 1 receptor, type I & NM_001123382 & 0.029 & 1.579 & 7.292 & 0.07 & 1.228 & 6.064 & 0.555 & -0.351 & 5.713 \\
\hline JUN & jun oncogene & NM_010591 & 0.003 & -1.205 & 5.081 & 0.39 & 0.233 & 4.849 & 0.001 & 1.438 & 6.287 \\
\hline NR0B2 & $\begin{array}{l}\text { nuclear receptor subfamily } 0 \text {, } \\
\text { group } \mathrm{B} \text {, member } 2\end{array}$ & NM_011850 & 0.012 & -1.395 & 9.029 & 0.062 & -0.913 & 9.942 & 0.275 & 0.482 & 10.424 \\
\hline NRIP1 & $\begin{array}{l}\text { nuclear receptor interacting } \\
\text { protein } 1\end{array}$ & NM_173440 & 0.003 & -1.221 & 5.919 & 0.031 & -0.715 & 6.634 & 0.095 & 0.506 & 7.14 \\
\hline PDGFRB & $\begin{array}{l}\text { platelet-derived growth factor } \\
\text { receptor, beta polypeptide }\end{array}$ & NM_008809 & 0 & -1.144 & 5.035 & 0.007 & -0.598 & 5.633 & 0.01 & 0.546 & 6.179 \\
\hline PPARA & $\begin{array}{l}\text { peroxisome proliferator- } \\
\text { activated receptor alpha }\end{array}$ & NM_001113418 & 0.008 & -1.269 & 9.622 & 0.757 & 0.095 & 9.613 & 0.012 & 1.168 & 10.89 \\
\hline STAT5A & $\begin{array}{l}\text { signal transducer and activator } \\
\text { of transcription } 5 \mathrm{~A}\end{array}$ & NM_011488 & 0.009 & -0.68 & 2.856 & 0.116 & 0.493 & 5.449 & 0.003 & 0.83 & 3.536 \\
\hline \multicolumn{12}{|c|}{ TR/RXR Activation } \\
\hline CYP7A1 & $\begin{array}{l}\text { cytochrome P450, family } 7 \text {, } \\
\text { subfamily A, polypeptide } 1\end{array}$ & NM_007824 & 0.064 & 1.472 & 9.635 & 0.082 & -1.292 & 7.267 & 0.012 & -2.291 & 8.163 \\
\hline DIO1 & deiodinase, iodothyronine, type I & NM_007860 & 0.11 & 0.418 & 12.432 & 0 & 1.671 & 10.761 & 0.001 & 1.253 & 12.014 \\
\hline FASN & fatty acid synthase & NM_007988 & 0.002 & -1.961 & 11.054 & 0.012 & -1.338 & 12.392 & 0.154 & 0.623 & 13.015 \\
\hline G6PC & $\begin{array}{l}\text { Glucose-6-phosphatase, } \\
\text { catalytic subunit }\end{array}$ & NM_008061 & 0.098 & -0.641 & 12.013 & 0.641 & 0.161 & 11.851 & 0.049 & 0.803 & 12.654 \\
\hline LDLR & $\begin{array}{l}\text { low density lipoprotein receptor } \\
\text { (familial hypercholesterolemia) } \\
\text { malic enzyme } 1 \text {, }\end{array}$ & NM_010700 & 0.005 & -1.457 & 9.068 & 0.121 & -0.625 & 9.692 & 0.043 & 0.743 & 3.31 \\
\hline ME1 & $\begin{array}{l}\text { NADP }(+) \text {-dependent, } \\
\text { cytosolic }\end{array}$ & NM_008615 & 0.012 & -1.137 & 11.44 & 0.017 & -1.058 & 12.499 & 0.7 & -0.172 & 11.28 \\
\hline PIK3R1 & $\begin{array}{l}\text { Phosphoinositide-3-kinase, } \\
\text { regulatory subunit } 1 \text { (alpha) }\end{array}$ & NM_001024955 & 0.001 & -1.124 & 6.417 & 0.061 & -0.437 & 3.074 & 0.003 & 0.891 & 7.234 \\
\hline RCAN2 & regulator of calcineurin 2 & NM_030598 & 0 & -2.667 & 5.18 & 0.018 & -0.922 & 6.101 & 0.001 & 1.746 & 7.847 \\
\hline SLC2A1 & $\begin{array}{l}\text { solute carrier family } 2 \\
\text { (facilitated glucose } \\
\text { transporter), member } 1\end{array}$ & NM_011400 & 0.034 & -0.838 & 4.409 & 0.04 & -0.799 & 5.208 & 0.693 & 0.09 & 4.814 \\
\hline SREBF1 & $\begin{array}{l}\text { sterol regulatory element } \\
\text { binding transcription factor } 1\end{array}$ & NM_011480 & 0.003 & -1.265 & 11.29 & 0.043 & -0.663 & 11.952 & 0.06 & 0.602 & 12.555 \\
\hline THRSP & $\begin{array}{l}\text { thyroid hormone responsive } \\
\text { (SPOT14 homolog, rat) }\end{array}$ & NM_009381 & 0.099 & -0.67 & 13.337 & 0.042 & -0.883 & 14.219 & 0.477 & -0.35 & 11.878 \\
\hline $\mathrm{UCP} 2$ & $\begin{array}{l}\text { uncoupling protein } 2 \\
\text { (mitochondrial, proton carrier) }\end{array}$ & NM_011671 & 0.032 & -0.608 & 6.714 & 0.007 & -0.881 & 7.595 & 0.26 & -0.273 & 7.322 \\
\hline
\end{tabular}


Continued

\begin{tabular}{|c|c|c|c|c|c|c|c|c|c|c|c|}
\hline CCND1 & cyclin D1 & NM_007631 & 0 & -1.599 & 5.005 & 0 & -1.239 & 6.244 & 0.041 & 0.355 & 7.465 \\
\hline $\mathrm{CCND} 2$ & cyclin D2 & NM_009829 & 0.001 & -0.606 & 4.175 & 0.001 & -0.944 & 5.89 & 0.132 & -0.175 & 2.597 \\
\hline CDK6 & Cyclin-dependent kinase 6 & NM_009873 & 0.003 & -1.2 & 5.302 & 0.015 & -0.841 & 6.143 & 0.202 & 0.359 & 6.501 \\
\hline GSK3B & $\begin{array}{l}\text { glycogen synthase kinase } \\
3 \text { beta }\end{array}$ & NM_019827 & 0.003 & -1.35 & 4.392 & 0.027 & -0.818 & 5.21 & 0.108 & 0.627 & 6.711 \\
\hline SMAD3 & SMAD family member 3 & NM_016769 & 0.005 & -0.99 & 4.439 & 0.105 & -0.438 & 4.877 & 0.052 & 0.552 & 5.429 \\
\hline \multicolumn{12}{|c|}{ IL-2 Signaling } \\
\hline CSNK2A1 & $\begin{array}{l}\text { casein kinase } 2 \text {, alpha } 1 \\
\text { polypeptide }\end{array}$ & NM_007788 & 0.001 & -1.087 & 7.111 & 0.015 & -0.604 & 7.715 & 0.036 & 0.483 & 8.198 \\
\hline JUN & jun oncogene & NM_010591 & 0.003 & -1.205 & 5.081 & 0.39 & 0.233 & 4.849 & 0.001 & 1.438 & 6.287 \\
\hline PIK3R1 & $\begin{array}{l}\text { Phosphoinositide-3-kinase, } \\
\text { regulatory subunit } 1 \text { (alpha) }\end{array}$ & NM_001024955 & 0.001 & -1.124 & 6.417 & 0.061 & -0.437 & 3.074 & 0.003 & 0.891 & 7.234 \\
\hline STAT5A & $\begin{array}{l}\text { signal transducer and activator } \\
\text { of transcription } 5 \mathrm{~A}\end{array}$ & NM_011488 & 0.009 & -0.68 & 2.856 & 0.116 & 0.493 & 5.449 & 0.003 & 0.83 & 3.536 \\
\hline \multicolumn{12}{|c|}{ JAK/Stat Signaling } \\
\hline PIK3R1 & $\begin{array}{l}\text { Phosphoinositide-3-kinase, } \\
\text { regulatory subunit } 1 \text { (alpha) }\end{array}$ & NM_001024955 & 0.001 & -1.124 & 6.417 & 0.061 & -0.437 & 3.074 & 0.003 & 0.891 & 7.234 \\
\hline SOCS2 & $\begin{array}{l}\text { suppressor of cytokine } \\
\text { signaling } 2\end{array}$ & NM_007706 & 0.003 & 2.46 & 8.84 & 0.254 & 0.074 & 2.291 & 0.005 & -1.893 & 6.011 \\
\hline SOCS3 & $\begin{array}{l}\text { suppressor of cytokine } \\
\text { signaling } 3\end{array}$ & NM_007707 & 0.006 & 0.9 & 5.801 & 0 & 1.482 & 4.318 & 0.039 & 0.582 & 4.901 \\
\hline STAT5A & $\begin{array}{l}\text { signal transducer and activator } \\
\text { of transcription } 5 \mathrm{~A}\end{array}$ & NM_011488 & 0.009 & -0.68 & 2.856 & 0.116 & 0.493 & 5.449 & 0.003 & 0.83 & 3.536 \\
\hline \multicolumn{12}{|c|}{ IL-4 Signaling } \\
\hline HLA-DMA & $\begin{array}{l}\text { major histocompatibility } \\
\text { complex, class II, DM alpha }\end{array}$ & NM_010386 & 0.068 & 0.532 & 5.799 & 0.308 & -0.268 & 6.068 & 0.015 & -0.8 & 5.268 \\
\hline HLA-DQB2 & $\begin{array}{l}\text { major histocompatibility } \\
\text { complex, class II, DQ beta } 2\end{array}$ & NM_207105 & 0.793 & -0.127 & 6.424 & 0.025 & -1.355 & 7.779 & 0.036 & -1.228 & 6.551 \\
\hline HLA-DRB1 & $\begin{array}{l}\text { major histocompatibility } \\
\text { complex, class II, DR beta } 1\end{array}$ & NM_010382 & 0.903 & -0.068 & 8.855 & 0.045 & -1.327 & 10.182 & 0.054 & -1.26 & 8.923 \\
\hline IL13RA1 & interleukin 13 receptor, alpha 1 & NM_133990 & 0.007 & 1.088 & 7.898 & 0.049 & 0.681 & 7.217 & 0.116 & -0.452 & 7.264 \\
\hline INPPL1 & $\begin{array}{l}\text { inositol polyphosphate } \\
\text { phosphatase-like } 1\end{array}$ & NM_001122739 & 0.006 & -0.981 & 5.224 & 0.058 & -0.561 & 5.785 & 0.132 & 0.42 & 6.205 \\
\hline PIK3R1 & $\begin{array}{l}\text { Phosphoinositide-3-kinase, } \\
\text { regulatory subunit } 1 \text { (alpha) }\end{array}$ & NM_001024955 & 0.001 & -1.124 & 6.417 & 0.061 & -0.437 & 3.074 & 0.003 & 0.891 & 7.234 \\
\hline \multicolumn{12}{|c|}{ Antigen Presentation Pathway } \\
\hline CD74 & $\begin{array}{l}\text { CD74 molecule, major } \\
\text { histocompatibility complex, } \\
\text { class II invariant chain }\end{array}$ & NM_001042605 & 0.219 & -0.511 & 9.262 & 0.017 & -1.202 & 10.464 & 0.112 & -0.691 & 9.773 \\
\hline HLA-DMA & $\begin{array}{l}\text { major histocompatibility } \\
\text { complex, class II, DM alpha }\end{array}$ & NM_010386 & 0.068 & 0.532 & 5.799 & 0.308 & -0.268 & 6.068 & 0.015 & -0.8 & 5.268 \\
\hline HLA-DQB2 & $\begin{array}{l}\text { major histocompatibility } \\
\text { complex, class II, DQ beta } 2\end{array}$ & NM_207105 & 0.793 & -0.127 & 6.424 & 0.025 & -1.355 & 7.779 & 0.036 & -1.228 & 6.551 \\
\hline HLA-DRB1 & $\begin{array}{l}\text { major histocompatibility } \\
\text { complex, class II, DR beta } 1\end{array}$ & NM_010382 & 0.903 & -0.068 & 8.855 & 0.045 & -1.327 & 10.182 & 0.054 & -1.26 & 8.923 \\
\hline
\end{tabular}

the total number of genes known to be associated with that pathway, 3) the total number of eligible genes included in the analysis, and 4) the total number of genes in the input data. Tables of $-\log (\mathrm{p}$-value), to rank the significance, were exported from IPA into JavaTreeView [10] to generate heatmaps (Supplement Figure 4). IPA presents pathway analysis data in part as interactive graphs. Pathway graphs deemed to be highly significant to UP780 mechanism of action are illustrated in the Supplement Figures 5 and 6. In addition, genes included in the significant pathways from all three contrasts were exported to Excel as Supplement Tables 1-4.

From the Ingenuity pathway analysis result of significant Canonical Pathways, the p-values derived from the evaluation of the pathways in association with the gene expression variations were $-\log _{10}$ transformed and plotted as heatmaps [10], for liver metabolic pathways (Supplement Figure 4(a)) and signaling pathways (Supplement Figure 4(b)) and for WAT metabolic pathways (Supplement Figure 4(c)) and signaling pathways (Supplement Figure 4(d)). The complete gene lists for individual pathways in Supplement Figure $\mathbf{4}$ are supplied as 


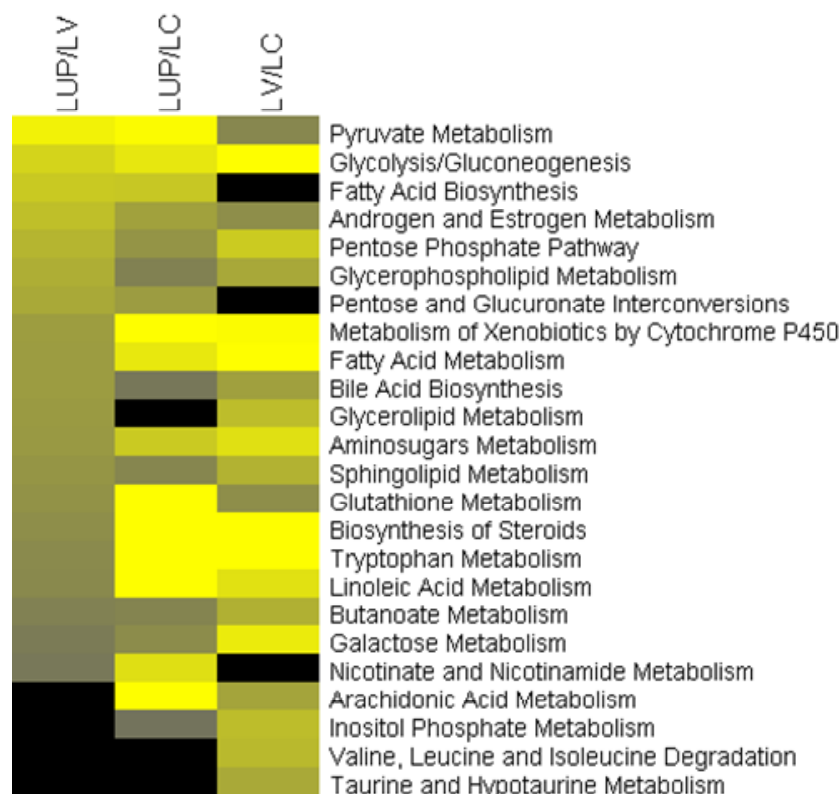

(a)

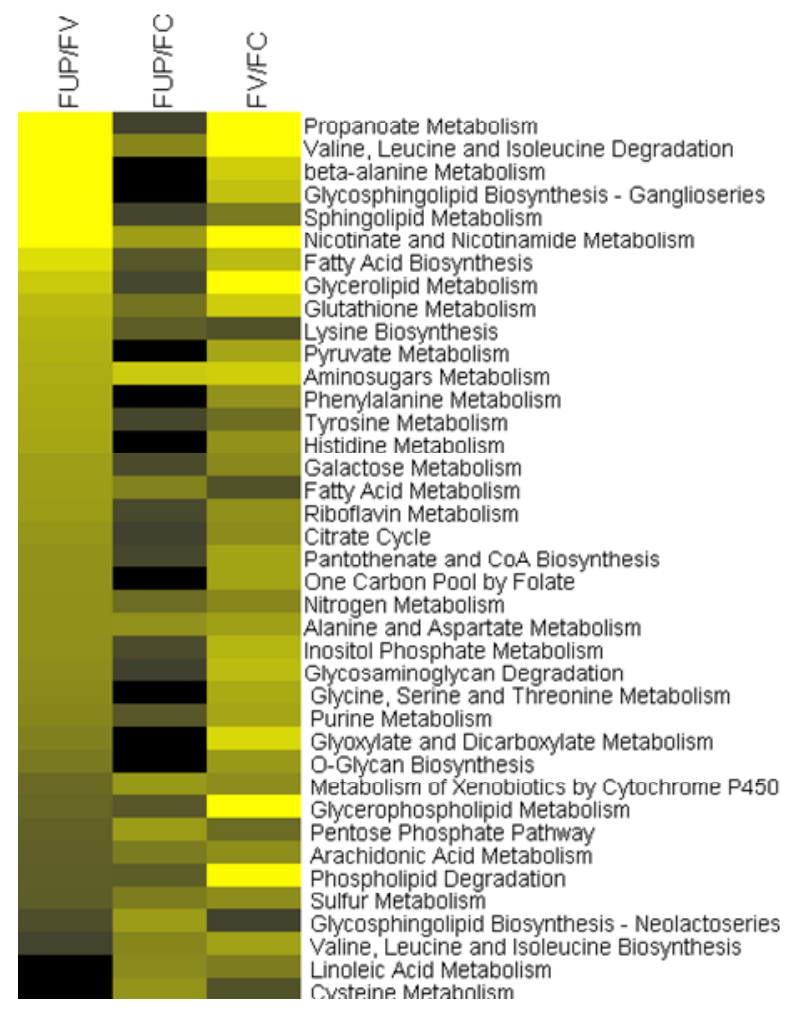

(c)

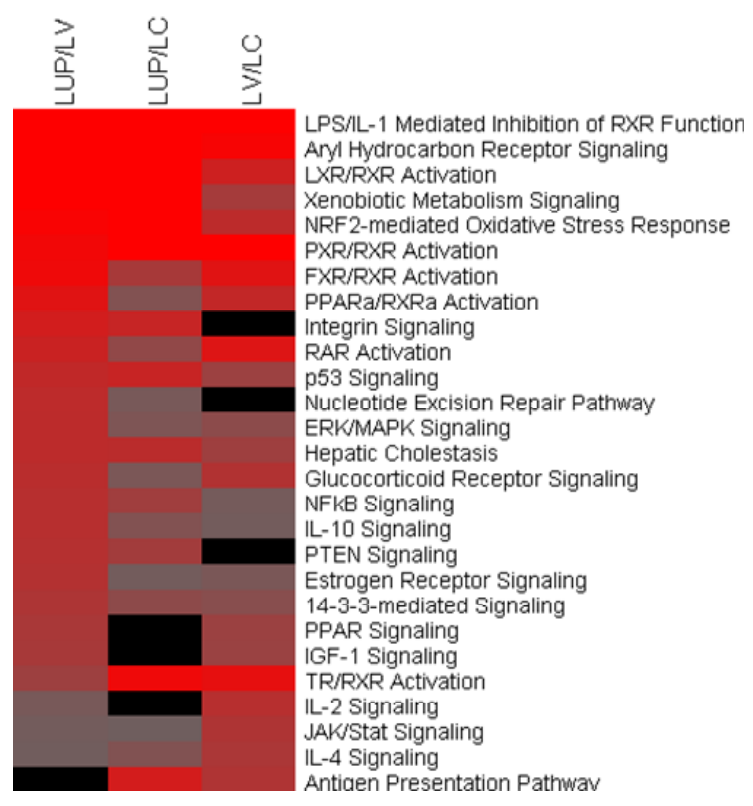

(b)

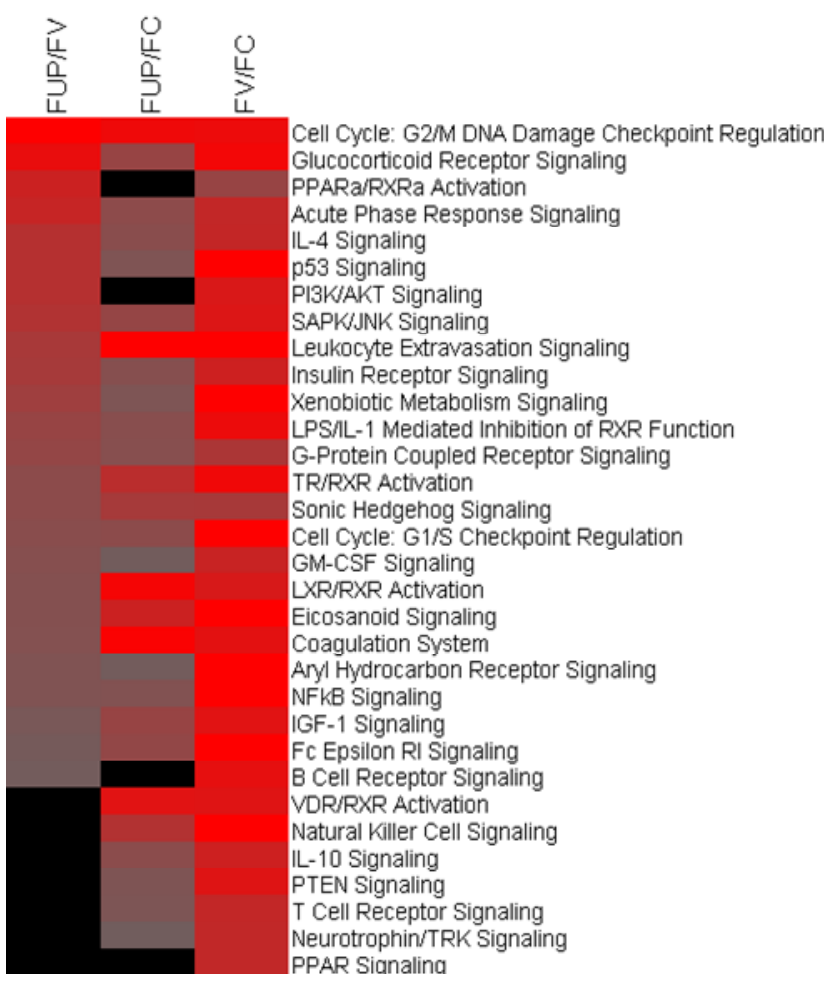

(d)

Supplement Figure 4. Significant pathways with gene expression variations measured by microarrays. Heatmaps [10] were used to illustrate the metabolic and signaling canonical pathways that passed at least one of the IPA statistic tests at $p<0.05$ for gene expression variations in between contrasting RNA samples of HFD + UP780 vs. HFD, HFD + UP780 vs. lean control, and HFD vs. lean control. The color gradients correspond to the $-\log _{10}$ transformed p-values from the IPA pathway analysis of one-tailed Fisher's exact tests, with yellow for the metabolic pathways and red for the signaling pathways, and black denoting missing values. A. liver metabolic pathways; B, liver signaling pathways; C, WAT metabolic pathways; and D, WAT signaling pathways. C is an exception in that the cutoff value for $\log _{2}$ ratio was set at 0.5 instead of 0.8 when conducting the IPA pathway analysis, as described in materials and methods. 


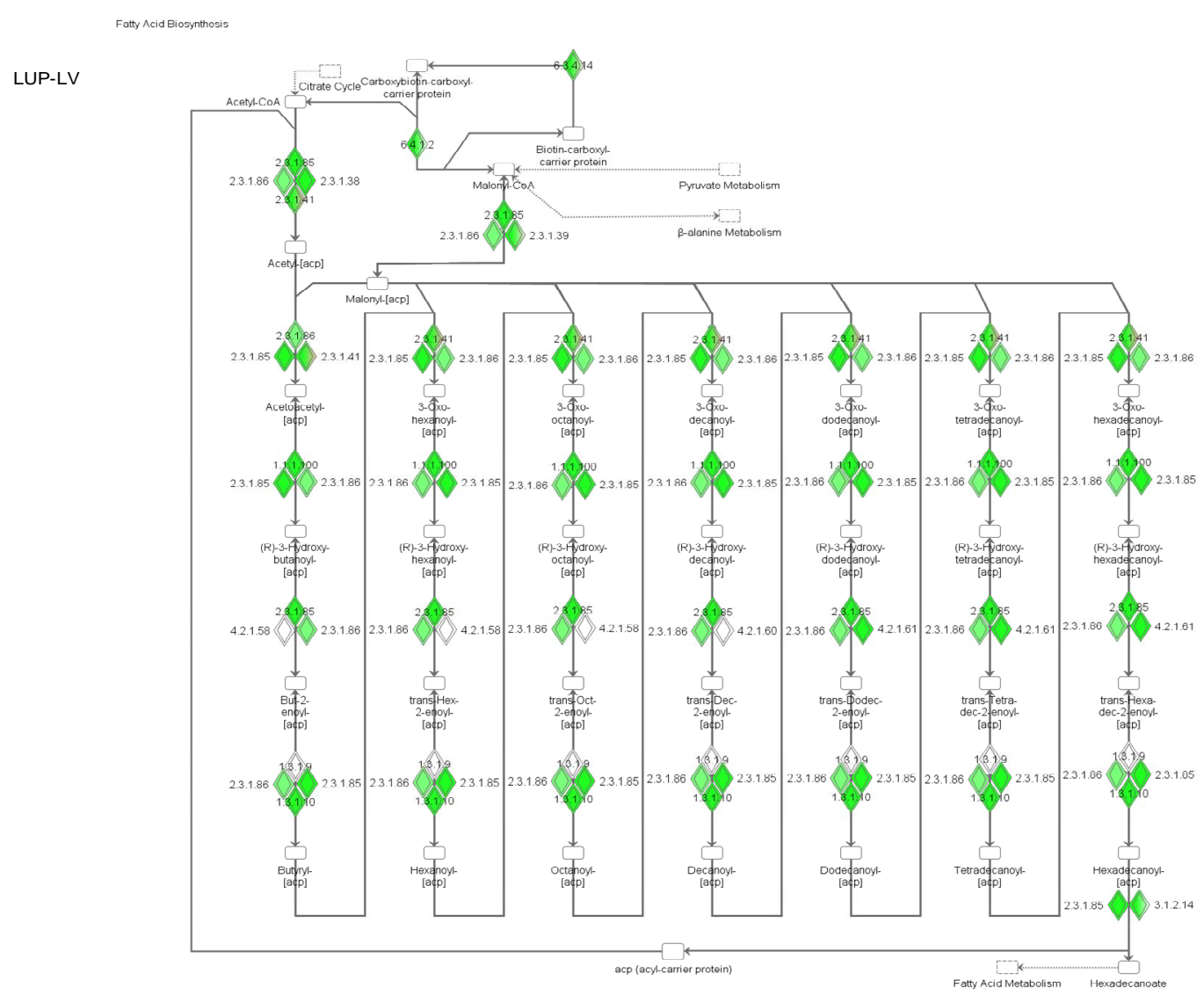

(a)

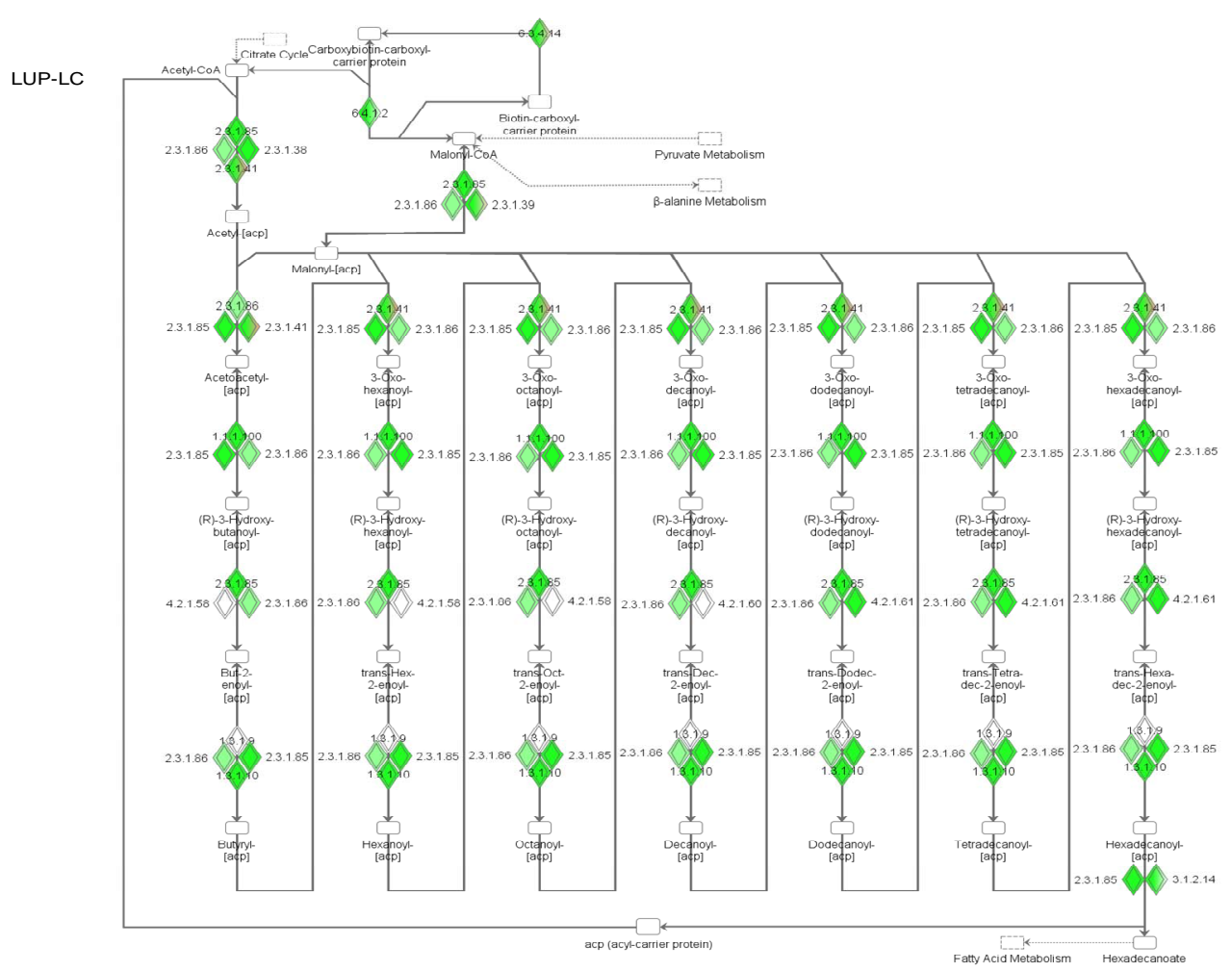

(b) 


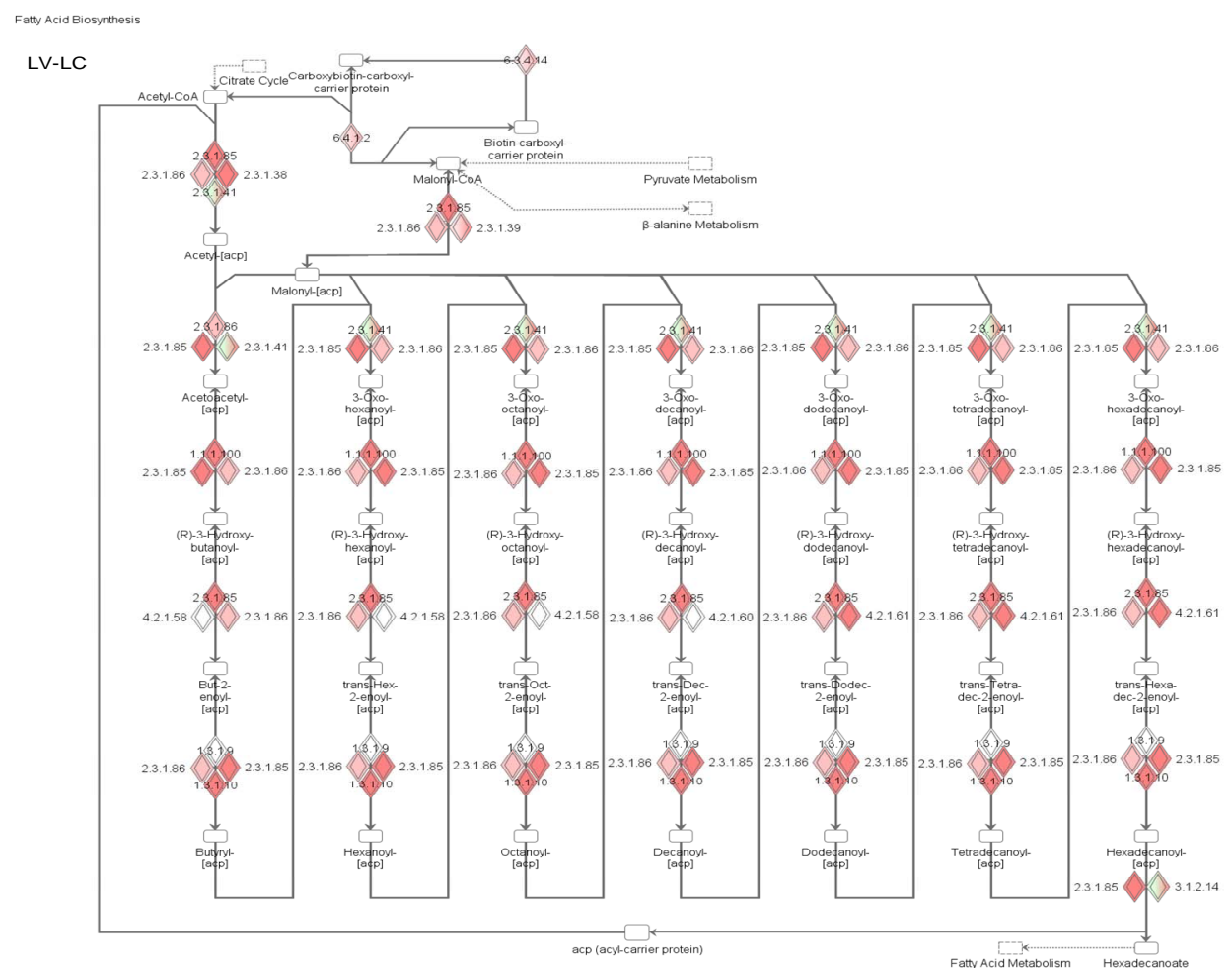

(c)

Supplement Figure 5. Liver canonical pathway of fatty acid biosynthesis. Fatty acid biosynthesis pathway figures for comparisons A, LUP-LV, B, LUP-LC, and C, LV-LC were overlaid with red (upregulation) and green (down-regulation) according to the values of $\log _{2}$ ratio, with color gradient denoting the scale of up- or down-regulation. The figures were exported from the Ingenuity Pathway Analysis.

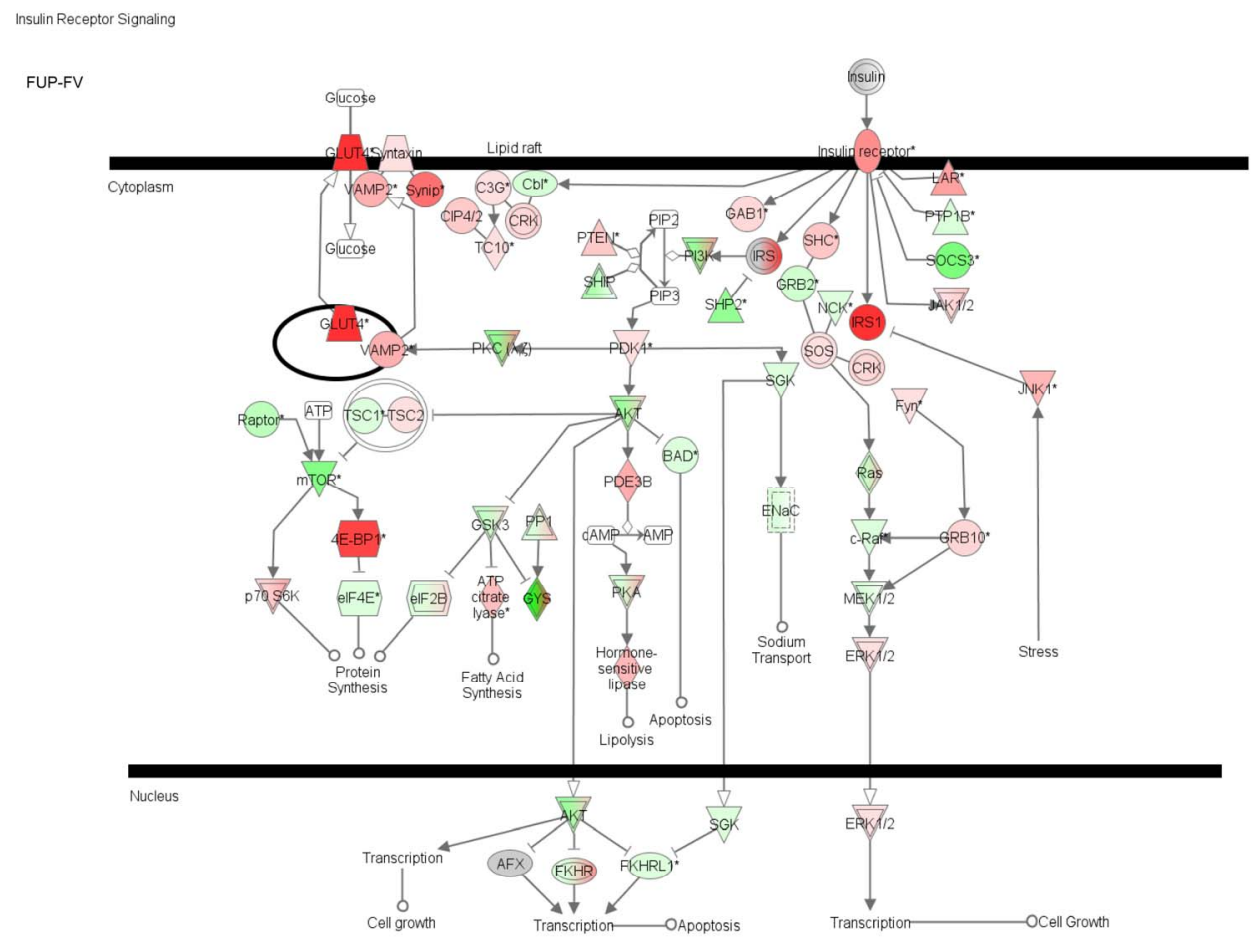




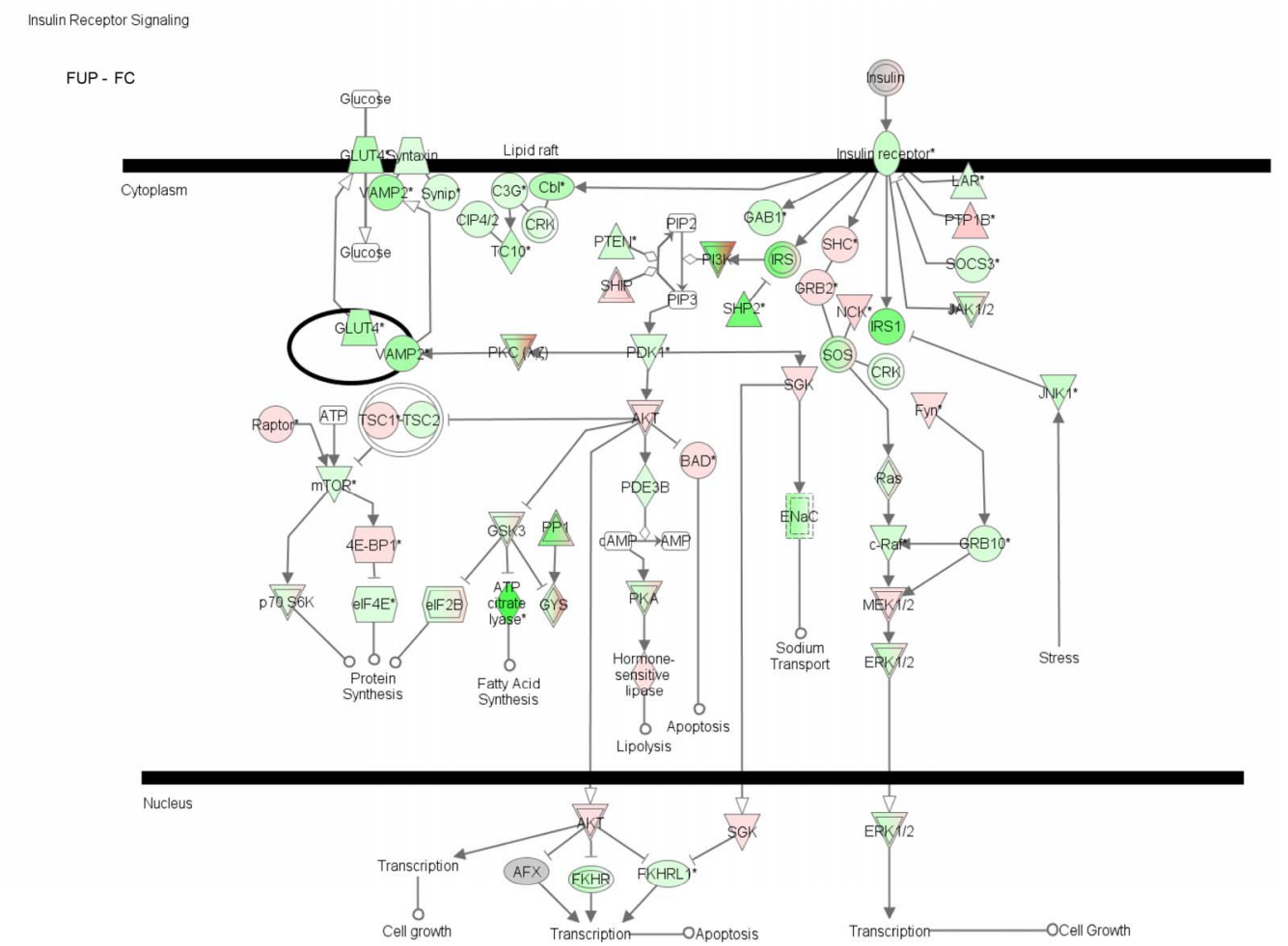

(1) 2000-2008 Ingenuily Systems, Inc. All rights reserryd.

Insulin Receptor Signaling

FV-FC (b)

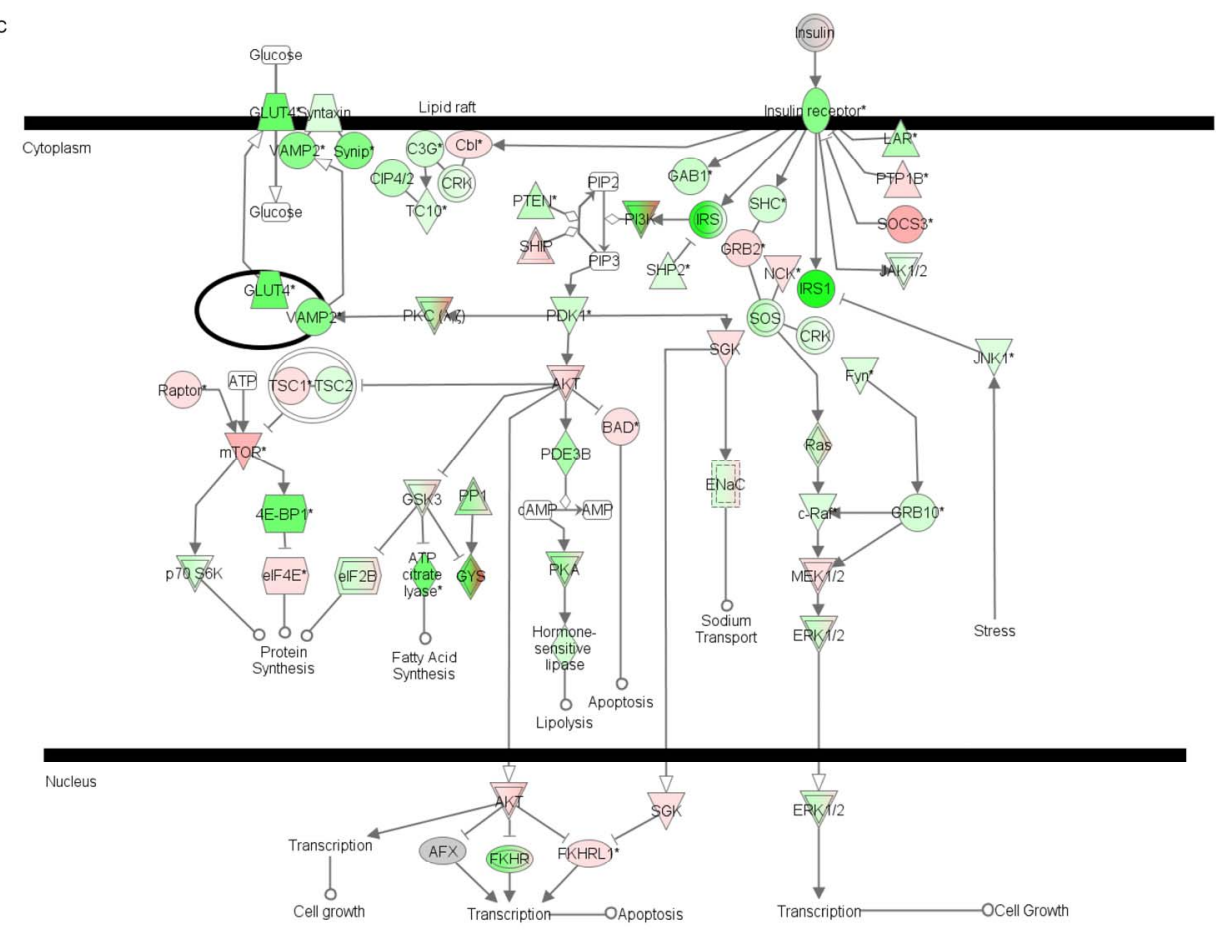

(c)

Supplement Figure 6. WAT canonical pathway of insulin receptor signaling. Insulin receptor signaling pathway figures for comparisons A, FUP-FV, B, FUP-FC, and C, FV-FC were overlaid with red (up-regulation) and green (down-regulation) according to the values of $\log _{2}$ ratio, with color gradient denoting the scale of up- or down-regulation. The figures were exported from the Ingenuity Pathway Analysis. 
Supplement Table 3.

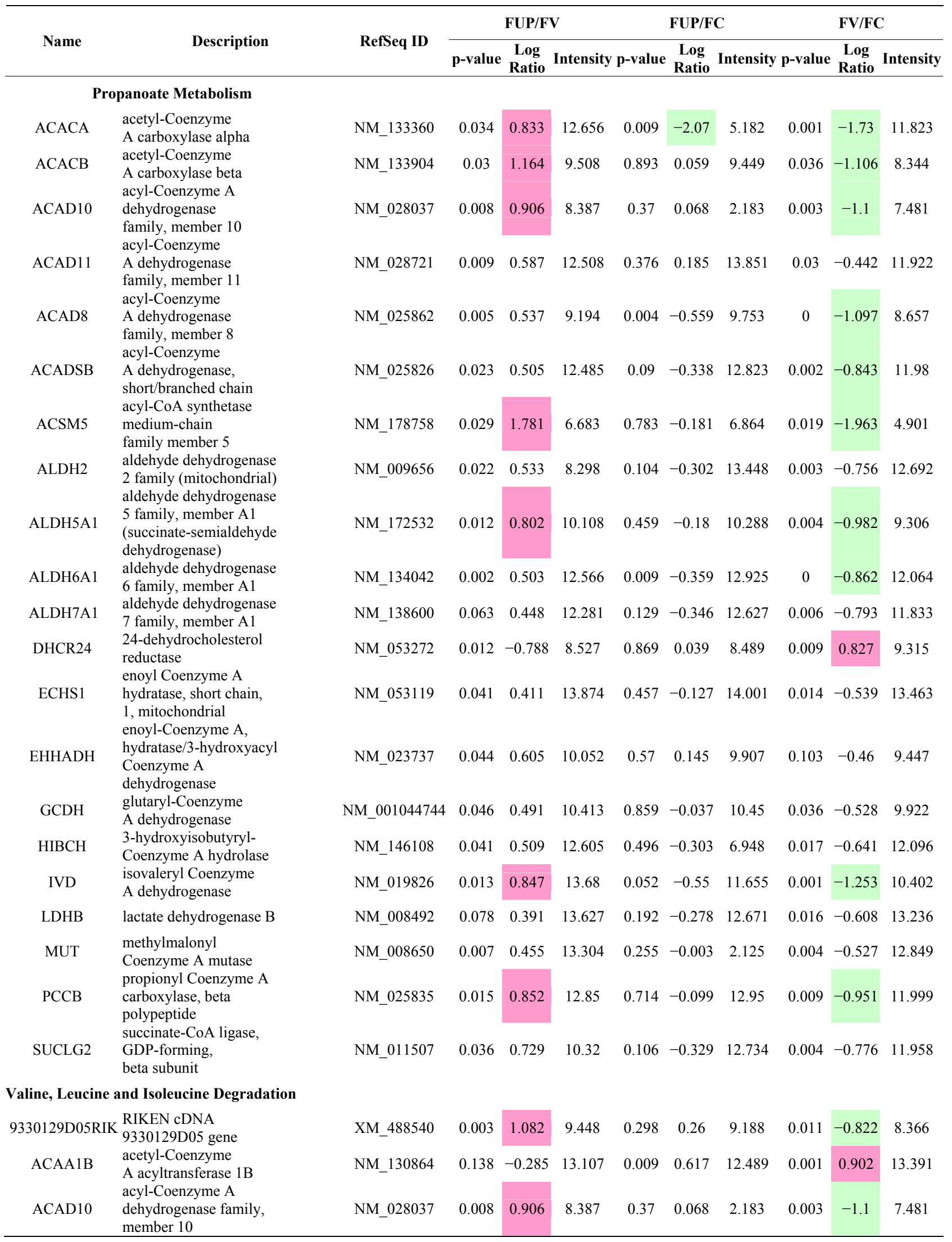


Continued

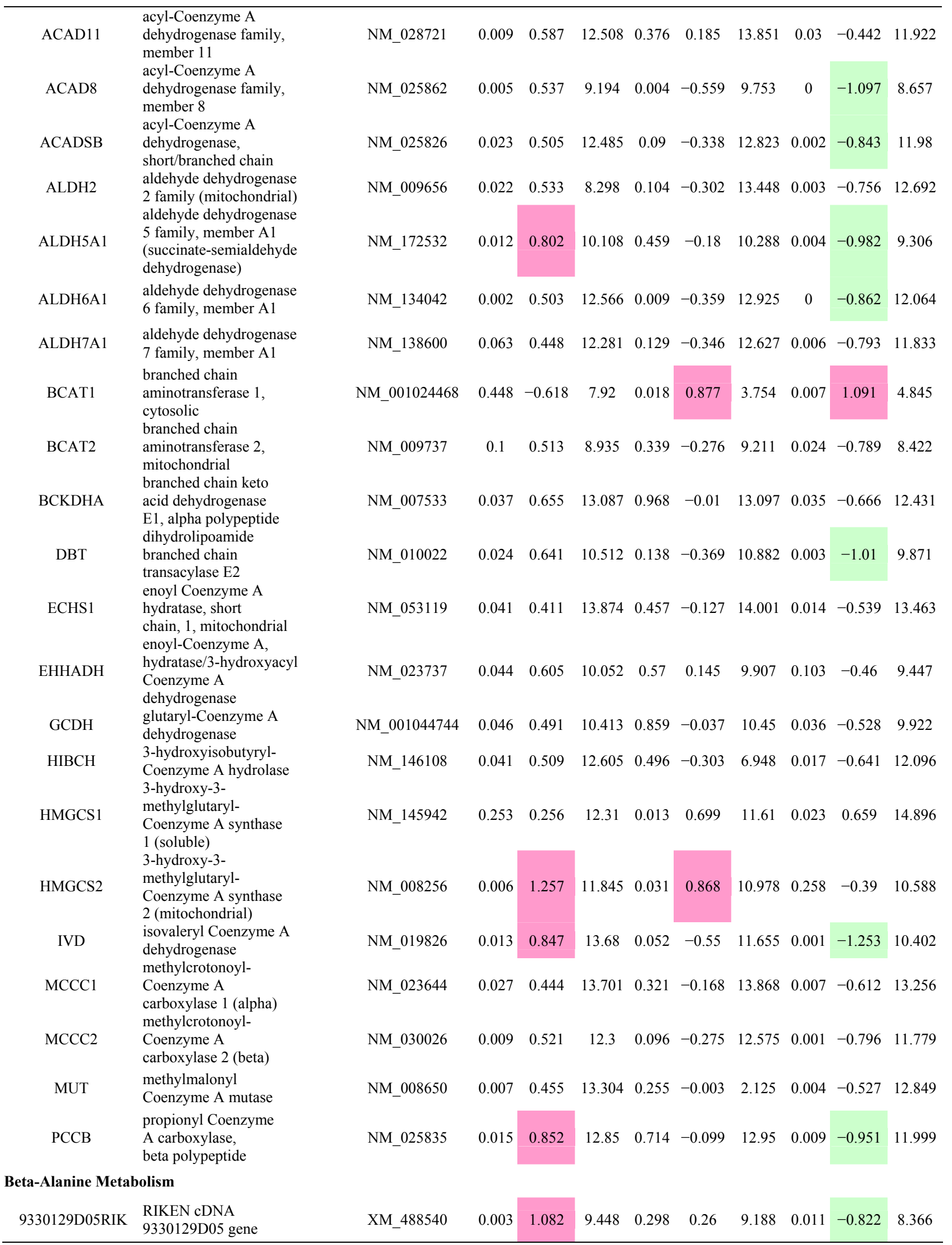


Continued

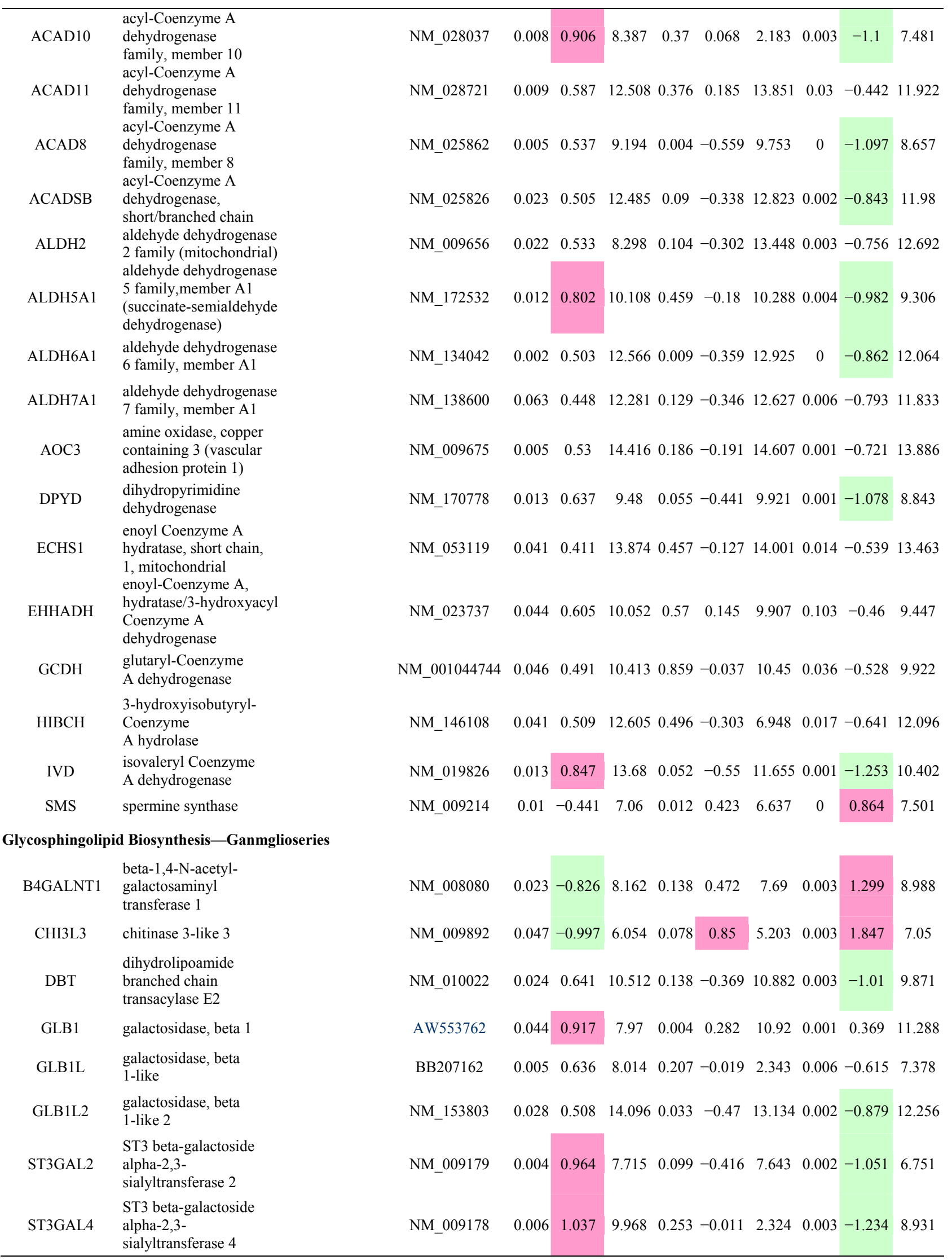


Continued

\begin{tabular}{|c|c|c|c|c|c|c|c|c|c|c|c|}
\hline ST6GALNAC4 & $\begin{array}{l}\text { ST6 (alpha-N-acetyl- } \\
\text { neuraminyl-2, 3-beta- } \\
\text { galactosyl-1,3)-N- } \\
\text { acetylgalactosaminide } \\
\text { alpha-2,6-sialyltransferase } 4 \\
\text { ST8 alpha-N-acetyl- } \\
\text { neuraminide alpha-2, } \\
\text { 8-sialyltransferase } 4\end{array}$ & NM_011373 & 0.005 & -0.842 & 2.759 & 0.059 & 0.467 & 4.842 & 0.001 & 1.309 & 4.287 \\
\hline \multicolumn{12}{|c|}{ Sphingolipid Metabolism } \\
\hline ASAH2 & $\begin{array}{l}\text { N-acylsphingosine } \\
\text { amidohydrolase } \\
\text { (non-lysosomal } \\
\text { ceramidase) } 2\end{array}$ & NM_018830 & 0.002 & 0.564 & 9.084 & 0.039 & -0.286 & 9.37 & 0 & -0.849 & 8.52 \\
\hline $\begin{array}{c}\text { CERK } \\
\text { (includes EG:64781) }\end{array}$ & ceramide kinase & NM_145475 & 0.153 & -0.486 & 9.449 & 0.059 & 0.686 & 8.763 & 0.007 & 1.172 & 9.935 \\
\hline GALC & galactosylceramidase & NM_008079 & 0.198 & -0.391 & 10.185 & 0.002 & 1.087 & 4.748 & 0.002 & 1.059 & 5.806 \\
\hline GLA & galactosidase, alpha & NM_013463 & 0.045 & -1.008 & 8.5 & 0.051 & 0.969 & 7.53 & 0.002 & 1.977 & 9.508 \\
\hline GLB1 & galactosidase, beta 1 & --- & 0.044 & 0.917 & 7.97 & 0.004 & 0.282 & 10.92 & 0.001 & 0.369 & 11.288 \\
\hline GLB1L & galactosidase, beta 1-like & -- & 0.005 & 0.636 & 8.014 & 0.207 & -0.019 & 2.343 & 0.006 & -0.615 & 7.378 \\
\hline GLB1L2 & galactosidase, beta 1-like 2 & NM_153803 & 0.028 & 0.508 & 14.096 & 0.033 & -0.47 & 13.134 & 0.002 & -0.879 & 12.256 \\
\hline KDSR & $\begin{array}{l}\text { 3-ketodihydrosphingosine } \\
\text { reductase }\end{array}$ & NM_027534 & 0.004 & 0.76 & 9.115 & 0.093 & -0.337 & 9.452 & 0.001 & -1.097 & 8.355 \\
\hline PPAP2A & $\begin{array}{l}\text { phosphatidic } \\
\text { acid phosphatase } \\
\text { type } 2 \mathrm{~A}\end{array}$ & NM_008247 & 0.154 & -0.308 & 11.42 & 0.309 & 0.21 & 11.209 & 0.033 & 0.518 & 11.728 \\
\hline SPHK1 & sphingosine kinase 1 & NM_011451 & 0.017 & -1.173 & 4.766 & 0.113 & 0.668 & 4.098 & 0.002 & 1.841 & 5.939 \\
\hline SULF1 & sulfatase 1 & NM_172294 & 0.074 & 0.661 & 11.097 & 0.284 & -0.315 & 2.943 & 0.049 & -0.753 & 10.436 \\
\hline SULF2 & sulfatase 2 & NM_028072 & 0.002 & 0.66 & 12.889 & 0.545 & 0.245 & 8.922 & 0.003 & -0.627 & 12.229 \\
\hline UGCG & $\begin{array}{l}\text { UDP-glucose ceramide } \\
\text { glucosyltransferase }\end{array}$ & NM_011673 & 0.001 & 0.744 & 7.738 & 0.121 & 0.247 & 7.49 & 0.01 & -0.368 & 6.274 \\
\hline VNN1 & vanin 1 & NM_011704 & 0.003 & 0.913 & 9.747 & 0.019 & 0.614 & 9.133 & 0.173 & -0.3 & 8.834 \\
\hline VNN2 & vanin 2 & NM_011979 & 0.005 & 1.429 & 10.815 & 0.745 & -0.118 & 10.932 & 0.004 & -1.547 & 9.386 \\
\hline \multicolumn{12}{|c|}{ Nicotine and Nicotinamide Metabolism } \\
\hline ACVR2A & activin A receptor, type IIA & NM_007396 & 0.06 & -0.395 & 5.998 & 0.109 & 0.322 & 5.676 & 0.005 & 0.717 & 6.393 \\
\hline AKT2 & $\begin{array}{l}\text { v-akt murine thymoma viral } \\
\text { oncogene homolog } 2\end{array}$ & NM_001110208 & 0.02 & 0.692 & 11.06 & 0.489 & 0.164 & 10.896 & 0.016 & -0.439 & 13 \\
\hline ARAF & $\begin{array}{l}\text { v-raf murine sarcoma } 3611 \\
\text { viral oncogene homolog }\end{array}$ & NM_009703 & 0.038 & 0.376 & 10.45 & 0.258 & 0.245 & 11.406 & 0.02 & -0.912 & 3.647 \\
\hline BST1 & $\begin{array}{l}\text { bone marrow stromal cell } \\
\text { antigen } 1\end{array}$ & NM_009763 & 0.186 & -0.466 & 8.101 & 0.32 & 0.338 & 7.763 & 0.041 & 0.804 & 8.566 \\
\hline CD38 & CD38 molecule & NM_007646 & 0.002 & 1.162 & 7.285 & 0.035 & -0.377 & 10.359 & 0 & -1.043 & 9.315 \\
\hline $\mathrm{CDC} 2$ & $\begin{array}{l}\text { cell division cycle } 2, \mathrm{G} 1 \text { to } \\
\mathrm{S} \text { and } \mathrm{G} 2 \text { to } \mathrm{M}\end{array}$ & NM_007659 & 0.013 & -1.395 & 8.342 & 0.02 & 1.253 & 7.088 & 0 & 2.648 & 9.736 \\
\hline CDK6 & cyclin-dependent kinase 6 & NM_009873 & 0.024 & -0.762 & 9.029 & 0.093 & 0.629 & 7.834 & 0.003 & 1.211 & 9.791 \\
\hline $\mathrm{CDK} 7$ & cyclin-dependent kinase 7 & NM_009874 & 0.043 & -0.591 & 5.752 & 0.161 & -0.283 & 6.617 & 0.023 & -0.533 & 6.084 \\
\hline CSNK1D & casein kinase 1 , delta & NM_027874 & 0.036 & 0.593 & 10.45 & 0.253 & -0.043 & 2.526 & 0.026 & -0.345 & 9.897 \\
\hline EIF2AK2 & $\begin{array}{l}\text { eukaryotic translation } \\
\text { initiation actor } 2 \text {-alpha } \\
\text { kinase } 2\end{array}$ & NM_011163 & 0.034 & 0.58 & 6.376 & 0.261 & 0.163 & 6.524 & 0.088 & -0.433 & 5.796 \\
\hline ENPP1 & $\begin{array}{l}\text { ectonucleotide } \\
\text { pyrophosphatase/ } \\
\text { phosphodiesterase } 1\end{array}$ & NM_008813 & 0.046 & -1.405 & 5.35 & 0.185 & 0.845 & 4.505 & 0.007 & 2.25 & 6.755 \\
\hline
\end{tabular}




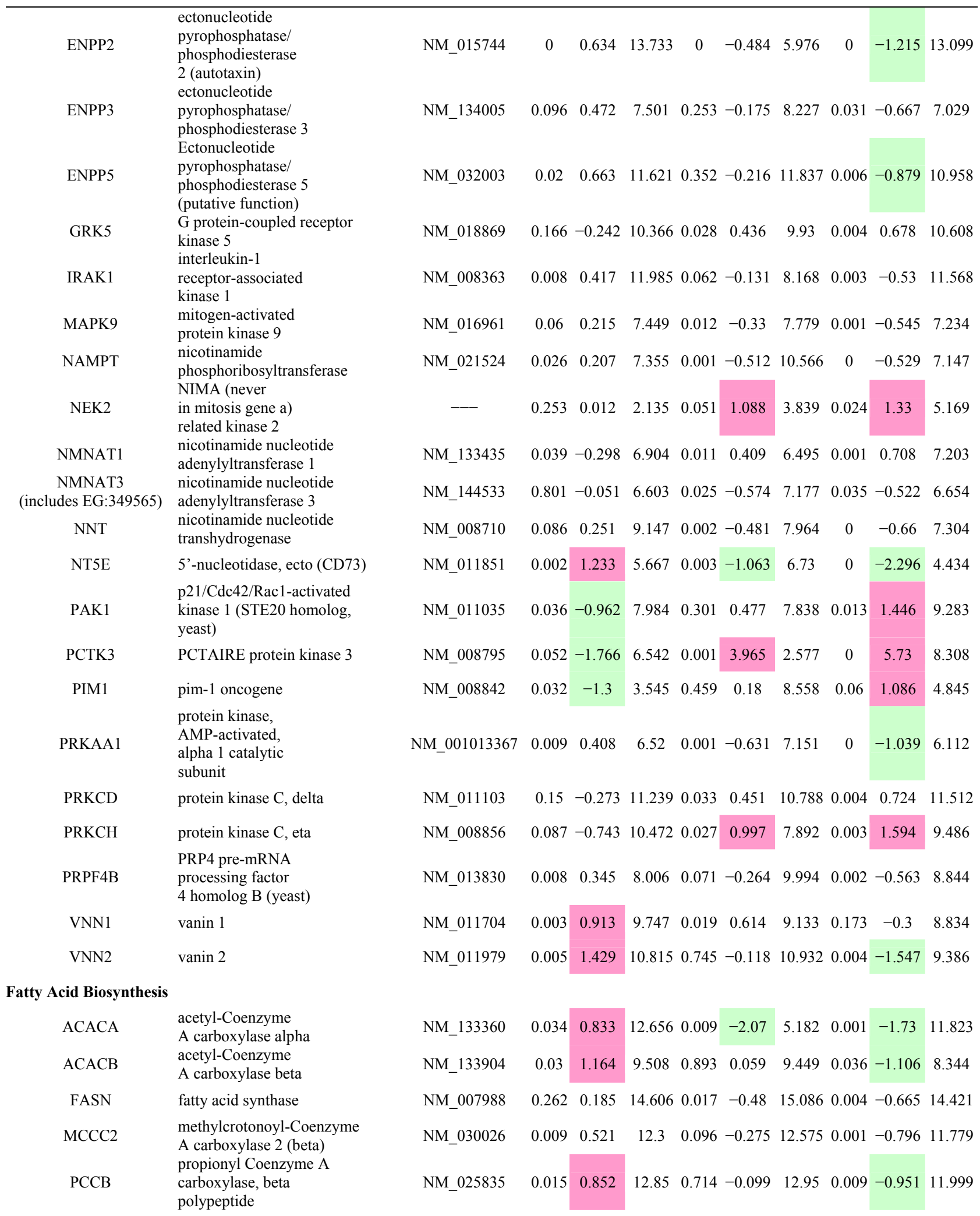

\section{Glycerolipid Metabolism}

ADHFE1 alcohol dehydrogenase, iron containing, 1

$\begin{array}{llllllllll}\text { NM_175236 } & 0.024 & 0.506 & 13.325 & 0.188 & -0.253 & 13.578 & 0.004 & -0.76 & 12.819\end{array}$ 


\section{Continued}

\begin{tabular}{|c|c|c|c|c|c|c|c|c|c|c|c|}
\hline & $\begin{array}{l}\text { 1-acylglycerol-3- } \\
\text { phosphate }\end{array}$ & & & & & & & & & & \\
\hline AGPAT5 & $\begin{array}{l}\text { O-acyltransferase } 5 \\
\text { (lysophosphatidic acid } \\
\text { acyltransferase, epsilon) } \\
\text { aldo-keto reductase family }\end{array}$ & NM_026792 & 0.006 & -0.453 & 10.34 & 0.243 & 0.2 & 9.39 & 0.002 & 0.574 & 10.793 \\
\hline AKR1B10 & $\begin{array}{l}1, \text { member B10 } \\
\text { (aldose reductase) }\end{array}$ & NM_172398 & 0.026 & -0.34 & 11.359 & 0.023 & 0.349 & 11.01 & 0.001 & 0.69 & 11.699 \\
\hline ALDH2 & $\begin{array}{l}\text { aldehyde dehydrogenase } 2 \\
\text { family (mitochondrial) }\end{array}$ & NM_009656 & 0.022 & 0.533 & 8.298 & 0.104 & -0.302 & 13.448 & 0.003 & -0.756 & 12.692 \\
\hline ALDH5A1 & $\begin{array}{l}\text { aldehyde dehydrogenase } 5 \\
\text { family, member A1 } \\
\text { (succinate-semialdehyde } \\
\text { dehydrogenase) }\end{array}$ & NM_172532 & 0.012 & 0.802 & 10.108 & 0.459 & -0.18 & 10.288 & 0.004 & -0.982 & 9.306 \\
\hline ALDH7A1 & $\begin{array}{l}\text { aldehyde dehydrogenase } 7 \\
\text { family, member A1 }\end{array}$ & NM_138600 & 0.063 & 0.448 & 12.281 & 0.129 & -0.346 & 12.627 & 0.006 & -0.793 & 11.833 \\
\hline APOC2 & apolipoprotein C-II & NM_009695 & 0.187 & -0.44 & 9.316 & 0.073 & 0.639 & 8.677 & 0.01 & 1.08 & 9.756 \\
\hline $\begin{array}{c}\text { CERK } \\
\text { (includes EG:64781) }\end{array}$ & ceramide kinase & NM_145475 & 0.153 & -0.486 & 9.449 & 0.059 & 0.686 & 8.763 & 0.007 & 1.172 & 9.935 \\
\hline DAGLB & diacylglycerol lipase, beta & NM_144915 & 0.054 & -0.527 & 10.114 & 0.08 & 0.466 & 9.649 & 0.004 & 0.992 & 10.641 \\
\hline DGKZ & $\begin{array}{l}\text { diacylglycerol kinase, } \\
\text { zeta } 104 \mathrm{kDa}\end{array}$ & NM_138306 & 0.106 & -0.399 & 11.397 & 0.017 & 0.6 & 7.504 & 0.004 & 0.841 & 8.345 \\
\hline GK & glycerol kinase & NM_008194 & 0.03 & -0.897 & 7.821 & 0.564 & 0.193 & 6.204 & 0.018 & 1.006 & 7.21 \\
\hline GLA & galactosidase, alpha & NM_013463 & 0.045 & -1.008 & 8.5 & 0.051 & 0.969 & 7.53 & 0.002 & 1.977 & 9.508 \\
\hline GLB1 & galactosidase, beta 1 & --- & 0.044 & 0.917 & 7.97 & 0.004 & 0.282 & 10.92 & 0.001 & 0.369 & 11.288 \\
\hline GLB1L & $\begin{array}{l}\text { galactosidase, beta } \\
\text { 1-like }\end{array}$ & -- & 0.005 & 0.636 & 8.014 & 0.207 & -0.019 & 2.343 & 0.006 & -0.615 & 7.378 \\
\hline GLB1L2 & $\begin{array}{l}\text { galactosidase, beta } \\
\text { 1-like } 2\end{array}$ & NM_153803 & 0.028 & 0.508 & 14.096 & 0.033 & -0.47 & 13.134 & 0.002 & -0.879 & 12.256 \\
\hline GLYCTK & glycerate kinase & NM_001039586 & 0.155 & -0.622 & 3.75 & 0.069 & 0.844 & 2.906 & 0.008 & 1.466 & 4.371 \\
\hline GPAM & $\begin{array}{l}\text { glycerol-3-phosphate } \\
\text { acyltransferase, } \\
\text { mitochondrial }\end{array}$ & NM_008149 & 0.019 & 0.977 & 9.215 & 0.15 & -0.377 & 13.572 & 0.005 & -1.326 & 8.238 \\
\hline LIPA & $\begin{array}{l}\text { lipase A, lysosomal acid, } \\
\text { cholesterol esterase } \\
\text { (Wolman disease) }\end{array}$ & NM_001111100 & 0.044 & -0.971 & 9.896 & 0.027 & 0.828 & 12.45 & 0.002 & 1.498 & 13.949 \\
\hline LIPF & lipase, gastric & NM_026334 & 0.21 & -1.319 & 8.153 & 0.01 & 3.418 & 4.734 & 0.002 & 4.738 & 9.472 \\
\hline MGLL & monoglyceride lipase & NM_011844 & 0.003 & 0.274 & 14.677 & 0.019 & 0.185 & 14.492 & 0.017 & 0.819 & 5.255 \\
\hline MOGAT1 & $\begin{array}{l}\text { monoacylglycerol } \\
\text { O-acyltransferase } 1 \\
\text { patatin-like phospholipase }\end{array}$ & NM_026713 & 0.045 & 1.23 & 10.98 & 0.274 & -0.589 & 11.569 & 0.009 & -1.819 & 9.75 \\
\hline PNPLA3 & $\begin{array}{l}\text { domain } \\
\text { containing } 3\end{array}$ & NM_054088 & 0.309 & 0.351 & 9.154 & 0.157 & -0.51 & 9.663 & 0.033 & -0.861 & 8.803 \\
\hline PPAP2A & $\begin{array}{l}\text { phosphatidic } \\
\text { acid phosphatase } \\
\text { type } 2 \mathrm{~A}\end{array}$ & NM_008247 & 0.154 & -0.308 & 11.42 & 0.309 & 0.21 & 11.209 & 0.033 & 0.518 & 11.728 \\
\hline SPHK1 & sphingosine kinase 1 & NM_011451 & 0.017 & -1.173 & 4.766 & 0.113 & 0.668 & 4.098 & 0.002 & 1.841 & 5.939 \\
\hline TCAG7.1260 & $\begin{array}{l}\text { similar to aldo-keto } \\
\text { reductase } \\
\text { family } 1 \text {, member B10 }\end{array}$ & NM_008012 & 0.059 & -0.593 & 12.179 & 0.599 & 0.143 & 12.036 & 0.027 & 0.736 & 12.772 \\
\hline \multicolumn{12}{|c|}{ Glutathione Metabolism } \\
\hline G6PD2 & $\begin{array}{l}\text { glucose-6-phosphate } \\
\text { dehydrogenase } 2\end{array}$ & NM_008062 & 0.086 & 0.208 & 11.592 & 0.001 & 0.59 & 11.002 & 0.009 & 0.381 & 11.384 \\
\hline GCLM & $\begin{array}{l}\text { glutamate-cysteine ligase, } \\
\text { modifier subunit }\end{array}$ & NM_008129 & 0.138 & -0.358 & 10.577 & 0.366 & -0.214 & 7.458 & 0.04 & 0.546 & 10.935 \\
\hline GGT6 & gamma-glutamyltransferase 6 & NM_027819 & 0.002 & -1.32 & 4.6 & 0.123 & 0.479 & 4.12 & 0 & 1.799 & 5.919 \\
\hline GPX3 & $\begin{array}{l}\text { glutathione peroxidase } 3 \\
\text { (plasma) }\end{array}$ & NM_001083929 & 0.008 & 0.692 & 15.37 & 0.063 & -0.41 & 15.78 & 0.001 & -1.102 & 14.677 \\
\hline GSTA3 & glutathione S-transferase A3 & NM_001077353 & 0.061 & 0.953 & 11.415 & 0.127 & -0.725 & 9.233 & 0.006 & -1.656 & 7.577 \\
\hline
\end{tabular}


Continued

\begin{tabular}{|c|c|c|c|c|c|c|c|c|c|c|c|}
\hline GSTA4 & glutathione S-transferase A4 & NM_010357 & 0.04 & 0.853 & 11.386 & 0.122 & -0.589 & 11.975 & 0.004 & -1.441 & 10.533 \\
\hline GSTO1 & $\begin{array}{l}\text { glutathione S-transferase } \\
\text { omega } 1\end{array}$ & NM_010362 & 0.102 & -0.283 & 10.549 & 0.006 & 0.463 & 12.792 & 0.001 & 0.673 & 13.464 \\
\hline GSTT1 & $\begin{array}{l}\text { glutathione S-transferase } \\
\text { theta } 1\end{array}$ & NM_008185 & 0.013 & 0.59 & 12.791 & 0.026 & -0.502 & 13.293 & 0.001 & -1.092 & 12.201 \\
\hline GSTT2 & $\begin{array}{l}\text { glutathione S-transferase } \\
\text { theta } 2\end{array}$ & NM_010361 & 0.006 & 0.683 & 11.146 & 0.63 & -0.086 & 11.232 & 0.004 & -0.77 & 10.463 \\
\hline GSTT3 & $\begin{array}{l}\text { glutathione S-transferase, } \\
\text { theta } 3\end{array}$ & NM_133994 & 0.022 & 0.862 & 8.133 & 0.007 & -1.124 & 9.257 & 0 & -1.987 & 7.271 \\
\hline H6PD & $\begin{array}{l}\text { hexose-6-phosphate } \\
\text { dehydrogenase (glucose } \\
\text { 1-dehydrogenase) }\end{array}$ & NM_173371 & 0.002 & 0.688 & 14.002 & 0.939 & -0.011 & 14.013 & 0.002 & -0.699 & 13.314 \\
\hline IDH2 & $\begin{array}{l}\text { isocitrate dehydrogenase } 2 \\
(\mathrm{NADP}+), \text { mitochondrial }\end{array}$ & NM_173011 & 0.014 & 0.505 & 13.076 & 0.951 & 0.01 & 13.067 & 0.016 & -0.496 & 12.571 \\
\hline LNPEP & $\begin{array}{l}\text { leucyl/cystinyl } \\
\text { aminopeptidase }\end{array}$ & NM_172827 & 0.002 & 0.539 & 11.772 & 0.05 & -0.046 & 2.178 & 0 & -0.787 & 11.232 \\
\hline LTC4S & leukotriene $\mathrm{C} 4$ synthase & NM_008521 & 0.665 & -0.042 & 14.476 & 0 & 0.748 & 13.728 & 0 & 0.79 & 14.517 \\
\hline MGST2 & $\begin{array}{l}\text { microsomal glutathione } \\
\text { S-transferase } 2\end{array}$ & NM_174995 & 0.043 & -0.457 & 10.739 & 0.327 & 0.192 & 10.547 & 0.011 & 0.649 & 11.196 \\
\hline PGDS & $\begin{array}{l}\text { prostaglandin D2 synthase, } \\
\text { hematopoietic }\end{array}$ & NM_019455 & 0.112 & -1.715 & 7.268 & 0.103 & 1.77 & 5.498 & 0.009 & 3.485 & 8.984 \\
\hline RAB15 & $\begin{array}{l}\text { RAB } 15, \text { member RAS } \\
\text { onocogene family }\end{array}$ & NM_134050 & 0.18 & -0.669 & 7.353 & 0.106 & 0.837 & 6.516 & 0.014 & 1.507 & 8.023 \\
\hline TRHDE & $\begin{array}{l}\text { thyrotropin-releasing } \\
\text { hormone degrading } \\
\text { enzyme }\end{array}$ & NM_146241 & 0.118 & 0.991 & 4.864 & 0.058 & -1.27 & 6.134 & 0.006 & -2.261 & 3.873 \\
\hline \multicolumn{12}{|c|}{ ysine Biosynthesis } \\
\hline AASDHPPT & $\begin{array}{l}\text { aminoadipate-semialdehyde } \\
\text { dehydrogenase- } \\
\text { phosphopantetheinyl } \\
\text { transferase }\end{array}$ & NM_026276 & 0.017 & 0.56 & 7.337 & 0.036 & -0.463 & 7.8 & 0.001 & -1.024 & 6.777 \\
\hline VNN1 & vanin 1 & NM_011704 & 0.003 & 0.913 & 9.747 & 0.019 & 0.614 & 9.133 & 0.173 & -0.3 & 8.834 \\
\hline $\mathrm{VNN} 2$ & vanin 2 & NM_011979 & 0.005 & 1.429 & 10.815 & 0.745 & -0.118 & 10.932 & 0.004 & -1.547 & 9.386 \\
\hline \multicolumn{12}{|c|}{ yruvate Metabolism } \\
\hline ACACA & $\begin{array}{l}\text { acetyl-Coenzyme } \\
\text { A carboxylase alpha }\end{array}$ & NM_133360 & 0.034 & 0.833 & 12.656 & 0.009 & -2.07 & 5.182 & 0.001 & -1.73 & 11.823 \\
\hline $\mathrm{ACACB}$ & $\begin{array}{l}\text { acetyl-Coenzyme } \\
\text { A carboxylase beta } \\
\text { acyl-CoA synthetase }\end{array}$ & NM_133904 & 0.03 & 1.164 & 9.508 & 0.893 & 0.059 & 9.449 & 0.036 & -1.106 & 8.344 \\
\hline ACSM5 & $\begin{array}{l}\text { medium-chain } \\
\text { family member } 5\end{array}$ & NM_178758 & 0.029 & 1.781 & 6.683 & 0.783 & -0.181 & 6.864 & 0.019 & -1.963 & 4.901 \\
\hline AKR1B10 & $\begin{array}{l}\text { aldo-keto reductase } \\
\text { family } 1, \text { member B10 } \\
\text { (aldose reductase) }\end{array}$ & NM_172398 & 0.026 & -0.34 & 11.359 & 0.023 & 0.349 & 11.01 & 0.001 & 0.69 & 11.699 \\
\hline ALDH2 & $\begin{array}{l}\text { aldehyde dehydrogenase } 2 \\
\text { family (mitochondrial) }\end{array}$ & NM_009656 & 0.022 & 0.533 & 8.298 & 0.104 & -0.302 & 13.448 & 0.003 & -0.756 & 12.692 \\
\hline ALDH5A1 & $\begin{array}{l}\text { aldehyde dehydrogenase } 5 \\
\text { family, member A1 } \\
\text { (succinate-semialdehyde } \\
\text { dehydrogenase) }\end{array}$ & NM_172532 & 0.012 & 0.802 & 10.108 & 0.459 & -0.18 & 10.288 & 0.004 & -0.982 & 9.306 \\
\hline ALDH7A1 & $\begin{array}{l}\text { aldehyde dehydrogenase } \\
7 \text { family, member A1 } \\
\text { branched chain keto acid }\end{array}$ & NM_138600 & 0.063 & 0.448 & 12.281 & 0.129 & -0.346 & 12.627 & 0.006 & -0.793 & 11.833 \\
\hline BCKDHA & $\begin{array}{l}\text { dehydrogenase } \mathrm{E} 1 \text {, alpha } \\
\text { polypeptide }\end{array}$ & NM_007533 & 0.037 & 0.655 & 13.087 & 0.968 & -0.01 & 13.097 & 0.035 & -0.666 & 12.431 \\
\hline LDHB & lactate dehydrogenase B & NM_008492 & 0.078 & 0.391 & 13.627 & 0.192 & -0.278 & 12.671 & 0.016 & -0.608 & 13.236 \\
\hline LDHD & lactate dehydrogenase D & NM_027570 & 0.033 & 0.88 & 9.491 & 0.574 & -0.179 & 9.868 & 0.055 & -0.762 & 8.611 \\
\hline NKD1 & $\begin{array}{l}\text { naked cuticle homolog } 1 \\
\text { (Drosophila) }\end{array}$ & NM_027280 & 0.147 & -0.383 & 8.007 & 0.177 & 0.353 & 6.959 & 0.021 & 0.703 & 8.389 \\
\hline NUDT7 & $\begin{array}{l}\text { nudix (nucleoside } \\
\text { diphosphate linked } \\
\text { moiety X)-type motif } 7\end{array}$ & NM_024437 & 0.001 & -0.568 & 11.735 & 0.058 & 0.313 & 12.288 & 0 & 0.776 & 12.302 \\
\hline
\end{tabular}


Continued

\begin{tabular}{|c|c|c|c|c|c|c|c|c|c|c|c|}
\hline $\mathrm{PC}$ & pyruvate carboxylase & NM_008797 & 0.053 & 0.355 & 14.585 & 0.334 & -0.157 & 14.741 & 0.013 & -0.511 & 14.23 \\
\hline PCK1 & $\begin{array}{l}\text { phosphoenolpyruvate } \\
\text { carboxykinase } 1 \text { (soluble) }\end{array}$ & NM_011044 & 0.002 & 2.193 & 12.827 & 0.783 & 0.181 & 12.921 & 0.002 & -2.229 & 10.633 \\
\hline $\begin{array}{c}\text { PDHA1 } \\
\text { (includes EG:5160) }\end{array}$ & $\begin{array}{l}\text { pyruvate dehydrogenase } \\
\text { (lipoamide) alpha } 1\end{array}$ & NM_008810 & 0.012 & 0.255 & 14.666 & 0.003 & -0.349 & 15.014 & 0 & -0.603 & 14.411 \\
\hline PDHB & $\begin{array}{l}\text { pyruvate dehydrogenase } \\
\text { (lipoamide) beta }\end{array}$ & NM_024221 & 0.306 & 0.149 & 14.083 & 0.019 & -0.774 & 10.036 & 0.006 & -0.541 & 13.934 \\
\hline RWDD2B & RWD domain containing $2 \mathrm{~B}$ & NM_016924 & 0.014 & -0.6 & 7.627 & 0.747 & 0.061 & 7.566 & 0.009 & 0.661 & 8.227 \\
\hline TCAG7.1260 & $\begin{array}{l}\text { similar to aldo-keto } \\
\text { reductase family } 1 \text {, } \\
\text { member B10 }\end{array}$ & NM_008012 & 0.059 & -0.593 & 12.179 & 0.599 & 0.143 & 12.036 & 0.027 & 0.736 & 12.772 \\
\hline \multicolumn{12}{|c|}{ Aminosugars Metabolism } \\
\hline CHI3L3 & chitinase 3 -like 3 & NM_009892 & 0.047 & -0.997 & 6.054 & 0.078 & 0.85 & 5.203 & 0.003 & 1.847 & 7.05 \\
\hline CMAH & $\begin{array}{l}\text { cytidine monophosphate- } \\
\text { N-acetylneuraminic acid } \\
\text { hydroxylase(CMP-N- } \\
\text { acetylneuraminate } \\
\text { monooxygenase) } \\
\text { pseudogene } \\
\text { cytidine monophosphate }\end{array}$ & NM_001111110 & 0.038 & 0.563 & 5.526 & 0.181 & -0.07 & 3.162 & 0.13 & -0.375 & 4.964 \\
\hline CMAS & $\begin{array}{l}\mathrm{N} \text {-acetylneuraminic acid } \\
\text { synthetase }\end{array}$ & NM_009908 & 0.102 & -0.223 & 11.727 & 0.034 & 0.314 & 11.413 & 0.003 & 0.537 & 11.95 \\
\hline CYB561 & cytochrome b-561 & BE133856 & 0.231 & 0.052 & 2.178 & 0.146 & 0.39 & 9.951 & 0.049 & 0.571 & 10.522 \\
\hline HK1 & hexokinase 1 & NM_010438 & 0.042 & 0.813 & 7.697 & 0.195 & 0.464 & 7.233 & 0.316 & -0.349 & 6.884 \\
\hline $\mathrm{HK} 2$ & hexokinase 2 & NM_013820 & 0.31 & 0.195 & 11.454 & 0.024 & -0.519 & 11.973 & 0.006 & -0.713 & 11.259 \\
\hline HK3 & hexokinase 3 (white cell) & NM_001033245 & 0.03 & -0.966 & 8.121 & 0.017 & 1.122 & 6.999 & 0.001 & 2.087 & 9.086 \\
\hline NANS & $\begin{array}{l}\text { N-acetylneuraminic } \\
\text { acid synthase } \\
\text { (sialic acid synthase) }\end{array}$ & NM_053179 & 0.002 & -0.663 & 9.19 & 0.025 & 0.229 & 11.614 & 0 & 0.545 & 12.159 \\
\hline PDE1A & $\begin{array}{l}\text { phosphodiesterase } 1 \mathrm{~A}, \\
\text { calmodulin-dependent }\end{array}$ & NM_001009978 & 0.003 & 1.239 & 8.699 & 0.059 & -0.608 & 9.306 & 0 & -1.847 & 7.46 \\
\hline PDE2A & $\begin{array}{l}\text { phosphodiesterase } 2 \mathrm{~A}, \\
\text { cGMP-stimulated }\end{array}$ & NM_001008548 & 0.148 & -0.252 & 10.092 & 0.004 & 0.683 & 9.41 & 0.001 & 0.935 & 10.345 \\
\hline PDE3B & $\begin{array}{l}\text { phosphodiesterase } 3 \mathrm{~B}, \\
\text { cGMP-inhibited }\end{array}$ & NM_011055 & 0.003 & 0.491 & 13.119 & 0.129 & -0.179 & 13.298 & 0 & -0.67 & 12.628 \\
\hline PDE4B & $\begin{array}{l}\text { phosphodiesterase } 4 \mathrm{~B}, \\
\text { cAMP-specific } \\
\text { (phosphodiesterase E4 } \\
\text { dunce homolog, Drosophila) }\end{array}$ & NM_019840 & 0 & 1.104 & 8.99 & 0.001 & 0.883 & 8.107 & 0.222 & -0.222 & 7.885 \\
\hline PDE7A & phosphodiesterase 7A & NM_001122759 & 0.14 & -0.436 & 8.998 & 0.003 & 1.237 & 8.55 & 0.001 & 1.448 & 9.997 \\
\hline PDE7B & phosphodiesterase 7B & NM_013875 & 0.11 & -0.672 & 9.416 & 0.113 & 0.666 & 8.75 & 0.009 & 1.339 & 10.088 \\
\hline PDE8B & phosphodiesterase 8B & NM_172263 & 0.043 & -1.083 & 3.146 & 0.803 & 0.111 & 3.035 & 0.03 & 1.194 & 4.229 \\
\hline PGM3 & phosphoglucomutase 3 & NM_028352 & 0.135 & 0.35 & 8.521 & 0.451 & -0.164 & 8.685 & 0.044 & -0.514 & 8.172 \\
\hline RENBP & renin binding protein & NM_023132 & 0.019 & -0.632 & 10.641 & 0.029 & 0.571 & 10.07 & 0.001 & 1.204 & 11.273 \\
\hline UAP1 & $\begin{array}{l}\text { UDP-N-acteylglucosamine } \\
\text { pyrophosphorylase } 1\end{array}$ & NM_133806 & 0.006 & 0.434 & 10.855 & 0.123 & -0.229 & 9.853 & 0.002 & -0.547 & 10.421 \\
\hline \multicolumn{12}{|c|}{ Phenylalanine Metabolism } \\
\hline ALDH2 & $\begin{array}{l}\text { aldehyde dehydrogenase } 2 \\
\text { family (mitochondrial) }\end{array}$ & NM_009656 & 0.022 & 0.533 & 8.298 & 0.104 & -0.302 & 13.448 & 0.003 & -0.756 & 12.692 \\
\hline ALDH3B1 & $\begin{array}{l}\text { aldehyde dehydrogenase } 3 \\
\text { family, member B1 } \\
\text { amine oxidase, copper }\end{array}$ & NM_026316 & 0.017 & -0.56 & 7.848 & 0.046 & 0.431 & 7.417 & 0.001 & 0.992 & 8.409 \\
\hline AOC3 & $\begin{array}{l}\text { containing } 3 \text { (vascular } \\
\text { adhesion protein } 1 \text { ) }\end{array}$ & NM_009675 & 0.005 & 0.53 & 14.416 & 0.186 & -0.191 & 14.607 & 0.001 & -0.721 & 13.886 \\
\hline DBT & $\begin{array}{l}\text { dihydrolipoamide branched } \\
\text { chain transacylase E2 }\end{array}$ & NM_010022 & 0.024 & 0.641 & 10.512 & 0.138 & -0.369 & 10.882 & 0.003 & -1.01 & 9.871 \\
\hline
\end{tabular}




\section{Continued}

\begin{tabular}{|c|c|c|c|c|c|c|c|c|c|c|c|}
\hline DHCR24 & $\begin{array}{l}\text { 24-dehydrocholesterol } \\
\text { reductase }\end{array}$ & NM_053272 & 0.012 & -0.788 & 8.527 & 0.869 & 0.039 & 8.489 & 0.009 & 0.827 & 9.315 \\
\hline GOT1 & $\begin{array}{l}\text { glutamic-oxaloacetic } \\
\text { transaminase } 1, \text { soluble } \\
\text { (aspartate aminotransferase } 1 \text { ) }\end{array}$ & NM_010324 & 0.798 & -0.052 & 9.489 & 0.038 & 0.51 & 8.978 & 0.026 & 0.563 & 9.541 \\
\hline MAOA & monoamine oxidase A & NM_173740 & 0.01 & -0.523 & 12.262 & 0.582 & -0.229 & 7.565 & 0.008 & 0.559 & 12.784 \\
\hline MAOB & monoamine oxidase B & NM_172778 & 0.038 & 0.463 & 12.2 & 0.035 & -0.473 & 12.673 & 0.002 & -0.936 & 11.737 \\
\hline MIF & $\begin{array}{l}\text { macrophage migration } \\
\text { inhibitory factor } \\
\text { (glycosylation-inhibiting } \\
\text { factor) }\end{array}$ & NM_010798 & 0.049 & -0.256 & 13.282 & 0.037 & 0.277 & 13.005 & 0.002 & 0.534 & 13.539 \\
\hline \multicolumn{12}{|c|}{ Tyrosine Metabolism } \\
\hline ADHFE1 & $\begin{array}{l}\text { alcohol dehydrogenase, iron } \\
\text { containing, } 1\end{array}$ & NM_175236 & 0.024 & 0.506 & 13.325 & 0.188 & -0.253 & 13.578 & 0.004 & -0.76 & 12.819 \\
\hline ALDH2 & $\begin{array}{l}\text { aldehyde dehydrogenase } \\
2 \text { family (mitochondrial) }\end{array}$ & NM_009656 & 0.022 & 0.533 & 8.298 & 0.104 & -0.302 & 13.448 & 0.003 & -0.756 & 12.692 \\
\hline ALDH3B1 & $\begin{array}{l}\text { aldehyde dehydrogenase } \\
3 \text { family, member B1 } \\
\text { amine oxidase, copper }\end{array}$ & NM_026316 & 0.017 & -0.56 & 7.848 & 0.046 & 0.431 & 7.417 & 0.001 & 0.992 & 8.409 \\
\hline $\mathrm{AOC} 3$ & $\begin{array}{l}\text { containing } 3 \text { (vascular } \\
\text { adhesion protein } 1 \text { ) } \\
\text { branched chain keto acid }\end{array}$ & NM_009675 & 0.005 & 0.53 & 14.416 & 0.186 & -0.191 & 14.607 & 0.001 & -0.721 & 13.886 \\
\hline BCKDHA & $\begin{array}{l}\text { dehydrogenase } \\
\text { E1, alpha polypeptide }\end{array}$ & NM_007533 & 0.037 & 0.655 & 13.087 & 0.968 & -0.01 & 13.097 & 0.035 & -0.666 & 12.431 \\
\hline DBT & $\begin{array}{l}\text { dihydrolipoamide branched } \\
\text { chain transacylase E2 }\end{array}$ & NM_010022 & 0.024 & 0.641 & 10.512 & 0.138 & -0.369 & 10.882 & 0.003 & -1.01 & 9.871 \\
\hline FRRS1 & ferric-chelate reductase 1 & NM_001113478 & 0.039 & -0.542 & 9.868 & 0.038 & 0.545 & 9.323 & 0.002 & 1.087 & 10.41 \\
\hline GOT1 & $\begin{array}{l}\text { glutamic-oxaloacetic } \\
\text { transaminase } 1, \text { soluble } \\
\text { (aspartate aminotransferase } 1 \text { ) }\end{array}$ & NM_010324 & 0.798 & -0.052 & 9.489 & 0.038 & 0.51 & 8.978 & 0.026 & 0.563 & 9.541 \\
\hline MAOA & monoamine oxidase A & NM_173740 & 0.01 & -0.523 & 12.262 & 0.582 & -0.229 & 7.565 & 0.008 & 0.559 & 12.784 \\
\hline MAOB & monoamine oxidase B & NM_172778 & 0.038 & 0.463 & 12.2 & 0.035 & -0.473 & 12.673 & 0.002 & -0.936 & 11.737 \\
\hline MIF & $\begin{array}{l}\text { macrophage migration } \\
\text { inhibitory factor } \\
\text { (glycosylation-inhibiting } \\
\text { factor) }\end{array}$ & NM_010798 & 0.049 & -0.256 & 13.282 & 0.037 & 0.277 & 13.005 & 0.002 & 0.534 & 13.539 \\
\hline \multicolumn{12}{|c|}{ Histidine Metabolism } \\
\hline ALDH2 & $\begin{array}{l}\text { aldehyde dehydrogenase } \\
2 \text { family (mitochondrial) }\end{array}$ & NM_009656 & 0.022 & 0.533 & 8.298 & 0.104 & -0.302 & 13.448 & 0.003 & -0.756 & 12.692 \\
\hline ALDH3B1 & $\begin{array}{l}\text { aldehyde dehydrogenase } \\
3 \text { family, member B1 }\end{array}$ & NM_026316 & 0.017 & -0.56 & 7.848 & 0.046 & 0.431 & 7.417 & 0.001 & 0.992 & 8.409 \\
\hline ALDH5A1 & $\begin{array}{l}\text { aldehyde dehydrogenase } \\
5 \text { family, member A1 } \\
\text { (succinate-semialdehyde } \\
\text { dehydrogenase) }\end{array}$ & NM_172532 & 0.012 & 0.802 & 10.108 & 0.459 & -0.18 & 10.288 & 0.004 & -0.982 & 9.306 \\
\hline ALDH7A1 & $\begin{array}{l}\text { aldehyde dehydrogenase } \\
7 \text { family, member A1 } \\
\text { amine oxidase, copper }\end{array}$ & NM_138600 & 0.063 & 0.448 & 12.281 & 0.129 & -0.346 & 12.627 & 0.006 & -0.793 & 11.833 \\
\hline $\mathrm{AOC} 3$ & $\begin{array}{l}\text { containing } 3 \text { (vascular } \\
\text { adhesion protein } 1)\end{array}$ & NM_009675 & 0.005 & 0.53 & 14.416 & 0.186 & -0.191 & 14.607 & 0.001 & -0.721 & 13.886 \\
\hline DBT & $\begin{array}{l}\text { dihydrolipoamide branched } \\
\text { chain transacylase E2 }\end{array}$ & NM_010022 & 0.024 & 0.641 & 10.512 & 0.138 & -0.369 & 10.882 & 0.003 & -1.01 & 9.871 \\
\hline HARS2 & $\begin{array}{l}\text { histidyl-tRNA synthetase } 2 \text {, } \\
\text { mitochondrial (putative) }\end{array}$ & NM_080636 & 0.014 & 0.56 & 9.206 & 0.522 & 0.12 & 5.406 & 0.02 & -0.516 & 8.646 \\
\hline HNMT & $\begin{array}{l}\text { histamine } \\
\text { N-methyltransferase }\end{array}$ & NM_080462 & 0.018 & 0.452 & 11.034 & 0.211 & -0.199 & 11.233 & 0.003 & -0.651 & 10.582 \\
\hline MAOA & monoamine oxidase A & NM_173740 & 0.01 & -0.523 & 12.262 & 0.582 & -0.229 & 7.565 & 0.008 & 0.559 & 12.784 \\
\hline MAOB & monoamine oxidase B & NM_172778 & 0.038 & 0.463 & 12.2 & 0.035 & -0.473 & 12.673 & 0.002 & -0.936 & 11.737 \\
\hline PRPS1 & $\begin{array}{l}\text { phosphoribosyl } \\
\text { pyrophosphate } \\
\text { synthetase } 1 \\
\end{array}$ & NM_021463 & 0.038 & -0.472 & 13.71 & 0.005 & 0.76 & 12.225 & 0 & 1.185 & 13.41 \\
\hline
\end{tabular}


Continued

Galactose Metabolism

\begin{tabular}{|c|c|}
\hline AKR1B10 & $\begin{array}{l}\text { aldo-keto reductase } \\
\text { family } 1, \text { member B10 } \\
\text { (aldose reductase) }\end{array}$ \\
\hline GAA & $\begin{array}{l}\text { glucosidase, alpha; acid } \\
\text { (Pompe disease, glycogen } \\
\text { storage disease type II) }\end{array}$ \\
\hline GLA & galactosidase, alpha \\
\hline GLB1 & galactosidase, beta 1 \\
\hline GLB1L & galactosidase, beta 1-like \\
\hline GLB1L2 & galactosidase, beta 1 -like 2 \\
\hline HK1 & hexokinase 1 \\
\hline HK2 & hexokinase 2 \\
\hline HK3 & hexokinase 3 (white cell) \\
\hline PFKM & $\begin{array}{l}\text { phosphofructokinase, } \\
\text { muscle }\end{array}$ \\
\hline PGM1 & phosphoglucomutase 1 \\
\hline PGM3 & phosphoglucomutase 3 \\
\hline TCAG7.1260 & $\begin{array}{l}\text { similar to aldo-keto } \\
\text { reductase family } 1 \text {, } \\
\text { member B } 10\end{array}$ \\
\hline UGP2 & $\begin{array}{l}\text { UDP-glucose } \\
\text { pyrophosphorylase } 2\end{array}$ \\
\hline
\end{tabular}

\section{Fatty Acid Metabolism}

\begin{tabular}{|c|c|}
\hline $0330120 \mathrm{D} 0$ & RIKEN cDNA \\
\hline 9330I29D0SRIK & 9330129D05 gene \\
\hline ACAA1B & $\begin{array}{l}\text { acetyl-Coenzyme } \\
\text { A acyltransferase } 1 \mathrm{~B}\end{array}$ \\
\hline ACAD10 & $\begin{array}{l}\text { acyl-Coenzyme A } \\
\text { dehydrogenase } \\
\text { family, member } 10\end{array}$ \\
\hline ACAD11 & $\begin{array}{l}\text { acyl-Coenzyme A } \\
\text { dehydrogenase } \\
\text { family, member } 11\end{array}$ \\
\hline ACAD8 & $\begin{array}{l}\text { acyl-Coenzyme A } \\
\text { dehydrogenase } \\
\text { family, member } 8\end{array}$ \\
\hline ACADSB & $\begin{array}{l}\text { acyl-Coenzyme A } \\
\text { dehydrogenase, } \\
\text { short/branched chain }\end{array}$ \\
\hline $\mathrm{ACOX} 3$ & $\begin{array}{l}\text { acyl-Coenzyme } \\
\text { A oxidase } 3 \text {, pristanoyl }\end{array}$ \\
\hline ADHFE1 & $\begin{array}{l}\text { alcohol dehydrogenase, } \\
\text { iron containing, } 1\end{array}$ \\
\hline ALDH2 & $\begin{array}{l}\text { aldehyde dehydrogenase } \\
2 \text { family (mitochondrial) }\end{array}$ \\
\hline ALDH5A1 & $\begin{array}{l}\text { aldehyde dehydrogenase } \\
5 \text { family, member A1 } \\
\text { (succinate-semialdehyde } \\
\text { dehydrogenase) }\end{array}$ \\
\hline ALDH7A1 & $\begin{array}{l}\text { aldehyde dehydrogenase } \\
7 \text { family, member A1 }\end{array}$ \\
\hline CPT1A & $\begin{array}{l}\text { carnitine palmitoyltransferase } \\
\text { 1A (liver) }\end{array}$ \\
\hline CYP2C44 & $\begin{array}{l}\text { cytochrome P450, family } 2, \\
\text { subfamily c, polypeptide } 44\end{array}$ \\
\hline CYP2C70 & $\begin{array}{l}\text { cytochrome } \mathrm{P} 450 \text {, family } 2 \text {, } \\
\text { subfamily c, polypeptide } 70\end{array}$ \\
\hline
\end{tabular}

\begin{tabular}{|c|c|c|c|c|c|c|c|c|c|}
\hline NM_172398 & 0.026 & -0.34 & 11.359 & 0.023 & 0.349 & 11.01 & 0.001 & 0.69 & 11.699 \\
\hline NM 008064 & 0.003 & 0.668 & 10.984 & 0.395 & 0.133 & 10.851 & 0.006 & -0.318 & 9.011 \\
\hline NM_013463 & 0.045 & -1.008 & 8.5 & 0.051 & 0.969 & 7.53 & 0.002 & 1.977 & 9.508 \\
\hline AW553762 & 0.044 & 0.917 & 7.97 & 0.004 & 0.282 & 10.92 & 0.001 & 0.369 & 11.288 \\
\hline BB207162 & 0.005 & 0.636 & 8.014 & 0.207 & -0.019 & 2.343 & 0.006 & -0.615 & 7.378 \\
\hline NM 153803 & 0.028 & 0.508 & 14.096 & 0.033 & -0.47 & 13.134 & 0.002 & -0.879 & 12.256 \\
\hline NM 010438 & 0.042 & 0.813 & 7.697 & 0.195 & 0.464 & 7.233 & 0.316 & -0.349 & 6.884 \\
\hline NM 013820 & 0.31 & 0.195 & 11.454 & 0.024 & -0.519 & 11.973 & 0.006 & -0.713 & 11.259 \\
\hline NM 001033245 & 0.03 & -0.966 & 8.121 & 0.017 & 1.122 & 6.999 & 0.001 & 2.087 & 9.086 \\
\hline NM_021514 & 0.031 & 0.497 & 9.384 & 0.311 & -0.198 & 9.582 & 0.007 & -0.694 & 8.888 \\
\hline NM_025700 & 0.07 & 0.346 & 13.557 & 0.353 & -0.16 & 13.716 & 0.018 & -0.506 & 13.21 \\
\hline NM_028352 & 0.135 & 0.35 & 8.521 & 0.451 & -0.164 & 8.685 & 0.044 & -0.514 & 8.172 \\
\hline NM_008012 & 0.059 & -0.593 & 12.179 & 0.599 & 0.143 & 12.036 & 0.027 & 0.736 & 12.772 \\
\hline NM_139297 & 0.009 & 0.325 & 13.374 & 0.002 & -0.468 & 11.745 & 0 & -0.747 & 10.998 \\
\hline XM_488540 & 0.003 & 1.082 & 9.448 & 0.298 & 0.26 & 9.188 & 0.011 & -0.822 & 8.366 \\
\hline NM_130864 & 0.138 & -0.285 & 13.107 & 0.009 & 0.617 & 12.489 & 0.001 & 0.902 & 13.391 \\
\hline NM_028037 & 0.008 & 0.906 & 8.387 & 0.37 & 0.068 & 2.183 & 0.003 & -1.1 & 7.481 \\
\hline NM 028721 & 0.009 & 0.587 & 12.508 & 0.376 & 0.185 & 13.851 & 0.03 & -0.442 & 11.922 \\
\hline NM_025862 & 0.005 & 0.537 & 9.194 & 0.004 & -0.559 & 9.753 & 0 & -1.097 & 8.657 \\
\hline NM 025826 & 0.023 & 0.505 & 12.485 & 0.09 & -0.338 & 12.823 & 0.002 & -0.843 & 11.98 \\
\hline NM_030721 & 0.324 & 0.182 & 7.467 & 0.014 & 0.571 & 6.896 & 0.061 & 0.388 & 7.285 \\
\hline NM_175236 & 0.024 & 0.506 & 13.325 & 0.188 & -0.253 & 13.578 & 0.004 & -0.76 & 12.819 \\
\hline NM_009656 & 0.022 & 0.533 & 8.298 & 0.104 & -0.302 & 13.448 & 0.003 & -0.756 & 12.692 \\
\hline NM_172532 & 0.012 & 0.802 & 10.108 & 0.459 & -0.18 & 10.288 & 0.004 & -0.982 & 9.306 \\
\hline NM_138600 & 0.063 & 0.448 & 12.281 & 0.129 & -0.346 & 12.627 & 0.006 & -0.793 & 11.833 \\
\hline NM_013495 & 0.609 & 0.073 & 12.711 & 0.005 & 0.578 & 12.134 & 0.009 & 0.505 & 12.638 \\
\hline NM_001001446 & 0.001 & -2.814 & 5.549 & 0.002 & 2.405 & 3.144 & 0 & 5.219 & 8.363 \\
\hline NM_145499 & 0.038 & -1.289 & 2.723 & 0.426 & 0.418 & 2.305 & 0.012 & 1.707 & 4.012 \\
\hline
\end{tabular}




\section{Continued}

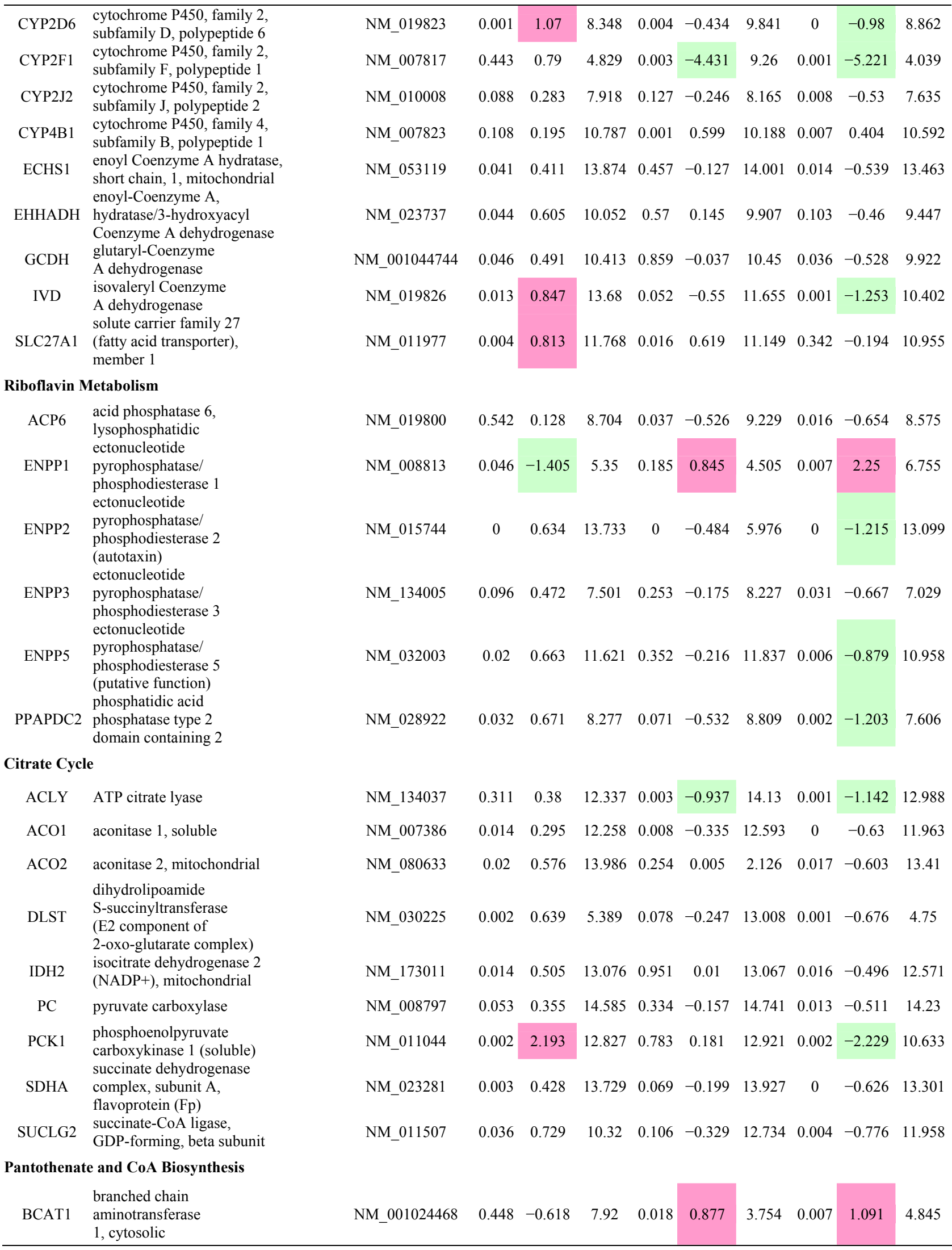




\section{Continued}

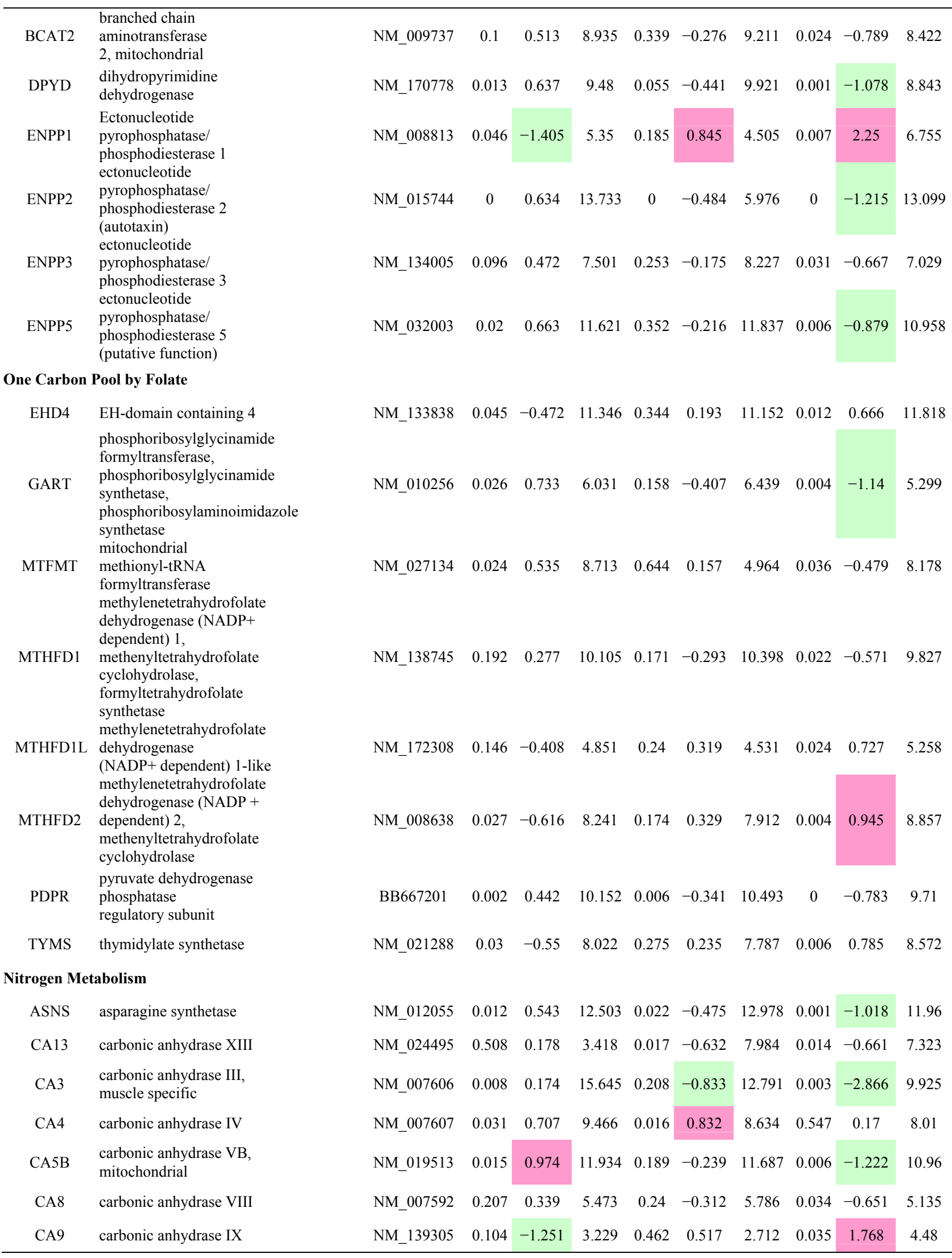




$\begin{array}{cl}\text { CTH } & \begin{array}{l}\text { cystathionase } \\ \text { (cystathionine } \\ \text { gamma-lyase) } \\ \text { pyruvate dehydrogenase } \\ \text { phosphatase } \\ \text { regulatory subunit } \\ \text { protein tyrosine } \\ \text { phosphatase, } \\ \text { receptor type, G } \\ \text { PTPRG }\end{array} \\ & \text { vanin 1 } \\ \text { VNN1 } & \text { vanin 2 }\end{array}$

\section{Alanine and Aspartate Metabolism}

$\begin{array}{cl}\text { ADSL } & \begin{array}{l}\text { adenylosuccinate lyase } \\ \text { adenylosuccinate synthase } \\ \text { like 1 }\end{array} \\ \text { ADSSL1 } & \begin{array}{c}\text { asparagine synthetase } \\ \text { ASS1 }\end{array} \\ \text { CRAT } & \text { carnitine acetyltransferase } \\ \text { DDO } & \begin{array}{l}\text { D-aspartate oxidase } \\ \text { glutamic-oxaloacetic } \\ \text { transaminase 1, soluble } \\ \text { (aspartate aminotransferase 1) } \\ \text { glutamic pyruvate } \\ \text { transaminase (alanine } \\ \text { aminotransferase) } 2\end{array} \\ \text { GPT1 } & \begin{array}{l}\text { pyruvate carboxylase } \\ \text { pyruvate dehydrogenase } \\ \text { (lipoamide) alpha 1 } \\ \text { pyruvate dehydrogenase } \\ \text { (lipoamide) beta }\end{array} \\ \text { PC } & \begin{array}{l}\text { PDH1 } \\ \text { PDHB }\end{array}\end{array}$

\begin{tabular}{cccccccccccc} 
NM_009634 & 0.198 & 0.28 & 10.082 & 0.214 & -0.269 & 10.351 & 0.029 & -0.55 & 9.801 \\
\hline NM_007421 & 0.023 & -0.956 & 9.522 & 0.016 & 1.041 & 8.481 & 0.001 & 1.996 & 10.477 \\
NM_012055 & 0.012 & 0.543 & 12.503 & 0.022 & -0.475 & 12.978 & 0.001 & -1.018 & 11.96 \\
\hline NM_007494 & 0.002 & -1.845 & 6.465 & 0.694 & 0.154 & 6.31 & 0.002 & 1.999 & 8.309 \\
NM_007760 & 0.003 & 0.607 & 11.47 & 0.312 & 0.123 & 4.974 & 0.002 & -0.617 & 10.863 \\
NM_027442 & 0.043 & 0.662 & 7.798 & 0.144 & -0.436 & 8.234 & 0.005 & -1.099 & 7.136 \\
\hline NM_010324 & 0.798 & -0.052 & 9.489 & 0.038 & 0.51 & 8.978 & 0.026 & 0.563 & 9.541 \\
& & & & & & & & & & & \\
\hline NM_173866 & 0.02 & 0.917 & 11.372 & 0.027 & -0.589 & 11.014 & 0.001 & -1.195 & 9.819 \\
\hline NM_008797 & 0.053 & 0.355 & 14.585 & 0.334 & -0.157 & 14.741 & 0.013 & -0.511 & 14.23 \\
NM_008810 & 0.012 & 0.255 & 14.666 & 0.003 & -0.349 & 15.014 & 0 & -0.603 & 14.411 \\
NM_024221 & 0.306 & 0.149 & 14.083 & 0.019 & -0.774 & 10.036 & 0.006 & -0.541 & 13.934
\end{tabular}

\section{Inositol Phosphate Metabolism}

\begin{tabular}{|c|c|c|c|c|c|c|c|c|c|c|c|}
\hline $\operatorname{ACVR} 2 \mathrm{~A}$ & activin A receptor, type IIA & NM_007396 & 0.06 & -0.395 & 5.998 & 0.109 & 0.322 & 5.676 & 0.005 & 0.717 & 6.393 \\
\hline AKT2 & $\begin{array}{l}\text { v-akt murine thymoma } \\
\text { viral oncogene homolog } 2\end{array}$ & NM_00111020 & 0.02 & 0.692 & 11.06 & 0.489 & 0.164 & 10.896 & 0.016 & -0.439 & 13 \\
\hline ARAF & $\begin{array}{l}\text { v-raf murine sarcoma } 3611 \\
\text { viral oncogene homolog }\end{array}$ & NM_009703 & 0.038 & 0.376 & 10.45 & 0.258 & 0.245 & 11.406 & 0.02 & -0.912 & 3.647 \\
\hline $\mathrm{CDC} 2$ & $\begin{array}{l}\text { cell division cycle } 2, \mathrm{G} 1 \text { to } \mathrm{S} \\
\text { and } \mathrm{G} 2 \text { to } \mathrm{M}\end{array}$ & NM_007659 & 0.013 & -1.395 & 8.342 & 0.02 & 1.253 & 7.088 & 0 & 2.648 & 9.736 \\
\hline CDK6 & cyclin-dependent kinase 6 & NM_009873 & 0.024 & -0.762 & 9.029 & 0.093 & 0.629 & 7.834 & 0.003 & 1.211 & 9.791 \\
\hline CDK7 & cyclin-dependent kinase 7 & NM_009874 & 0.043 & -0.591 & 5.752 & 0.161 & -0.283 & 6.617 & 0.023 & -0.533 & 6.084 \\
\hline CSNK1D & casein kinase 1 , delta & NM_027874 & 0.036 & 0.593 & 10.45 & 0.253 & -0.043 & 2.526 & 0.026 & -0.345 & 9.897 \\
\hline EIF2AK2 & $\begin{array}{l}\text { eukaryotic translation } \\
\text { initiation factor 2-alpha } \\
\text { kinase } 2\end{array}$ & NM_011163 & 0.034 & 0.58 & 6.376 & 0.261 & 0.163 & 6.524 & 0.088 & -0.433 & 5.796 \\
\hline GRK5 & $\begin{array}{l}\text { G protein-coupled receptor } \\
\text { kinase } 5\end{array}$ & NM_018869 & 0.166 & -0.242 & 10.366 & 0.028 & 0.436 & 9.93 & 0.004 & 0.678 & 10.608 \\
\hline INPP1 & $\begin{array}{l}\text { inositol } \\
\text { polyphosphate-1-phosphatase } \\
\text { inositol }\end{array}$ & NM_008384 & 0.012 & 0.798 & 8.696 & 0.987 & 0.004 & 8.692 & 0.013 & -0.794 & 7.898 \\
\hline INPP5D & $\begin{array}{l}\text { polyphosphate-5-phosphatase, } \\
145 \mathrm{kDa}\end{array}$ & NM_001110192 & 0.028 & -0.539 & 7.477 & 0.083 & 0.388 & 6.693 & 0.006 & 0.776 & 8.016 \\
\hline INPP5E & $\begin{array}{l}\text { Inositol } \\
\text { polyphosphate-5-phosphatase, } \\
72 \mathrm{kDa} \\
\text { interleukin-1 }\end{array}$ & NM_033134 & 0.036 & 0.373 & 8.194 & 0.202 & -0.2 & 8.394 & 0.006 & -0.573 & 7.821 \\
\hline IRAK1 & $\begin{array}{l}\text { receptor-associated } \\
\text { kinase } 1\end{array}$ & NM_008363 & 0.008 & 0.417 & 11.985 & 0.062 & -0.131 & 8.168 & 0.003 & -0.53 & 11.568 \\
\hline
\end{tabular}




\section{Continued}

\begin{tabular}{|c|c|c|c|c|c|c|c|c|c|c|c|}
\hline MAPK9 & $\begin{array}{l}\text { mitogen-activated } \\
\text { protein kinase } 9\end{array}$ & NM_016961 & 0.06 & 0.215 & 7.449 & 0.012 & -0.33 & 7.779 & 0.001 & -0.545 & 7.234 \\
\hline NEK2 & $\begin{array}{l}\text { NIMA (never in } \\
\text { mitosis gene } \\
\text { a)-related kinase } 2\end{array}$ & BB203873 & 0.253 & 0.012 & 2.135 & 0.051 & 1.088 & 3.839 & 0.024 & 1.33 & 5.169 \\
\hline PAK1 & $\begin{array}{l}\text { p21/Cdc42/Rac1-activated } \\
\text { kinase } 1 \text { (STE20 homolog, } \\
\text { yeast) }\end{array}$ & NM_011035 & 0.036 & -0.962 & 7.984 & 0.301 & 0.477 & 7.838 & 0.013 & 1.446 & 9.283 \\
\hline PCTK3 & PCTAIRE protein kinase 3 & NM_008795 & 0.052 & -1.766 & 6.542 & 0.001 & 3.965 & 2.577 & 0 & 5.73 & 8.308 \\
\hline PI4K2A & $\begin{array}{l}\text { phosphatidylinositol } \\
\text { 4-kinase type } 2 \text { alpha }\end{array}$ & NM_145501 & 0.013 & -0.277 & 11.346 & 0.002 & 0.453 & 7.825 & 0 & 0.619 & 11.623 \\
\hline PI4K2B & $\begin{array}{l}\text { phosphatidylinositol } \\
\text { 4-kinase type } 2 \text { beta }\end{array}$ & NM_025951 & 0.056 & -0.355 & 8.647 & 0.018 & 0.693 & 6.639 & 0.002 & 0.749 & 9.001 \\
\hline PIK3CA & $\begin{array}{l}\text { phosphoinositide-3-kinase, } \\
\text { catalytic, alpha polypeptide }\end{array}$ & NM_008839 & 0.001 & 0.645 & 6.755 & 0.127 & -0.249 & 7.833 & 0 & -0.815 & 6.11 \\
\hline PIK3CD & $\begin{array}{l}\text { phosphoinositide-3-kinase, } \\
\text { catalytic, delta polypeptide }\end{array}$ & NM_001029837 & 0.053 & -0.548 & 6.216 & 0.256 & -0.386 & 9.26 & 0.012 & 0.813 & 6.764 \\
\hline PIK3R1 & $\begin{array}{l}\text { phosphoinositide-3-kinase, } \\
\text { regulatory subunit } 1 \text { (alpha) }\end{array}$ & NM_001024955 & 0.009 & 0.628 & 9.645 & 0.001 & -0.697 & 13.043 & 0 & -1.402 & 9.017 \\
\hline PIK3R3 & $\begin{array}{l}\text { phosphoinositide-3-kinase, } \\
\text { regulatory subunit } 3 \text { (gamma) }\end{array}$ & NM_181585 & 0.281 & -0.286 & 7.827 & 0.06 & 0.555 & 7.271 & 0.012 & 0.841 & 8.112 \\
\hline PIM1 & pim-1 oncogene & NM_008842 & 0.032 & -1.3 & 3.545 & 0.459 & 0.18 & 8.558 & 0.06 & 1.086 & 4.845 \\
\hline PIP5K1C & $\begin{array}{l}\text { phosphatidylinositol-4- } \\
\text { phosphate 5-kinase, } \\
\text { type I, gamma }\end{array}$ & NM_008844 & 0.057 & -0.483 & 9.721 & 0.647 & 0.1 & 9.621 & 0.029 & 0.582 & 10.204 \\
\hline PLCB4 & phospholipase $\mathrm{C}$, beta 4 & NM_013829 & 0.015 & 1.036 & 4.286 & 0.28 & -0.212 & 10.733 & 0.01 & -1.154 & 3.251 \\
\hline PLCD1 & phospholipase C, delta 1 & NM_019676 & 0.013 & 0.645 & 10.652 & 0.094 & -0.374 & 11.027 & 0.001 & -1.019 & 10.007 \\
\hline PLCD3 & phospholipase $\mathrm{C}$, delta 3 & NM_152813 & 0.056 & 0.609 & 6.56 & 0.478 & -0.196 & 6.756 & 0.02 & -0.806 & 5.951 \\
\hline PLCG2 & $\begin{array}{l}\text { phospholipase C, } \\
\text { gamma } 2 \\
\text { (phosphatidylinositol-specific) }\end{array}$ & NM_172285 & 0.014 & -0.475 & 9.296 & 0.439 & 0.116 & 9.181 & 0.005 & 0.591 & 9.771 \\
\hline PLCL2 & phospholipase C-like 2 & NM_013880 & 0.031 & -0.398 & 9.447 & 0.301 & 0.161 & 9.285 & 0.007 & 0.559 & 9.844 \\
\hline PRKAA1 & $\begin{array}{l}\text { protein kinase, } \\
\text { AMP-activated, alpha } 1 \\
\text { catalytic subunit }\end{array}$ & NM_001013367 & 0.009 & 0.408 & 6.52 & 0.001 & -0.631 & 7.151 & 0 & -1.039 & 6.112 \\
\hline PRKCD & protein kinase $\mathrm{C}$, delta & NM_011103 & 0.15 & -0.273 & 11.239 & 0.033 & 0.451 & 10.788 & 0.004 & 0.724 & 11.512 \\
\hline PRKCH & protein kinase $\mathrm{C}$, eta & NM_008856 & 0.087 & -0.743 & 10.472 & 0.027 & 0.997 & 7.892 & 0.003 & 1.594 & 9.486 \\
\hline PRPF4B & $\begin{array}{l}\text { PRP4 pre-mRNA processing } \\
\text { factor } 4 \text { homolog B (yeast) }\end{array}$ & NM_013830 & 0.008 & 0.345 & 8.006 & 0.071 & -0.264 & 9.994 & 0.002 & -0.563 & 8.844 \\
\hline \multicolumn{12}{|c|}{ Glycosaminoglycan Degradation } \\
\hline AFP & alpha-fetoprotein & NM_007423 & 0.068 & -1.708 & 2.718 & 0.114 & 0.381 & 3.333 & 0.022 & 0.631 & 3.964 \\
\hline CHI3L3 & chitinase 3-like 3 & NM_009892 & 0.047 & -0.997 & 6.054 & 0.078 & 0.85 & 5.203 & 0.003 & 1.847 & 7.05 \\
\hline GALNS & $\begin{array}{l}\text { galactosamine ( } \mathrm{N} \text {-acetyl)- } \\
\text { 6-sulfate sulfatase } \\
\text { (Morquio syndrome, } \\
\text { mucopolysaccharidosis } \\
\text { type IVA) }\end{array}$ & NM_016722 & 0.129 & -0.279 & 9.491 & 0.08 & 0.334 & 9.157 & 0.008 & 0.613 & 9.77 \\
\hline GLB1 & galactosidase, beta 1 & AW553762 & 0.044 & 0.917 & 7.97 & 0.004 & 0.282 & 10.92 & 0.001 & 0.369 & 11.288 \\
\hline GLB1L & galactosidase, beta 1-like & BB207162 & 0.005 & 0.636 & 8.014 & 0.207 & -0.019 & 2.343 & 0.006 & -0.615 & 7.378 \\
\hline GLB1L2 & galactosidase, beta 1-like 2 & NM_153803 & 0.028 & 0.508 & 14.096 & 0.033 & -0.47 & 13.134 & 0.002 & -0.879 & 12.256 \\
\hline GUSB & glucuronidase, beta & NM_010368 & 0.101 & -0.432 & 12.27 & 0.023 & 0.747 & 10.177 & 0.002 & 1.093 & 12.702 \\
\hline IDS & $\begin{array}{l}\text { iduronate 2-sulfatase } \\
\text { (Hunter syndrome) }\end{array}$ & NM_001038990 & 0.025 & 0.303 & 7.605 & 0.028 & -0.268 & 12.593 & 0.001 & -0.527 & 12.066 \\
\hline MGEA5 & $\begin{array}{l}\text { meningioma expressed } \\
\text { antigen } 5 \text { (hyaluronidase) }\end{array}$ & NM_023799 & 0.004 & 0.38 & 10.546 & 0.074 & -0.234 & 12.444 & 0.001 & -0.535 & 10.166 \\
\hline SULF1 & sulfatase 1 & NM_172294 & 0.074 & 0.661 & 11.097 & 0.284 & -0.315 & 2.943 & 0.049 & -0.753 & 10.436 \\
\hline SULF2 & sulfatase 2 & NM_028072 & 0.002 & 0.66 & 12.889 & 0.545 & 0.245 & 8.922 & 0.003 & -0.627 & 12.229 \\
\hline
\end{tabular}


Supplement Table 4.

\begin{tabular}{|c|c|c|c|c|c|c|c|c|c|c|c|}
\hline \multirow{2}{*}{ Name } & \multirow{2}{*}{ Description } & \multirow{2}{*}{ RefSeq ID } & \multicolumn{3}{|c|}{ FUP/FV } & \multicolumn{3}{|c|}{ FUP/FC } & \multicolumn{3}{|c|}{ FV/FC } \\
\hline & & & p-value & $\begin{array}{c}\text { Log } \\
\text { Ratio }\end{array}$ & Intensity & p-value & $\begin{array}{c}\text { Log } \\
\text { Ratio }\end{array}$ & Intensity & p-value & $\begin{array}{c}\text { Log } \\
\text { Ratio }\end{array}$ & Intensity \\
\hline \multicolumn{12}{|c|}{$\begin{array}{l}\text { Cell Cycle: G2/M DNA Damage } \\
\text { Checkpoint Regulation }\end{array}$} \\
\hline BRCA1 & breast cancer 1 , early onset & NM_009764 & 0.045 & -1.721 & 4.598 & 0.265 & 0.843 & 3.755 & 0.009 & 2.564 & 6.318 \\
\hline CCNB1 & cyclin B1 & NM_172301 & 0.026 & -1.571 & 5.055 & 0.064 & 1.214 & 3.841 & 0.002 & 2.785 & 6.626 \\
\hline $\mathrm{CCNB} 2$ & cyclin B2 & NM_007630 & 0.016 & -1.52 & 7.083 & 0.031 & 1.282 & 5.8 & 0.001 & 2.802 & 8.602 \\
\hline $\mathrm{CDC} 2$ & $\begin{array}{l}\text { cell division cycle } 2, \\
\text { G1 to } \mathrm{S} \text { and } \mathrm{G} 2 \text { to } \mathrm{M}\end{array}$ & NM_007659 & 0.013 & -1.395 & 8.342 & 0.02 & 1.253 & 7.088 & 0 & 2.648 & 9.736 \\
\hline SKP2 & $\begin{array}{l}\text { S-phase kinase-associated } \\
\text { protein } 2(\mathrm{p} 45)\end{array}$ & NM_013787 & 0.214 & -0.599 & 3.876 & 0.138 & 0.737 & 3.139 & 0.02 & 1.337 & 4.476 \\
\hline TOP2A & $\begin{array}{l}\text { topoisomerase (DNA) II } \\
\text { alpha } 170 \mathrm{kDa}\end{array}$ & NM_011623 & 0.023 & -1.53 & 6.184 & 0.076 & 1.083 & 5.1 & 0.002 & 2.614 & 7.714 \\
\hline UBD & ubiquitin D & NM_023137 & 0.022 & -2.072 & 12.159 & 0.001 & 4.475 & 7.683 & 0 & 6.547 & 14.23 \\
\hline YWHAE & $\begin{array}{l}\text { tyrosine } 3 \text {-monooxygenase/ } \\
\text { tryptophan 5-monooxygenase } \\
\text { activation protein, epsilon } \\
\text { polypeptide }\end{array}$ & BF714941 & 0.012 & 1.219 & 5.874 & 0.053 & -0.267 & 8.76 & 0.003 & -1.598 & 4.655 \\
\hline YWHAZ & $\begin{array}{l}\text { tyrosine } 3 \text {-monooxygenase/ } \\
\text { tryptophan 5-monooxygenase } \\
\text { activation protein, zeta } \\
\text { polypeptide }\end{array}$ & NM_011740 & 0.008 & -0.876 & 7.273 & 0.447 & -0.188 & 7.461 & 0.024 & 0.688 & 8.148 \\
\hline \multicolumn{12}{|c|}{ Glucocorticoid Receptor Signaling } \\
\hline AGT & $\begin{array}{l}\text { angiotensinogen (serpin } \\
\text { peptidase inhibitor, clade } \\
\text { A, member } 8 \text { ) }\end{array}$ & NM_007428 & 0.012 & 1.903 & 12.813 & 0.207 & -0.772 & 13.584 & 0.002 & -2.674 & 10.91 \\
\hline AR & $\begin{array}{l}\text { androgen receptor } \\
\text { (dihydrotestosterone receptor; } \\
\text { testicular feminization; spinal } \\
\text { and bulbar muscular atrophy; } \\
\text { Kennedy disease) }\end{array}$ & NM_013476 & 0.001 & 0.866 & 10.48 & 0.031 & -0.445 & 10.925 & 0 & -1.311 & 9.615 \\
\hline BCL3 & B-cell CLL/lymphoma 3 & NM_033601 & 0.03 & -0.392 & 8.281 & 0.002 & 0.684 & 7.596 & 0 & 1.076 & 8.672 \\
\hline CCL13 & $\begin{array}{l}\text { chemokine (C-C motif) } \\
\text { ligand } 13\end{array}$ & NM_011333 & 0.001 & -1.425 & 10.787 & 0 & 1.683 & 9.103 & 0 & 3.109 & 12.212 \\
\hline CCL3 & $\begin{array}{l}\text { chemokine (C-C motif) } \\
\text { ligand } 3\end{array}$ & NM_011337 & 0.033 & -1.316 & 4.068 & 0.019 & 1.505 & 2.563 & 0.001 & 2.821 & 5.383 \\
\hline CD163 & CD163 molecule & NM_053094 & 0.072 & 0.681 & 10.343 & 0.108 & -0.591 & 10.934 & 0.006 & -1.272 & 9.662 \\
\hline CDKN1A & $\begin{array}{l}\text { cyclin-dependent kinase } \\
\text { inhibitor } 1 \mathrm{~A}(\mathrm{p} 21, \mathrm{Cip} 1)\end{array}$ & NM_001111099 & 0.026 & -0.679 & 9.893 & 0.001 & 1.468 & 8.425 & 0 & 2.146 & 10.571 \\
\hline CDKN1C & $\begin{array}{l}\text { cyclin-dependent kinase } \\
\text { inhibitor } 1 \mathrm{C}(\mathrm{p} 57, \mathrm{Kip} 2)\end{array}$ & NM_009876 & 0.223 & 0.223 & 9.726 & 0.008 & -0.634 & 10.36 & 0.002 & -0.857 & 9.503 \\
\hline CXCL3 & $\begin{array}{l}\text { chemokine (C-X-C motif) } \\
\text { ligand } 3\end{array}$ & NM_009140 & 0.919 & 0.061 & 4.962 & 0.048 & 1.422 & 3.541 & 0.055 & 1.361 & 4.901 \\
\hline ESR1 & estrogen receptor 1 & NM_007956 & 0.041 & 0.52 & 6.097 & 0.033 & -0.551 & 6.648 & 0.002 & -1.071 & 5.577 \\
\hline
\end{tabular}




\section{Continued}

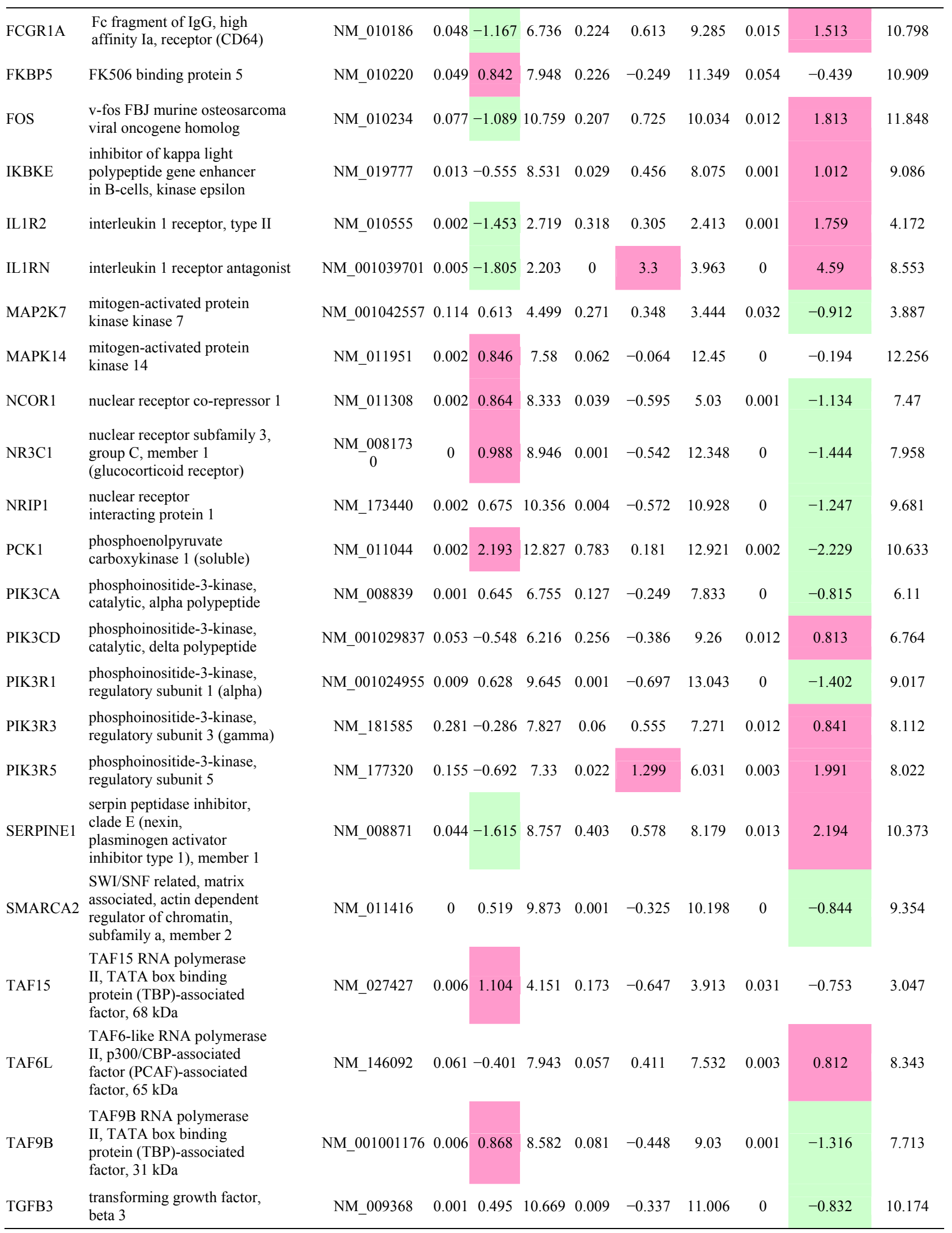




\section{Continued}

\begin{tabular}{llllllllllllllll}
\hline TGFBR2 & $\begin{array}{l}\text { transforming growth factor, } \\
\text { beta receptor II (70/80 kDa) }\end{array}$ & NM_009371 & 0.001 & 0.966 & 9.972 & 0.218 & 0.228 & 9.744 & 0.004 & -0.739 & 9.005 \\
TRA@ & T cell receptor alpha locus & XM_001471582 & 0.038 & -1.438 & 8.857 & 0.035 & 1.472 & 7.385 & 0.002 & 2.909 & 10.295 \\
VCAM1 & $\begin{array}{l}\text { vascular cell adhesion } \\
\text { molecule 1 }\end{array}$ & NM_011693 & 0.078 & -0.706 & 6.165 & 0.225 & 0.452 & 5.714 & 0.013 & 1.158 & 6.872
\end{tabular}

PPARa/RXRa Activation

\begin{tabular}{|c|c|}
\hline ACVR1C & $\begin{array}{l}\text { activin A receptor, } \\
\text { type IC }\end{array}$ \\
\hline ADCY7 & adenylate cyclase 7 \\
\hline BCL3 & B-cell CLL/lymphoma 3 \\
\hline CYP2C44 & $\begin{array}{l}\text { cytochrome } \mathrm{P} 450 \text {, family } \\
2 \text {, subfamily c, } \\
\text { polypeptide } 44\end{array}$ \\
\hline CYP2C70 & $\begin{array}{l}\text { cytochrome } \mathrm{P} 450 \text {, family } \\
2 \text {, subfamily c, } \\
\text { polypeptide } 70\end{array}$ \\
\hline GK & glycerol kinase \\
\hline GPD2 & $\begin{array}{l}\text { glycerol-3-phosphate } \\
\text { dehydrogenase } 2 \\
\text { (mitochondrial) }\end{array}$ \\
\hline IKBKE & $\begin{array}{l}\text { inhibitor of kappa } \\
\text { light polypeptide gene } \\
\text { enhancer in B-cells, } \\
\text { kinase epsilon }\end{array}$ \\
\hline IL1R2 & $\begin{array}{l}\text { interleukin } 1 \text { receptor, } \\
\text { type II }\end{array}$ \\
\hline INSR & insulin receptor \\
\hline IRS1 & $\begin{array}{l}\text { insulin receptor } \\
\text { substrate } 1\end{array}$ \\
\hline MAP2K7 & $\begin{array}{l}\text { mitogen-activated } \\
\text { protein kinase kinase } 7\end{array}$ \\
\hline MAPK14 & $\begin{array}{l}\text { mitogen-activated } \\
\text { protein kinase } 14\end{array}$ \\
\hline NCOR1 & $\begin{array}{l}\text { nuclear receptor } \\
\text { co-repressor } 1\end{array}$ \\
\hline PLCB4 & $\begin{array}{l}\text { phospholipase } \mathrm{C} \text {, } \\
\text { beta } 4\end{array}$ \\
\hline PLCD1 & $\begin{array}{l}\text { phospholipase } \mathrm{C} \text {, } \\
\text { delta } 1\end{array}$ \\
\hline PLCD3 & $\begin{array}{l}\text { phospholipase } \mathrm{C} \text {, } \\
\text { delta } 3\end{array}$ \\
\hline SLC27A1 & $\begin{array}{l}\text { solute carrier family } \\
27 \text { (fatty acid transporter), } \\
\text { member } 1\end{array}$ \\
\hline TGFB3 & $\begin{array}{l}\text { transforming growth } \\
\text { factor, beta } 3\end{array}$ \\
\hline TGFBR2 & $\begin{array}{l}\text { transforming growth } \\
\text { factor, beta receptor } \\
\text { II }(70 / 80 \mathrm{kDa})\end{array}$ \\
\hline
\end{tabular}

\begin{tabular}{|c|c|c|c|c|c|c|c|c|c|}
\hline NM_001033369 & 0.001 & 0.859 & 8.051 & 0.002 & -0.725 & 8.777 & 0 & -1.584 & 7.192 \\
\hline NM_001037723 & 0.08 & -0.758 & 10.645 & 0.204 & 0.467 & 7.078 & 0.019 & 1.034 & 8.113 \\
\hline NM_033601 & 0.03 & -0.392 & 8.281 & 0.002 & 0.684 & 7.596 & 0 & 1.076 & 8.672 \\
\hline NM_001001446 & 0.001 & -2.814 & 5.549 & 0.002 & 2.405 & 3.144 & 0 & 5.219 & 8.363 \\
\hline NM_145499 & 0.038 & -1.289 & 2.723 & 0.426 & 0.418 & 2.305 & 0.012 & 1.707 & 4.012 \\
\hline NM_008194 & 0.03 & -0.897 & 7.821 & 0.564 & 0.193 & 6.204 & 0.018 & 1.006 & 7.21 \\
\hline NM_010274 & 0.008 & 1.084 & 5.657 & 0.001 & -1.621 & 7.277 & 0 & -2.704 & 4.573 \\
\hline NM_019777 & 0.013 & -0.555 & 8.531 & 0.029 & 0.456 & 8.075 & 0.001 & 1.012 & 9.086 \\
\hline NM_010555 & 0.002 & -1.453 & 2.719 & 0.318 & 0.305 & 2.413 & 0.001 & 1.759 & 4.172 \\
\hline NM_001033381 & 0 & 0.668 & 9.937 & 0.022 & -0.275 & 10.212 & 0 & -0.943 & 9.269 \\
\hline NM_010570 & 0.006 & 1.387 & 11.258 & 0.089 & -0.681 & 11.939 & 0.001 & -2.067 & 9.872 \\
\hline NM_001042557 & 0.114 & 0.613 & 4.499 & 0.271 & 0.348 & 3.444 & 0.032 & -0.912 & 3.887 \\
\hline NM_011951 & 0.002 & 0.846 & 7.58 & 0.062 & -0.064 & 12.45 & 0 & -0.194 & 12.256 \\
\hline NM_011308 & 0.002 & 0.864 & 8.333 & 0.039 & -0.595 & 5.03 & 0.001 & -1.134 & 7.47 \\
\hline NM_013829 & 0.015 & 1.036 & 4.286 & 0.28 & -0.212 & 10.733 & 0.01 & -1.154 & 3.251 \\
\hline NM_019676 & 0.013 & 0.645 & 10.652 & 0.094 & -0.374 & 11.027 & 0.001 & -1.019 & 10.007 \\
\hline NM_152813 & 0.056 & 0.609 & 6.56 & 0.478 & -0.196 & 6.756 & 0.02 & -0.806 & 5.951 \\
\hline NM_011977 & 0.004 & 0.813 & 11.768 & 0.016 & 0.619 & 11.149 & 0.342 & -0.194 & 10.955 \\
\hline NM_009368 & 0.001 & 0.495 & 10.669 & 0.009 & -0.337 & 11.006 & 0 & -0.832 & 10.174 \\
\hline NM_009371 & 0.001 & 0.966 & 9.972 & 0.218 & 0.228 & 9.744 & 0.004 & -0.739 & 9.005 \\
\hline
\end{tabular}

Acute Phase Response Signaling 
Continued

\begin{tabular}{|c|c|c|c|c|c|c|c|c|c|c|c|}
\hline AGT & $\begin{array}{l}\text { angiotensinogen } \\
\text { (serpin peptidase } \\
\text { inhibitor, clade } \\
\text { A, member } 8 \text { ) }\end{array}$ & NM_007428 & 0.012 & 1.903 & 12.813 & 0.207 & -0.772 & 13.584 & 0.002 & -2.674 & 10.91 \\
\hline BCL3 & $\begin{array}{l}\text { B-cell } \\
\text { CLL/lymphoma } 3\end{array}$ & NM_033601 & 0.03 & -0.392 & 8.281 & 0.002 & 0.684 & 7.596 & 0 & 1.076 & 8.672 \\
\hline $\mathrm{C} 2$ & $\begin{array}{l}\text { complement } \\
\text { component } 2\end{array}$ & NM_013484 & 0.005 & 0.859 & 12.656 & 0.057 & -0.441 & 14.039 & 0.001 & -1.319 & 11.797 \\
\hline $\mathrm{CP}$ & $\begin{array}{l}\text { ceruloplasmin } \\
\text { (ferroxidase) }\end{array}$ & NM_001042611 & 0.003 & 0.867 & 11.589 & 0.016 & -0.513 & 11.028 & 0 & -1.278 & 10.722 \\
\hline FOS & $\begin{array}{l}\text { v-fos FBJ murine } \\
\text { osteosarcoma viral } \\
\text { oncogene homolog }\end{array}$ & NM_010234 & 0.077 & -1.089 & 10.759 & 0.207 & 0.725 & 10.034 & 0.012 & 1.813 & 11.848 \\
\hline FRAP1 & $\begin{array}{l}\text { FK506 binding } \\
\text { protein 12-rapamycin } \\
\text { associated protein } 1\end{array}$ & NM_020009 & 0.05 & -0.825 & 4.157 & 0.274 & -0.144 & 10.371 & 0.031 & 0.938 & 4.981 \\
\hline HMOX1 & $\begin{array}{l}\text { heme oxygenase } \\
\text { (decycling) } 1\end{array}$ & NM_010442 & 0.242 & -0.495 & 9.717 & 0.194 & 0.557 & 9.16 & 0.032 & 1.052 & 10.212 \\
\hline IKBKE & $\begin{array}{l}\text { inhibitor of kappa } \\
\text { light polypeptide } \\
\text { gene enhancer in } \\
\text { B-cells, kinase epsilon }\end{array}$ & NM_019777 & 0.013 & -0.555 & 8.531 & 0.029 & 0.456 & 8.075 & 0.001 & 1.012 & 9.086 \\
\hline IL1RN & $\begin{array}{l}\text { interleukin } 1 \text { receptor } \\
\text { antagonist }\end{array}$ & NM_001039701 & 0.005 & -1.805 & 2.203 & 0 & 3.3 & 3.963 & 0 & 4.59 & 8.553 \\
\hline MAP2K 7 & $\begin{array}{l}\text { mitogen-activated } \\
\text { protein kinase kinase } 7\end{array}$ & NM_001042557 & 0.114 & 0.613 & 4.499 & 0.271 & 0.348 & 3.444 & 0.032 & -0.912 & 3.887 \\
\hline MAPK14 & $\begin{array}{l}\text { mitogen-activated } \\
\text { protein kinase } 14\end{array}$ & NM_011951 & 0.002 & 0.846 & 7.58 & 0.062 & -0.064 & 12.45 & 0 & -0.194 & 12.256 \\
\hline NR3C1 & $\begin{array}{l}\text { nuclear receptor } \\
\text { subfamily } 3 \text {, group } \\
\mathrm{C} \text {, member } 1 \\
\text { (glucocorticoid receptor) }\end{array}$ & NM_008173 & 0 & 0.988 & 8.946 & 0.001 & -0.542 & 12.348 & 0 & -1.444 & 7.958 \\
\hline ORM1 & orosomucoid 1 & NM_011016 & 0.001 & -1.35 & 6.237 & 0 & 1.542 & 4.695 & 0 & 2.892 & 7.587 \\
\hline PIK3CA & $\begin{array}{l}\text { phosphoinositide-3-kinase, } \\
\text { catalytic, alpha polypeptide }\end{array}$ & NM_008839 & 0.001 & 0.645 & 6.755 & 0.127 & -0.249 & 7.833 & 0 & -0.815 & 6.11 \\
\hline PIK3CD & $\begin{array}{l}\text { phosphoinositide-3-kinase, } \\
\text { catalytic, delta polypeptide }\end{array}$ & NM_001029837 & 0.053 & -0.548 & 6.216 & 0.256 & -0.386 & 9.26 & 0.012 & 0.813 & 6.764 \\
\hline PIK3R1 & $\begin{array}{l}\text { phosphoinositide-3-kinase, } \\
\text { regulatory subunit } 1 \text { (alpha) }\end{array}$ & NM_001024955 & 0.009 & 0.628 & 9.645 & 0.001 & -0.697 & 13.043 & 0 & -1.402 & 9.017 \\
\hline PIK3R3 & $\begin{array}{l}\text { phosphoinositide-3-kinase, } \\
\text { regulatory subunit } 3 \text { (gamma) }\end{array}$ & NM_181585 & 0.281 & -0.286 & 7.827 & 0.06 & 0.555 & 7.271 & 0.012 & 0.841 & 8.112 \\
\hline RBP7 & $\begin{array}{l}\text { retinol binding protein } 7 \text {, } \\
\text { cellular }\end{array}$ & NM_022020 & 0.209 & 0.547 & 10.121 & 0.008 & 1.48 & 8.64 & 0.052 & 0.934 & 9.574 \\
\hline SAA2 & serum amyloid A2 & NM_011315 & 0.015 & -2.323 & 11.267 & 0.738 & 0.245 & 11.022 & 0.01 & 2.568 & 13.59 \\
\hline SERPINA1 & $\begin{array}{l}\text { serpin peptidase inhibitor, } \\
\text { clade A (alpha-1 } \\
\text { antiproteinase, antitrypsin), } \\
\text { member } 1\end{array}$ & NM_009243 & 0.002 & -1.046 & 4.653 & 0.264 & 0.242 & 4.411 & 0 & 1.288 & 5.699 \\
\hline SERPINE1 & $\begin{array}{l}\text { serpin peptidase inhibitor, } \\
\text { clade E (nexin, plasminogen } \\
\text { activator inhibitor type } 1 \text { ), } \\
\text { member } 1\end{array}$ & NM_008871 & 0.044 & -1.615 & 8.757 & 0.403 & 0.578 & 8.179 & 0.013 & 2.194 & 10.373 \\
\hline SERPINF1 & $\begin{array}{l}\text { serpin peptidase inhibitor, } \\
\text { clade F (alpha- } 2 \text { antiplasmin, } \\
\text { pigment epithelium } \\
\text { derived factor), member } 1\end{array}$ & NM_011340 & 0.57 & 0.092 & 13.765 & 0.001 & 0.924 & 12.841 & 0.001 & 0.757 & 13.916 \\
\hline
\end{tabular}


Continued

\begin{tabular}{|c|c|c|c|c|c|c|c|c|c|c|c|}
\hline TNFRSF11B & $\begin{array}{l}\text { tumor necrosis factor } \\
\text { receptor superfamily, } \\
\text { member } 11 \mathrm{~b} \\
\text { (osteoprotegerin) }\end{array}$ & NM_008764 & 0.147 & 0.525 & 6.2 & 0.075 & -0.675 & 6.875 & 0.008 & -1.2 & 5.675 \\
\hline \multicolumn{12}{|l|}{ P53 Signaling } \\
\hline BAX & $\begin{array}{l}\text { BCL2-associated X } \\
\text { protein }\end{array}$ & NM_007527 & 0.033 & -0.451 & 11.466 & 0.056 & 0.386 & 11.079 & 0.002 & 0.837 & 11.917 \\
\hline BIRC5 & $\begin{array}{l}\text { baculoviral IAP } \\
\text { repeat-containing } 5 \\
\text { (survivin) }\end{array}$ & NM_001012273 & 0.03 & -1.655 & 6.71 & 0.074 & 1.274 & 5.436 & 0.002 & 2.929 & 8.366 \\
\hline BRCA1 & $\begin{array}{l}\text { breast cancer } 1 \text {, } \\
\text { early onset }\end{array}$ & NM_009764 & 0.045 & -1.721 & 4.598 & 0.265 & 0.843 & 3.755 & 0.009 & 2.564 & 6.318 \\
\hline CDKN1A & $\begin{array}{l}\text { cyclin-dependent } \\
\text { kinase inhibitor 1A } \\
\text { (p21, Cip1) }\end{array}$ & NM_001111099 & 0.026 & -0.679 & 9.893 & 0.001 & 1.468 & 8.425 & 0 & 2.146 & 10.571 \\
\hline $\mathrm{E} 2 \mathrm{~F} 1$ & E2F transcription factor 1 & NM_007891 & 0.085 & -0.354 & 6.977 & 0.016 & 0.663 & 8.141 & 0.002 & 0.904 & 7.331 \\
\hline GADD45B & $\begin{array}{l}\text { growth arrest } \\
\text { and DNA-damage-inducible, } \\
\text { beta }\end{array}$ & NM_008655 & 0.003 & -0.949 & 10.17 & 0.089 & 0.407 & 9.762 & 0 & 1.356 & 11.118 \\
\hline HDAC9 & histone deacetylase 9 & NM_024124 & 0.11 & -0.461 & 8.363 & 0.131 & 0.43 & 7.933 & 0.011 & 0.891 & 8.824 \\
\hline MAPK14 & $\begin{array}{l}\text { mitogen-activated protein } \\
\text { kinase } 14\end{array}$ & NM_011951 & 0.002 & 0.846 & 7.58 & 0.062 & -0.064 & 12.45 & 0 & -0.194 & 12.256 \\
\hline PIK3CA & $\begin{array}{l}\text { phosphoinositide-3-kinase, } \\
\text { catalytic, alpha polypeptide }\end{array}$ & NM_008839 & 0.001 & 0.645 & 6.755 & 0.127 & -0.249 & 7.833 & 0 & -0.815 & 6.11 \\
\hline PIK3CD & $\begin{array}{l}\text { phosphoinositide-3-kinase, } \\
\text { catalytic, delta polypeptide }\end{array}$ & NM_001029837 & 0.053 & -0.548 & 6.216 & 0.256 & -0.386 & 9.26 & 0.012 & 0.813 & 6.764 \\
\hline PIK3R1 & $\begin{array}{l}\text { phosphoinositide-3-kinase, } \\
\text { regulatory subunit } 1 \text { (alpha) }\end{array}$ & NM_001024955 & 0.009 & 0.628 & 9.645 & 0.001 & -0.697 & 13.043 & 0 & -1.402 & 9.017 \\
\hline PIK3R3 & $\begin{array}{l}\text { phosphoinositide-3-kinase, } \\
\text { regulatory subunit } 3 \text { (gamma) }\end{array}$ & NM_181585 & 0.281 & -0.286 & 7.827 & 0.06 & 0.555 & 7.271 & 0.012 & 0.841 & 8.112 \\
\hline PIK3R5 & $\begin{array}{l}\text { phosphoinositide-3-kinase, } \\
\text { regulatory subunit } 5\end{array}$ & NM_177320 & 0.155 & -0.692 & 7.33 & 0.022 & 1.299 & 6.031 & 0.003 & 1.991 & 8.022 \\
\hline PLAGL1 & $\begin{array}{l}\text { pleiomorphic adenoma } \\
\text { gene-like } 1\end{array}$ & NM_009538 & 0.002 & 1.079 & 13.007 & 0.029 & -0.604 & 13.61 & 0 & -1.683 & 11.928 \\
\hline RB1 & $\begin{array}{l}\text { retinoblastoma } 1 \\
\text { (including osteosarcoma) }\end{array}$ & NM_009029 & 0.038 & -0.65 & 4.483 & 0.098 & 0.483 & 4.001 & 0.003 & 1.133 & 5.134 \\
\hline SIRT1 & $\begin{array}{l}\text { sirtuin (silent mating } \\
\text { type information regulation } \\
2 \text { homolog) } 1 \text { (S. cerevisiae) }\end{array}$ & NM_019812 & 0.103 & 0.352 & 7.59 & 0.048 & -0.451 & 8.041 & 0.004 & -0.804 & 7.237 \\
\hline THBS1 & thrombospondin 1 & NM_011580 & 0.001 & 1.08 & 11.08 & 0.199 & 0.399 & 11.387 & 0.002 & -0.984 & 10 \\
\hline WT1 & Wilms tumor 1 & NM_144783 & 0.047 & 0.689 & 8.517 & 0.041 & -0.721 & 9.238 & 0.002 & -1.411 & 7.827 \\
\hline
\end{tabular}

\section{IL-4 Signaling}

\begin{tabular}{|c|c|c|c|c|c|c|c|c|c|c|c|}
\hline FRAP1 & $\begin{array}{l}\text { FK506 binding protein } \\
\text { 12-rapamycin associated } \\
\text { protein } 1\end{array}$ & NM_020009 & 0.05 & -0.825 & 4.157 & 0.274 & -0.144 & 10.371 & 0.031 & 0.938 & 4.981 \\
\hline HLA-DMB & $\begin{array}{l}\text { major histocompatibility } \\
\text { complex, class II, DM beta }\end{array}$ & NM_010387 & 0.004 & -1.038 & 9.338 & 0.03 & 0.435 & 11.761 & 0 & 1.094 & 12.855 \\
\hline HMGA1 & $\begin{array}{l}\text { high mobility group } \\
\text { AT-hook } 1\end{array}$ & NM_001025427 & 0.028 & -0.867 & 10.864 & 0.023 & 0.911 & 9.953 & 0.001 & 1.778 & 11.731 \\
\hline IRS1 & insulin receptor substrate 1 & NM_010570 & 0.006 & 1.387 & 11.258 & 0.089 & -0.681 & 11.939 & 0.001 & -2.067 & 9.872 \\
\hline
\end{tabular}


Continued

\begin{tabular}{|c|c|c|c|c|c|c|c|c|c|c|c|}
\hline NR3C1 & $\begin{array}{l}\text { nuclear receptor subfamily } \\
3 \text {, group C, member } 1 \\
\text { (glucocorticoid receptor) }\end{array}$ & NM_008173 & 0 & 0.988 & 8.946 & 0.001 & -0.542 & 12.348 & 0 & -1.444 & 7.958 \\
\hline PIK3CA & $\begin{array}{l}\text { phosphoinositide-3-kinase, } \\
\text { catalytic, alpha polypeptide }\end{array}$ & NM_008839 & 0.001 & 0.645 & 6.755 & 0.127 & -0.249 & 7.833 & 0 & -0.815 & 6.11 \\
\hline PIK3CD & $\begin{array}{l}\text { phosphoinositide-3-kinase, } \\
\text { catalytic, delta polypeptide }\end{array}$ & NM_001029837 & 0.053 & -0.548 & 6.216 & 0.256 & -0.386 & 9.26 & 0.012 & 0.813 & 6.764 \\
\hline PIK3R3 & $\begin{array}{l}\text { phosphoinositide-3-kinase, } \\
\text { regulatory subunit } 3 \text { (gamma) }\end{array}$ & NM_181585 & 0.281 & -0.286 & 7.827 & 0.06 & 0.555 & 7.271 & 0.012 & 0.841 & 8.112 \\
\hline PIK3R5 & $\begin{array}{l}\text { phosphoinositide-3-kinase, } \\
\text { regulatory subunit } 5\end{array}$ & NM_177320 & 0.155 & -0.692 & 7.33 & 0.022 & 1.299 & 6.031 & 0.003 & 1.991 & 8.022 \\
\hline \multicolumn{12}{|c|}{ PI3K/AKT Signaling } \\
\hline BCL3 & B-cell CLL/lymphoma 3 & NM_033601 & 0.03 & -0.392 & 8.281 & 0.002 & 0.684 & 7.596 & 0 & 1.076 & 8.672 \\
\hline CDKN1A & $\begin{array}{l}\text { cyclin-dependent kinase } \\
\text { inhibitor } 1 \mathrm{~A}(\mathrm{p} 21, \mathrm{Cip} 1)\end{array}$ & NM_001111099 & 0.026 & -0.679 & 9.893 & 0.001 & 1.468 & 8.425 & 0 & 2.146 & 10.571 \\
\hline CDKN1B & $\begin{array}{l}\text { cyclin-dependent kinase } \\
\text { inhibitor } 1 \mathrm{~B}(\mathrm{p} 27, \mathrm{Kip} 1)\end{array}$ & NM_009875 & 0.125 & 0.39 & 8.696 & 0.093 & -0.436 & 9.132 & 0.009 & -0.826 & 8.306 \\
\hline EIF4EBP1 & $\begin{array}{l}\text { eukaryotic translation } \\
\text { initiation factor } 4 \mathrm{E} \\
\text { binding protein } 1\end{array}$ & NM_007918 & 0.016 & 1.108 & 9.708 & 0.838 & 0.03 & 14.414 & 0.013 & -1.158 & 8.599 \\
\hline FOXO1 & forkhead box O1 & NM_019739 & 0.007 & 0.656 & 10.756 & 0.1 & -0.323 & 11.079 & 0.001 & -0.979 & 10.1 \\
\hline FRAP1 & $\begin{array}{l}\text { FK506 binding protein } \\
\text { 12-rapamycin } \\
\text { associated protein } 1\end{array}$ & NM_020009 & 0.05 & -0.825 & 4.157 & 0.274 & -0.144 & 10.371 & 0.031 & 0.938 & 4.981 \\
\hline GYS2 & $\begin{array}{l}\text { glycogen synthase } 2 \\
\text { (liver) }\end{array}$ & NM_145572 & 0.005 & -1.67 & 8.426 & 0.085 & 0.809 & 7.617 & 0.001 & 2.479 & 10.096 \\
\hline IKBKE & $\begin{array}{l}\text { inhibitor of kappa light } \\
\text { polypeptide gene enhancer } \\
\text { in B-cells, kinase epsilon }\end{array}$ & NM_019777 & 0.013 & -0.555 & 8.531 & 0.029 & 0.456 & 8.075 & 0.001 & 1.012 & 9.086 \\
\hline MAPK8IP1 & $\begin{array}{l}\text { mitogen-activated protein } \\
\text { kinase } 8 \text { interacting protein } 1\end{array}$ & NM_011162 & 0.007 & 1.17 & 7.242 & 0.05 & -0.722 & 7.964 & 0.001 & -1.892 & 6.071 \\
\hline PIK3CA & $\begin{array}{l}\text { phosphoinositide-3-kinase, } \\
\text { catalytic, alpha polypeptide }\end{array}$ & NM_008839 & 0.001 & 0.645 & 6.755 & 0.127 & -0.249 & 7.833 & 0 & -0.815 & 6.11 \\
\hline PIK3CD & $\begin{array}{l}\text { phosphoinositide-3-kinase, } \\
\text { catalytic, delta polypeptide }\end{array}$ & NM_001029837 & 0.053 & -0.548 & 6.216 & 0.256 & -0.386 & 9.26 & 0.012 & 0.813 & 6.764 \\
\hline PIK3R1 & $\begin{array}{l}\text { phosphoinositide-3-kinase, } \\
\text { regulatory subunit } 1 \text { (alpha) }\end{array}$ & NM_001024955 & 0.009 & 0.628 & 9.645 & 0.001 & -0.697 & 13.043 & 0 & -1.402 & 9.017 \\
\hline PIK3R3 & $\begin{array}{l}\text { phosphoinositide-3-kinase, } \\
\text { regulatory subunit } 3 \\
\text { (gamma) }\end{array}$ & NM_181585 & 0.281 & -0.286 & 7.827 & 0.06 & 0.555 & 7.271 & 0.012 & 0.841 & 8.112 \\
\hline $\begin{array}{l}\text { PPP2R3A } \\
\text { (includes EG:5523) }\end{array}$ & $\begin{array}{l}\text { protein phosphatase } 2 \\
\text { (formerly } 2 \mathrm{~A} \text { ), regulatory } \\
\text { subunit B", alpha }\end{array}$ & XM_001474396 & 0.007 & 0.486 & 6.878 & 0.004 & -0.55 & 7.428 & 0 & -1.036 & 6.392 \\
\hline YWHAE & $\begin{array}{l}\text { tyrosine } 3 \text {-monooxygenase/ } \\
\text { tryptophan } 5 \text {-monooxygenase } \\
\text { activation protein, epsilon } \\
\text { polypeptide }\end{array}$ & BF714941 & 0.012 & 1.219 & 5.874 & 0.053 & -0.267 & 8.76 & 0.003 & -1.598 & 4.655 \\
\hline YWHAZ & $\begin{array}{l}\text { tyrosine } 3 \text {-monooxygenase/ } \\
\text { tryptophan } 5 \text {-monooxygenase } \\
\text { activation protein, } \\
\text { zeta polypeptide }\end{array}$ & NM_011740 & 0.008 & -0.876 & 7.273 & 0.447 & -0.188 & 7.461 & 0.024 & 0.688 & 8.148 \\
\hline
\end{tabular}


Continued

\section{SAPK/JNK Signaling}

GNG2 guanine nucleotide binding protein (G protein), gamma 2

GNG7 guanine nucleotide binding

protein (G protein), gamma 7

IRS1 insulin receptor substrate 1

MAP2K7 mitogen-activated protein kinase kinase 7

MAP3K13 mitogen-activated protein kinase kinase kinase 13

$\begin{array}{ll}\text { MAP3K3 } & \begin{array}{l}\text { mitogen-activated protein } \\ \text { kinase kinase kinase } 3\end{array} \\ \text { mitogen-activated protein }\end{array}$

$\begin{array}{ll}\text { MAP3K3 } & \begin{array}{l}\text { mitogen-activated protein } \\ \text { kinase kinase kinase } 3\end{array} \\ \text { mitogen-activated protein }\end{array}$

MAP4K1 kinase kinase kinase kinase 1

MAPK8IP1 mitogen-activated protein kinase 8 interacting protein 1

PIK3CA phosphoinositide-3-kinase, catalytic, alpha polypeptide

PIK3CD phosphoinositide-3-kinase, catalytic, delta polypeptide

PIK3R1 phosphoinositide-3-kinase, regulatory subunit 1 (alpha)

PIK3R3 phosphoinositide-3-kinase, regulatory subunit 3 (gamma)

PIK3R5 phosphoinositide-3-kinase, regulatory subunit 5

TRA@ T cell receptor alpha locus

TRG@ T cell receptor gamma locus

\section{Leukocyte Extravasation Signaling}

$\begin{array}{ll}\text { ACTN1 } & \text { actinin, alpha 1 } \\ \text { ACTN3 } & \text { actinin, alpha 3 } \\ \text { ARHGAP4 } & \begin{array}{l}\text { Rho GTPase activating } \\ \text { protein 4 }\end{array} \\ \text { ARHGAP6 } & \begin{array}{l}\text { Rho GTPase activating } \\ \text { protein 6 }\end{array} \\ \text { ARHGAP9 } & \begin{array}{l}\text { Rho GTPase activating } \\ \text { protein } 9\end{array} \\ \text { BTK } & \begin{array}{l}\text { Bruton agammaglobulinemia } \\ \text { tyrosine kinase }\end{array} \\ \text { CD44 } & \begin{array}{l}\text { CD44 molecule } \\ \text { (Indian blood group) }\end{array} \\ \text { CLDN12 } & \begin{array}{l}\text { claudin 12 } \\ \text { claudin 5 (transmembrane } \\ \text { protein deleted in } \\ \text { velocardiofacial syndrome) } \\ \text { catenin } \\ \text { (cadherin-associated } \\ \text { protein), alpha 1, 102 kDa }\end{array} \\ \text { CLDN5 } & \\ \text { CTNNA1 } & \\ & \end{array}$

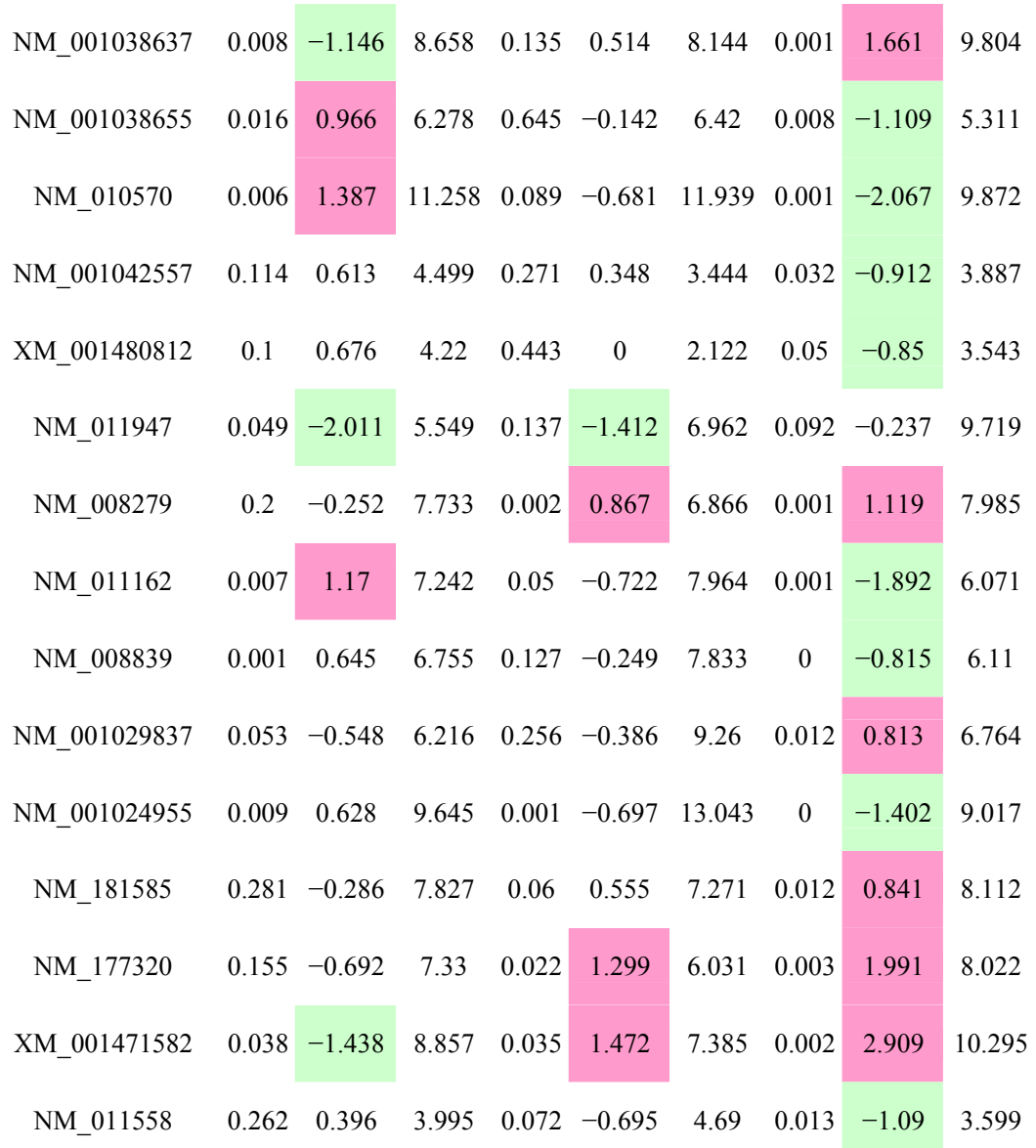

\begin{tabular}{|c|c|c|c|c|c|c|c|c|c|}
\hline NM_134156 & 0.032 & -0.786 & 5.706 & 0.04 & 0.743 & 8.142 & 0.002 & 1.523 & 6.492 \\
\hline NM_013456 & 0.221 & 0.612 & 7.425 & 0.03 & -1.26 & 8.685 & 0.005 & -1.873 & 6.813 \\
\hline NM_138630 & 0.022 & -0.612 & 5.938 & 0.262 & 0.249 & 5.689 & 0.005 & 0.861 & 6.55 \\
\hline NM_009707 & 0.08 & -0.982 & 5.421 & 0.688 & 0.199 & 5.222 & 0.044 & 1.181 & 6.404 \\
\hline NM_146011 & 0.027 & -0.886 & 9 & 0.032 & 0.848 & 8.152 & 0.001 & 1.735 & 9.887 \\
\hline NM_013482 & 0.009 & -1.057 & 9.376 & 0.607 & 0.153 & 9.223 & 0.005 & 1.21 & 10.433 \\
\hline NM_001039150 & 0.036 & -0.906 & 10.775 & 0.019 & 1.077 & 6.791 & 0.001 & 1.916 & 8.707 \\
\hline NM_022890 & 0.035 & 0.523 & 7.849 & 0.039 & -0.504 & 8.353 & 0.002 & -1.027 & 7.326 \\
\hline NM_013805 & 0.029 & 1.096 & 12.816 & 0.045 & 0.977 & 11.839 & 0.771 & -0.119 & 11.72 \\
\hline NM_009818 & 0.03 & 0.666 & 5.007 & 0.129 & -0.096 & 13.283 & 0.005 & -1.025 & 4.342 \\
\hline
\end{tabular}




\section{Continued}

\begin{tabular}{|c|c|c|c|c|c|c|c|c|c|c|c|}
\hline CXCR4 & $\begin{array}{l}\text { chemokine (C-X-C motif) } \\
\text { receptor } 4\end{array}$ & NM_009911 & 0.413 & -0.397 & 7 & 0.125 & 0.8 & 6.2 & 0.037 & 1.198 & 7.397 \\
\hline CYBA & $\begin{array}{l}\text { cytochrome b- } 245 \text {, alpha } \\
\text { polypeptide }\end{array}$ & NM_007806 & 0.068 & -0.399 & 13.656 & 0.025 & 0.532 & 13.123 & 0.002 & 0.932 & 14.055 \\
\hline CYBB & $\begin{array}{l}\text { cytochrome b- } 245 \text {, } \\
\text { beta polypeptide } \\
\text { (chronic granulomatous } \\
\text { disease) }\end{array}$ & NM_007807 & 0.045 & -0.569 & 10.756 & 0.087 & 0.461 & 10.295 & 0.004 & 1.03 & 11.325 \\
\hline DLC1 & deleted in liver cancer 1 & NM_015802 & 0.051 & 0.403 & 12.01 & 0.007 & -0.554 & 9.799 & 0.001 & -0.823 & 8.976 \\
\hline ITGB2 & $\begin{array}{l}\text { integrin, beta } 2 \text { (complement } \\
\text { component } 3 \text { receptor } 3 \text { and } 4 \\
\text { subunit) }\end{array}$ & NM_008404 & 0.077 & -0.456 & 13.308 & 0.011 & 0.774 & 12.534 & 0.001 & 1.229 & 13.764 \\
\hline MAPK14 & $\begin{array}{l}\text { mitogen-activated protein } \\
\text { kinase } 14\end{array}$ & NM_011951 & 0.002 & 0.846 & 7.58 & 0.062 & -0.064 & 12.45 & 0 & -0.194 & 12.256 \\
\hline MMP11 & $\begin{array}{l}\text { matrix metallopeptidase } 11 \\
(\text { stromelysin } 3)\end{array}$ & NM_008606 & 0.139 & -0.636 & 7.553 & 0.418 & 0.326 & 7.227 & 0.041 & 0.962 & 8.189 \\
\hline MMP12 & $\begin{array}{l}\text { matrix metallopeptidase } 12 \\
\text { (macrophage elastase) }\end{array}$ & NM_008605 & 0.447 & -0.687 & 13.129 & 0.012 & 2.956 & 10.173 & 0.005 & 3.643 & 13.816 \\
\hline MMP13 & $\begin{array}{l}\text { matrix metallopeptidase } 13 \\
\text { (collagenase } 3 \text { ) }\end{array}$ & NM_008607 & 0.082 & -1.477 & 2.74 & 0.546 & 0.455 & 2.285 & 0.033 & 1.932 & 4.217 \\
\hline MMP3 & $\begin{array}{l}\text { matrix metallopeptidase } 3 \\
\text { (stromelysin } 1 \text {, progelatinase) }\end{array}$ & NM_010809 & 0.207 & -1.303 & 5.923 & 0.193 & 1.348 & 4.574 & 0.027 & 2.651 & 7.226 \\
\hline MMP9 & $\begin{array}{l}\text { matrix metallopeptidase } 9 \\
\text { (gelatinase } \mathrm{B}, 92 \mathrm{kDa} \\
\text { gelatinase, } 92 \mathrm{kDa} \text { type } \\
\text { IV collagenase) }\end{array}$ & NM_013599 & 0.081 & 2.265 & 7.787 & 0.268 & -1.057 & 9.127 & 0.019 & -3.411 & 5.522 \\
\hline NCF1C & $\begin{array}{l}\text { neutrophil cytosolic } \\
\text { factor } 1 \mathrm{C} \text { pseudogene }\end{array}$ & NM_010876 & 0.157 & -0.222 & 11.784 & 0.003 & 1.001 & 7.382 & 0.001 & 0.766 & 12.007 \\
\hline NCF4 & $\begin{array}{l}\text { neutrophil cytosolic } \\
\text { factor } 4,40 \mathrm{kDa}\end{array}$ & NM_008677 & 0.024 & -0.596 & 9.787 & 0.028 & 0.575 & 9.212 & 0.001 & 1.171 & 10.383 \\
\hline PECAM1 & $\begin{array}{l}\text { platelet/endothelial } \\
\text { cell adhesion molecule } \\
\text { (CD31 antigen) }\end{array}$ & NM_001032378 & 0.011 & 0.891 & 9.643 & 0.142 & 0.424 & 9.219 & 0.112 & -0.467 & 8.752 \\
\hline PIK3CA & $\begin{array}{l}\text { phosphoinositide-3-kinase, } \\
\text { catalytic, alpha polypeptide }\end{array}$ & NM_008839 & 0.001 & 0.645 & 6.755 & 0.127 & -0.249 & 7.833 & 0 & -0.815 & 6.11 \\
\hline PIK3CD & $\begin{array}{l}\text { phosphoinositide-3-kinase, } \\
\text { catalytic, delta polypeptide }\end{array}$ & NM_001029837 & 0.053 & -0.548 & 6.216 & 0.256 & -0.386 & 9.26 & 0.012 & 0.813 & 6.764 \\
\hline PIK3R1 & $\begin{array}{l}\text { phosphoinositide-3-kinase, } \\
\text { regulatory subunit } 1 \text { (alpha) }\end{array}$ & NM_001024955 & 0.009 & 0.628 & 9.645 & 0.001 & -0.697 & 13.043 & 0 & -1.402 & 9.017 \\
\hline PIK3R3 & $\begin{array}{l}\text { phosphoinositide-3-kinase, } \\
\text { regulatory subunit } 3 \text { (gamma) }\end{array}$ & NM_181585 & 0.281 & -0.286 & 7.827 & 0.06 & 0.555 & 7.271 & 0.012 & 0.841 & 8.112 \\
\hline PIK3R5 & $\begin{array}{l}\text { phosphoinositide-3-kinase, } \\
\text { regulatory subunit } 5\end{array}$ & NM_177320 & 0.155 & -0.692 & 7.33 & 0.022 & 1.299 & 6.031 & 0.003 & 1.991 & 8.022 \\
\hline PRKCH & protein kinase $\mathrm{C}$, eta & NM_008856 & 0.087 & -0.743 & 10.472 & 0.027 & 0.997 & 7.892 & 0.003 & 1.594 & 9.486 \\
\hline PRKD1 & protein kinase D1 & NM_008858 & 0 & 0.377 & 10.713 & 0 & -0.515 & 11.227 & 0 & -0.892 & 10.336 \\
\hline RDX & radixin & NM_001104616 & 0 & 1.015 & 7.9 & 0.003 & -0.276 & 12.632 & 0 & -0.645 & 11.988 \\
\hline SELPLG & selectin P ligand & NM_009151 & 0.01 & -0.604 & 11.224 & 0.187 & 0.248 & 10.976 & 0.002 & 0.852 & 11.828 \\
\hline TEC & tec protein tyrosine kinase & NM_001113460 & 0.039 & -0.422 & 10.126 & 0.005 & 0.697 & 9.429 & 0 & 1.119 & 10.548 \\
\hline
\end{tabular}




\section{Continued}

\begin{tabular}{|c|c|c|c|c|c|c|c|c|c|c|c|}
\hline TIMP1 & $\begin{array}{l}\text { TIMP metallopeptidase } \\
\text { inhibitor } 1\end{array}$ & NM_001044384 & 0.023 & -1.025 & 9.675 & 0.032 & 0.94 & 8.734 & 0.001 & 1.965 & 10.699 \\
\hline TIMP3 & $\begin{array}{l}\text { TIMP metallopeptidase } \\
\text { inhibitor } 3 \text { (Sorsby } \\
\text { fundus dystrophy, } \\
\text { pseudoinflammatory) }\end{array}$ & NM_011595 & 0 & 1.066 & 9.076 & 0.393 & -0.121 & 12.275 & 0 & -1.012 & 8.01 \\
\hline TIMP4 & $\begin{array}{l}\text { TIMP metallopeptidase } \\
\text { inhibitor } 4\end{array}$ & NM_080639 & 0.018 & 0.772 & 13.367 & 0.404 & -0.217 & 13.585 & 0.006 & -0.99 & 12.595 \\
\hline VAV1 & $\begin{array}{l}\text { vav } 1 \text { guanine nucleotide } \\
\text { exchange factor }\end{array}$ & NM_011691 & 0.044 & -0.704 & 5.755 & 0.209 & 0.391 & 5.363 & 0.007 & 1.095 & 6.458 \\
\hline VAV3 & $\begin{array}{l}\text { vav } 3 \text { guanine nucleotide } \\
\text { exchange factor }\end{array}$ & NM_020505 & 0.072 & -0.768 & 8.743 & 0.116 & 0.582 & 3.591 & 0.009 & 1.336 & 9.51 \\
\hline VCAM1 & $\begin{array}{l}\text { vascular cell adhesion } \\
\text { molecule } 1\end{array}$ & NM_011693 & 0.078 & -0.706 & 6.165 & 0.225 & 0.452 & 5.714 & 0.013 & 1.158 & 6.872 \\
\hline \multicolumn{12}{|c|}{ Insulin Receptor Signaling } \\
\hline ACLY & ATP citrate lyase & NM_134037 & 0.311 & 0.38 & 12.337 & 0.003 & -0.937 & 14.13 & 0.001 & -1.142 & 12.988 \\
\hline EIF4EBP1 & $\begin{array}{l}\text { eukaryotic translation } \\
\text { initiation factor } 4 \mathrm{E} \\
\text { binding protein } 1\end{array}$ & NM_007918 & 0.016 & 1.108 & 9.708 & 0.838 & 0.03 & 14.414 & 0.013 & -1.158 & 8.599 \\
\hline FOXO1 & forkhead box $\mathrm{O} 1$ & NM_019739 & 0.007 & 0.656 & 10.756 & 0.1 & -0.323 & 11.079 & 0.001 & -0.979 & 10.1 \\
\hline FRAP1 & $\begin{array}{l}\text { FK506 binding protein } \\
\text { 12-rapamycin } \\
\text { associated protein } 1\end{array}$ & NM_020009 & 0.05 & -0.825 & 4.157 & 0.274 & -0.144 & 10.371 & 0.031 & 0.938 & 4.981 \\
\hline GYS1 & $\begin{array}{l}\text { glycogen synthase } 1 \\
\text { (muscle) }\end{array}$ & NM_030678 & 0.011 & 1.096 & 7.294 & 0.493 & -0.225 & 7.52 & 0.005 & -1.321 & 6.199 \\
\hline GYS2 & $\begin{array}{l}\text { glycogen synthase } 2 \\
\text { (liver) }\end{array}$ & NM_145572 & 0.005 & -1.67 & 8.426 & 0.085 & 0.809 & 7.617 & 0.001 & 2.479 & 10.096 \\
\hline INSR & insulin receptor & NM_001033381 & 0 & 0.668 & 9.937 & 0.022 & -0.275 & 10.212 & 0 & -0.943 & 9.269 \\
\hline IRS1 & insulin receptor substrate 1 & NM_010570 & 0.006 & 1.387 & 11.258 & 0.089 & -0.681 & 11.939 & 0.001 & -2.067 & 9.872 \\
\hline PIK3CA & $\begin{array}{l}\text { phosphoinositide-3-kinase, } \\
\text { catalytic, alpha polypeptide }\end{array}$ & NM_008839 & 0.001 & 0.645 & 6.755 & 0.127 & -0.249 & 7.833 & 0 & -0.815 & 6.11 \\
\hline PIK3CD & $\begin{array}{l}\text { phosphoinositide-3-kinase, } \\
\text { catalytic, delta polypeptide }\end{array}$ & NM_001029837 & 0.053 & -0.548 & 6.216 & 0.256 & -0.386 & 9.26 & 0.012 & 0.813 & 6.764 \\
\hline PIK3R1 & $\begin{array}{l}\text { phosphoinositide-3-kinase, } \\
\text { regulatory subunit } 1 \text { (alpha) }\end{array}$ & NM_001024955 & 0.009 & 0.628 & 9.645 & 0.001 & -0.697 & 13.043 & 0 & -1.402 & 9.017 \\
\hline PIK3R3 & $\begin{array}{l}\text { phosphoinositide-3-kinase, } \\
\text { regulatory subunit } 3 \text { (gamma) }\end{array}$ & NM_181585 & 0.281 & -0.286 & 7.827 & 0.06 & 0.555 & 7.271 & 0.012 & 0.841 & 8.112 \\
\hline PIK3R5 & $\begin{array}{l}\text { phosphoinositide-3-kinase, } \\
\text { regulatory subunit } 5\end{array}$ & NM_177320 & 0.155 & -0.692 & 7.33 & 0.022 & 1.299 & 6.031 & 0.003 & 1.991 & 8.022 \\
\hline PRKCH & protein kinase $\mathrm{C}$, eta & NM_008856 & 0.087 & -0.743 & 10.472 & 0.027 & 0.997 & 7.892 & 0.003 & 1.594 & 9.486 \\
\hline SLC2A4 & $\begin{array}{l}\text { solute carrier family } 2 \\
\text { (facilitated glucose } \\
\text { transporter), member } 4\end{array}$ & NM_009204 & 0.029 & 1.368 & 12.889 & 0.309 & -0.393 & 12.374 & 0.014 & -1.205 & 11.169 \\
\hline STXBP4 & syntaxin binding protein 4 & --- & 0.003 & 0.858 & 5.13 & 0.567 & -0.11 & 5.239 & 0.002 & -0.968 & 4.271 \\
\hline VAMP2 & $\begin{array}{l}\text { vesicle-associated membrane } \\
\text { protein } 2 \text { (synaptobrevin } 2 \text { ) }\end{array}$ & NM_009497 & 0.079 & 0.464 & 7.815 & 0.081 & -0.46 & 8.274 & 0.005 & -0.924 & 7.351 \\
\hline \multicolumn{12}{|c|}{ Xenobiotic Metabolism Signaling } \\
\hline
\end{tabular}


Continued

\begin{tabular}{|c|c|c|c|c|c|c|c|c|c|c|c|}
\hline $\mathrm{ABCB} 1$ & $\begin{array}{l}\text { ATP-binding cassette, } \\
\text { sub-family B (MDR/TAP), } \\
\text { member } 1\end{array}$ & NM_011076 & 0.006 & 0.761 & 5.988 & 0.157 & -0.401 & 8.141 & 0.001 & -1.052 & 5.227 \\
\hline ALDH3B1 & $\begin{array}{l}\text { aldehyde dehydrogenase } 3 \\
\text { family, member B1 }\end{array}$ & NM_026316 & 0.017 & -0.56 & 7.848 & 0.046 & 0.431 & 7.417 & 0.001 & 0.992 & 8.409 \\
\hline ALDH5A1 & $\begin{array}{l}\text { aldehyde dehydrogenase } 5 \\
\text { family, member } \\
\text { A1 (succinate-semialdehyde } \\
\text { dehydrogenase) }\end{array}$ & NM_172532 & 0.012 & 0.802 & 10.108 & 0.459 & -0.18 & 10.288 & 0.004 & -0.982 & 9.306 \\
\hline ALDH6A1 & $\begin{array}{l}\text { aldehyde dehydrogenase } 6 \\
\text { family, member A1 }\end{array}$ & NM_134042 & 0.002 & 0.503 & 12.566 & 0.009 & -0.359 & 12.925 & 0 & -0.862 & 12.064 \\
\hline ARNT & $\begin{array}{l}\text { aryl hydrocarbon receptor } \\
\text { nuclear translocator }\end{array}$ & NM_001037737 & 0.01 & 0.831 & 6.119 & 0.002 & -0.259 & 8.705 & 0 & -0.425 & 8.28 \\
\hline CAMK2D & $\begin{array}{l}\text { calcium/ } \\
\text { calmodulin-dependent } \\
\text { protein kinase (CaM kinase) } \\
\text { II delta }\end{array}$ & NM_001025438 & 0.062 & 0.087 & 2.365 & 0.496 & -0.25 & 7.43 & 0.038 & -0.902 & 6.528 \\
\hline $\begin{array}{l}\text { CES1 } \\
\text { (includes EG:1066) }\end{array}$ & $\begin{array}{l}\text { carboxylesterase } 1 \\
\text { (monocyte/macrophage } \\
\text { serine esterase } 1 \text { ) }\end{array}$ & NM_053200 & 0.007 & 1.036 & 13.647 & 0.27 & -0.33 & 13.056 & 0.002 & -1.382 & 11.674 \\
\hline CHST11 & $\begin{array}{l}\text { carbohydrate } \\
\text { (chondroitin 4) } \\
\text { sulfotransferase } 11\end{array}$ & NM_021439 & 0.112 & -0.274 & 2.418 & 0.025 & 0.687 & 8.607 & 0.01 & 0.85 & 9.457 \\
\hline CITED2 & $\begin{array}{l}\text { Cbp/p300-interacting } \\
\text { transactivator, with } \\
\text { Glu/Asp-rich } \\
\text { carboxy-terminal domain, } 2\end{array}$ & NM_010828 & 0.028 & 0.615 & 11.678 & 0.162 & -0.343 & 12.022 & 0.004 & -0.958 & 11.064 \\
\hline CUL3 & cullin 3 & NM_016716 & 0.001 & 0.599 & 8.051 & 0.017 & -0.329 & 8.38 & 0 & -0.928 & 7.452 \\
\hline FMO1 & $\begin{array}{l}\text { flavin containing } \\
\text { monooxygenase } 1\end{array}$ & NM_010231 & 0.033 & 0.909 & 13.444 & 0.163 & -0.526 & 13.971 & 0.004 & -1.435 & 12.536 \\
\hline GSTA3 & $\begin{array}{l}\text { glutathione } \\
\text { S-transferase A3 }\end{array}$ & NM_001077353 & 0.061 & 0.953 & 11.415 & 0.127 & -0.725 & 9.233 & 0.006 & -1.656 & 7.577 \\
\hline GSTA4 & $\begin{array}{l}\text { glutathione } \\
\text { S-transferase A4 }\end{array}$ & NM_010357 & 0.04 & 0.853 & 11.386 & 0.122 & -0.589 & 11.975 & 0.004 & -1.441 & 10.533 \\
\hline GSTT1 & $\begin{array}{l}\text { glutathione } \\
\text { S-transferase theta } 1\end{array}$ & NM_008185 & 0.013 & 0.59 & 12.791 & 0.026 & -0.502 & 13.293 & 0.001 & -1.092 & 12.201 \\
\hline HMOX1 & $\begin{array}{l}\text { heme oxygenase } \\
\text { (decycling) } 1\end{array}$ & NM_010442 & 0.242 & -0.495 & 9.717 & 0.194 & 0.557 & 9.16 & 0.032 & 1.052 & 10.212 \\
\hline KEAP1 & $\begin{array}{l}\text { kelch-like } \\
\text { ECH-associated } \\
\text { protein } 1\end{array}$ & NM_001110305 & 0.017 & 0.972 & 9.352 & 0.174 & 0.466 & 8.886 & 0.145 & -0.505 & 8.381 \\
\hline LIPA & $\begin{array}{l}\text { lipase A, lysosomal } \\
\text { acid, cholesterol esterase } \\
\text { (Wolman disease) }\end{array}$ & NM_001111100 & 0.044 & -0.971 & 9.896 & 0.027 & 0.828 & 12.45 & 0.002 & 1.498 & 13.949 \\
\hline MAOB & monoamine oxidase $\mathrm{B}$ & NM_172778 & 0.038 & 0.463 & 12.2 & 0.035 & -0.473 & 12.673 & 0.002 & -0.936 & 11.737 \\
\hline MAP2K7 & $\begin{array}{l}\text { mitogen-activated protein } \\
\text { kinase kinase } 7\end{array}$ & NM_001042557 & 0.114 & 0.613 & 4.499 & 0.271 & 0.348 & 3.444 & 0.032 & -0.912 & 3.887 \\
\hline MAP3K3 & $\begin{array}{l}\text { mitogen-activated protein } \\
\text { kinase kinase kinase } 3\end{array}$ & NM_011947 & 0.049 & -2.011 & 5.549 & 0.137 & -1.412 & 6.962 & 0.092 & -0.237 & 9.719 \\
\hline MAPK14 & $\begin{array}{l}\text { mitogen-activated } \\
\text { protein kinase } 14\end{array}$ & NM_011951 & 0.002 & 0.846 & 7.58 & 0.062 & -0.064 & 12.45 & 0 & -0.194 & 12.256 \\
\hline NFKB2 & $\begin{array}{l}\text { nuclear factor of kappa } \\
\text { light polypeptide gene } \\
\text { enhancer in B-cells } \\
2(\text { p } 49 / \text { p } 100)\end{array}$ & NM_019408 & 0.3 & -0.283 & 8.379 & 0.045 & 0.625 & 7.754 & 0.01 & 0.908 & 8.662 \\
\hline
\end{tabular}


Continued

\begin{tabular}{|c|c|c|c|c|c|c|c|c|c|c|c|}
\hline NRIP1 & $\begin{array}{l}\text { nuclear receptor } \\
\text { interacting protein } 1\end{array}$ & NM_173440 & 0.002 & 0.675 & 10.356 & 0.004 & -0.572 & 10.928 & 0 & -1.247 & 9.681 \\
\hline PIK3CA & $\begin{array}{l}\text { phosphoinositide-3-kinase, } \\
\text { catalytic, alpha polypeptide }\end{array}$ & NM_008839 & 0.001 & 0.645 & 6.755 & 0.127 & -0.249 & 7.833 & 0 & -0.815 & 6.11 \\
\hline PIK3CD & $\begin{array}{l}\text { phosphoinositide-3-kinase, } \\
\text { catalytic, delta polypeptide }\end{array}$ & NM_001029837 & 0.053 & -0.548 & 6.216 & 0.256 & -0.386 & 9.26 & 0.012 & 0.813 & 6.764 \\
\hline PIK3R1 & $\begin{array}{l}\text { phosphoinositide-3-kinase, } \\
\text { regulatory subunit } 1 \text { (alpha) }\end{array}$ & NM_001024955 & 0.009 & 0.628 & 9.645 & 0.001 & -0.697 & 13.043 & 0 & -1.402 & 9.017 \\
\hline PIK3R3 & $\begin{array}{l}\text { phosphoinositide-3-kinase, } \\
\text { regulatory subunit } 3 \text { (gamma) }\end{array}$ & NM_181585 & 0.281 & -0.286 & 7.827 & 0.06 & 0.555 & 7.271 & 0.012 & 0.841 & 8.112 \\
\hline PIK3R5 & $\begin{array}{l}\text { phosphoinositide-3-kinase, } \\
\text { regulatory subunit } 5\end{array}$ & NM_177320 & 0.155 & -0.692 & 7.33 & 0.022 & 1.299 & 6.031 & 0.003 & 1.991 & 8.022 \\
\hline $\begin{array}{l}\text { PPP2R3A } \\
\text { (includes EG:5523) }\end{array}$ & $\begin{array}{l}\text { protein phosphatase } 2 \\
\text { (formerly } 2 \text { A), regulatory } \\
\text { subunit B", alpha }\end{array}$ & XM_001474396 & 0.007 & 0.486 & 6.878 & 0.004 & -0.55 & 7.428 & 0 & -1.036 & 6.392 \\
\hline PRKCH & $\begin{array}{l}\text { protein kinase } \mathrm{C} \text {, } \\
\text { eta }\end{array}$ & NM_008856 & 0.087 & -0.743 & 10.472 & 0.027 & 0.997 & 7.892 & 0.003 & 1.594 & 9.486 \\
\hline PRKD1 & protein kinase D1 & NM_008858 & 0 & 0.377 & 10.713 & 0 & -0.515 & 11.227 & 0 & -0.892 & 10.336 \\
\hline SULT1A1 & $\begin{array}{l}\text { sulfotransferase family, } \\
\text { cytosolic, 1A, } \\
\text { phenol-preferring, } \\
\text { member } 1\end{array}$ & NM_133670 & 0.054 & 0.635 & 13.709 & 0.529 & -0.179 & 13.888 & 0.022 & -0.814 & 13.073 \\
\hline SULT1E1 & $\begin{array}{l}\text { sulfotransferase family } \\
1 \mathrm{E} \text {, estrogen-preferring, } \\
\text { member } 1\end{array}$ & NM_023135 & 0.056 & 0.446 & 10.503 & 0.004 & -0.856 & 11.36 & 0 & -1.303 & 10.057 \\
\hline \multicolumn{12}{|c|}{$\begin{array}{l}\text { LPS/IL-1 Mediated Inhibition } \\
\text { of RXR Function }\end{array}$} \\
\hline $\mathrm{ABCB} 1$ & $\begin{array}{l}\text { ATP-binding cassette, } \\
\text { sub-family } \\
\text { B (MDR/TAP), } \\
\text { member } 1\end{array}$ & NM_011076 & 0.006 & 0.761 & 5.988 & 0.157 & -0.401 & 8.141 & 0.001 & -1.052 & 5.227 \\
\hline ABCG1 & $\begin{array}{l}\text { ATP-binding cassette, } \\
\text { sub-family G (WHITE), } \\
\text { member } 1\end{array}$ & NM_009593 & 0.097 & -0.535 & 11.624 & 0.022 & 0.827 & 10.798 & 0.002 & 1.361 & 12.159 \\
\hline ALDH3B1 & $\begin{array}{l}\text { aldehyde dehydrogenase } \\
3 \text { family, member B1 }\end{array}$ & NM_026316 & 0.017 & -0.56 & 7.848 & 0.046 & 0.431 & 7.417 & 0.001 & 0.992 & 8.409 \\
\hline ALDH5A1 & $\begin{array}{l}\text { aldehyde dehydrogenase } \\
5 \text { family, member } \\
\text { A1 (succinate-semialdehyde } \\
\text { dehydrogenase) }\end{array}$ & NM_172532 & 0.012 & 0.802 & 10.108 & 0.459 & -0.18 & 10.288 & 0.004 & -0.982 & 9.306 \\
\hline ALDH6A1 & $\begin{array}{l}\text { aldehyde dehydrogenase } \\
6 \text { family, member A1 }\end{array}$ & NM_134042 & 0.002 & 0.503 & 12.566 & 0.009 & -0.359 & 12.925 & 0 & -0.862 & 12.064 \\
\hline APOC2 & apolipoprotein C-II & NM_009695 & 0.187 & -0.44 & 9.316 & 0.073 & 0.639 & 8.677 & 0.01 & 1.08 & 9.756 \\
\hline $\begin{array}{l}\text { APOC4 } \\
\text { (includes EG:346) }\end{array}$ & apolipoprotein C-IV & NM_007385 & 0 & -2.248 & 2.126 & 0.996 & 0.001 & 2.125 & 0 & 2.249 & 4.375 \\
\hline CHST11 & $\begin{array}{l}\text { carbohydrate } \\
\text { (chondroitin 4) } \\
\text { sulfotransferase } 11\end{array}$ & NM_021439 & 0.112 & -0.274 & 2.418 & 0.025 & 0.687 & 8.607 & 0.01 & 0.85 & 9.457 \\
\hline FABP4 & $\begin{array}{l}\text { fatty acid binding } \\
\text { protein } 4 \text {, adipocyte }\end{array}$ & NM_024406 & 0.001 & 1.771 & 10.72 & 0.438 & -0.247 & 10.967 & 0 & -2.018 & 8.949 \\
\hline FABP5 & $\begin{array}{l}\text { fatty acid binding } \\
\text { protein } 5 \\
\text { (psoriasis-associated) }\end{array}$ & NM_010634 & 0.018 & -0.471 & 13.231 & 0.007 & 0.594 & 12.636 & 0 & 1.065 & 13.702 \\
\hline FABP7 & $\begin{array}{l}\text { fatty acid binding } \\
\text { protein } 7 \text {, brain }\end{array}$ & NM_021272 & 0.032 & -1.602 & 5.956 & 0.017 & 1.882 & 4.074 & 0.001 & 3.484 & 7.558 \\
\hline FMO1 & $\begin{array}{l}\text { flavin containing } \\
\text { monooxygenase } 1\end{array}$ & NM_010231 & 0.033 & 0.909 & 13.444 & 0.163 & -0.526 & 13.971 & 0.004 & -1.435 & 12.536 \\
\hline
\end{tabular}


Continued

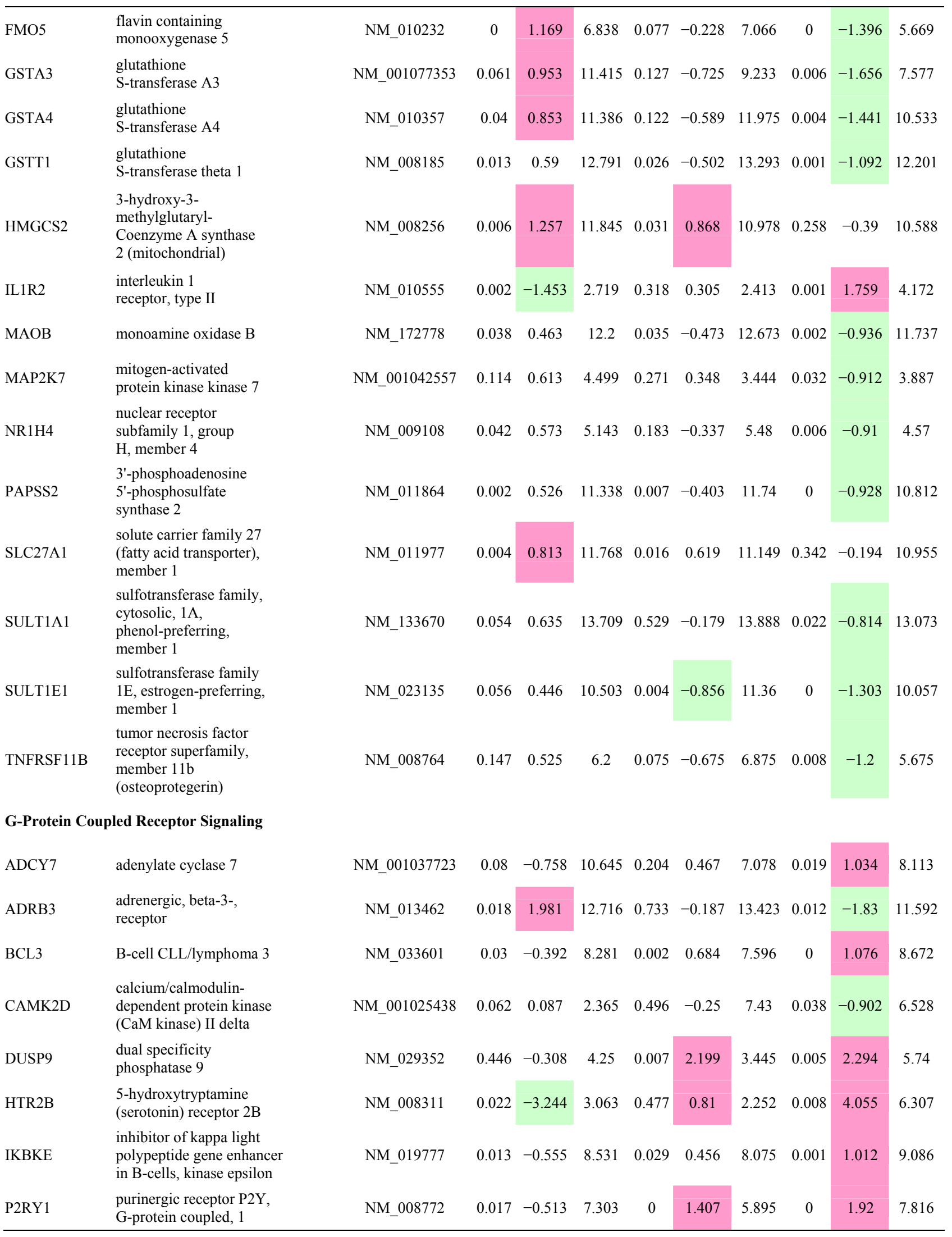


Continued

\begin{tabular}{|c|c|c|c|c|c|c|c|c|c|c|c|}
\hline P2RY6 & $\begin{array}{l}\text { pyrimidinergic receptor } \\
\text { P2Y, G-protein coupled, } 6\end{array}$ & NM_183168 & 0.047 & -0.82 & 11.171 & 0.169 & 0.518 & 10.653 & 0.006 & 1.338 & 11.991 \\
\hline PDE1A & $\begin{array}{l}\text { phosphodiesterase } \\
1 \mathrm{~A}, \text { calmodulin- } \\
\text { dependent }\end{array}$ & NM_001009978 & 0.003 & 1.239 & 8.699 & 0.059 & -0.608 & 9.306 & 0 & -1.847 & 7.46 \\
\hline PDE2A & $\begin{array}{l}\text { phosphodiesterase } 2 \mathrm{~A} \text {, } \\
\text { cGMP-stimulated }\end{array}$ & NM_001008548 & 0.148 & -0.252 & 10.092 & 0.004 & 0.683 & 9.41 & 0.001 & 0.935 & 10.345 \\
\hline PDE7A & phosphodiesterase 7A & NM_001122759 & 0.14 & -0.436 & 8.998 & 0.003 & 1.237 & 8.55 & 0.001 & 1.448 & 9.997 \\
\hline PDE8B & phosphodiesterase 8B & NM_172263 & 0.043 & -1.083 & 3.146 & 0.803 & 0.111 & 3.035 & 0.03 & 1.194 & 4.229 \\
\hline PIK3CD & $\begin{array}{l}\text { phosphoinositide-3-kinase, } \\
\text { catalytic, delta polypeptide }\end{array}$ & NM_001029837 & 0.053 & -0.548 & 6.216 & 0.256 & -0.386 & 9.26 & 0.012 & 0.813 & 6.764 \\
\hline PIK3R1 & $\begin{array}{l}\text { phosphoinositide-3-kinase, } \\
\text { regulatory subunit } 1 \text { (alpha) }\end{array}$ & NM_001024955 & 0.009 & 0.628 & 9.645 & 0.001 & -0.697 & 13.043 & 0 & -1.402 & 9.017 \\
\hline PIK3R3 & $\begin{array}{l}\text { phosphoinositide-3-kinase, } \\
\text { regulatory subunit } 3 \text { (gamma) }\end{array}$ & NM_181585 & 0.281 & -0.286 & 7.827 & 0.06 & 0.555 & 7.271 & 0.012 & 0.841 & 8.112 \\
\hline PIK3R5 & $\begin{array}{l}\text { phosphoinositide-3-kinase, } \\
\text { regulatory subunit } 5\end{array}$ & NM_177320 & 0.155 & -0.692 & 7.33 & 0.022 & 1.299 & 6.031 & 0.003 & 1.991 & 8.022 \\
\hline PLCB4 & phospholipase C, beta 4 & NM_013829 & 0.015 & 1.036 & 4.286 & 0.28 & -0.212 & 10.733 & 0.01 & -1.154 & 3.251 \\
\hline RGS18 & $\begin{array}{l}\text { regulator of G-protein } \\
\text { signaling } 18\end{array}$ & NM_022881 & 0.026 & -0.815 & 9.106 & 0.629 & 0.151 & 8.392 & 0.016 & 0.915 & 9.921 \\
\hline RGS4 & $\begin{array}{l}\text { regulator of G-protein } \\
\text { signaling } 4\end{array}$ & NM_009062 & 0.004 & 1.013 & 6.633 & 0.074 & 0.496 & 6.137 & 0.065 & -0.517 & 5.619 \\
\hline \multicolumn{12}{|c|}{ TR/RXR Activation } \\
\hline ACACA & $\begin{array}{l}\text { acetyl-Coenzyme A } \\
\text { carboxylase alpha }\end{array}$ & NM_133360 & 0.912 & 0.064 & 3.113 & 0.009 & -2.07 & 5.182 & 0.008 & -2.134 & 3.048 \\
\hline BCL3 & B-cell CLL/lymphoma 3 & NM_033601 & 0.03 & -0.392 & 8.281 & 0.002 & 0.684 & 7.596 & 0 & 1.076 & 8.672 \\
\hline F10 & coagulation factor $\mathrm{X}$ & NM_007972 & 0.11 & -0.315 & 3.27 & 0.002 & 1.908 & 6.065 & 0 & 1.201 & 3.585 \\
\hline FRAP1 & $\begin{array}{l}\text { FK506 binding protein } \\
\text { 12-rapamycin } \\
\text { associated protein } 1\end{array}$ & NM_020009 & 0.05 & -0.825 & 4.157 & 0.274 & -0.144 & 10.371 & 0.031 & 0.938 & 4.981 \\
\hline KLF9 & Kruppel-like factor 9 & NM_010638 & 0.003 & 0.552 & 12.606 & 0.002 & -0.476 & 13.011 & 0 & -0.861 & 12.15 \\
\hline LDLR & $\begin{array}{l}\text { low density lipoprotein } \\
\text { receptor (familial } \\
\text { hypercholesterolemia) }\end{array}$ & NM_010700 & 0 & -0.928 & 9.28 & 0.237 & -0.036 & 3.487 & 0 & 0.9 & 10.207 \\
\hline NCOR1 & $\begin{array}{l}\text { nuclear receptor } \\
\text { co-repressor } 1\end{array}$ & NM_011308 & 0.002 & 0.864 & 8.333 & 0.039 & -0.595 & 5.03 & 0.001 & -1.134 & 7.47 \\
\hline PCK1 & $\begin{array}{l}\text { phosphoenolpyruvate } \\
\text { carboxykinase } 1 \\
\text { (soluble) }\end{array}$ & NM_011044 & 0.002 & 2.193 & 12.827 & 0.783 & 0.181 & 12.921 & 0.002 & -2.229 & 10.633 \\
\hline PIK3CA & $\begin{array}{l}\text { phosphoinositide- } \\
\text { 3-kinase, catalytic, } \\
\text { alpha polypeptide }\end{array}$ & NM_008839 & 0.001 & 0.645 & 6.755 & 0.127 & -0.249 & 7.833 & 0 & -0.815 & 6.11 \\
\hline
\end{tabular}




\section{Continued}

\begin{tabular}{|c|c|c|c|c|c|c|c|c|c|c|c|}
\hline PIK3CD & $\begin{array}{l}\text { phosphoinositide-3- } \\
\text { kinase, catalytic, } \\
\text { delta polypeptide }\end{array}$ & NM_001029837 & 0.053 & -0.548 & 6.216 & 0.256 & -0.386 & 9.26 & 0.012 & 0.813 & 6.764 \\
\hline PIK3R3 & $\begin{array}{l}\text { phosphoinositide-3- } \\
\text { kinase, regulatory } \\
\text { subunit } 3 \text { (gamma) }\end{array}$ & NM_181585 & 0.281 & -0.286 & 7.827 & 0.06 & 0.555 & 7.271 & 0.012 & 0.841 & 8.112 \\
\hline PIK3R5 & $\begin{array}{l}\text { phosphoinositide-3- } \\
\text { kinase, regulatory } \\
\text { subunit } 5\end{array}$ & NM_177320 & 0.155 & -0.692 & 7.33 & 0.022 & 1.299 & 6.031 & 0.003 & 1.991 & 8.022 \\
\hline THRA & $\begin{array}{l}\text { thyroid hormone receptor, } \\
\text { alpha (erythroblastic } \\
\text { leukemia viral } \\
\text { (v-erb-a) oncogene } \\
\text { homolog, avian) }\end{array}$ & NM_178060 & 0.011 & 0.496 & 11.44 & 0.007 & -0.551 & 11.991 & 0 & -1.047 & 10.944 \\
\hline UCP2 & $\begin{array}{l}\text { uncoupling protein } \\
2 \text { (mitochondrial, } \\
\text { proton carrier) }\end{array}$ & NM_011671 & 0.056 & -0.533 & 12.598 & 0.009 & 0.836 & 11.761 & 0.001 & 1.369 & 13.13 \\
\hline \multicolumn{12}{|c|}{ Sonic Hedgehog Signaling } \\
\hline $\mathrm{C} 2$ & complement component 2 & NM_013484 & 0.005 & 0.859 & 12.656 & 0.057 & -0.441 & 14.039 & 0.001 & -1.319 & 11.797 \\
\hline C3AR1 & $\begin{array}{l}\text { complement component } \\
\text { 3a receptor } 1\end{array}$ & NM_009779 & 0.037 & -1.017 & 11.903 & 0.062 & 1.088 & 10.166 & 0.003 & 1.917 & 11.113 \\
\hline C5AR1 & $\begin{array}{l}\text { complement component } \\
\text { 5a receptor } 1\end{array}$ & NM_008555 & 0.996 & -0.002 & 3.631 & 0.012 & -1.298 & 4.929 & 0.012 & -1.296 & 3.633 \\
\hline CCNB1 & cyclin B1 & NM_007577 & 0.094 & -0.801 & 8.231 & 0.072 & 0.665 & 9.86 & 0.011 & 1.095 & 10.955 \\
\hline GLI2 & $\begin{array}{l}\text { GLI-Kruppel family } \\
\text { member GLI2 }\end{array}$ & NM_172301 & 0.026 & -1.571 & 5.055 & 0.064 & 1.214 & 3.841 & 0.002 & 2.785 & 6.626 \\
\hline MASP1 & $\begin{array}{l}\text { mannan-binding lectin } \\
\text { serine peptidase } 1 \\
\text { (C4/C2 activating } \\
\text { component of } \\
\text { Ra-reactive factor) }\end{array}$ & NM_007659 & 0.013 & -1.395 & 8.342 & 0.02 & 1.253 & 7.088 & 0 & 2.648 & 9.736 \\
\hline \multicolumn{12}{|c|}{ Cell Cycle: G1/S Checkpoint Regulation } \\
\hline CCNE1 & cyclin E1 & NM_007633 & 0.071 & -0.671 & 7.728 & 0.14 & 0.523 & 7.205 & 0.008 & 1.194 & 8.398 \\
\hline CDK6 & cyclin-dependent kinase 6 & NM_009873 & 0.024 & -0.762 & 9.029 & 0.093 & 0.629 & 7.834 & 0.003 & 1.211 & 9.791 \\
\hline CDKN1A & $\begin{array}{l}\text { cyclin-dependent kinase } \\
\text { inhibitor } 1 \mathrm{~A}(\mathrm{p} 21, \mathrm{Cip} 1)\end{array}$ & NM_001111099 & 0.026 & -0.679 & 9.893 & 0.001 & 1.468 & 8.425 & 0 & 2.146 & 10.571 \\
\hline CDKN1B & $\begin{array}{l}\text { cyclin-dependent kinase } \\
\text { inhibitor } 1 \mathrm{~B}(\mathrm{p} 27, \mathrm{Kip} 1)\end{array}$ & NM_009875 & 0.125 & 0.39 & 8.696 & 0.093 & -0.436 & 9.132 & 0.009 & -0.826 & 8.306 \\
\hline CDKN2B & $\begin{array}{l}\text { cyclin-dependent kinase } \\
\text { inhibitor } 2 \mathrm{~B} \\
\text { (p15, inhibits CDK4) }\end{array}$ & NM_007670 & 0 & -1.013 & 9.99 & 0.835 & 0.032 & 9.957 & 0 & 1.045 & 11.003 \\
\hline $\mathrm{E} 2 \mathrm{~F} 1$ & E2F transcription factor 1 & NM_007891 & 0.085 & -0.354 & 6.977 & 0.016 & 0.663 & 8.141 & 0.002 & 0.904 & 7.331 \\
\hline E2F6 & E2F transcription factor 6 & NM_033270 & 0.009 & -1.162 & 7.857 & 0.014 & 1.06 & 6.797 & 0 & 2.222 & 9.019 \\
\hline HDAC11 & histone deacetylase 11 & NM_144919 & 0.015 & 0.825 & 6.416 & 0.229 & -0.036 & 2.48 & 0.017 & -0.8 & 5.59 \\
\hline
\end{tabular}


Continued

\begin{tabular}{|c|c|c|c|c|c|c|c|c|c|c|c|}
\hline HDAC9 & histone deacetylase 9 & NM_024124 & 0.11 & -0.461 & 8.363 & 0.131 & 0.43 & 7.933 & 0.011 & 0.891 & 8.824 \\
\hline RB1 & $\begin{array}{l}\text { retinoblastoma } 1 \\
\text { (including } \\
\text { osteosarcoma) }\end{array}$ & NM_009029 & 0.038 & -0.65 & 4.483 & 0.098 & 0.483 & 4.001 & 0.003 & 1.133 & 5.134 \\
\hline SKP2 & $\begin{array}{l}\text { S-phase kinase- } \\
\text { associated protein } \\
2(\mathrm{p} 45)\end{array}$ & NM_013787 & 0.214 & -0.599 & 3.876 & 0.138 & 0.737 & 3.139 & 0.02 & 1.337 & 4.476 \\
\hline TGFB3 & $\begin{array}{l}\text { transforming growth } \\
\text { factor, beta } 3\end{array}$ & NM_009368 & 0.001 & 0.495 & 10.669 & 0.009 & -0.337 & 11.006 & 0 & -0.832 & 10.174 \\
\hline
\end{tabular}

\section{GM-CSF Signaling}

$\begin{array}{ll}\text { BCL2A1 } & \begin{array}{l}\text { BCL2-related protein A1 } \\ \text { calcium/calmodulin- } \\ \text { dependent protein } \\ \text { kinase (CaM kinase) } \\ \text { II delta }\end{array} \\ \text { CAMK2D } & \text { hemopoietic cell kinase } \\ \text { HCK } & \begin{array}{l}\text { v-yes-1 Yamaguchi } \\ \text { sarcoma viral related } \\ \text { oncogene homolog }\end{array} \\ \text { LYN } & \begin{array}{l}\text { phosphoinositide-3-kinase, } \\ \text { catalytic, alpha polypeptide } \\ \text { phosphoinositide-3-kinase, } \\ \text { catalytic, delta polypeptide }\end{array} \\ \text { PIK3CD } & \begin{array}{l}\text { phosphoinositide-3-kinase, } \\ \text { regulatory subunit 1 (alpha) } \\ \text { phosphoinositide-3-kinase, } \\ \text { PIK3R1 }\end{array} \\ \text { regulatory subunit 3 (gamma) } \\ \text { PIK3R3 }\end{array}$

\section{LXR/RXR Activation}

$\begin{array}{ll}\text { ABCG1 } & \begin{array}{l}\text { ATP-binding cassette, } \\ \text { sub-family G (WHITE), } \\ \text { member 1 }\end{array} \\ \text { ACACA } & \begin{array}{l}\text { acetyl-Coenzyme A } \\ \text { carboxylase alpha }\end{array} \\ \text { APOC2 } & \text { apolipoprotein C-II } \\ \text { APOC4 } & \text { apolipoprotein C-IV } \\ \text { (includes EG:346) } & \begin{array}{l}\text { chemokine (C-C motif) } \\ \text { ligand 7 }\end{array} \\ \text { interleukin 1 receptor, } \\ \text { type II } \\ \text { IL1R2 } & \begin{array}{l}\text { interleukin 1 receptor } \\ \text { antagonist } \\ \text { low density lipoprotein } \\ \text { receptor (familial } \\ \text { hypercholesterolemia) }\end{array} \\ & \end{array}$


Continued

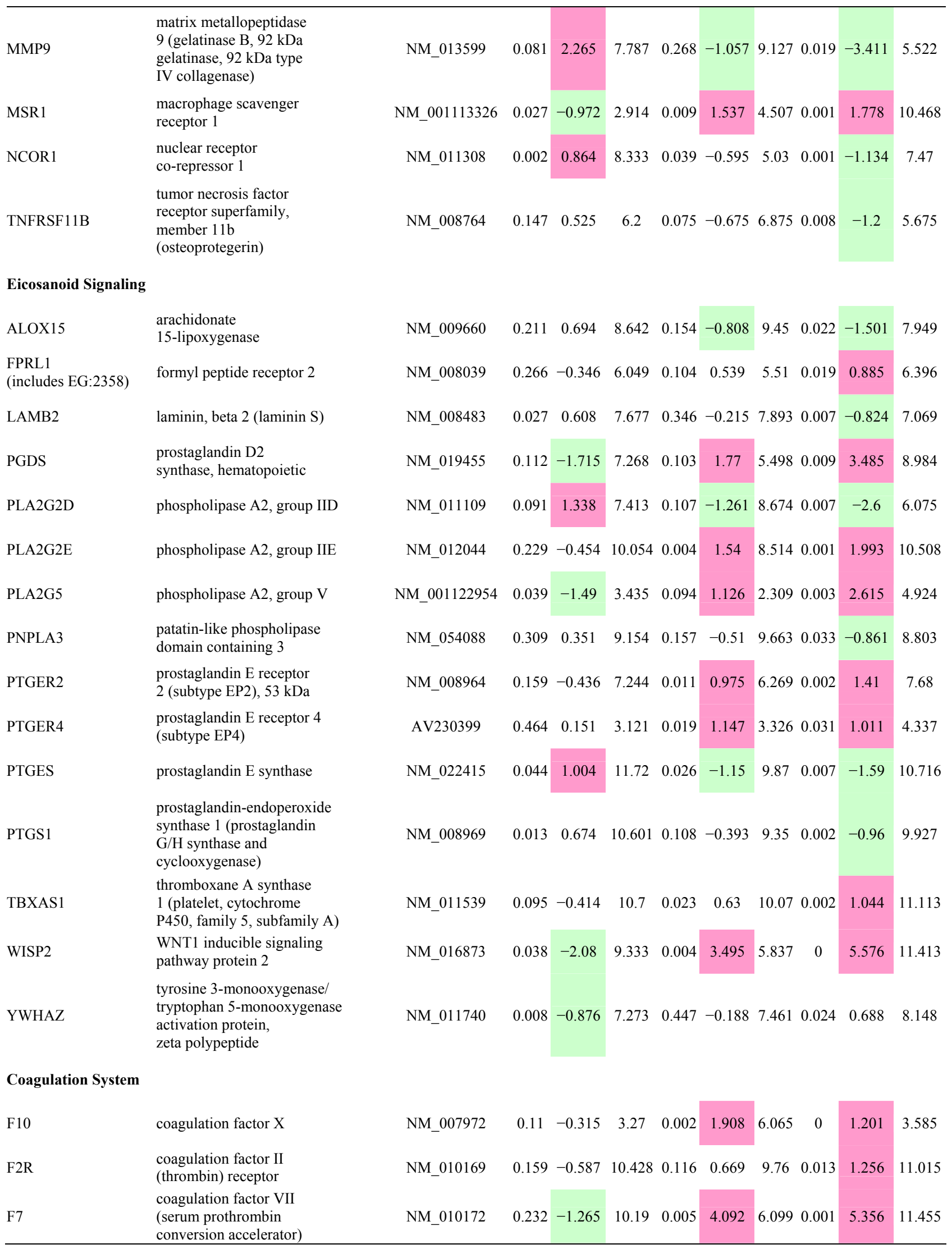


Continued

\begin{tabular}{|c|c|c|c|c|c|c|c|c|c|c|c|}
\hline PLAUR & $\begin{array}{l}\text { plasminogen activator, } \\
\text { urokinase receptor }\end{array}$ & NM_011113 & 0.009 & -0.415 & 9.151 & 0 & 0.855 & 8.296 & 0 & 1.27 & 9.565 \\
\hline SERPINA1 & $\begin{array}{l}\text { serpin peptidase inhibitor, } \\
\text { clade A (alpha-1 } \\
\text { antiproteinase, antitrypsin), } \\
\text { member } 1\end{array}$ & NM_009243 & 0.002 & -1.046 & 4.653 & 0.264 & 0.242 & 4.411 & 0 & 1.288 & 5.699 \\
\hline SERPINE1 & $\begin{array}{l}\text { serpin peptidase inhibitor, } \\
\text { clade E (nexin, plasminogen } \\
\text { activator inhibitor type } 1 \text { ), } \\
\text { member } 1\end{array}$ & NM_008871 & 0.044 & -1.615 & 8.757 & 0.403 & 0.578 & 8.179 & 0.013 & 2.194 & 10.373 \\
\hline TFPI & $\begin{array}{l}\text { tissue factor pathway } \\
\text { inhibitor (lipoprotein- } \\
\text { associated } \\
\text { coagulation inhibitor) }\end{array}$ & NM_011576 & 0.045 & 0.771 & 8.877 & 0.004 & -0.514 & 9.297 & 0.002 & -1.422 & 9.384 \\
\hline THBD & thrombomodulin & NM_009378 & 0.001 & 0.777 & 12.751 & 0.001 & -0.829 & 13.58 & 0 & -1.606 & 11.974 \\
\hline \multicolumn{12}{|c|}{ Aryl Hydrocarbon Receptor Signaling } \\
\hline ALDH3B1 & $\begin{array}{l}\text { aldehyde dehydrogenase } \\
3 \text { family, member B1 }\end{array}$ & NM_026316 & 0.017 & -0.56 & 7.848 & 0.046 & 0.431 & 7.417 & 0.001 & 0.992 & 8.409 \\
\hline ALDH5A1 & $\begin{array}{l}\text { aldehyde dehydrogenase } 5 \\
\text { family, member A1 } \\
\text { (succinate-semialdehyde } \\
\text { dehydrogenase) }\end{array}$ & NM_172532 & 0.012 & 0.802 & 10.108 & 0.459 & -0.18 & 10.288 & 0.004 & -0.982 & 9.306 \\
\hline ALDH6A1 & $\begin{array}{l}\text { aldehyde dehydrogenase } 6 \\
\text { family, member A1 }\end{array}$ & NM_134042 & 0.002 & 0.503 & 12.566 & 0.009 & -0.359 & 12.925 & 0 & -0.862 & 12.064 \\
\hline ARNT & $\begin{array}{l}\text { aryl hydrocarbon receptor } \\
\text { nuclear translocator }\end{array}$ & NM_001037737 & 0.01 & 0.831 & 6.119 & 0.002 & -0.259 & 8.705 & 0 & -0.425 & 8.28 \\
\hline BAX & BCL2-associated $X$ protein & NM_007527 & 0.033 & -0.451 & 11.466 & 0.056 & 0.386 & 11.079 & 0.002 & 0.837 & 11.917 \\
\hline CCNA2 & cyclin A2 & NM_009828 & 0.02 & -1.43 & 7.361 & 0.015 & 1.519 & 5.842 & 0.001 & 2.949 & 8.79 \\
\hline CCNE1 & cyclin E1 & NM_007633 & 0.071 & -0.671 & 7.728 & 0.14 & 0.523 & 7.205 & 0.008 & 1.194 & 8.398 \\
\hline CDK6 & cyclin-dependent kinase 6 & NM_009873 & 0.024 & -0.762 & 9.029 & 0.093 & 0.629 & 7.834 & 0.003 & 1.211 & 9.791 \\
\hline CDKN1A & $\begin{array}{l}\text { cyclin-dependent kinase } \\
\text { inhibitor } 1 \mathrm{~A}(\mathrm{p} 21, \mathrm{Cip} 1)\end{array}$ & NM_001111099 & 0.026 & -0.679 & 9.893 & 0.001 & 1.468 & 8.425 & 0 & 2.146 & 10.571 \\
\hline CDKN1B & $\begin{array}{l}\text { cyclin-dependent kinase } \\
\text { inhibitor } 1 \mathrm{~B}(\mathrm{p} 27, \mathrm{Kip} 1)\end{array}$ & NM_009875 & 0.125 & 0.39 & 8.696 & 0.093 & -0.436 & 9.132 & 0.009 & -0.826 & 8.306 \\
\hline $\mathrm{E} 2 \mathrm{~F} 1$ & E2F transcription factor 1 & NM_007891 & 0.085 & -0.354 & 6.977 & 0.016 & 0.663 & 8.141 & 0.002 & 0.904 & 7.331 \\
\hline ESR1 & estrogen receptor 1 & NM_007956 & 0.041 & 0.52 & 6.097 & 0.033 & -0.551 & 6.648 & 0.002 & -1.071 & 5.577 \\
\hline FOS & $\begin{array}{l}\text { v-fos FBJ murine } \\
\text { osteosarcoma viral } \\
\text { oncogene homolog }\end{array}$ & NM_010234 & 0.077 & -1.089 & 10.759 & 0.207 & 0.725 & 10.034 & 0.012 & 1.813 & 11.848 \\
\hline GSTA3 & $\begin{array}{l}\text { glutathione } \\
\text { S-transferase A3 }\end{array}$ & NM_001077353 & 0.061 & 0.953 & 11.415 & 0.127 & -0.725 & 9.233 & 0.006 & -1.656 & 7.577 \\
\hline GSTA4 & $\begin{array}{l}\text { glutathione } \\
\text { S-transferase A4 }\end{array}$ & NM_010357 & 0.04 & 0.853 & 11.386 & 0.122 & -0.589 & 11.975 & 0.004 & -1.441 & 10.533 \\
\hline GSTT1 & $\begin{array}{l}\text { glutathione } \\
\text { S-transferase theta } 1\end{array}$ & NM_008185 & 0.013 & 0.59 & 12.791 & 0.026 & -0.502 & 13.293 & 0.001 & -1.092 & 12.201 \\
\hline HSPB2 & $\begin{array}{l}\text { heat shock } \\
27 \mathrm{kDa} \text { protein } 2\end{array}$ & NM_024441 & 0.003 & -0.869 & 8.93 & 0.083 & 0.393 & 8.537 & 0 & 1.262 & 9.799 \\
\hline NFIA & nuclear factor I/A & NM_001122952 & 0.002 & 0.799 & 6.289 & 0.004 & -0.657 & 6.946 & 0 & -1.456 & 5.49 \\
\hline
\end{tabular}


Continued

\begin{tabular}{|c|c|c|c|c|c|c|c|c|c|c|c|}
\hline NFKB2 & $\begin{array}{l}\text { nuclear factor of kappa } \\
\text { light polypeptide gene } \\
\text { enhancer in B-cells } 2 \\
\text { (p49/p100) }\end{array}$ & NM_019408 & 0.3 & -0.283 & 8.379 & 0.045 & 0.625 & 7.754 & 0.01 & 0.908 & 8.662 \\
\hline NR2F1 & $\begin{array}{l}\text { nuclear receptor subfamily } \\
2, \text { group F, member } 1\end{array}$ & NM_010151 & 0.022 & 0.744 & 5.675 & 0.052 & -0.594 & 6.269 & 0.001 & -1.338 & 4.931 \\
\hline NRIP1 & $\begin{array}{l}\text { nuclear receptor interacting } \\
\text { protein } 1\end{array}$ & NM_173440 & 0.002 & 0.675 & 10.356 & 0.004 & -0.572 & 10.928 & 0 & -1.247 & 9.681 \\
\hline $\mathrm{RB} 1$ & $\begin{array}{l}\text { retinoblastoma } 1 \\
\text { (including osteosarcoma) }\end{array}$ & NM_009029 & 0.038 & -0.65 & 4.483 & 0.098 & 0.483 & 4.001 & 0.003 & 1.133 & 5.134 \\
\hline TGFB3 & $\begin{array}{l}\text { transforming growth factor, } \\
\text { beta } 3\end{array}$ & NM_009368 & 0.001 & 0.495 & 10.669 & 0.009 & -0.337 & 11.006 & 0 & -0.832 & 10.174 \\
\hline \multicolumn{12}{|c|}{ NFkB Signaling } \\
\hline BCL3 & B-cell CLL/lymphoma 3 & NM_033601 & 0.03 & -0.392 & 8.281 & 0.002 & 0.684 & 7.596 & 0 & 1.076 & 8.672 \\
\hline BMP4 & $\begin{array}{l}\text { bone morphogenetic } \\
\text { protein } 4\end{array}$ & NM_007554 & 0.004 & 1.211 & 10.683 & 0.476 & -0.209 & 10.892 & 0.002 & -1.421 & 9.471 \\
\hline CARD10 & $\begin{array}{l}\text { caspase recruitment } \\
\text { domain family, member } 10\end{array}$ & NM_130859 & 0.006 & 0.725 & 11.039 & 0.286 & -0.209 & 11.248 & 0.002 & -0.934 & 10.315 \\
\hline CD40 & $\begin{array}{l}\text { CD40 molecule, TNF } \\
\text { receptor superfamily } \\
\text { member } 5\end{array}$ & NM_011611 & 0.005 & -0.654 & 7.344 & 0.168 & 0.241 & 7.103 & 0.001 & 0.895 & 7.998 \\
\hline EGFR & $\begin{array}{l}\text { epidermal growth factor } \\
\text { receptor (erythroblastic } \\
\text { leukemia viral (v-erb-b) } \\
\text { oncogene homolog, avian) }\end{array}$ & NM_007912 & 0.251 & 0.419 & 4.992 & 0.095 & -0.381 & 9.611 & 0.024 & -0.976 & 4.573 \\
\hline IL1R2 & $\begin{array}{l}\text { interleukin } 1 \text { receptor, } \\
\text { type II }\end{array}$ & NM_010555 & 0.002 & -1.453 & 2.719 & 0.318 & 0.305 & 2.413 & 0.001 & 1.759 & 4.172 \\
\hline IL1RN & $\begin{array}{l}\text { interleukin } 1 \text { receptor } \\
\text { antagonist }\end{array}$ & NM_001039701 & 0.005 & -1.805 & 2.203 & 0 & 3.3 & 3.963 & 0 & 4.59 & 8.553 \\
\hline INSR & insulin receptor & NM_001033381 & 0 & 0.668 & 9.937 & 0.022 & -0.275 & 10.212 & 0 & -0.943 & 9.269 \\
\hline MAP2K7 & $\begin{array}{l}\text { mitogen-activated protein } \\
\text { kinase kinase } 7\end{array}$ & NM_001042557 & 0.114 & 0.613 & 4.499 & 0.271 & 0.348 & 3.444 & 0.032 & -0.912 & 3.887 \\
\hline MAP3K3 & $\begin{array}{l}\text { mitogen-activated protein } \\
\text { kinase kinase kinase } 3\end{array}$ & NM_011947 & 0.049 & -2.011 & 5.549 & 0.137 & -1.412 & 6.962 & 0.092 & -0.237 & 9.719 \\
\hline NFKB2 & $\begin{array}{l}\text { nuclear factor of kappa } \\
\text { light polypeptide gene } \\
\text { enhancer in B-cells } 2 \\
\text { (p49/p100) }\end{array}$ & NM_019408 & 0.3 & -0.283 & 8.379 & 0.045 & 0.625 & 7.754 & 0.01 & 0.908 & 8.662 \\
\hline PIK3CA & $\begin{array}{l}\text { phosphoinositide-3-kinase, } \\
\text { catalytic, alpha polypeptide }\end{array}$ & NM_008839 & 0.001 & 0.645 & 6.755 & 0.127 & -0.249 & 7.833 & 0 & -0.815 & 6.11 \\
\hline PIK3CD & $\begin{array}{l}\text { phosphoinositide-3-kinase, } \\
\text { catalytic, delta polypeptide }\end{array}$ & NM_001029837 & 0.053 & -0.548 & 6.216 & 0.256 & -0.386 & 9.26 & 0.012 & 0.813 & 6.764 \\
\hline PIK3R1 & $\begin{array}{l}\text { phosphoinositide-3-kinase, } \\
\text { regulatory subunit } 1 \text { (alpha) }\end{array}$ & NM_001024955 & 0.009 & 0.628 & 9.645 & 0.001 & -0.697 & 13.043 & 0 & -1.402 & 9.017 \\
\hline PIK3R3 & $\begin{array}{l}\text { phosphoinositide-3-kinase, } \\
\text { regulatory subunit } 3 \text { (gamma) }\end{array}$ & NM_181585 & 0.281 & -0.286 & 7.827 & 0.06 & 0.555 & 7.271 & 0.012 & 0.841 & 8.112 \\
\hline PIK3R5 & $\begin{array}{l}\text { phosphoinositide-3-kinase, } \\
\text { regulatory subunit } 5\end{array}$ & NM_177320 & 0.155 & -0.692 & 7.33 & 0.022 & 1.299 & 6.031 & 0.003 & 1.991 & 8.022 \\
\hline TLR1 & toll-like receptor 1 & NM_030682 & 0.043 & -1.217 & 7.019 & 0.195 & 0.699 & 6.32 & 0.007 & 1.916 & 8.236 \\
\hline TLR7 & toll-like receptor 7 & NM_133211 & 0.083 & -0.704 & 3.197 & 0.405 & 0.317 & 7.567 & 0.042 & 0.904 & 8.47 \\
\hline TLR8 & toll-like receptor 8 & NM_133212 & 0.048 & -1.566 & 5.652 & 0.104 & 1.213 & 4.438 & 0.004 & 2.779 & 7.218 \\
\hline
\end{tabular}


Continued

\begin{tabular}{|c|c|c|c|c|c|c|c|c|c|c|c|}
\hline TNFRSF11A & $\begin{array}{l}\text { tumor necrosis factor } \\
\text { receptor superfamily, } \\
\text { member } 11 \mathrm{a}, \mathrm{NFKB} \\
\text { activator }\end{array}$ & NM_009399 & 0.046 & -0.864 & 2.489 & 0.385 & 0.345 & 4.948 & 0.018 & 1.169 & 6.117 \\
\hline TNFRSF11B & $\begin{array}{l}\text { tumor necrosis factor } \\
\text { receptor superfamily, } \\
\text { member } 11 \mathrm{~b} \\
\text { (osteoprotegerin) }\end{array}$ & NM_008764 & 0.147 & 0.525 & 6.2 & 0.075 & -0.675 & 6.875 & 0.008 & -1.2 & 5.675 \\
\hline TRA@ & $\begin{array}{l}\mathrm{T} \text { cell receptor alpha } \\
\text { locus }\end{array}$ & XM_001471582 & 0.038 & -1.438 & 8.857 & 0.035 & 1.472 & 7.385 & 0.002 & 2.909 & 10.295 \\
\hline TRAF3 & $\begin{array}{l}\text { TNF receptor-associated } \\
\text { factor } 3\end{array}$ & NM_001048206 & 0.046 & -0.562 & 3.927 & 0.146 & 0.376 & 3.551 & 0.005 & 0.939 & 4.489 \\
\hline TRAF5 & $\begin{array}{l}\text { TNF receptor-associated } \\
\text { factor } 5\end{array}$ & NM_011633 & 0.001 & -0.463 & 7.543 & 0 & 0.469 & 7.074 & 0 & 0.932 & 8.006 \\
\hline \multicolumn{12}{|c|}{ IGF-1 Signaling } \\
\hline FOS & $\begin{array}{l}\text { v-fos FBJ murine } \\
\text { osteosarcoma viral } \\
\text { oncogene homolog }\end{array}$ & NM_010234 & 0.077 & -1.089 & 10.759 & 0.207 & 0.725 & 10.034 & 0.012 & 1.813 & 11.848 \\
\hline FOXO1 & forkhead box O1 & NM_019739 & 0.007 & 0.656 & 10.756 & 0.1 & -0.323 & 11.079 & 0.001 & -0.979 & 10.1 \\
\hline IGF1R & $\begin{array}{l}\text { insulin-like growth } \\
\text { factor } 1 \text { receptor }\end{array}$ & NM_010513 & 0.01 & 0.745 & 8.221 & 0.228 & -0.275 & 8.496 & 0.002 & -1.019 & 7.476 \\
\hline IGFBP2 & $\begin{array}{l}\text { insulin-like growth factor } \\
\text { binding protein } 2,36 \mathrm{kDa}\end{array}$ & NM_008342 & 0.005 & 0.601 & 6.253 & 0 & -1.694 & 7.948 & 0 & -2.296 & 5.652 \\
\hline IRS1 & insulin receptor substrate 1 & NM_010570 & 0.006 & 1.387 & 11.258 & 0.089 & -0.681 & 11.939 & 0.001 & -2.067 & 9.872 \\
\hline $\mathrm{NOV}$ & $\begin{array}{l}\text { nephroblastoma } \\
\text { overexpressed gene }\end{array}$ & NM_010930 & 0.089 & 0.901 & 7.881 & 0.379 & -0.424 & 8.306 & 0.024 & -1.326 & 6.98 \\
\hline PIK3CA & $\begin{array}{l}\text { phosphoinositide-3-kinase, } \\
\text { catalytic, alpha polypeptide }\end{array}$ & NM_008839 & 0.001 & 0.645 & 6.755 & 0.127 & -0.249 & 7.833 & 0 & -0.815 & 6.11 \\
\hline PIK3CD & $\begin{array}{l}\text { phosphoinositide-3-kinase, } \\
\text { catalytic, delta polypeptide }\end{array}$ & NM_001029837 & 0.053 & -0.548 & 6.216 & 0.256 & -0.386 & 9.26 & 0.012 & 0.813 & 6.764 \\
\hline PIK3R1 & $\begin{array}{l}\text { phosphoinositide-3-kinase, } \\
\text { regulatory subunit } 1 \text { (alpha) }\end{array}$ & NM_001024955 & 0.009 & 0.628 & 9.645 & 0.001 & -0.697 & 13.043 & 0 & -1.402 & 9.017 \\
\hline PIK3R3 & $\begin{array}{l}\text { phosphoinositide-3-kinase, } \\
\text { regulatory subunit } 3 \text { (gamma) }\end{array}$ & NM_181585 & 0.281 & -0.286 & 7.827 & 0.06 & 0.555 & 7.271 & 0.012 & 0.841 & 8.112 \\
\hline PIK3R5 & $\begin{array}{l}\text { phosphoinositide-3-kinase, } \\
\text { regulatory subunit } 5\end{array}$ & NM_177320 & 0.155 & -0.692 & 7.33 & 0.022 & 1.299 & 6.031 & 0.003 & 1.991 & 8.022 \\
\hline PRKCH & protein kinase $\mathrm{C}$, eta & NM_008856 & 0.087 & -0.743 & 10.472 & 0.027 & 0.997 & 7.892 & 0.003 & 1.594 & 9.486 \\
\hline YWHAE & $\begin{array}{l}\text { tyrosine } 3 \text {-monooxygenase/ } \\
\text { tryptophan } 5 \text {-monooxygenase } \\
\text { activation protein, epsilon } \\
\text { polypeptide }\end{array}$ & BF714941 & 0.012 & 1.219 & 5.874 & 0.053 & -0.267 & 8.76 & 0.003 & -1.598 & 4.655 \\
\hline YWHAZ & $\begin{array}{l}\text { tyrosine } 3 \text {-monooxygenase/ } \\
\text { tryptophan 5-monooxygenase } \\
\text { activation protein, } \\
\text { zeta polypeptide }\end{array}$ & NM_011740 & 0.008 & -0.876 & 7.273 & 0.447 & -0.188 & 7.461 & 0.024 & 0.688 & 8.148 \\
\hline
\end{tabular}




\section{Continued}

\begin{tabular}{|c|c|c|c|c|c|c|c|c|c|c|c|}
\hline BTK & $\begin{array}{l}\text { Bruton agammaglobulinemia } \\
\text { tyrosine kinase }\end{array}$ & NM_013482 & 0.009 & -1.057 & 9.376 & 0.607 & 0.153 & 9.223 & 0.005 & 1.21 & 10.433 \\
\hline FCER1A & $\begin{array}{l}\text { Fc fragment of } \operatorname{IgE} \text {, high } \\
\text { affinity I, receptor for; alpha } \\
\text { polypeptide }\end{array}$ & NM_010184 & 0.05 & -1.043 & 7.485 & 0.808 & 0.109 & 7.375 & 0.035 & 1.152 & 8.528 \\
\hline FCER1G & $\begin{array}{l}\text { Fc fragment of } \operatorname{IgE} \text {, high } \\
\text { affinity I, receptor for; } \\
\text { gamma polypeptide }\end{array}$ & NM_010185 & 0.032 & -0.573 & 14.157 & 0.256 & 0.26 & 13.897 & 0.006 & 0.833 & 14.73 \\
\hline $\mathrm{LCP} 2$ & $\begin{array}{l}\text { lymphocyte cytosolic protein } \\
2(\mathrm{SH} 2 \text { domain containing } \\
\text { leukocyte protein of } 76 \mathrm{kDa})\end{array}$ & NM_010696 & 0.082 & -0.362 & 9.448 & 0.03 & 0.488 & 8.96 & 0.002 & 0.85 & 9.809 \\
\hline LYN & $\begin{array}{l}\text { v-yes-1 Yamaguchi sarcoma } \\
\text { viral related oncogene homolog }\end{array}$ & NM_001111096 & 0.047 & -0.516 & 10.223 & 0.211 & 0.291 & 9.933 & 0.008 & 0.806 & 10.739 \\
\hline MAP2K 7 & $\begin{array}{l}\text { mitogen-activated protein } \\
\text { kinase kinase } 7\end{array}$ & NM_001042557 & 0.114 & 0.613 & 4.499 & 0.271 & 0.348 & 3.444 & 0.032 & -0.912 & 3.887 \\
\hline MAPK14 & $\begin{array}{l}\text { mitogen-activated protein } \\
\text { kinase } 14\end{array}$ & NM_011951 & 0.002 & 0.846 & 7.58 & 0.062 & -0.064 & 12.45 & 0 & -0.194 & 12.256 \\
\hline PIK3CA & $\begin{array}{l}\text { phosphoinositide-3-kinase, } \\
\text { catalytic, alpha polypeptide }\end{array}$ & NM_008839 & 0.001 & 0.645 & 6.755 & 0.127 & -0.249 & 7.833 & 0 & -0.815 & 6.11 \\
\hline PIK3CD & $\begin{array}{l}\text { phosphoinositide-3-kinase, } \\
\text { catalytic, delta polypeptide }\end{array}$ & NM_001029837 & 0.053 & -0.548 & 6.216 & 0.256 & -0.386 & 9.26 & 0.012 & 0.813 & 6.764 \\
\hline PIK3R1 & $\begin{array}{l}\text { phosphoinositide-3-kinase, } \\
\text { regulatory subunit } 1 \text { (alpha) }\end{array}$ & NM_001024955 & 0.009 & 0.628 & 9.645 & 0.001 & -0.697 & 13.043 & 0 & -1.402 & 9.017 \\
\hline PIK3R3 & $\begin{array}{l}\text { phosphoinositide-3-kinase, } \\
\text { regulatory subunit } 3 \text { (gamma) }\end{array}$ & NM_181585 & 0.281 & -0.286 & 7.827 & 0.06 & 0.555 & 7.271 & 0.012 & 0.841 & 8.112 \\
\hline PIK3R5 & $\begin{array}{l}\text { phosphoinositide-3-kinase, } \\
\text { regulatory subunit } 5\end{array}$ & NM_177320 & 0.155 & -0.692 & 7.33 & 0.022 & 1.299 & 6.031 & 0.003 & 1.991 & 8.022 \\
\hline PLA2G2D & phospholipase A2, group IID & NM_011109 & 0.091 & 1.338 & 7.413 & 0.107 & -1.261 & 8.674 & 0.007 & -2.6 & 6.075 \\
\hline PLA2G5 & phospholipase A2, group V & NM_001122954 & 0.039 & -1.49 & 3.435 & 0.094 & 1.126 & 2.309 & 0.003 & 2.615 & 4.924 \\
\hline PRKCH & protein kinase $\mathrm{C}$, eta & NM_008856 & 0.087 & -0.743 & 10.472 & 0.027 & 0.997 & 7.892 & 0.003 & 1.594 & 9.486 \\
\hline PRKD1 & protein kinase D1 & NM_008858 & 0 & 0.377 & 10.713 & 0 & -0.515 & 11.227 & 0 & -0.892 & 10.336 \\
\hline VAV1 & $\begin{array}{l}\text { vav } 1 \text { guanine nucleotide } \\
\text { exchange factor }\end{array}$ & NM_011691 & 0.044 & -0.704 & 5.755 & 0.209 & 0.391 & 5.363 & 0.007 & 1.095 & 6.458 \\
\hline VAV3 & $\begin{array}{l}\text { vav } 3 \text { guanine nucleotide } \\
\text { exchange factor }\end{array}$ & NM_020505 & 0.072 & -0.768 & 8.743 & 0.116 & 0.582 & 3.591 & 0.009 & 1.336 & 9.51 \\
\hline \multicolumn{12}{|c|}{ B Cell Receptor Signaling } \\
\hline BCL2A1 & BCL2-related protein A1 & NM_007534 & 0.11 & -0.784 & 10.911 & 0.058 & 0.973 & 9.938 & 0.005 & 1.756 & 11.694 \\
\hline BCL3 & B-cell CLL/lymphoma 3 & NM_033601 & 0.03 & -0.392 & 8.281 & 0.002 & 0.684 & 7.596 & 0 & 1.076 & 8.672 \\
\hline BLNK & B-cell linker & NM_008528 & 0.054 & -1.111 & 11.996 & 0.09 & 0.942 & 11.054 & 0.004 & 2.053 & 13.107 \\
\hline BTK & $\begin{array}{l}\text { Bruton agammaglobulinemia } \\
\text { tyrosine kinase }\end{array}$ & NM_013482 & 0.009 & -1.057 & 9.376 & 0.607 & 0.153 & 9.223 & 0.005 & 1.21 & 10.433 \\
\hline CAMK2D & $\begin{array}{l}\text { calcium/calmodulin-dependent } \\
\text { protein kinase (CaM kinase) } \\
\text { II delta }\end{array}$ & NM_001025438 & 0.062 & 0.087 & 2.365 & 0.496 & -0.25 & 7.43 & 0.038 & -0.902 & 6.528 \\
\hline CARD10 & $\begin{array}{l}\text { caspase recruitment domain } \\
\text { family, member } 10\end{array}$ & NM_130859 & 0.006 & 0.725 & 11.039 & 0.286 & -0.209 & 11.248 & 0.002 & -0.934 & 10.315 \\
\hline
\end{tabular}




\begin{tabular}{|c|c|c|c|c|c|c|c|c|c|c|c|}
\hline \multicolumn{12}{|l|}{ Continued } \\
\hline FCGR2A & $\begin{array}{l}\text { Fc fragment of IgG, low } \\
\text { affinity IIa, receptor (CD32) }\end{array}$ & NM_010188 & 0.051 & -0.467 & 12.2 & 0.125 & 0.343 & 11.857 & 0.005 & 0.81 & 12.667 \\
\hline FRAP1 & $\begin{array}{l}\text { FK506 binding protein } \\
\text { 12-rapamycin associated } \\
\text { protein } 1\end{array}$ & NM_020009 & 0.05 & -0.825 & 4.157 & 0.274 & -0.144 & 10.371 & 0.031 & 0.938 & 4.981 \\
\hline IKBKE & $\begin{array}{l}\text { inhibitor of kappa light } \\
\text { polypeptide gene enhancer } \\
\text { in B-cells, kinase epsilon }\end{array}$ & NM_019777 & 0.013 & -0.555 & 8.531 & 0.029 & 0.456 & 8.075 & 0.001 & 1.012 & 9.086 \\
\hline LYN & $\begin{array}{l}\text { v-yes-1 Yamaguchi sarcoma } \\
\text { viral related oncogene homolog }\end{array}$ & NM_001111096 & 0.047 & -0.516 & 10.223 & 0.211 & 0.291 & 9.933 & 0.008 & 0.806 & 10.739 \\
\hline MAP2K7 & $\begin{array}{l}\text { mitogen-activated protein } \\
\text { kinase kinase } 7\end{array}$ & NM_001042557 & 0.114 & 0.613 & 4.499 & 0.271 & 0.348 & 3.444 & 0.032 & -0.912 & 3.887 \\
\hline MAP3K13 & $\begin{array}{l}\text { mitogen-activated protein } \\
\text { kinase kinase kinase } 13\end{array}$ & XM_001480812 & 0.1 & 0.676 & 4.22 & 0.443 & 0 & 2.122 & 0.05 & -0.85 & 3.543 \\
\hline MAP3K3 & $\begin{array}{l}\text { mitogen-activated protein } \\
\text { kinase kinase kinase } 3\end{array}$ & NM_011947 & 0.049 & -2.011 & 5.549 & 0.137 & -1.412 & 6.962 & 0.092 & -0.237 & 9.719 \\
\hline MAPK14 & $\begin{array}{l}\text { mitogen-activated protein } \\
\text { kinase } 14\end{array}$ & NM_011951 & 0.002 & 0.846 & 7.58 & 0.062 & -0.064 & 12.45 & 0 & -0.194 & 12.256 \\
\hline PIK3AP1 & $\begin{array}{l}\text { phosphoinositide-3-kinase } \\
\text { adaptor protein } 1\end{array}$ & NM_031376 & 0.056 & -1.386 & 6.584 & 0.312 & 0.652 & 5.932 & 0.013 & 2.038 & 7.97 \\
\hline PIK3CA & $\begin{array}{l}\text { phosphoinositide-3-kinase, } \\
\text { catalytic, alpha polypeptide }\end{array}$ & NM_008839 & 0.001 & 0.645 & 6.755 & 0.127 & -0.249 & 7.833 & 0 & -0.815 & 6.11 \\
\hline PIK3CD & $\begin{array}{l}\text { phosphoinositide-3-kinase, } \\
\text { catalytic, delta polypeptide }\end{array}$ & NM_001029837 & 0.053 & -0.548 & 6.216 & 0.256 & -0.386 & 9.26 & 0.012 & 0.813 & 6.764 \\
\hline PIK3R1 & $\begin{array}{l}\text { phosphoinositide-3-kinase, } \\
\text { regulatory subunit } 1 \text { (alpha) }\end{array}$ & NM_001024955 & 0.009 & 0.628 & 9.645 & 0.001 & -0.697 & 13.043 & 0 & -1.402 & 9.017 \\
\hline PIK3R3 & $\begin{array}{l}\text { phosphoinositide-3-kinase, } \\
\text { regulatory subunit } 3 \text { (gamma) }\end{array}$ & NM_181585 & 0.281 & -0.286 & 7.827 & 0.06 & 0.555 & 7.271 & 0.012 & 0.841 & 8.112 \\
\hline PIK3R5 & $\begin{array}{l}\text { phosphoinositide-3-kinase, } \\
\text { regulatory subunit } 5\end{array}$ & NM_177320 & 0.155 & -0.692 & 7.33 & 0.022 & 1.299 & 6.031 & 0.003 & 1.991 & 8.022 \\
\hline VAV1 & $\begin{array}{l}\text { vav } 1 \text { guanine nucleotide } \\
\text { exchange factor }\end{array}$ & NM_011691 & 0.044 & -0.704 & 5.755 & 0.209 & 0.391 & 5.363 & 0.007 & 1.095 & 6.458 \\
\hline VAV3 & $\begin{array}{l}\text { vav } 3 \text { guanine nucleotide } \\
\text { exchange factor }\end{array}$ & NM_020505 & 0.072 & -0.768 & 8.743 & 0.116 & 0.582 & 3.591 & 0.009 & 1.336 & 9.51 \\
\hline
\end{tabular}

Supplement Tables 1-4. Heatmaps in Supplement Figure 4 listed the pathways by rank order of statistical significance.

\subsection{Comparison to Similar Microarray Data}

Microarray results a few years ago were notorious for data variability when comparing similar studies from different laboratories. To confirm our microarray result to the published gene expression studies, two similar liver microarray datasets from similar DIO mouse models [11, 12] were compared to our LC/LV/LUP dataset. Side-byside comparisons were remarkably similar. One dataset, that of the resveratrol treated DIO model [11], was identical to our experimental design of lean control, HFD, and HFD+resveratrol treatments. Not only were the comparisons between lean control and HFD similar, but also the comparisons between LUP vs. LV and HFD + resveratrol vs. HFD similar. Resveratrol, a phenolic compound from grape, activates sirtuin, a protein known from yeast, Drosophila, and C. elegan to prolong life span when sirtuin activity is heightened in response to caloric restriction [11]. The similarity between UP780 and resveratrol was observed in both the highest differential gene expressions and in the significant metabolic and signaling pathways. Resveratrol was discovered through high throughput screening for sirtuin activation [11], while UP780's discovery was designed not to be specific for enzymatic modification, but for increased adiponectin secretion from differentiate 3T3-L1 adipocytes [1].

\section{REFERENCES}

[1] Yimam, M., Zhao, J., Corneliusen, B., Pantier, M., Brownell, L. and Jia, Q. (2012) UP780, a chromone enriched Aloe composition, improves insulin sensitivity. Metabolic Syndrome and Related Disorders, 10, 319-386.

[2] GeneChip Expression Analysis Technical Manual. http://media.affymetrix.com/support/downloads/manuals/ expression_analysis_technical_manual.pdf

[3] Affymetrix Expression Console Software. 
http://www.affymetrix.com/estore/browse/level seven so ftware products_only.jsp?navMode $=34000 \&$ productI $\bar{d}=1$ 31414\&navAction=jump\&aId=productsNav\#1_3

[4] Bioconductor. http://www.bioconductor.org/

[5] Gentleman, R., Carey, V., Huber, W., Irizarry, R. and Dudoit, A. (2005) Bioinformatics and computational biology solutions using R and Bioconductor. Springer, New York. doi:10.1007/0-387-29362-0

[6] Smyth, G. (2004) Linear models and empirical Bayes methods for assessing differential expression in microarray experiments. Statistical Applications in Genetics and Molecular Biology, 3, 1544-6115. doi:10.2202/1544-6115.1027

[7] OMIM': Online Mendelian Inheritance in Man $^{\circledR}$. http://omim.org/

[8] Ingenuity pathway analysis. http://www.ingenuity.com/

[9] Wu, Z. and Irizarry, R.A. (2004) Preprocessing of oligo- nucleotide array data. Nature Biotechnology, 22, 656-658. doi:10.1038/nbt0604-656b

[10] Saldanha, A.J. (2004) Java Treeview-extensible visualizetion of microarray data. Bioinformatics, 20, 3246-3248. doi:10.1093/bioinformatics/bth349

[11] Baur, J.A., Pearson, K.J., Price, N.L., Jamieson, H.A., Lerin, C., Kalra, A., Prabhu, V.V., Allard, J.S., Lopez-Lluch, G., Lewis, K., Pistell, P.J., Poosala, S., Becker, K.G., Boss, O., Gwinn, D., Wang, M., Ramaswamy, S., Fishbein, K.W., Spencer, R.G., Lakatta, E.G., Le Couteur, D., Shaw, R.J., Navas, P., Puigserver, P., Ingram, D.K., de Cabo, R. and Sinclair, D.A. (2006) Resveratrol improves health and survival of mice on a high-calorie diet. Nature, 444, 337342. doi:10.1038/nature05354

[12] Chan, M.Y., Zhao, Y. and Heng, C.K. (2008) Sequential responses to high-fat and high-calorie feeding in an obese mouse model. Obesity (Silver Spring), 16, 972-978. doi:10.1038/oby.2008.32 